\title{
Animal Welfare
}

1

\section{EFFECT OF RACTOPAMINE-HCL ON MUSCLE FIBER TYPES AND FINISHING BARROW EXHAUSTION}

\author{
J. A. Noel 1, ${ }^{\star}$, T. J. Barstow ${ }^{2}$, R. M. Broxterman 2, G. D. McCoy 1, K. J. Phelps 1, J. M. Gonzalez ${ }^{1}$ \\ 1Department of Animal Science and Industry, ²Department of Kinesiology, Kansas State University, Manhattan, United \\ States
}

Objectives: Ractopamine-HCI (RAC; Paylean, Elanco Animal Health, Greenfield, IN) shifts muscle fiber type toward glycolytic metabolism. Pigs fed RAC are more susceptible to stress and fatigue when handled roughly. Previous studies utilized the presence of blood metabolites as the indicators of fatigue. Wireless electromyography (EMG) can be used to directly measure muscle activation characteristics, which may predict fatigue. Specifically, EMG measures root mean square (RMS) and median power frequency (MdPF) as indicators of muscle fiber recruitment and action potential conduction velocity, respectively. The objective of this study was to determine the effect of RAC on muscle fiber type, exercise tolerance, and EMG when barrows are subjected to increased levels of activity.

Materials and Methods: Twenty finishing barrows (PIC $337 \times 1050$; initial BW = $108 \pm 4 \mathrm{~kg}$ ) were subjected to a randomized complete block design. Block consisted of rep and within each rep, barrows were randomly assigned to 1 of 2 dietary treatments: the basal diet plus 0 ppm (CON) or 10 ppm of RAC (RAC+). Barrows were fed experimental diets for the last 32 days of finishing and at the completion of feeding, barrows were subjected to a routine where they were briskly walked/run around a circular track until subjective exhaustion was achieved. Data including time, distance, and speed were measured during movement. Wireless EMG sensors (Tringo'TM Wireless EMG, Delsys, Natick, MA) were affixed to the Deltoideus (DT), Triceps brachii lateral head (TLH), Tensor fasciae latae (TFL), and Semitendinosus (ST) muscles. Following harvest, muscle fiber type distribution of muscles were measured ( $n=5$ per treatment).

Results: No difference $(P=0.858)$ was found for barrow speed between treatments. Barrows from the RAC+ treatment reached subjective exhaustion quicker and covered less distance than CON barrows $(P<0.041)$. There was a muscle $\times$ treatment interaction ( $P=0.003$ ) for RMS values. Ractopamine did not affect RMS values in the DT, TLH, and TFL muscles $(P>0.644)$; however RAC+ barrows had decreased $(P<0.001)$ values in the ST. Over all muscles, RMS of RAC+ barrows' was reduced $(P=0.022)$. There was no muscle $\times$ treatment interaction $(P=0.179)$ or treatment main effect $(P=0.308)$ for end time MdPF values; however, muscles from RAC+ barrows tended to have greater $(P=0.100)$ MdPF than CON barrows. There was a muscle $\times$ treatment interaction $(P=0.016)$ for the percentage of type IIB fibers. Ractopamine did not affect the percentage of type IIB fibers in the DT, ST, and TLH muscles $(P>0.155)$; however, RAC+ barrows had increased $(P=0.002)$ percentage of type IIB fibers in the TFL. Over all muscles, RAC+ barrows tended to have more $(P=0.134)$ type IIB fibers than CON barrows.

Conclusion: Similar to previous studies, RAC increased the onset of subjective exhaustion when barrows were subjected to increased levels of activity. Muscles from RAC+ barrows tended to contain more type IIB fibers than CON barrows, 
while EMG data indicated that RAC barrows had a reduction in motor unit activity and tended to have greater action potential conduction velocity at the end of the increased activity protocol. These data suggest that RAC contributes to the development of subjective exhaustion, possibly through a shift in muscle fiber type characteristics.

Keywords: Electromyography, Muscle exhaustion, Ractopamine-HCl, Swine 


\section{Consumer Topics}

\section{2}

\section{ANIMAL WELFARE IN ISLAM}

K. M. Pufpaff $1,{ }^{*}$

${ }^{1}$ Islamic Food and Nutrition Council of America, Park Ridge, United States

Objectives: Within the current controversies over animal welfare it is easy to spot the difference in practice and outlook among different cultural, national views and standards of animal care and treatment. However, the future best interest of animals is most likely served not by conflict among their caregivers but by finding points of agreement with a basis in unbiased science to institute further industry wide improvements.

The objective of this review was to present an historic overview of the status of animal welfare within Islam and look at how this historic viewpoint can inform modern advancements and dialog in animal care and handling. Within Islam, as well as in the world at large, the need to provide sufficient volume of food has put the needs of people ahead of the welfare of food producing animals.

The following text emphasizes the fact that for food to truly meet the spirit of halal laws, animal welfare should not be a burden of modern production but an integral part of any wholly halal process. People often point to certain teachings of Prophet Muhammad, peace and blessings be upon him (PBUH), about kindness to animals as evidence of his kindness as a person but a disconnect has grown between that fact and the fact that these teachings did not just apply to his kindness but also to the belief that animals deserve treatment as individual beings and not merely mobile food.

Materials and Methods: The materials used to help connect the teachings of early Islam with modern viewpoints about animal welfare were references to animals and their care in the Quran and the teachings of Prophet Muhammad (PBUH) known as Hadith. These teachings were then examined in tandem with the Five Freedoms that have become the mainstay of modern animal welfare efforts. The Five Freedoms are as follows:

Freedom from thirst and hunger - by ready access to fresh water and a diet to maintain full health and vigor Freedom from discomfort - by providing an appropriate environment including shelter and a comfortable resting area Freedom from pain, injury, and disease - by prevention or rapid diagnosis and treatment Freedom to express most normal behavior - by providing sufficient space, proper facilities, and company of the animal's own kind

Freedom from fear and distress - by ensuring conditions and treatment which avoid mental suffering

Results: This review found that there is historic Islamic text that supports every one of the Five Freedoms. In regards particularly to slaughter there is a Hadith that says "Verily God has prescribed Ihsaan (proficiency, perfection) in all things. So if you kill then kill well; and if you slaughter, then slaughter well. Let each one of you sharpen his blade and let him 
spare suffering to the animal he slaughters." The overarching themes within early Islamic teachings as they apply to animal welfare are twofold: Animals are individuals that experience life in a way parallel to humans, and thus deserve parallel consideration, and humans were given a greater gift of cognitive understanding than our animal counterparts which gives us certain rights and responsibilities over animals and most particularly over the ones that contribute to our food supply.

In conclusion, by focusing on the principles recorded in early Islamic teachings it is possible to open a supportive dialog between science and faith that can lead to animal welfare improvements without antagonism.

\section{Conclusion:}

Keywords: Animal Welfare, Religious Slaughter 


\section{Consumer Topics}

CONSUMER PREFERENCE OF GROUND BEEF PATTIES WITH VARYING PERCENTAGES OF FINELY TEXTURED BEEF

M. M. Neilson 1, ${ }^{\star}$, D. VanOverebeke ${ }^{1}$, S. Depue ${ }^{2}$, J. Lusk ${ }^{2}$, B. Norwood ${ }^{2}$, R. Ramanathan ${ }^{1}$, S. Howard ${ }^{3}$, G. Mafi ${ }^{1}$ ${ }^{1}$ Animal Science, ${ }^{2}$ Agricultural Economics , Oklahoma State University, Stillwater, ${ }^{3}$ Cargill Meat Solutions, Wichita , United States

Objectives: In 2014 U.S. citizens consumed 25.5 billion pounds of beef. With the shortage of cattle around the country, beef companies have found a processing technique that utilizes more of the product. This product is commonly known as Finely Textured Beef (FTB). The overall goal of this study was to evaluate consumers' preferences of ground beef patties with varying levels of FTB.

Materials and Methods: Three different treatments were utilized during the study, 0\% FTB, 15\% FTB, and Max Inclusion FTB. All patties were a final makeup of $81 \%$ lean and $19 \%$ fat with a variance of $+/-1 \%$. Fifty-eight patties of each treatment were served to 229 consumers $(n=687)$. Patties were thawed for $24 \mathrm{~h}$ prior to cooking. Each patty was cooked for $9 \mathrm{~min}$ at $400^{\circ} \mathrm{C}$ until it reached an internal temperature of $74^{\circ} \mathrm{C}$. Each patty was evenly cut into four sections, and placed in the appropriately labeled container. For the sensory panel, samples were labeled with a circle $(0 \%$ FTB), square (15\% FTB), and triangle (max inclusion FTB). Each sample was evaluated on a 9-point hedonic scale for traits of tenderness, flavor, juiciness, and satisfaction of overall eating quality.

Results: The consumer panel consisted of 91 males and 138 females with an average of 29.7y and an average income between $\$ 50,000$ and $\$ 59,999$. There was significant difference in tenderness between the $0 \% \mathrm{FTB}, 15 \% \mathrm{FTB}$, and max inclusion FTB $(P<0.05)$. The max inclusion was more tender $(P<0.05)$ than the $0 \%$ FTB and $15 \%$ FTB. Flavor, juiciness and satisfaction of overall eating quality were not significantly different $(P>0.05)$ between $0 \% \mathrm{FTB}, 15 \% \mathrm{FTB}$, and max inclusion FTB.

Conclusion: In conclusion, consumers showed a preference for max inclusion FTB for tenderness but numerically differences were minor. However, they showed no preference for flavor, juiciness, and satisfaction of overall eating quality between the three treatment groups. This is positive for our industry as consumers cannot detect a difference in ground beef patties with the inclusion of FTB.

Conclusion:

Keywords: Consumer Preference, Finely Textured Beef , Ground Beef 


\title{
Consumer Topics
}

4

\section{RESTING STATE CONNECTIVITY OF THE MEDIAL ORBITOFRONTAL CORTEX IS ALTERED AFTER EATING VARYING QUALITIES OF STEAK}

\author{
M. R. Mazon ${ }^{1,}{ }^{*}$, W. N. Tapp ${ }^{1}$, T. H. Davis ${ }^{2}$, D. Paniukov ${ }^{2}$, M. F. Miller ${ }^{1}$ \\ ${ }^{1}$ Animal and Food Sciences, ${ }^{2}$ Psychological Sciences, Texas Tech University, Lubbock, United States
}

Objectives: Activation of brain regions after food consumption has been evaluated using functional magnetic resonance imaging (fMRI). This technique has not exploited response of many solid foods such as steak. Delivery of solid stimuli to the scanner limits evaluation utilizing fMRI. Resting state fMRI scanning can show activated brain regions by observing downstream effects of connectivity correlated to connected regions. Literature shows these connected regions reflect functional connectivity between other regions. Neural response of other foods suggest that hedonic brain circuits will also be activated during the process of eating steak. The objective of this experiment was to evaluate the connectivity of brain regions after consuming different qualities of steak.

Materials and Methods: Resting state scans of trained participants $(n=8)$ were taken before, directly after, and after an extended period of time (25-30 minutes) of receiving either high or low quality steak samples; resting state scans measured connections to the medial orbitofrontal cortex (mOFC). After 48 hours partcipants were fed the other steak sample and rescanned in the same manner. Hemodynamic fluctuation was shown by blood oxygen level dependant imaging during fMRI procedures. Initial images were taken in the scanner before eating. Participants came out of the scanning room, and were fed their steak sample. Immediately after consumption, participants marked a $152.4 \mathrm{~mm}$ anchored visual analog line scale (VAS) at any point along the line, as a subjective sensory evaluation. The VAS was anchored as terrible, very poor, poor, fair, good, very good, and excellent, at 0, 25.4, 50.8, 76.2, 101.6, 127.0, and 152.4 $\mathrm{mm}$, respectively. Participants re-entered the scanning room, and scans were taken as soon as possible. Panelists left the room and were instructed to cleanse their palates before re-entry into the scanning room where a final scan was taken. Analysis of fMRI data was conducted using fMRI Expert Analysis Tool. A priori evaluation was conducted to evaluate connectivity to the mOFC. Analysis of VAS data was conducted using SAS.

Results: Differences in connectivity were observed in the amygdala and hippocampus. Connectivity of regions were correlated to the mOFC ( $P \leq 0.05)$. High quality steak samples had mean VAS measurements of $140.46,134.37,142.75$ and 139.19, for tenderness, juiciness, flavor, and overall liking, respectively. Low quality steak samples had mean VAS measurements of $49.28,49.53,49.02$, and 52.58 , for tenderness, juiciness, flavor, and overall liking, respectively. Scores for high quality steak samples were greater $(P \leq 0.01)$ than low quality samples for all palatability traits.

Conclusion: This shows differences in brain connectivity and hedonic liking after consumption of steak of different qualities. This relationship between VAS and fMRI data, suggest that connected regions respond to different qualities of steak differently. There is a great deal of literature describing how the mOFC is linked to value-based decision making 
and forming memory. This implies that connected regions could influence hedonic value placed on steak. This research adds knowledge and understanding to the many recent advances in neural topography.

Keywords: Beef, Blood Oxygen Level Dependant, Hemodynamic , Neuroimaging, Sensory Evaluation 


\title{
Consumer Topics
}

5

\section{THE USE OF JUST-ABOUT-RIGHT (JAR) SCALES TO IDENTIFY DRIVERS OF CUSTOMER ACCEPTANCE FOR LOW-SODIUM ITALIAN SALAMI}

\author{
M. A. de Almeida ${ }^{1, *}$, N. D. M. Villanueva ${ }^{2}$, E. Saldaña ${ }^{1}$, J. S. D. S. Pinto ${ }^{1}$, S. G. Fadda ${ }^{3}$, C. J. Contreras Castillo ${ }^{1}$ \\ ${ }^{1}$ Agroindustry, Food and Nutriction, Sao Paulo University, Piracicaba, Brazil, 2Facultad de Ingeniería Agraria, Universidad \\ Católica Sedes Sapientiae, Lima, Peru, ${ }^{3}$ Centro de Referencia para Lactobacilos, San Miguel do Tucuman, Argentina
}

Objectives: To evaluate the effects of sodium chloride $(\mathrm{NaCl})$ reduction replaced by combinations of potassium chloride $(\mathrm{KCl})$ and calcium chloride $\left(\mathrm{CaCl}_{2}\right)$ with the use of Just-About-Right (JAR) scales to identify drivers of customer acceptance to produce low-sodium salami.

Materials and Methods: We compared low-sodium salami developed in laboratory (sample No. $580-8.8 \mathrm{~g} \mathrm{~kg}^{-1} \mathrm{Of}_{\text {sodium }}$ $(\mathrm{Na})$ and $290 \mathrm{~g} \mathrm{~kg}^{-1}$ of fat) with three brands of Italian salami: more commercialized salami (sample No. $635-16.1 \mathrm{~g} \mathrm{Kg}^{-}$ ${ }^{1} \mathrm{Na}, 300 \mathrm{~g} \mathrm{~kg}^{-1} \mathrm{of}$ fat), higher market salami (No. $372-17.9 \mathrm{~g} \mathrm{~kg}^{-1} \mathrm{Na}, 230 \mathrm{~g} \mathrm{~kg}^{-1} \mathrm{of}$ fat) and high-sodium content salami (428 $25.6 \mathrm{~g} \mathrm{~kg}^{-1} \mathrm{Na}, 237 \mathrm{~g} \mathrm{~kg}^{-1}$ of fat). Sixty consumers participated in the test (31.7\% males and $68.3 \%$ females) and received the monadic samples according to the Latin Square experimental design. Consumers evaluated the overall acceptance of salamis using the nine-point hedonic scale. Texture, characteristic flavor, color and salt content were assessedusing the Just-About-Right scale. The results were analyzed by the principal component analysis (PCA) based on the Pearson correlation to identify the influence of the measured attributes using the JAR scale for product acceptance to adopt procedures for the reformulation of low-sodium salami. The results of the JAR scale were analyzed using PCA by software XLSTAT (Addinsoft, New York, USA).

Results: Three groups are shown graphically (Figure 1) as function of JAR responses. The first group is composed of scores 1, 2 and 3 representing the responses "less than ideal". The second group is formed by score 4 representing "ideal", and the third group is formed by scores 5, 6 and 7 showing responses "more than ideal". For the sample under development in the laboratory (No. 580), consumers considered the salami dark. For salt content, the sample showed high values ( $50 \%$ of consumers) from "less than ideal" to "ideal". It is favorable for the research purpose that a high number of consumers do not notice the replacement of $\mathrm{NaCl}$ by mixture of potassium chloride $2.5 \mathrm{~g} \mathrm{Kg}^{-1}+2.5 \mathrm{~g} \mathrm{Kg}^{-1}$ calcium chloride. However, texture and characteristic flavor of Italian salami presented a high percentage of consumers below ideal. The other samples were the basis for the salami reformulation developed in laboratory, commercial samples No. 428 and 635 had higher percentages of the optimum point for all attributes (color, texture, characteristic flavor and salt content). These responses were expected because these products are the most consumed in the Brazilian market. Furthermore, the commercial sample No.372 showed high percentage of the optimum point for the attributes of texture and salt content. The variance in the PCA showed that two main components explained $99 \%$. Moreover, the attributes of texture, flavor characteristic and salt content are related to the principal component 1 . Also, the overall quality and color 
are correlated with the principal component 2. According to the sensory analysis, all samples have different sensory characteristics, however, each differs from the other samples. Sample 372 showed distinct color and sample 635, different overall quality, acceptance texture and sodium content.

Image:
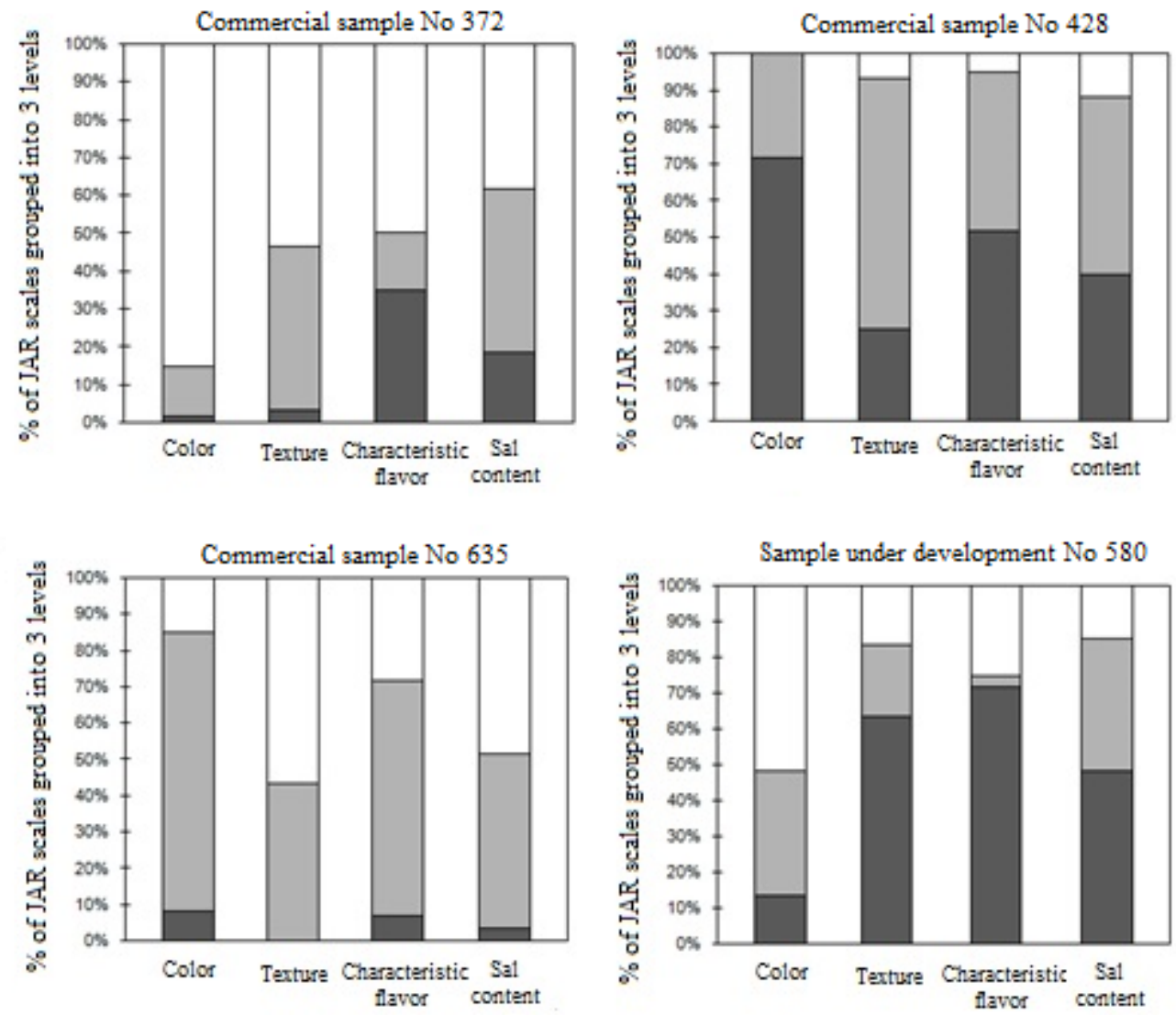

Less than ideal

- Ideal $\square$ More than ideal

Figure 1 - Percentage of responses JAR scales grouped into 3 levels. Less than ideal; Ideal; More than ideal for attributes: color, texture, characteristic flavor and salt content.

Conclusion: New formulation of low-sodium salami under development should contain the characteristics of texture and residual taste indicated in the commercial samples.

Keywords: Italian salami, low-sodium , principal component analysis 


\section{Consumer Topics}

\section{NEURAL CONNECTIVITY OF THE RIGHT AND LEFT NUCLEUS ACCUMBENS AFTER EATING HIGH AND LOW QUALITY STEAK}

W. N. Tapp ${ }^{1, *}$, T. H. Davis ${ }^{2}$, D. Paniukov², M. F. Miller ${ }^{1}$

${ }^{1}$ Animal and Food Sciences, ${ }^{2}$ Psychological Sciences, Texas Tech University, Lubbock, United States

Objectives: Functional magnetic resonance imaging (fMRI) has evaluated activation of brain regions after consumption of many foods, but researchers have yet to capitalize this technology to analye many solid foods such as steak. Literature shows that spatially consistent networks, resting state networks, reflect functional connectivity between brain regions. Resting state scans show connected regions by evaluating downstream effects of neural connectivity correlated to other regions. As shown in other foods, we believe that hedonic circuits will be activated while eating steak. The objective of this experiment was to evaluate brain connectivity to the right and left nucleus accumbens after consuming different steak qualities.

Materials and Methods: Resting state scans of trained participants $(n=8)$ were taken before, directly after, and after an extended time (25-30 minutes) of receiving high or low quality steak samples. All samples were cooked to a medium degree of doneness with a clamshell grill. Using this same design, participants were re-scanned on a separate day of eating the opposite quality steak. Resting state scans measured connections to the right and left nucleus accumbens. Blood oxygen level dependant imaging displayed hemodynamic fluctuation through the brain during fMRI procedures. Initial images were taken in the scanner. Participants left the scanning room, and were fed their sample. Then marked a $152.4 \mathrm{~mm}$ anchored visual analog scale (VAS) at any point along the line, to evaluate tenderness, juiciness, flavor, and overall liking. The VAS was anchored as terrible, very poor, poor, fair, good, very good, and excellent, at $0,25.4,50.8,76.2,101.6,127.0$, and $152.4 \mathrm{~mm}$, respectively. Participants re-entered the scanning room, and scans were taken as soon as possible. Participants left the scanning room to cleanse their palates before reentering and taking a final scan. Analysis of fMRI data was conducted using fMRI Expert Analysis Tool. A priori evaluation was conducted to evaluate connectivity to the right and left nucleus accumbens. Analysis of VAS data was conducted using SAS.

Results: Quality differences in connectivity correlated to the right and left nucleus accumbens were observed in the medial orbitofrontal cortex (mOFC), amygdala, and hippocampus regions $(P \leq 0.05)$. High quality steak samples had mean VAS measurements of 140.5, 134.4, 142.8 and 139.2, for tenderness, juiciness, flavor, and overall liking, respectively. Low quality steak samples had mean VAS measurements of 49.3, 49.5, 49.0, and 52.6, for tenderness, juiciness, flavor, and overall liking, respectively. High quality samples elicited greater VAS measurements $(P \leq 0.01)$ for each palatability trait compared to low quality steaks. 
Conclusion: The relationship between VAS and fMRI data suggest that connected regions respond to different qualities of steak differently. A general increase in connectivity to the right and left nucleus accumbens was observed in the hippocampus and mOFC after consuming high quality steak. Previous research suggests the nucleus accumbens is a candidate for mediation of forming hedonic properties of food. This information could lead to new methods used to develop and market meat products. In recent years there have been numerous advances made in neural topography. This research adds knowledge to many other areas of study about responses to hedonic stimuli.

Keywords: Beef, Blood Oxygen Level Dependant, Hemodynamic, Neuroimaging, Sensory Evaluation 


\title{
Consumer Topics
}

\section{HONDURAN CONSUMER EVALUATION OF HONDURAN AND UNITED STATES BEEF FROM DIFFERENT PRODUCTION AND PROCESSING SYSTEMS}

\author{
M. R. Phelps 1,*, A. R. Gomez ${ }^{1}$, A. J. Garmyn ${ }^{1}$, T. G. O'Quinn ${ }^{2}$, J. C. Brooks ${ }^{1}$, M. F. Miller ${ }^{1}$ \\ 1Department of Animal and Food Sciences, Texas Tech University, Lubbock, ${ }^{2}$ Department of Animal Sciences and \\ Industry, Kansas State University, Manhattan , United States
}

Objectives: In Honduras, the primary type of cattle is Bos indicus, dairy type, or a cross between the two; whereas in the United States (US), primarily Bos taurus cattle are used for beef production. One of the main production goals in Honduras is milk production. Therefore, many of the cattle used are considered dual purpose, initially used for dairy production, having a secondary use for beef production. Because of production and processing systems, Central American countries tend to have lower quality meat. In order to combat the low quality resulting from these inherent factors, enhancement methods have been implemented. Therefore, the objective of this study was to evaluate the effects of production system, processing system, and country of origin on the palatability of strip loin steaks as determined by Honduran consumers $(n=240)$.

Materials and Methods: US-sourced strip loins from grain-finished cattle were selected to equally represent: USDA Select quality grade $(n=10)$ and Top (upper $2 / 3)$ Choice $(n=10)$. Strip loins from Honduras included dual-purpose cattle (HDP; $n=10$ ), grain-fed (HGF; $n=10$ ), sugar-cane (HSC; $n=10$ ), enhanced dual purpose (EDP; $n=10$ ), enhanced grain-fed (EGF; $n=10$ ) and enhanced sugar-cane (ESC; $n=10$ ). After $21 \mathrm{~d}$ of anaerobic storage, strip loins were fabricated into 2.5 $\mathrm{cm}$-thick steaks and frozen $\left(-20^{\circ} \mathrm{C}\right)$. Steaks were thawed, cooked on clamshell grills to a well-done $\left(77^{\circ} \mathrm{C}\right)$ degree of doneness, portioned into eight uniform pieces, and served warm to panelists. Each sample was evaluated on an 8-point hedonic scale for tenderness, flavor, juiciness and overall liking; and each trait was classified as acceptable or unacceptable. Willingness to pay (WTP) for each sample was rated in Honduran Lempiras (HLN) $0 \mathrm{HNL}, 140.91 \mathrm{HNL}$, 281.82 HNL, and 469.70 HNL per kilogram. Data for sensory attributes were analyzed using the GLIMMIX procedure of SAS as a completely randomized design that included the fixed effect of treatment and the random effect of panelists and an alpha level of 0.05 .

Results: Undoubtedly, EGF was most preferred of all treatments as indicated by greater palatability scores, acceptability, and WTP than any other treatment $(P<0.05)$. Conversely, DP exhibited the poorest eating quality as shown by lower scores, acceptability, and WTP than any other treatment $(P<0.05)$. US-sourced samples were scored alike for all traits with similar acceptability $(P>0.05)$. Overall, Honduran consumers ranked Honduran-sourced (non-enhanced) samples as follows: GF $>\mathrm{SC}>\mathrm{DP}(P<0.05)$. The enhanced samples were scored greater than their non-enhanced counterparts $(P<0.05)$. Enhancing HSC produced scores similar $(P>0.05)$ to HGF. Likewise, EDP were not different from HSC $(P>$ 
0.05). Without enhancement, only HGF was comparable to either TC or SE $(P>0.05)$, with the exception that TC had greater tenderness than HGF $(P<0.05)$.

Conclusion: Honduran consumers can detect eating quality differences between various finishing diets and are willing to pay more for steak samples they prefer. Moreover, enhancement can improve eating quality scores and acceptability of Honduran samples so that they are comparable or superior to US sourced beef samples.

Keywords: Beef, Consumer, Enhancement, Honduras 


\section{Consumer Topics}

\section{BEEF FLAVOR ATTRIBUTES AND CONSUMER PERCEPTION II}

T. J. Luckemeyer ${ }^{1,{ }^{*}}$, R. K. Miller ${ }^{1}$, C. R. Kerth ${ }^{1}$, K. Adhikari 2

${ }^{1}$ Animal Science/Meat Science, Texas A\&M University, College Station, 2Food Science, University of Georgia Athens, Athens, United States

Objectives: Beef flavor has been shown to be an important component of consumer acceptance and overall liking; however, it is complex and is composed of multiple attributes. Additionally, consumer attitudes vary in factors that drive acceptance and it has been hypothesized that beef flavor drivers may differ for consumers who eat beef 1 to 2 times per week compared to heavy beefeaters. Our objectives were to create varying levels of positive and negative beef flavor attributes, measure these attributes with an expert trained meat descriptive flavor panel, identify the volatile compound and measure consumer liking for light beef eaters, and to understand the relationships between trained descriptive flavor attributes, volatile flavor compounds, beef chemical attributes and light beef-eater consumer liking.

Materials and Methods: Levels of positive and negative beef flavor attributes were created by identifying beef cuts (Choice strip loins (TLS), high pH [>6.0]) strip loins (HphTLS), Choice top sirloin butts (CTSS), Choice tenderloins (CT), Select bottom rounds (SBR), and Choice bottom rounds (CBR)) from 10 beef carcasses. Cuts were cooked to $58{ }^{\circ} \mathrm{C}$ and $80^{\circ} \mathrm{C}$ utilizing a clamshell grill (TLS, HphTLS, CTSS and CT), food-service grill (TLS, HphTLS, CTSS and CT), or crock-pot (SBR and CBR). Trained beef descriptive flavor and texture attributes, consumer liking ( $n=80$ per city in Olathe, KS; State College, PA; and Portland, OR), and gas chromatography with dual sniff ports (GC/MS/O) were utilized to measure flavor. Warner-Bratzler shear force, fatty acid composition, non-heme iron and myoglobin content, $\mathrm{pH}$, and fat and moisture analysis were determined to understand chemical components relationship to the aforementioned beef flavor measures.

Results: Cooking method, cut, and internal temperature impacted beef descriptive flavor and texture attributes and consumer liking ratings $(P<0.05)$. Beef identity was higher in CT, CTLS, HphTLS and CTSS cooked on the grill to $80^{\circ} \mathrm{C}$ $(P<0.05)$. When these steaks were cooked on the clamshell grill, beef identity was lower $(P<0.05)$. Roasts cooked in crockpots had lower beef identity $(P<0.05)$ and HphTLS had less beef identity than CTLS cooked on the clamshell grill to 58 or $80^{\circ} \mathrm{C}$ or cooked on the grill to $58^{\circ} \mathrm{C}$. Brown/roasted was lower and bloody/serumy were higher when steaks or roasts were cooked to lower internal temperature endpoints. Fat-like flavor was higher in CTLS and lower in roasts regardless of cooking method. Flavor, beef flavor and overall liking were rated similarly across treatments and treatments affected consumer ratings $(P<0.05)$. Consumers rated CT and CTSS cooked on the grill to either 58 or $80^{\circ} \mathrm{C}$ highest for overall, overall flavor, beef flavor, and grill flavor liking $(P<0.05)$. As brown/roasted and fat-like increased, consumer liking increased $(P<0.05)$. Aromatic volatile compounds $(n=248)$ were identified. Fifteen aromatic volatile chemicals accounted 
for $57 \%$ of consumer overall like/dislike. Partial least squares regression $\left(R^{2}=0.87\right)$ showed relationships between trained descriptive flavor and texture attributes, consumer liking and volatile aromatic chemical compounds.

Conclusion: When beef flavor differed as determined by descriptive beef flavor attributes or aromatic volatile compounds, consumer liking was impacted for light beefeaters. Key aromatic volatile compounds or descriptive flavor attributes could be used to increase consumer overall liking for light beefeaters.

Keywords: Beef flavor

\section{Consumer Topics}

10

\section{DETERMINATION OF THE EFFECT OF BRANDING ON CONSUMER PALATABILITY RATINGS OF BEEF STRIP LOIN STEAKS}

A. K. Wilfong 1, ${ }^{\text {, }}$ K. V. Ognoskie ${ }^{1}$, J. M. Gonzalez ${ }^{1}$, T. A. Houser ${ }^{1}$, E. A. E. Boyle ${ }^{1}$, J. A. Unruh 1 , T. G. O'Quinn ${ }^{1}$

${ }^{1}$ Animal Science and Industry, Kansas State University, Manhattan, United States

Objectives: The objective of this study was to determine how consumer palatability ratings of beef strip loin steaks are affected when products are identified with a brand or USDA grade.

Materials and Methods: Strip loins ( $n=40 ; 8$ / treatment) were selected to represent five quality levels - USDA Select, Low Choice, Prime, Certified Angus Beef ${ }^{\circledR}(C A B$; upper 2/3 Choice), and Select from phenotypical Angus cattle. Strip loins were stored under vacuum at $0-4^{\circ} \mathrm{C}$ for 21 days prior to steak fabrication. After aging, $2.5 \mathrm{~cm}$ thick steaks were cut from the strip loins, pairing consecutively cut steaks for consumer evaluation. Steaks were frozen and stored $\left(-20^{\circ} \mathrm{C}\right)$ until subsequent testing. Steaks were thawed $24 \mathrm{~h}$ at $2-4^{\circ} \mathrm{C}$ prior to evaluation, and cooked in a convection oven (DFG-100-3 Series, GS Blodgett Co., Inc. Burlington, VT) to $71^{\circ} \mathrm{C}$, monitored by thermocouples attached to a Doric Mini-trend Data Logger (Model 205 B-1-c OFT, Doric Scientific, San Diego, CA). Following cooking, steaks were cut into $1 \mathrm{~cm}$ cubes and immediately served to consumers. Consumer panelists $(n=112)$, recruited from Manhattan, $K S$ and the surrounding communities, evaluated samples for tenderness, juiciness, flavor liking, and overall liking on $10 \mathrm{~cm}$ line-scales anchored at end and mid-points. Additionally, consumers rated each palatability trait as either acceptable or unacceptable and rated the sample as either unsatisfactory, everyday quality, better than everyday quality, or premium quality. Samples were fed in two rounds - blind and non-blind testing. For blind testing, consumers were served one sample from each treatment, in a random order with treatments not disclosed. For non-blinded testing, samples were identified with the treatment prior to the serving of each sample. Samples evaluated by consumers were paired for blind and non-blind testing, allowing for minimal variation across testing rounds.

Results: During blind testing, Prime and $\mathrm{CAB}^{\circledR}$ were rated better $(P<0.05)$ than Select and Select Angus samples for flavor and overall liking; however when treatments were disclosed, Select Angus samples were rated similar $(P>0.05)$ to 
$\mathrm{CAB}^{\circledR}$ samples for flavor. Also, $\mathrm{CAB}^{\circledR}$ was rated similar $(P>0.05)$ to Low Choice for overall liking in blind testing; however, $\mathrm{CAB}^{\circledR}$ was rated greater $(P<0.05)$ than all treatments other than Prime in non-blind testing. Treatment disclosure positively affected $(P<0.05)$ consumer flavor and overall liking ratings for $\mathrm{CAB}^{\circledR}$, Prime, and Angus Select samples. Additionally, USDA grade knowledge decreased $(P<0.05)$ tenderness ratings for Select samples. Moreover, treatment knowledge increased $(P<0.05)$ the percentage of $\mathrm{CAB}^{\circledR}$ samples rated as acceptable for juiciness and the percentage of Angus Select samples rated acceptable for flavor and overall liking. Finally, brand disclosure increased $(P<0.05)$ the percentage of samples rated as premium quality for Prime and Angus Select samples and the percentage of samples rated as better than everyday quality for $\mathrm{CAB}^{\circledR}$ samples.

Conclusion: These results indicate brand knowledge has an effect on consumer perception of beef palatability traits. Multiple traits were rated better for Prime, $\mathrm{CAB}^{\circledR}$, and Angus Select products indicating these products received an increase in palatability perception when identified with the brand.

Keywords: beef, brand recognition, consumer, palatability, strip loin 


\section{Consumer Topics}

11

\section{REFERENCES FOR MINOR BEEF FLAVOR DESCRIPTIVE ATTRIBUTES}

H. Laird ${ }^{1, *}$, K. Koppel ${ }^{2}$, R. K. Miller ${ }^{1}$, C. R. Kerth ${ }^{1}$

${ }^{1}$ Animal Science, Texas A\&M University, College Station, ${ }^{2 H u m a n}$ Nutrition , Kansas State Univeristy , Manhattan, United States

Objectives: The Beef Flavor Lexicon was published in 2011 and has been used to understand pre- and post-harvest factors that affect beef flavor. Additionally the new cookery and sensory guidelines were published in 2015 and included the Beef Flavor Lexicon. The Beef Flavor Lexicon includes major and minor flavor attributes. Each attribute is defined and references are given to provide an understanding of the attribute and how to identify intensity difference. Minor beef flavor attributes are not always present in beef samples or are usually present at low levels. There has been difficulty using the references from the Beef Flavor Lexicon for these attributes. Our objective was to develop new beef flavor references for minor attributes using a ground beef model system. These references were used to provide intensity of the minor beef flavor attributes at two intensity levels.

Materials and Methods: Minor beef flavor attributes $(n=24)$ were green-haylike, umami, barnyard, rancid, heated oil, chemical, apricot, green, asparagus, cumin, floral, beet, chocolate/cocoa, medicinal, petroleum-like, smokey/charcoal, smokey/wood, dairy, buttery, cooked milk, sour milk/dairy, refrigerator stale, soapy, and warmed over. Commercial ground beef ( $20 \%$ chemical lipid) was purchased. For green-haylike, umami, barnyard and rancid, dried parsley, Accent, white pepper and vegetable oil heated in a microwave, respectively, were added at two levels. Heated oil, bleach, apricots or apricot nector, fresh parsley, and canned asparagus were added to ground beef at two levels for heated oil, chemical, apricot, green and asparagus flavor attributes. Cumin, jasmine green tea, canned beet juice chocolate pudding mix, cough spray, petroleum jelly were added at two levels to the ground beef for cumin, floral, beet, chocolate, medicinal, and petroleum like. For the attributes, smoky charcoal, smoky wood, dairy, buttery, cooked milk, sour milk/dairy, and soapy, charsol and applewood liquid smoke, heavy whipping cream, imitation butter, Babybel swiss cheese and Colby cheese, Original Laughing Cow Swiss cheese and Ivory soap was added to the ground beef at two different levels. Refrigerator stale and warmed over flavor samples were cooked and kept in the refrigerator for two different periods of time and the latter was reheated prior to serving. Expert, trained beef flavor descriptive attribute panelists $(n=5)$ with extensive experience using the Beef Flavor lexicon evaluated ground beef samples, independently rated the sample for the specified attribute. After evaluation, panelists came to consensus on intensity level for each reference sample. Panelists evaluated each formula twice.

Results: Panelists identified intensity differences in the ground beef formulations for the 24 attributes. 
Conclusion: Minor beef flavor descriptive attributes were identified in a ground beef model system using formulations defined. When using these formulas, the 24 minor beef flavor attributes were identified at two levels of intensity and assisted panelists in understanding the definition and how to scale for each attribute.

Keywords: Beef flavor, beef lexicon, Sensory Evaluation, trained panel 


\section{Consumer Topics}

12

\section{PORK CUT PRESENTATION EFFECT ON CONSUMER SENSORY RATINGS}

T. Yao ${ }^{1, *}$, H. Laird ${ }^{2}$, R. Miller ${ }^{2}$, C. Kerth ${ }^{2}$

${ }^{1}$ Animal Science, ${ }^{2}$ Texas A\&M University, College Station, United States

Objectives: New cookery and sensory guidelines for whole muscle meat have been published (AMSA, 2015) and include methods for presentation of whole muscle meat (chops or steaks) to consumers in central location tests. Researchers commonly present whole muscle meat to consumers for evaluation as either pre-cut, standard sized cubes or as whole or a portion of a whole steak or chop to allow the consumer to cut their own meat piece. While either method of presentation is acceptable, understanding if method of presentation (whole versus cubes) affects consumer ratings has not been examined. Our objective was to understand if presentation method (whole versus cubes) affected consumer overall, flavor, juiciness or tenderness liking for whole muscle pork chops.

Materials and Methods: Pork loin chops $(n=200)$ were randomly assigned for presentation as intact (half of a pork loin chop presented to a consumer on a white plate with a stainless steal fork and knife) or as cubes (two $1.27 \mathrm{~cm}$ cubes presented in a plastic soufflé cup with a toothpick). Pork loin chops were cooked on a flat electric grill to $70^{\circ} \mathrm{C}$ internal temperature monitored by copper constantan thermocouples inserted in the geometric center. After cooking, chops were cut in half. Consumers $(n=100)$, selected to eat pork 1 or more times per week, evaluated the pork chops over 2 d. Each consumer was presented 4 samples (whole versus cubes from 2 pork chops). Samples were served in random order. Consumers rated overall liking, flavor liking, juiciness liking and tenderness liking using 9-point, end and center labeled hedonic scales. Data were analyzed for ANOVA using the GLM procedure of SAS (v9.3, SAS Institute, Inc., Cary, NC) where session and order were defined as blocks and treatment (whole versus cubes) was defined as the treatment. Least squares means were calculated and when significant $(P<0.05)$, least squares means were separated using Fisher's LSD.

Results: Consumer ratings for overall liking, flavor liking, and juiciness liking were not affected by serving presentation $(P=0.51,0.96$, and 0.36 , respectively). However, consumers rated whole muscle samples higher for tenderness like than cubes $(6.2$ vs $5.3+0.16 ; P<0.001)$. Variations in consumer ratings were similar across treatments.

Conclusion: These results indicate that when conducting consumer central location sensory evaluations, researchers should consider presenting samples as whole muscle samples instead of cubes when tenderness is an important consumer attribute. Whole muscle products, like pork chops, are traditionally consumed with consumers cutting their own portions. In the process of cutting, consumers assess information related to tenderness that influences tenderness liking ratings. It is not known if this information is related to size of portion that they cut or if information on ease or resistance during cutting affects their tenderness ratings. 
Keywords: cube, pork loin chop, sensory, whole muscle meat 


\section{Consumer Topics}

13

\section{FLAVOR AND TENDERNESS DESCRIPTIVE ATTRIBUTES IN STEAKS WITH DIFFERENT STEAK THICKNESS, QUALITY GRADE AND COOKING SURFACE TEMPERATURES}

M. Berto ${ }^{1, *}$, C. R. Kerth ${ }^{1}$, R. K. Miller ${ }^{1}$, J. W. Savell ${ }^{1}$

1Department of Animal Science, Texas A\&M University, College Station, United States

Objectives: Beef flavor is comprised partly from aromas generated from either thermal lipid degradation (TLD) or Maillard browning reactions. Maillard reactions (MR) occur during cooking and are influenced by length of time the surface of a steak is exposed to heat and the surface temperature of the heating unit. Steak thickness affects the length of time of cooking and provides greater opportunity for MR during cooking. The interaction of TLD and MR products during cooking of HS and TC strip loin steaks is not known. It is hypothesized that flavor of HS and TC steaks can be improved by optimizing the surface browning of strip loin steaks using combinations of steak thickness (thicker steaks require longer time in contact with the cooking surface for browning) and grill temperature (temperature controls the rate and extent of browning). Our objectives were to create varying levels of positive and negative beef flavor attributes by inducing differences in TLD and MR products and measuring these attributes with an expert trained meat descriptive flavor panel with steak differing in quality grades (HS and TC), thickness $(1.27$ and $3.81 \mathrm{~cm})$ and grill temperature $\left(176^{\circ} \mathrm{C}\right.$ or $\left.232^{\circ} \mathrm{C}\right)$ cooked on a flat commercial grill.

Materials and Methods: Beef strip loins (TC and HS; n=32) were sliced 3.81 and $1.27 \mathrm{~cm}$ thick. Thawed steaks were cooked on an electric commercial flat grill set at either $176^{\circ} \mathrm{C}$ or $232^{\circ} \mathrm{C}$ to an internal cook temperature of $71^{\circ} \mathrm{C}$. Trained beef descriptive flavor and texture attributes were evaluated using a 6-member expert, trained flavor and meat texture descriptive attribute panel trained on the beef lexicon.

Results: Beef flavor $(n=44)$ and beef texture $(n=4)$ attributes were evaluated. Attributes that were barely or not detected $(n=31)$ were not presented and included green hay-like, liver-like, sour aromatic, animal hair, barnyard, rancid, heated oil, chemical, leather, apricot, green, asparagus, musty/earthy, cumin, floral, beet, chocolate/cocoa, medicinal, petroleum, smokey wood, spoiled, dairy, buttery, cooked milk, sour milk/sour dairy, refrigerator stale, soapy, warmed over, painty, fishy and cardboard. Quality grade did not affect most flavor attributes, except thick TC steaks had higher beef identity and brown/roasted flavor than TC and HS $1.27 \mathrm{~cm}$ steaks $(P<0.05)$. The HS $3.81 \mathrm{~cm}$ steaks had the lowest fat-like flavor $(P<0.05)$. The thickness by grill temperature interaction was significant $(P<0.05)$ for metallic, umami, overall sweet, sweet, sour, salt, bitter and burnt flavor or basic tastes. The TC, $3.81 \mathrm{~cm}$ steaks had lower levels of umami, overall sweet, sweet and higher levels of bitter and burnt flavor. The 3.81-cm-thick steaks had lower levels of bloody/serumy and high smokey charcoal flavor aromatics, and were more tender $(P<0.05)$ than the $1.27 \mathrm{~cm}$ steaks. However, quality grade did not affect $(P>0.05)$ bloody/serumy and smokey charcoal flavor aromatics, or tenderness. Steaks cooked on the grill at $176^{\circ} \mathrm{C}$ were higher in bloody/serumy, lower in smokey charcoal, and were tougher than steaks cooked on the grill at $232^{\circ} \mathrm{C}(P<0.05)$. 
Conclusion: Steak thickness and grill temperature affect the major flavor attributes of beef.

Keywords: Beef Flavor, Beef Lexicon, Maillard Reaction, Steak Thickness, Trained Panel 


\section{Consumer Topics}

14

\section{INFLUENCE OF BRAND RECOGNITION ON CONSUMER PERCEPTION OF BEEF PALATABILITY OF TOP LOIN STEAKS}

O. Ron 1,*, T. G. O'Quinn ${ }^{2}$, A. J. Garmyn ${ }^{1}$, J. C. Brooks ${ }^{1}$, M. F. Miller ${ }^{1}$

${ }^{1}$ Animal \& Food Sciences, Texas Tech University, Lubbock, TX, ${ }^{2}$ Animal Sciences and Industry, Kansas State University, Manhattan, KS, United States

Objectives: With more consumers gravitating away from conventionally raised meat products because of concerns about health, nutrition, animal welfare or sustainability; understanding the impact that brand and production systems play on consumer perception of palatability and consumer preference is integral to understanding consumer palatability and bias. The purpose of this study was to compare consumer palatability trait scores of beef strip loins representing varied production systems or brands in a blind and obscured taste panel.

Materials and Methods: Strip loins were selected to represent a Grain-Fed Natural (Natural), Certified Angus Beef ${ }^{\circledR}(C A B)$, Local Grass Fed (LGF), USDA Select (Select), and USDA Certified Organic (Organic) production systems. After $21 \mathrm{~d}$ of storage, strip loins were cut into $2.5 \mathrm{~cm}$ thick steaks and stored at $-20^{\circ} \mathrm{C}$ until analysis. Thawed samples were cooked on a belt grill to a medium degree of doneness $\left(71^{\circ} \mathrm{C}\right)$ and evaluated by consumers $(n=120)$ for flavor, juiciness, tenderness and overall liking. Each trait was rated on a $100 \mathrm{~mm}$ verbally anchored line scale. Each panelist was served two, $1 \mathrm{~cm} \times 1$ $\mathrm{cm}$, pieces per sample. Initially, panelists were served steaks representing the five production system treatments without any knowledge of their identity (blind). Next, panelists were served five USDA Select samples but were read a short description of each production system treatment before each sample, leading them to believe they were sampling a steak from that treatment. However, all samples evaluated were paired from the same strip loin as the Select samples evaluated during blind testing.

Results: When consumers were fed the samples blind, Natural and CAB samples were scored higher than all other treatments for all palatability traits $(P<0.05)$. Organic was scored lower $(P<0.05)$ than LGF or Select for tenderness, while both LGF and Organic were rated lower $(P<0.05)$ than Select for flavor and overall liking. When consumers were fed USDA Select samples they believed were actually from different production systems, CAB were rated 10.3, 13.4, and 11.3 units higher $(P<0.05)$ with Organic rating 6.8, 9.0, and 7.6 units higher $(P<0.05)$ for tenderness, flavor, and overall liking, respectively, when compared to scores from blindly served USDA Select samples they had previously evaluated. Moreover, consumers scored overall liking of LGF 6.7 units higher $(P<0.05)$ and Natural 7.7 units higher $(P<$ $0.05)$ for flavor than USDA Select steaks served blind. Interestingly, juiciness scores did not differ $(P>0.05)$ between the blind Select or any of the 5 Select samples that consumers believed were from different production systems.

Conclusion: These results indicate brand recognition can have significant impacts on consumer assessment of

palatability. Most prominently, when consumers heard verbal descriptions for CAB and Organic production systems this 
elicited improved responses for tenderness, flavor, and overall liking although consumers were unknowingly sampling USDA Select steak samples. Verbal descriptions for Natural boosted scores for flavor, while overall liking improved when consumers believed they were sampling LGF. In no instances did brand recognition have a negative effect on tenderness, juiciness, flavor, or overall liking.

Keywords: Beef, Bias, Consumer Palatability, Production Systems, sensory 


\section{Consumer Topics}

15

\section{DETERMINATION OF THE EFFECT OF BRAND AND PRODUCT IDENTIFICATION ON CONSUMER PALATABILITY RATINGS OF GROUND BEEF PATTIES}

K. V. Ognoskie 1, ${ }^{\star}$, A. K. Wilfong ${ }^{1}$, J. M. Gonzalez ${ }^{1}$, T. A. Houser ${ }^{1}$, E. A. E. Boyle ${ }^{1}$, J. A. Unruh ${ }^{1}$, T. G. O'Quinn ${ }^{1}$ ${ }^{1}$ Animal Science and Industry, Kansas State University, Manhattan , United States

Objectives: The objective of this study was to determine the effect of brand and product identification on consumer palatability ratings of ground beef patties.

Materials and Methods: Six treatments (six 4.5kg-chubs / treatment) were selected to represent a variety of product types, fat levels and brands and included: 90/10 Certified Angus Beef ${ }^{\circledR}$ (CAB) ground sirloin, 90/10 commodity, 80/20 CAB ${ }^{\circledR}$ ground chuck, 80/20 commodity ground chuck, 80/20 commodity, and 73/27 CAB ${ }^{\circledR}$. Ground beef was transported under refrigeration to Kansas State University Meat Laboratory and stored at $0-4{ }^{\circ} \mathrm{C}$ prior to patty formation. Ground beef chubs were fabricated into $226.8 \mathrm{~g}$ patties using a patty former (Super Model 54 Food Portioning Unit, Hollymatic, Countryside, II). Formed patties were paired and identified, with two consecutively formed patties assigned to blinded consumer testing and the following two assigned to the non-blinded testing. Patties were frozen and stored at $-20^{\circ} \mathrm{C}$ until subsequent analysis. Patties were thawed at $2-4^{\circ} \mathrm{C}$ for $24 \mathrm{~h}$ prior to evaluation, and prepared using a convection oven (DFG-100-3 Series, GS Blodgett Co. Inc., Burlington, VT), to $74^{\circ} \mathrm{C}$ monitored by thermocouples connected to a Doric Mini-trend Data Logger 205 B-1-c OFT (Doric Scientific, Dan Diego, CA). Following cooking, patties were cut into quarters and served to consumers $(n=112)$ who evaluated samples in two rounds for tenderness, juiciness, flavor, texture, and overall liking on $10 \mathrm{~cm}$ line scales anchored on both ends and at the midpoint with descriptive terms. Also, each trait was rated as acceptable or unacceptable and the sample was classified as unsatisfactory, everyday quality, better than everyday quality, or premium quality. The first evaluation round included one sample from each treatment served in a random order with all treatments blinded to consumers. In the second round, consumers evaluated one sample from each treatment in a random order and were informed of the product type and brand prior to evaluation.

Results: Few differences were observed among treatments during blind testing for all palatability traits, with 90/10 commodity rating less $(P<0.05)$ than all other treatments for tenderness and less $(P<0.05)$ than 80/20 commodity for overall liking. However, when treatment was revealed to consumers, 90/10 $\mathrm{CAB}^{\circledR}$ ground sirloin rated the greatest $(P<$ $0.05)$ for tenderness, flavor, texture, and overall liking. Also, the percentage of samples rated as acceptable for tenderness, flavor, texture, and overall liking were greatest $(P<0.05)$ for $90 / 10 \mathrm{CAB}^{\circledR}$ ground sirloin when treatments were known.

Treatment disclosure increased $(P<0.05)$ tenderness, juiciness, flavor, and overall liking ratings for $90 / 10 \mathrm{CAB}^{\circledR}$ ground sirloin samples as well as flavor and overall liking ratings for $80 / 20 \mathrm{CAB}^{\circledR}$ ground chuck. Also, greater percentages $(P<$ 
0.05 ) of samples were rated as acceptable overall for all $\mathrm{CAB}^{\circledR}$ products evaluated when products were identified with the brand.

Conclusion: These results indicate few palatability differences among ground beef treatments when tested blind.

However, when product and brand were identified, multiple treatments received increased ratings for palatability traits.

Therefore, branding and product awareness have a large effect on consumer perception of ground beef palatability.

Keywords: Beef, consumer, ground beef, palatability, sensory 


\title{
Consumer Topics
}

17

\section{QUANTIFYING ATTITUDES AND KNOWLEDGE CHANGE TOWARD ANIMAL WELFARE AND SUSTAINABILITY OF ANIMAL AGRICULTURE AND THE SAFETY AND HEALTHFULNESS OF MUSCLE FOODS}

\author{
C. Carr 1, ${ }^{*}$, K. Abrams ${ }^{1}$, V. Velinsky ${ }^{1}$, L. Eubanks ${ }^{1}$, D. Johnson ${ }^{1}$ \\ 1 University of Florida, Gainesville, United States
}

Objectives: The average American is now at least three generations removed from production agriculture. This leads to the disconnection between how the public views agriculture and how scientists and producers view it, resulting in consumer distrust of science and commercial food production. It is this lack of trust which leads to consumer confusion and the urge to grasp at multiple solutions. However, a growing number of consumers in developed countries are aspiring to "know where their food comes from". Animal agriculture needs to explain the technology which will be used to sustainably feed 9 billion people by 2050 .

During the summer of 2014, the undergraduate consumer education course "The Meat We Eat" which has been taught on campus at the University of Florida for over 40 consecutive spring and fall semesters was taught as a Massive Open Online Course to over 20,700 people from 169 different countries enrolled via the Coursera platform.

https://www.coursera.org/course/meatweeat.

Materials and Methods: The purpose of the course was to create a more informed consumer about the quality, safety, healthfulness and sustainability of muscle foods and address current issues in animal agriculture in developed and developing countries. A secondary initiative is to improve the transparency of meat animal agriculture in the U.S. and internationally. Lectures covered all aspects of muscle foods production, processing, preparation, cooking and storage. Additionally, the role of muscle foods in a balanced diet was addressed as well as issues which contribute to consumers limiting or eliminating meat from their diets. Students were asked to complete an online inquiry prior to and after completing the class including questions to assess: attitude toward the meat industry $(n=4)$, slaughter attitude $(n=$ $5)$, need for slaughter transparency $(n=6)$, perceptions of the meat industry's transparency $(n=6)$, and knowledge $(n=$ 9). Student responses were combined to make composite values then averaged to generate values.

Results: The table below depicts the value of these kinds of extension activities relative to improving attitudes toward animal agriculture.

Table 1. Impact of program completion on attitudes toward or knowledge about animal agriculturea

\begin{tabular}{|l|l|l|l|}
\hline & Pre $(\mathrm{n}=490)$ & Post $(\mathrm{n}=226)$ & $P$-value \\
\hline Attitude toward meat $^{\mathrm{b}}$ & $9.9 \pm 0.1$ & $11.4 \pm 0.2$ & 0.001 \\
\hline Attitude toward slaughter $^{\mathrm{b}}$ & $11.4 \pm 0.2$ & $14.2 \pm 0.3$ & 0.001 \\
\hline Need for slaughter transparency $^{\mathrm{b}}$ & $18.9 \pm 0.2$ & $18.7 \pm 0.2$ & 0.57 \\
\hline Perception of meat industry's transparency $^{\mathrm{b}}$ & $15.6 \pm 0.2$ & $18.1 \pm 0.3$ & 0.001 \\
\hline Quiz score $^{b}$ & $69.6 \pm 0.9$ & $78.2 \pm 1.3$ & 0.001 \\
\hline
\end{tabular}

aGreater values indicate improved attitudes/perceptions toward meat industry or improved knowledge about industry. 


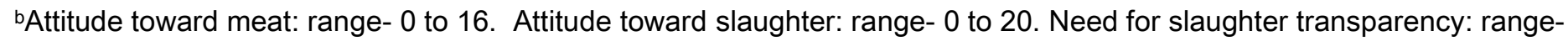
6 to 24. Perception of meat industry's transparency: range- 6 to 24. Need for slaughter transparency range- 6 to 24 . Eight problem quiz score: range- 0 to 100 .

Conclusion: Massive Open Online Courses about muscle food production can have exceptional impact on the attitudes of consumers worldwide.

Keywords: Animal Agriculture, Animal Welfare, Consumer Education 


\section{Education and Extension Tools}

18

\section{STUDENTS' PERCEPTIONS REGARDING THE USE OF TOPHAT AS AN INTERACTIVE TOOL IN MEAT SCIENCE CLASS}

M. M. Neilson ${ }^{1, *}$, G. Mafi ${ }^{1}$, K. Pfeiffer ${ }^{1}$, D. VanOverbeke ${ }^{1}$, R. Ramanathan ${ }^{1}$

1Animal Science, Oklahoma State University, Stillwater, United States

Objectives: Student interaction is a critical component to successful learning. New knowledge is better comprehended when students become involved in the classroom discussion. The overall goal of this study was to evaluate students' perception of utilizing the smartphone based interactive tool (TopHat) during the Introduction to Meat and Carcass Evaluation class.

Materials and Methods: Students were required to use this tool during the course. They were given instructions on how to download and join the course on the interactive tool during the initial week of class. The course, which was offered during the Fall of 2014 had 180 students. Ten questions were asked during the $12^{\text {th }}$ week of the course to evaluate the students' perception of TopHat. The scale of the survey was 1 (not at all true) to 7 (very true). One hundred twenty students participated in the survey.

Results: In the survey, $57 \%$ of the students indicated that using TopHat was of some value to them, $46 \%$ noted that TopHat helped them keep focused, $84 \%$ believed that it is a good review tool, $28 \%$ believed it helped them communicate with their instructor, $56 \%$ indicated it improved their study habits and was somewhat beneficial to them, $69 \%$ were willing to use TopHat again because it is useful and of value to them, and $63 \%$ believed using TopHat helped them do better in school. Additionally, from an instructor perspective, TopHat allows them to incorporate a variety of question formats and also an interactive review tool during lecture and for exam preparation.

Conclusion: In summary, interactive learning tools such as TopHat provide students with a collaborative learning experience and allow them to provide quick instructor feedback.

\section{Conclusion:}

Keywords: Engagement, Interaction, Meat Science , Student Learning 


\title{
Education and Extension Tools
}

19

\section{CASE STUDY APPROACHES FOR IMPROVING LEARNING AND DECISION-MAKING IN MEAT SAFETY}

\author{
A. Kollanoor-Johny ${ }^{1}$, A. Upadhyay ${ }^{2}$, C. Faustman ${ }^{2}$, K. Venkitanarayanan 2,*
}

${ }^{1}$ Animal Science, University of Minnesota, St. Paul, ${ }^{2}$ Animal Science, University of Connecticut, Storrs, United States

Objectives: The microbiological safety of foods is a significant concern for the health of U.S. citizens and the viability of the nation's food industry. Traditional approaches for teaching food safety and microbiology to undergraduate students have focused on instructor-centered lectures, rote memorization of the names and characteristics of microorganisms, and the role of processing for ensuring food safety. Integration of fundamental concepts for application within a 'real world' context promotes experiential learning by students. Case-study teaching provides a means to accomplish this by offering multiple approaches for effective instruction through 'real life' examples. Our objective was to increase the quantity and quality of undergraduate students enrolled with food safety and microbiology classes through innovative case study approaches.

Materials and Methods: Two case studies entitled "Hamburger safety: What tools should be used?" based on an interrupted case design, and "Who is responsible? E. coli in the kitchen" based on role-playing case design were developed for teaching in six different universities, and assess the impact of this approach on student learning outcomes. The first case focused on post-harvest treatments to control pathogenic E. coli $157: \mathrm{H} 7$ on beef carcasses, whereas the second case discussed a $E$. coli $\mathrm{O} 157: \mathrm{H} 7$ outbreak investigation process using a real case as an example.

Results: These cases are currently being taught in the participating institutions, and student performance in tests covering case study topics will be assessed.

Conclusion: The project is expected to result in an increased student interest and participation in food safety classes and improved learning of the subject, which could translate into enhanced problem solving skills, decision-making and knowledge application in workplace.

Keywords: Case study, meat safety, teaching 


\section{Environment, Production Systems}

20

\section{INFLUENCE OF GRAZING PRIOR TO FINISHING ON A HIGH CONCENTRATE RATION, ON COLOUR AND SENSORY CHARACTERISTICS OF MUSCLE FROM EARLY OR LATE MATURING BULLS SLAUGHTERED AT THE SAME CARCASS WEIGHT}

A. Moloney 1,*, M. McGee 1, E. O'Riordan 1, D. Marren 1, G. Mezgebo 2, F. Monahan 2, I. Richardson ${ }^{3}$

${ }^{1}$ AGRIC, Teagasc, Grange, Co. Meath, ${ }^{2}$ School of Agriculture and Food Science, UCD, Dublin, Ireland, ${ }^{3}$ School of Clinical Veterinary Science, University of Bristol, Langford, United Kingdom

Objectives: Irish suckler bull production systems are predominantly based on late-maturing (LM) genotypes offered high concentrate rations post-weaning. Inclusion of a grazing period prior to high concentrate finishing lowers production costs but achieving the required carcass fat cover at a market-specific weight is a challenge. Early-maturing (EM) genotypes may be more suited to this grass-based production system. The aim was to determine the impacts of genotype and grass forage inclusion in a sucker bull production system on aspects of carcass and meat quality.

Materials and Methods: Fifty six Spring-born LM (March 8) and EM (March 30) weaned bulls were assigned (December 1) to a 2 (genotype) $\times 2$ (production system (PS)) factorial arrangement of treatments. The PS were: concentrates ad libitum together with grass silage (GS) until slaughter (HC) or GS ad libitum and $2 \mathrm{~kg}$ concentrate for 123 days, followed by pasture for 99 days and then concentrates ad libitum together with GS (GHC). Bulls were slaughtered when estimated carcass weight of individual treatment groups was $380 \mathrm{~kg}$. Post slaughter (48 h), pH of the longissimus muscle at the 5/6 rib interface and lightness $(L)$, redness (a) and yellowness (b) of subcutaneous fat and muscle (after $1 \mathrm{~h}$ bloom) were recorded. A sample of cube roll (6/10 rib) was vacuum packaged and frozen for subsequent chemical analysis. The remainder was aged for $14 \mathrm{~d}\left(2^{\circ} \mathrm{C}\right)$ and analysed by a trained sensory panel. Data were subjected to analysis of variance using a model with terms for genotype, PS and their interaction. Initial age was used as a covariate where appropriate.

Results: Mean carcass weight $(381 \mathrm{~kg})$ did not differ $(P>0.05)$ between treatments. Mean age (months) at slaughter was greater $(P<0.05)$ for EM than LM in HC $(16.7 \vee 15.0)$ but similar $(P>0.05)$ for EM and LM $(18.6 \vee 18.3)$ in GHC. Both genotypes had similar fat cover in $\mathrm{HC}$ but LM had less $(P<0.05)$ than EM in GHC. Carcass fat was more yellow $(P<$ $0.05)$ for EM than LM. Muscle $\mathrm{pH}$ did not differ $(P>0.05)$ between treatments but muscle from $\mathrm{HC}$ had higher $(P<0.05)$ "L" and lower $(P<0.05)$ "a" values than muscle from GHC. Intra-muscular lipid concentration was higher $(P<0.05)$ for EM than LM and for HC than GHC. There was no difference $(P>0.05)$ in scores for tenderness, juiciness, beef flavour, abnormal flavour or overall liking between muscle from LM and EM. Muscle from HC had higher $(P<0.05)$ scores for tenderness, flavour liking and overall acceptability and lower $(P<0.05)$ scores for abnormal flavour compared to muscle from GHC. 
Conclusion: Using EM genotypes increased the likelihood of achieving adequate fat cover in a grass-based production system but had little impact on measured meat quality attributes. The changes in muscle colour and sensory characteristics due to incorporating grass forage are unlikely to be relevant to the consumer.

Keywords: Bulls, Maturity, Colour, Sensory characteristics 


\section{Environment, Production Systems}

\section{1}

\section{EFFECT OF FINISHING CATTLE WITH FODDER BEET ON CUTABILITY AND SUBPRIMAL YIELD OF BEEF STEER CARCASSES IN NEW ZEALAND}

J. E. Johnston 1, ${ }^{*}$, A. J. Garmyn ${ }^{1}$, R. J. Rathmann ${ }^{1}$, J. C. Brooks ${ }^{1}$, M. F. Miller ${ }^{1}$

${ }^{1}$ Animal Science, Texas Tech University, Lubbock, United States

Objectives: Traditionally the beef harvest numbers and the quality of cattle decline through the winter months (JuneSeptember) in New Zealand because of weather related availability of forage for grazing. Therefore, beef researchers have investigated the implementation of a feeding system utilizing fodder beet to finish beef steers. Fodder beet may provide a grazing alternative to allow more beef cattle to be finished through the winter months to maintain the beef supply.

Materials and Methods: Carcass sides $(n=493)$ were fabricated and weights were recorded for closely trimmed subprimals, lean trimmings, fat, and waste (bone) to determine if finishing steers $(n=281)$ with fodder beet (FB) the final 70-100 days before slaughter or with traditional winter forage finishing steers $(n=212)$ without FB (NFB) during the same time frame impacted meat weight and yield. Cattle, representing multiple production systems, were harvested from midJuly to October, 2014 at a commercial beef processing facility in the South Island of New Zealand. Carcasses were selected each day to represent a range of carcass weights within each treatment and fat cover within the grades or programs being fabricated for the day. Subprimals were monitored through trays equipped with RFID trackers and weights were captured electronically. Data were analyzed using the GLIMMIX procedure of SAS with finishing diet as fixed effect.

Results: Hot carcass side weight (HSW) was $3 \mathrm{~kg}$ heavier $(\mathrm{P}<0.01)$ for NFB than FB; thus HSW was used to calculate yield of subprimal cuts (as a percentage of HSW) for treatment comparisons. No differences were observed $(P>0.05)$ in carcass traits that would impact yield (rib fat, adjusted rib fat, or ribeye area). NFB carcasses produced $3.4 \mathrm{~kg}$ more total red meat than FB; however, total red meat yield ( $77.7 \%$ vs $77.4 \%)$ and total subprimal yield ( $55.9 \%$ vs $55.4 \%)$ was greater $(P<0.05)$ for FB than NFB carcasses, respectively. Differences in total red meat and subprimal yield are attributed primarily to cuts within the forequarter. Most notably, Ribeye (cube) roll (3.4 vs 3.3\%), chuck roll (4.9 vs $4.6 \%$ ), and clod (6.5 vs $6.3 \%$ ) had greater $(P<0.01$ ) yield (on a percentage of HSW basis) from FB carcasses compared to NFB. NFB carcasses had an advantage in yield for top sirloin butt (D-rump; +0.04\%) compared to FB, but FB carcasses had greater $(P<0.01)$ tenderloin yield $(+0.04 \%)$ than NFB. No differences in yield were observed for any other major hindquarter subprimals (topside/inside, outside flat, knuckle, or strip loin) when adjusting weights as a percentage HSW. However, FB carcasses offered a minor yield advantage (+0.02 to 0.03$)$ compared to NFB in smaller subprimals, such eye of round, tri tip, inside skirt, and chuck tender, while flap meat was greater $(+0.03 \%)$ for NFB than FB sides $(P<0.01)$. 
Conclusion: Fodder beet grazing could be used as an alternative finishing crop during the winter months to increase the quality of beef produced. However, more research is needed to determine differences in subprimal weights between finishing diets at similar end-point carcass weights. Finishing cattle with fodder beet improved the saleable (total red meat) and subprimal yield on a percentage basis, more notably in the forequarter, but taking cattle to heavier live weights prior to harvest could potentially increase yield on a weight basis, as well.

Keywords: Beef, Fodder Beet, Grass Fed 


\title{
Environment, Production Systems
}

\section{IMPACTS OF FINISHING SYSTEM (NEW ZEALAND GRASS, NEW ZEALAND FODDER BEET, OR US GRAIN) ON CONSUMER PERCEPTION OF TOP LOIN EATING QUALITY FOLLOWING 21 OR 35 D OF POSTMORTEM AGING}

\author{
A. J. Garmyn 1, ${ }^{*}$, R. J. Polkinghorne ${ }^{2}$, R. J. Rathmann ${ }^{1}$, J. C. Brooks ${ }^{1}$, M. F. Miller ${ }^{1}$ \\ ${ }^{1}$ Texas Tech University, Lubbock, United States, ${ }^{2}$ Merringanee, Murrurundi, Australia
}

Objectives: Due to advancements in New Zealand beef carcass grading, a branded program based on eating quality has recently emerged. As demand grows, the use of alternative finishing systems has been explored to supply beef cattle during winter months, when historically, cattle numbers and beef quality taper off due to limited grass supply. Due to the growing popularity of wintering dairy heifers on fodder beet (FB), beef researchers have adapted and tailored this feeding system to finish beef cattle to help meet the demand for high quality beef in New Zealand. The purpose of this portion of the study was to determine how consumers perceived beef from cattle finished on fodder beet the final 70-100 d before slaughter compared to traditional grass finishing and US grain finished cattle.

Materials and Methods: Within each finishing system, strip loins representing expected low and high eating quality (based on marbling and other quality parameters) were selected resulting in the following 6 treatments: fodder beet low quality (FBL), FB high quality (FBH), non FB low quality (NFBL), non FB high quality (NFBH), USDA Select (SEL), Top (upper 2/3) Choice (TC). Prior to $21 \mathrm{~d}$ postmortem, strip loins were fabricated into 2.5 -cm steaks for use in consumer testing. All steaks were vacuum packaged and frozen $(-10 \mathrm{C})$ at 21 or $35 \mathrm{~d}$ postmortem. A latin square design was utilized to balance the order and presentation of the 6 treatments aged either 21 or $35 \mathrm{~d}$. Steaks were cooked on a clamshell grill to a medium degree doneness and were served to consumers following a 3-min resting period. Consumers $(n=240)$ scored palatability traits (tenderness, juiciness, flavor liking, and overall liking) on 100-mm line scales verbally anchored at 0 (not tender, not juicy, dislike extremely) and 100 (very tender, very juicy, like extremely). Data were analyzed using the GLIMMIX procedure of SAS with treatment, aging period, and their interaction as the fixed effects. PROC CORR was used to examine relationships between palatability traits.

Results: No two-way interactions were observed $(P>0.05)$ for any palatability traits. Consumers scored steaks aged $35 \mathrm{~d}$ greater for tenderness, flavor liking, and overall liking compared to steaks aged $21 \mathrm{~d}(P<0.05)$, while juiciness was not impacted by aging or finishing diet $(P>0.05)$. Top choice and FBH were considered more tender $(P<0.05)$ than NFBL or SEL. Select flavor was less liked $(P<0.05)$ than any other treatment, regardless of postmortem aging. Overall, consumers liked TC, FBH, and NFBH more $(P<0.05)$ than SEL. Consumer overall liking was most strongly correlated to flavor liking $(r=0.92 ; P<0.01)$, but showed compelling relationships with both tenderness $(r=0.81)$ and juiciness $(r=$ $0.72)$ as well $(P<0.01)$.

Conclusion: Extending postmortem aging by $14 \mathrm{~d}$ improved eating quality scores due to greater tenderness, flavor, and overall liking. Juiciness was not impacted by postmortem aging or finishing diet. For each of the other palatability traits, 
SEL was scored less favorably than the other treatments, particularly TC. Interestingly, consumers did not discriminate between finishing systems, scoring TC, FBH, and NFBH similarly. Finishing beef cattle using fodder beet seems to be a viable option to supply beef cattle during winter months and meet demand for high quality beef.

Keywords: Beef, Consumer, Eating Quality, Finishing Diet, Fodder Beet 


\section{Environment, Production Systems}

23

\section{THE EFFECTS OF PHENOTYPIC SELECTION FOR RESIDUAL FEED INTAKE ON GROWTH PERFORMANCE AND CARCASS TRAITS IN ANGUS AND BRAUNVIEH-SIRED CATTLE}

P. T. Murray ${ }^{1,{ }^{*},}$ J. Wells ${ }^{1}$, R. Detweiler ${ }^{1}$, H. Gilleland ${ }^{1}$, D. Pringle ${ }^{1}$

${ }^{1}$ Animal and Dairy Science, University Of Georgia, Winterville, United States

Objectives: Improving feed efficiency has been identified as a priority by the US Beef Industry. Residual feed intake (RFI), defined as the difference between an animal's feed intake and its expected feed intake based on gain, is one tool that has been used to assess feed efficiency. Selection for improved feed efficiency using RFI is challenging because of the lack of EPDs for this trait and the difficulty of measuring feed intake in breeding cattle. Thus, the objective of this study was to determine the effects of phenotypic selection for RFI on the growth performance and carcass traits in Angus and Braunvieh/Angus cattle.

Materials and Methods: Angus cows were randomly mated to either Angus (A) or Braunvieh (BA) bulls ( $n=8)$ that had large measured differences in RFI (high vs low), resulting in four treatment groups: High RFI A, Low RFI A, High RFI BA, and Low RFI BA. Offspring (steers and heifers, $n=67$ ) over a 2-yr period, from the assigned matings were used to investigate the impact of RFI selection on growth and carcass measures. After weaning, cattle from year 1 were placed on grass for 4 months and then fed a concentrate diet. Feed intake was measured using a Calan gate feeding system. Cattle from year 2 were handled similarly except they were backgrounded for 11 months resulting in a shorter feeding period and older age at slaughter. Cattle were slaughtered as they approached a fat endpoint of $1.3 \mathrm{~cm}$ for $A$ and $1.0 \mathrm{~cm}$ for BA and carcass data was collected. Carcasses were fabricated into the major primals and weights were recorded. A 2.5-cm steak was removed from the striploin and aged $14 \mathrm{~d}$ for Slice Shear Force (SSF) determination. The data were analyzed using ANOVA with the main effects of breed, RFI selection, sex, year, and their first order interactions.

Results: Cattle from low RFI sires gained faster $(P=0.01)$, were heavier $(P=0.01)$ at slaughter, and tended to have greater $(P<0.10)$ gain:feed than cattle from high RFI sires. BA cattle were heavier $(P<0.05)$ entering the feedlot and tended $(P<0.10)$ to spend longer on feed with a lower $(P<0.05)$ gain:feed than $A$. As expected, steers were heavier $(P<0.01)$ than heifers throughout the feeding period. Neither breed nor RFI selection impacted $(P>0.30) R F I$; however, steers had lower $(P<0.01) R F I$ measures than heifers. Carcasses from low RFI sires were heavier $(P=0.02)$ with larger $(P<0.01) R E A$ and lower $(P=0.01)$ USDA yield grade compared to high RFI sires. No differences $(P>0.05)$ in USDA yield grade factors across breed type were found. Steers had heavier $(P<0.01)$ carcasses, lower $(P<0.01)$ backfat, larger $(P<0.01) R E A$, and lower $(P=0.01)$ USDA yield grade than heifers. Heifers tended to have higher $(P<0.10)$ marbling scores than steers; however, marbling score was not affected by breed or RFI selection. Carcass weight differences across RFI selection, breed, and sex explained the majority of the differences found in primal weights. Total primal yield $(\%)$ was greater $(P<0.01)$ in $B A$ vs 
A, low RFI vs high, and steers vs heifers. Tenderness was not affected by breed or RFI selection; however, heifers had lower $(P<0.01) S S F$ than steers.

Conclusion: These findings suggest that selection using phenotypic RFI in bulls had no effect on RFI in their first generation calves, although certain measures of growth and efficiency were improved. Further research is merited to determine the effects of phenotypic selection for RFI in a multi-generation study.

Keywords: beef, cattle, growth, residual feed intake 


\section{Meat and Poultry Processing, Ingredient Technology and Packaging}

25

\section{ASSESSMENT OF OAT FIBER TECHNOLOGY IN GROUND BEEF INTENDED FOR INTERNATIONAL MEAT FORMULATIONS}

J. Ball 1,*, J. Sawyer ${ }^{1}$, B. Lambert ${ }^{234}$, H. Ramirez ${ }^{15}$, L. Adcock ${ }^{1}$, R. Wyatt ${ }^{1}$, J. Costilla $^{6}$

${ }^{1}$ Animal Science and Veterinary Technology, ${ }^{2}$ College of Graduate Studies, 3Wildlife, Sustainability, and Ecosystem Sciences, Tarleton State University, Stephenville , ${ }^{4}$ Texas Agrilife Research, Texas A \& M University, College Station, ${ }^{5}$ Texas Agrilife Research, Texas A \& M University, Stephenville , ${ }^{6}$ Archer Daniels Midland Company, Decatur, United States

Objectives: With recent trends reducing the supply of beef cattle in the United States, consumer demand for inexpensive, convenient beef products such as ground beef patties has increased as the decrease in beef inventory has driven up the endpoint cost of beef. There are numerous ground beef technologies that can improve the fresh and cooked characteristics of ground beef, without causing dramatic changes to the taste and texture of the ground beef patty. The objective of this study was to identify the ideal percentage of oat fiber that could be incorporated into a ground beef patty formulation in an effort to reduce the cost of patty production along with a reduction in retail pricing.

Materials and Methods: For the current project, coarse ground beef (80:20, lean: fat) was purchased from a major beef processor (National Beef, Inc., Kansas City, MO, USA) and delivered to Tarleton State University. Ground beef (11.75 $\mathrm{kg} /$ treatment) was allocated to one of four treatments $(0,1.5,3.5$ and 4.5$)$ of oat fiber (SunOpta Ingredients, Edina, MN, USA). On day 14 from the box date, ground beef treatments were mixed with oat fiber and water (17\%), salt $(0.75 \%)$, phosphate $(0.40 \%)$, and black pepper $(0.25 \%)$ for $5 \mathrm{~min}$ in a butcher boy ribbon mixer. Following mixing, coarse grinds along with the rest of the ingredients were ground once through a 0.952 diameter $\mathrm{cm}$ plate with a four-blade knife using a Biro mixer/grinder. Once fine ground, treatments were formed into patties ( $N=65 /$ treatment) using a Hollymatic patty maker. Beef patties designated for instrumental tenderness, cook time, cook color, and cook yield were individually identified, placed into 3-mil vacuum barrier packages and stored at $4 \mathrm{C}$. Whereas, patties for simulated display, lipid oxidation, and moisture retention measurements were placed onto a styro-foam tray, overwrapped with a poly-vinyl chloride film (PVC) displayed for 7 days at $4 \mathrm{C}$ in a three-tiered refrigerated display case. Data collected throughout this study was analyzed as a completely randomized design with patty serving as the experimental unit using the PROC Mixed procedures of SAS.

Results: Instrumental fresh color values $\left(L^{*}, a^{*}\right.$, and $\left.b^{*}\right)$ decreased throughout the $7 \mathrm{~d}$ simulated display period $(P<$ $0.05)$. Increased usage rates of oat fiber in ground beef patties resulted in greater cook yields $(P<0.05)$. Instrumental cook color values for redness $\left(a^{*}\right)$ decreased as the percentage of oat fiber increased $(P<0.05)$ while values for lightness $\left(L^{*}\right)$ and yellowness $\left(b^{*}\right)$ values showed no differences across treatments with the addition of oat fiber $(P>0.05)$. Whereas, Allo-Kramer shear force values increased as oat fiber formulation percentages increased $(P<0.05)$. Lipid 
oxidation values showed no differences across treatments as the percentage of oat fiber increased within the ground beef application $(P>0.05)$. Also, there were no differences across treatment groups for moisture loss during the simulated retail display $(P>0.05)$. Lastly, cooking times were greater $(P<0.05)$ for patties manufactured with 3.5 and 4.5 percent oat fiber.

Conclusion: Oat fiber technology could be incorporated in the ground beef model of patties destined for international food service applications without causing detrimental effects to the fresh and cooked characteristics of the ground beef patty.

Keywords: Allo-Kramer Shear Force, Ground beef, Instrumental color, Oat fiber, TBARS 


\section{Meat and Poultry Processing, Ingredient Technology and Packaging}

\section{ASSESSMENT OF VEGETABLE BASED FIBERS IN GROUND BEEF INTENDED FOR INTERNATIONAL MEAT FORMULATIONS}

J. Ball 1, ${ }^{\star}$, J. Sawyer ${ }^{1}$, B. Lambert $23{ }^{4}$, H. Ramirez ${ }^{14}$, L. Adcock ${ }^{1}$, J. Costilla ${ }^{5}$, M. B. Mora García ${ }^{1}$

${ }^{1}$ Animal Science and Veterinary Technology, ${ }^{2}$ College of Graduate Studies, ${ }^{3 W}$ ildlife, Sustainability, and Ecosystem

Sciences, Tarleton State University, ${ }^{4}$ Texas Agrilife Research, Texas A \& M University, Stephenville, ${ }^{5}$ Archer Daniels

Mldland Company, Decatur, United States

Objectives: A reduction in the beef supply throughout recent years has forced the meat industry to meet consumer demand globally offering greater amounts of inexpensive beef products like ground beef patties. The beef industry's ability to produce a product without sacrificing quality is necessary to meet the demands of consumers as the industry strives to enhance the sustainability of beef cattle as a food source. In an effort to minimize the increase in beef pricing with a short inventory, the objective of this study was to identify a vegetable based fiber that could be added to the ground beef formulation to increase yield while maintaining consumer acceptability. Many plant derived technologies exist that can be incorporated within a ground beef formula that allow for improvements in shelf life and moisture retention without sacrificing taste, texture, and tenderness.

Materials and Methods: For the current project, coarse ground beef (80:20, lean: fat) was purchased from a major beef processor (National Beef, Inc., Kansas City, MO, USA) and delivered to Tarleton State University. Ground beef (11.18 $\mathrm{kg} /$ control; $10.67 \mathrm{~kg} /$ treatment) was allocated randomly to one of four treatments (Control, Oat Fiber, Pea Fiber, and Rice Fiber). Depending on the treatment group, the meat block consisted of the following: coarse ground beef $(78.1 \%)$, water $(17 \%)$, vegetable fiber $(3.5 \%)$, salt $(0.75 \%)$, phosphate $(0.40 \%)$, and black pepper $(0.25 \%)$. All treatments were mixed for $5 \mathrm{~min}$ in a butcher boy ribbon mixer (Model 250M, Selmer, Tennessee, USA). Following mixing, the meat block was fine ground through a 0.952 diameter cm plate with a four-blade knife using a Biro mixer/grinder (Marblehead, Ohio, USA). Once fine ground, the meat block treatments were formed into patties ( $N=65$ / treatment) using a Hollymatic patty maker. Patties designated for Allo-Kramer shear force, cook time, instrumental cook color, and cook yield were individually identified, placed into 3-mil vacuum barrier packages and frozen at - $10 \mathrm{C}$ until further analysis could be completed. Patties for simulated display, instrumental fresh color, lipid oxidation, and moisture retention measurements were placed onto a styro-foam tray, overwrapped with a poly-vinyl chloride film (PVC) and displayed for 5 days at $4 \mathrm{C}$ in a three-tiered refrigerated display case. Data collected throughout this study was analyzed using the PROC Mixed procedures of SAS (SAS Institute, Inc. Cary, NC). All data were analyzed as a completely randomized design with patty serving as the experimental unit. 
Results: Lipid oxidation values increased over the $7 \mathrm{~d}$ display period with only slight differences occurring across treatment groups $(P<0.05)$. Instrumental tenderness values for treatment groups with a vegetable based fiber were much higher than that of the control group, with the rice fiber treatment requiring more force than any other treatment $(P<0.05)$. Cook yield of the ground beef patty was improved by using a fiber technology $(P<0.05)$. As for surface color, lightness $\left(L^{*}\right)$ values increased with the addition of a vegetable based fiber while redness $\left(a^{\star}\right)$ and yellowness $\left(b^{\star}\right)$ decreased during simulated retail display across treatments $(P<0.05)$.

Conclusion: Vegetable based fibers can be incorporated within a ground beef application in an effort to increase production yields and cook yields while reducing the usage of expensive beef muscles during the formulation of ground beef patties for consumers.

Keywords: Allo-Kramer Shear Force, Ground beef, Oat fiber, Pea fiber, Rice fiber 


\section{Meat and Poultry Processing, Ingredient Technology and Packaging}

27

EFFECT OF AGE ON THE CARCASS, ORGAN AND PALATABILITY CHARACTERISTICS OF QUAIL AND CHICKEN MEAT.

P. O. Fakolade ${ }^{1,{ }^{*}}$, A. A. Adedoyin ${ }^{1}$

1Department of Animal Science, Osun State University, Osogbo, Nigeria

Objectives: A study to evaluate effect of age on carcass, organ and palatability of quail and chicken meat was evaluated. $120 \mathrm{birds}$ of chickens and quails were allocated in a completely randomized design fed ad-libitum for 20 weeks. $5 \mathrm{birds}$ were selected, slaughtered, boiled and fried at $100^{\circ} \mathrm{C}$ for 20 minutes. Results revealed that $(P<0.05)$ observed for organ characteristics for GIT, crop, spleen, kidney, proventiculus, heart, gizzard, liver, lungs and intestine. Same were observed for carcass evaluation. Figures revealed that there were gradual increase in weight of organs and carcasses as age increases from 4weeks- 20weeks. Palatability shows higher $(P<0.05)$ values at 8 weeks, when meats were processed. Boiled samples had higher figures of $6.50 \%$ for colour, $7.70 \%$ tenderness, $7.40 \%$ juiciness, $6.90 \%$ texture and $7.54 \%$ acceptability, than $6.33 \%$ colour, $7.00 \%$ tenderness, $7.20 \%$ juiciness, $7.00 \%$ texture and $7.30 \%$ acceptability for fried chicken. At 8 weeks quail followed same trend.

Materials and Methods: 120day-old chicken and quail were reared for 4 - 20weeks. 5birds at different weeks of age were randomly slaughtered. Carcass and organ were boiled and fried at $100^{\circ} \mathrm{C}$ for 20 minutes. Twenty trained panelist were allocated to the samples. A nine point hedonic scale was used to evaluate the palatability status of both samples.

Results:

Table 2

ORGAN CHARACTERISTIC OF QUAIL AND CHICKEN MEAT

\begin{tabular}{|l|l|l|l|l|l|}
\hline \hline & 4weeks & 8 weeks & 16 weeks & 20 weeks & $\begin{array}{c}\text { S } \\
\text { E }\end{array}$ \\
\hline $\begin{array}{l}\text { Varia } \\
\text { ble }\end{array}$ & Quail Chicken & Quail Chicken & Quail Chicken & Quail Chicken & \\
\hline $\begin{array}{l}\text { Crop } \\
\text { wt }\end{array}$ & $0.68^{d} \quad 8.23^{c}$ & $0.73^{d} \quad 10.28^{b}$ & $0.88^{d} 10.90^{b}$ & $1.50^{d}$ & $13.68^{a}$ \\
\end{tabular}




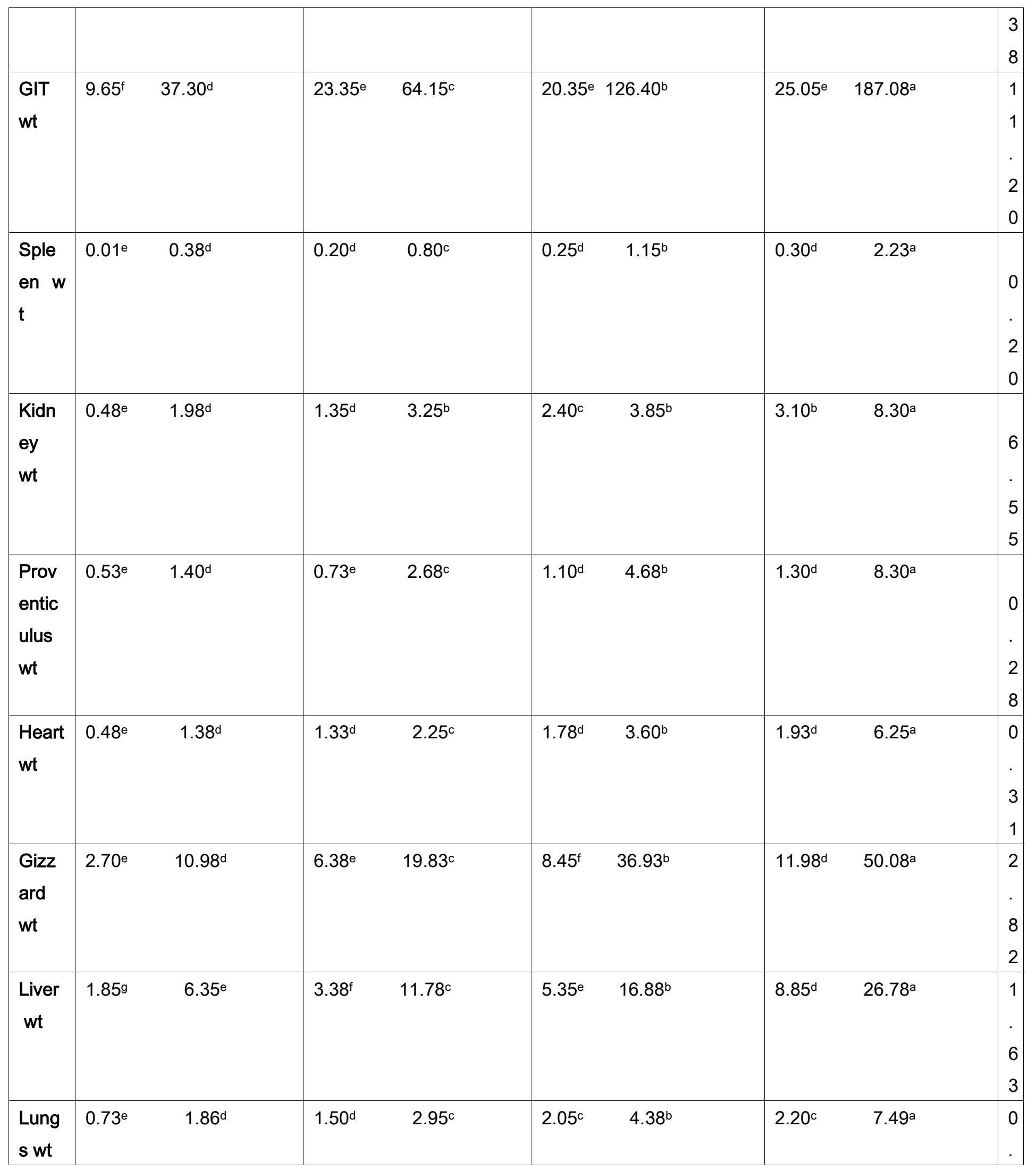




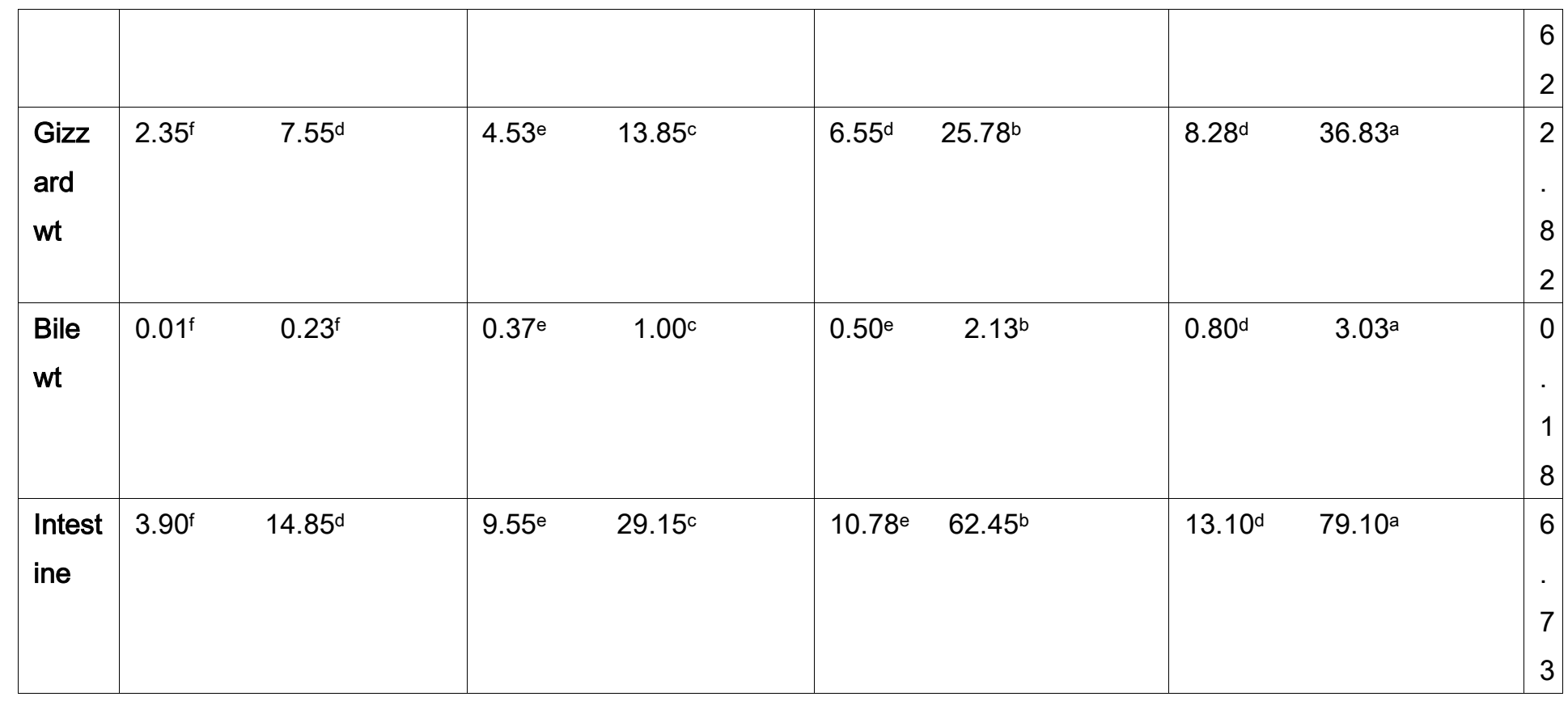

GIT - Gastro- intestinal tissue

Conclusion: Both birds respond best at 8 weeks; quail meat could be an alternative meat to chicken meat.

Keywords: Quail, chicken, age, carcass and organ. 


\title{
Meat and Poultry Processing, Ingredient Technology and Packaging
}

EXTRACTS OF GRAPE JUICE INDUSTRIAL RESIDUES AS NATURAL ANTIOXIDANT IN BRAZILIAN SAUSAGE (LINGUIÇA) WITH REDUCED NITRITE

\author{
G. B. Grecco ${ }^{1}$, R. N. Yagi ${ }^{1}$, F. A. Ribeiro ${ }^{2, *}$, W. L. Batista ${ }^{1}$, M. A. Andreo ${ }^{1}$, P. Sinnecker ${ }^{1}$, A. C. Venturini ${ }^{1}$ \\ ${ }^{1}$ Federal University of São Paulo, Diadema, 2University of São Paulo, Piracicaba, Brazil
}

Objectives: The objective of this study was to assess the partial replacement of nitrite by Isabel grape (Vitis labrusca) seed and peel extract as a natural antioxidant in sausages.

Materials and Methods: Twenty grams of dried grape residue were macerated with $100 \mathrm{ml}$ of ethanol $80 \%(\mathrm{v} / \mathrm{v})$ under mechanical agitation at room temperature and protected from light for $48 \mathrm{~h}$. The extract was filtered and the filtrate concentrated in vacuum at $65^{\circ} \mathrm{C}$. The residues were dissolved in water to a final volume of $50 \mathrm{ml}$, stored in amber glass bottles and kept under refrigeration. The total phenolic content $(P C)$ of extract was expressed in gallic acid equivalents (GAE) per $100 \mathrm{~g}$ (dry weight) of grape residue. A control formulation (T1) with $150 \mathrm{ppm}$ nitrite and without extract was prepared with 850 g.kg-1 pork meat, $150 \mathrm{~g} \cdot \mathrm{kg}^{-1}$ fat, $20 \mathrm{~g} \cdot \mathrm{kg}^{-1}$ sodium chloride, $1 \mathrm{~g}^{-k g^{-1}}$ sugar and $7 \mathrm{~g}^{-\mathrm{kg}^{-1}}$ sausage

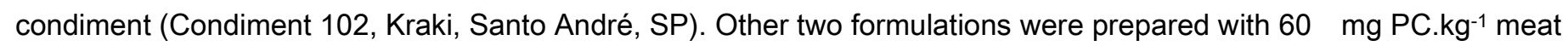
and reduced nitrite as follow: T2 (120 ppm) and T3 (90 ppm). Fresh pork and pork back fat were comminuted through a $14 \mathrm{~mm}$ steel plate and the mixture was homogenized in a cutter. The sausages were then placed in air-permeable polyethylene film and stored at $4^{\circ} \mathrm{C}$ for up to $21 \mathrm{~d}$. The enumeration of mesophilic aerobic bacteria on raw sausages was assessed by standard plate counting method and the plates were incubated for $48 \mathrm{~h}$ at $35 \pm 1^{\circ} \mathrm{C}$. The surface color of the raw sausages was measured using a portable colorimeter (observation angle of $2^{\circ}$ and illuminant $\mathrm{C}$ ). The sausages were cooked to a final internal temperature of $72^{\circ} \mathrm{C}$ before the sensory analyses. The sensory attributes of sausages (taste, flavor, appearance, firmness and overall acceptability) were evaluated through a consumer's acceptance analysis using a 9-point hedonic scale $(9=$ liked extremely to $1=$ disliked extremely). All analysis was undertaken in triplicate. The means were calculated by ANOVA using Statistica. Significant differences between means $(p<0.05)$ were determined by the Tukey test.

Results: The control had higher redness ( $a^{*}$ as a positive parameter in the sample's color) than the other samples up to 14 th day of refrigerated storage $(p<0.05)$. Lightness $\left(L^{*}\right)$ and yellowness $\left(b^{*}\right)$ did not show any specific trend. The statistical comparison showed that the samples containing 90 or $120 \mathrm{mg}$ nitrite. $\mathrm{kg}^{-1}$ did not show any significant differences from the control (150 ppm) for microbial contamination or sensory attributes. The maximum level of aerobic mesophilic bacteria reached during storage was approximately 3.7 log CFU.g-1 for all treatments.

Conclusion: Studies are required to further investigate these preliminary observations of non-microbial changes with combination of reduced nitrite and extract of grape residue. 
Keywords: replacement of nitrite 


\section{Meat and Poultry Processing, Ingredient Technology and Packaging}

29

\section{EFFECTS OF NOVEL NITRITE PACKAGING FILM ON THE MICROBIOLOGICAL FLORA OF BISON STRIP-LOIN STEAKS}

C. Narváez-Bravo ${ }^{1}$, A. R. Rodas-Gonzalez 2, ${ }^{*}$, C. Ding ${ }^{3}$, J. Ye ${ }^{3}$, O. López-Campos ${ }^{4}$, J. Galbraith ${ }^{5}$, D. Siegel ${ }^{6}$, J. Aalhus ${ }^{7}$ ${ }^{1}$ Food Science, ${ }^{2}$ Animal Science, University of Manitoba, Winnipeg, Canada, ${ }^{3}$ Food Science and Engineering, Inner Mongolia Agricultural University, Hohhot, Inner Mongolia, China, ${ }^{4}$ Livestock Gentec, Edmonton, ${ }^{5}$ Livestock Business Development Branch, Alberta Agriculture, Camrose, Canada, ${ }^{6}$ Division of Bemis, Curwood, Inc, Oshkosh, United States, ${ }^{7}$ Lacombe Research Centre, Agriculture and Agri-Food Canada, Lacombe, Canada

Objectives: This study was to determine the effect of different packaging types (overwrapped with polyvinyl chloride film = PVC, vacuum skin packaging = VSP, and vacuum skin packaged with nitrite film $=$ NIT), swabbed steak surface (bottom and top) and ageing time ( 2 and $9 \mathrm{~d}$ ) on bacterial populations of bison striploin steaks after $7 \mathrm{~d}$ of retail display.

Materials and Methods: Vacuum packaged wholesale strip-loins $(n=24)$ were purchased from a commercial slaughter plant and shipped to the Agriculture \& Agri-Food Research Centre (Lacombe AB, Canada) within $48 \mathrm{~h}$ post-mortem. Upon arrival, the sub-primals were unpackaged, lengths measured and transversely sectioned into two equal-length pieces. Strip-loin portions were then randomly assigned to two ageing times (immediate $-2 d$ and following one week of ageing $9 \mathrm{~d})$. Samples assigned to the ageing treatment were vacuum-packaged and stored at $3^{\circ} \mathrm{C}$. At each ageing time, the entire surface of the strip-loin portions was swabbed with pre-moistened peptone water sponges using aseptic techniques and then three $2.5 \mathrm{~cm}$-thick steaks were obtained (posterior end of the portion), total surface area was measured and steaks were randomly packaged in one of three different types of packaging (PVC; VSP; NIT) for retail display over $7 \mathrm{~d}$ at $3^{\circ} \mathrm{C}$ under fluorescent/incandescent lighting resulting in an intensity of $1020 \mathrm{~lx}$ at the meat surface for $14 \mathrm{~h} / \mathrm{d}$. At the end of retail display, steaks were removed, unwrapped and swabbed individually at the bottom and top surfaces of the steaks using aseptic techniques. All sponges were shipped immediately in a cooler held at $4^{\circ} \mathrm{C}$ to the University of Manitoba and processed within $24 \mathrm{~h}$ for microbiological analysis (coliforms, lactic acid bacteria and psychrophilic bacteria counts using conventional methods).

Results: In comparison to PVC packaging, both VSP and NIT packaging reduced the bacterial load on the meat by $\sim 2$ log for coliforms $(P<0.0001), \sim 0.5 \mathrm{log}$ for lactic acid bacteria $(P=0.005)$ and $\sim 1.5 \mathrm{log}$ for psychrophilic bacteria $(P=0.0001)$. There were no swabbed steak surface (top vs. bottom) by packaging treatment interactions $(P>0.05)$, which would have been expected if the nitrite in the packaging film had an antibacterial effect over and above the use of anaerobic vacuum skin packaging. As expected, increased ageing $(2 \mathrm{~d}$ vs. $9 \mathrm{~d} ; P<0.05)$ resulted in an increase in bacterial numbers $(\sim 2$ log) for coliforms, lactic acid bacteria and psychrophilic bacteria.

Conclusion: The NIT packaging system decreased the growth of bacteria during retail display, similar to other anaerobic packaging systems. 
Keywords: ageing time, bison, nitrite film packaging, spoilage bacteria 


\title{
Meat and Poultry Processing, Ingredient Technology and Packaging
}

31

\section{OXYGEN SCAVENGERS AFFECT MEAT PROPERTIES AND CARBON DIOXIDE AND CARBON MONOXIDE GAS CONCENTRATIONS IN LOW-OXYGEN MASTER PACKED GROUND BEEF}

\author{
I. S. Arteaga ${ }^{1, *}$, C. N. Cutter ${ }^{2}$, J. A. Campbell ${ }^{1}$, E. W. Mills ${ }^{1}$
}

${ }^{1}$ Animal Science, ${ }^{2}$ Food Science, The Pennsylvania State University, University Park, United States

Objectives: Residual oxygen in the headspace gas of low oxygen packages can trigger fresh meat discoloration. To reduce residual oxygen and maintain an ultra-low oxygen level, oxygen scavengers are frequently needed. In addition, carbon monoxide is often added in the package gas mixture to maintain a desirable red color due to formation of carboxymyoglobin pigment. This study investigates the possible benefit of combining carbon monoxide with an oxygen scavenger in master packs on storage and display stability of ground beef.

Materials and Methods: Duplicate ground beef samples, obtained from the Pennsylvania State University Meats Lab, were overwrap packaged and placed in impermeable packages with an atmosphere of $30 \% \mathrm{CO}_{2} / 70 \% \mathrm{~N}_{2}$ or $0.4 \% \mathrm{CO} / 30 \%$ $\mathrm{CO}_{2} / 69.6 \% \mathrm{~N}_{2}$ and with and without an oxygen scavenger. Master packed samples were stored in the dark at $0.5^{\circ} \mathrm{C}$ for up to 21 days. After storage, master packs were opened and overwrap packages were displayed at $4^{\circ} \mathrm{C}$ for up to 4 days under continuous fluorescent lighting (990 Lux). Storage time, display time, and the different package systems were evaluated in terms of headspace gas concentration $\left(\mathrm{O}_{2}, \mathrm{CO}_{2}\right.$, and $\left.\mathrm{CO}\right)$, lidding film deflation, color stability, CIE $\mathrm{L}^{*} \mathrm{a}^{*} \mathrm{~b}^{*}$ values and browning index, $\mathrm{pH}$, and microbial growth.

Results: Oxygen scavengers effectively reduced oxygen levels below $0.1 \%$. However, oxygen scavengers also contributed to carbon dioxide absorption and carbon monoxide production. Carbon monoxide concentration increased to $0.16 \%$ after 21 days of storage in a CO-free initial atmosphere $(p<0.05)$. It was demonstrated that there is an interaction between oxygen scavengers and ground beef for carbon monoxide production. Ground beef, master packed for 21 days with an initial headspace gas of $0.4 \% \mathrm{CO}$ and an oxygen scavenger, resulted in a carbon monoxide concentration of $0.52 \%$. Besides changes in headspace gas concentrations, oxygen scavengers increased meat color stability. Browning index, as a measurement of brown color formation, increased during display after 14 and 21 days of storage in master packs without oxygen scavengers $(p<0.05)$. Furthermore, meat redness, as indicated by $a^{*}$ values, was maintained for up to 21 days of storage and 2 days of display, only when oxygen scavengers were used in combination with carbon monoxide in master packs ( $p>0.05$ ). The use of oxygen scavengers led to decreased meat $\mathrm{pH}$ during display after 14 and 21 days of storage, while meat $\mathrm{pH}$ increased during display of ground beef master packed without oxygen scavengers. Lactic acid bacteria counts did not change with the package system $(p>0.05)$. However, psychrotrophic bacteria counts were higher after 14 and 21 days of storage when oxygen scavengers were not present $(p<0.05)$. In addition, the small difference between aerobic and anaerobic counts suggests that facultative anaerobes predominated. 
Conclusion: Oxygen scavengers can effectively prevent metmyoglobin formation during master pack storage and meat display. However, changes in carbon dioxide and carbon monoxide concentrations need to be considered as well. Even though the use of oxygen scavengers in combination with $\mathrm{CO}$ in master packed ground beef showed a considerable advantage, increased CO production caused by oxygen scavengers needs to be taken into account. Resulting carbon monoxide concentrations above that included in the initial headspace gas could potentially have regulatory and consumer implications.

Keywords: Carbon monoxide, Color stability, Ground beef, Master pack, Oxygen scavenger 


\section{Meat and Poultry Processing, Ingredient Technology and Packaging}

32

\section{USE OF STABILIZED RICE BRAN AND RICE BLEND IN GLUTEN FREE TURKEY MEATBALLS}

G. Prabhu 1,*, R. Husak ${ }^{1}$, R. Smith ${ }^{2}$

${ }^{1}$ PHD Technologies LLC, Ames, IA, ${ }^{2}$ Rice Bran Technologies, Scottsdale, AZ, United States

Objectives: Rice bran, a co-product of rice milling was once considered unfit as a food ingredient because of the active lipase enzyme resulting in rapid oxidation. Due to stabilizing technology which deactivates the enzyme early in the separation process, SRB has proved to be a unique, all-natural, minimally processed, non-allergen food ingredient. SRBL is comprised of SRB and rice flour in natural proportions achieving whole grain status. SRB and SRBL can be used to replace traditional binders and allergens like breadcrumbs and soy protein in meat products. In June 2008, SRB was approved by the USDA as a binder in comminuted meat and poultry products such as sausages, chicken patties, meatballs, meat loaf and meat patties where binders are approved.

The objective of this study was to evaluate quality characteristics of meatballs utilizing stabilized rice bran (SRB) and stabilized rice blend (SRBL) made from rice flour and rice bran to replace bread crumbs and meat.

Materials and Methods: Four treatments of turkey meatballs were formulated as shown in the table below:

\begin{tabular}{|l|l|l|l|l|}
\hline & Trt. 1 & Trt. 2 & Trt. 3 & Trt. 4 \\
\hline & Control & $2.38 \%$ RiBran 100 + 9.36\% RiBlend 100 & $9.50 \%$ RiBlend 100 & $12.00 \%$ RiBlend 100 \\
\hline Ingredient & $\%$ & $\%$ & $\%$ & $\%$ \\
\hline $\begin{array}{l}\text { Ground Turkey } \\
85 / 15\end{array}$ & $76.34 \%$ & $74.10 \%$ & $76.34 \%$ & $73.84 \%$ \\
\hline Water/lce & $9.50 \%$ & $9.50 \%$ & & \\
\hline Bread crumbs & $9.50 \%$ & $0.00 \%$ & $9.50 \%$ & $9.50 \%$ \\
\hline Sea salt & $0.26 \%$ & $0.26 \%$ & $0.00 \%$ & $0.00 \%$ \\
\hline Dextrose & $0.65 \%$ & $0.65 \%$ & $0.26 \%$ & $0.26 \%$ \\
\hline Black pepper & $0.05 \%$ & $0.05 \%$ & $0.65 \%$ & $0.65 \%$ \\
\hline Antioxidant & $0.29 \%$ & $0.29 \%$ & $0.05 \%$ & $0.05 \%$ \\
\hline Dried Vinegar & $0.50 \%$ & $0.50 \%$ & $0.29 \%$ & $0.29 \%$ \\
\hline Seasoning & $2.91 \%$ & $2.91 \%$ & $0.50 \%$ & $0.50 \%$ \\
\hline RiBran 200 & $0.00 \%$ & $2.38 \%$ & $2.91 \%$ & $2.91 \%$ \\
\hline RiBlend 100 & $0.00 \%$ & $9.36 \%$ & $0.00 \%$ & $0.00 \%$ \\
\hline
\end{tabular}




\begin{tabular}{|l|l|l|l|l|}
\hline Total & $\begin{array}{l}100.00 \\
\%\end{array}$ & $100.00 \%$ & $100.00 \%$ & $100.00 \%$ \\
\hline
\end{tabular}

Meat, non-meat ingredients and water were blended in a paddle mixer for no more than $3 \mathrm{~min}$. The mixture was formed into meatballs using a vacuum stuffer with a meatball attachment targeting $28 \mathrm{~g}$ per piece, fried in $375^{\circ} \mathrm{F}\left(190.55^{\circ} \mathrm{C}\right)$ canola oil for $30 \mathrm{sec}$. then cooked in a convection oven for 20 minutes at $380^{\circ} \mathrm{F}\left(193.33^{\circ} \mathrm{C}\right)$ under full steam to an internal temperature of $165^{\circ} \mathrm{F}\left(73.88^{\circ} \mathrm{C}\right)$. The cooked meatballs were then individually quick frozen in dry ice. Meatballs were evaluated for fry/cook yield, texture profile analysis using a Texture Analyzer equipped with a 3" flat probe and freezethaw purge.

Results: Fry/cook yields were significantly $(P<0.05)$ higher for all treatments compared to the control. The hardness, gumminess and chewiness values were significantly $(P<0.05)$ higher for all the treatments compared to the control. Freeze-thaw purge was significantly $(\mathrm{P}<0.05 \%)$ lower for all test treatments compared to the control. Statistical analysis was performed using ANOVA $(P<0.05)$ with StatView for Windows on three replications.

Conclusion: SRB is a functional, cost-effective ingredient that can improve cook yields while maintaining texture in comminuted products such as meatballs. SRB labeled "rice bran" and SRBL labeled "whole grain rice" or "whole grain brown rice" uniquely position current and next generation meat products to incorporate all-natural healthy ingredients while removing allergens.

Keywords: all natural, stabilized rice bran, rice flour, gluten free, whole grain brown rice, allergen free 


\section{Meat and Poultry Processing, Ingredient Technology and Packaging}

33

CRYOPROTECTIVE PROPERTY OF CHICKEN COLLAGEN HYDROLYSATE (CCH) ON ISOLATED ACTOMYOSIN (IAM)

L. Du ${ }^{1,{ }^{*}}$, M. Betti ${ }^{1}$

1Department of Agricultural, Food and Nutritional Science, University of Alberta, Edmonton, Canada

Objectives: Freezer storage is an important process to preserve meat products. However, it also results in freezing damage of meat. During freezer storage, deterioration of myofibrillar proteins plays an unfavorable role on the quality of meat products (e.g. surimi). To alleviate these undesirable changes and extend shelf-life, the addition of cryoprotectants in frozen meat products is necessary. Due to the strong sweetness of the commercial cryoprotectants (e.g. low molecular weight sugars and polyols), alternative food cryoprotectants are in demand. The objective of this study was to evaluate the cryoprotective properties of collagen hydrolysate $(\mathrm{CCH})$ derived from chicken skin against freeze-induced denaturation of isolated actomyosin (IAM).

Materials and Methods: $\mathrm{CCH}$ was prepared by trypsin digestion of collagen obtained from broiler chicken skin and IAM was isolated from fresh chicken breasts. Cryoprotective effect of $\mathrm{CCH}$ on IAM at different levels $(0 \%, 4 \%, 8 \%$ and $12 \%$ $\mathrm{w} / \mathrm{w}$ ) were evaluated by different approaches. Ice crystal diameters of the samples were first measured after 7 thermal cycles (stabilized at $-20^{\circ} \mathrm{C}$ and cycled between $-16{ }^{\circ} \mathrm{C}$ to $-12{ }^{\circ} \mathrm{C}$ ) using a polarized microscope. Scanning electron microscope (SEM) was employed to further detect the changes of the IAM microstructure at high magnifications (1000x, 5000x) after cycles and lyophilization. In addition, protein oxidation and crosslinking during freezing storage was assessed by examining the total and reactive sulfhydryl group content of the samples after 7 thermal cycles (between $-20^{\circ} \mathrm{C}$ and 4 ${ }^{\circ} \mathrm{C}$ in a refrigerator). The incorporation of $8 \%(\mathrm{w} / \mathrm{w})$ commercial cryoprotectants (sucrose: sorbitol=1:1) in IAM was used as a positive control in this study. The ice crystal size analysis and sulfhydryl group analysis were conducted in triplicate. Data were analyzed by one-way ANOVA and differences between means were determined using HSD Tukey's test at the $5 \%$ significance level.

Results: Results obtained in this research proved that the addition of $\mathrm{CCH}$ significantly $(p<0.001)$ reduced the ice growth in the IAM protein system after the freeze-thaw cycles with the smallest average ice crystal diameter of $1.86 \pm 0.09 \mu \mathrm{m}$ observed in $12 \% \mathrm{CCH}$. All the $\mathrm{CCH}$ treatments were not statistically different from the positive control of commercial cryprotectants. The SEM images of IAM with $\mathrm{CCH}$ treatment revealed diminished size of the holes in protein structure after freeze-thaw cycles, which might indicate the reduced ice dimension in the sample. IAM treated with $8 \%$ and $12 \%$ $\mathrm{CCH}$ presented the highest $(p<0.001)$ amount of total sulfhydryl groups $(36.0 \pm 0.4$ and $34.9 \pm 1.0, \mu \mathrm{mol} / \mathrm{g}$ protein, respectively) and reactive sulfhydryl groups (27.8 \pm 0.5 and $28.2 \pm 1.0, \mu \mathrm{mol} / \mathrm{g}$ protein, respectively) after the cycles, and they were in the same level of the IAM treated by the commercial cryoprotectants. 
Conclusion: These results confirmed the cryoprotective effect of $\mathrm{CCH}$ against protein oxidation and crosslinking, which might be associated with its inhibitive effect on ice growth. This study could benefit poultry processors by having better utilization of their low value by-products (e.g. skin) and consumers by providing them a non-sweet cryoprotectant.

Keywords: chicken skin, collagen hydrolysate, cryoprotective properties, ice crystal size, protein oxidation 


\title{
Meat and Poultry Processing, Ingredient Technology and Packaging
}

34

\section{SHELF-LIFE OF CASE-READY STEAK, STEW AND GROUND BEEF (LONGISSIMUS DORSI M.) IN MODIFIED ATMOSPHERE PACKAGING}

\author{
F. A. Ribeiro ${ }^{1, *}$, M. A. Almeida ${ }^{1}$, J. S. D. S. Pinto ${ }^{1}$, K. A. Guimarães ${ }^{1}$, E. S. Villa ${ }^{1}$, A. C. Venturini ${ }^{2}$, C. J. C. Castillo ${ }^{1}$ \\ 1 University of São Paulo, Piracicaba, ${ }^{2}$ Federal University of São Paulo, Diadema, Brazil
}

Objectives: The objective of this study was to evaluate color stability of Longissimus dorsimuscle from entire male cattle (Bos indicus), packaged in oxygen permeable wrapped-tray units and stored in a master bag system with oxygen scavengers.

Materials and Methods: Fresh vacuum-packaged beef LD muscles $(n=12)$ were stored for 12 d postmortem. LD steaks were cut into $1.5 \mathrm{~cm}$, placed on perforated styrofoam trays and overwrapped with micro perforated polyvinyl chloride (PVC) stretch film. LD stew $(1.0 \mathrm{~cm} \times 5.0 \mathrm{~cm})$ and ground beef $(\mathrm{LD}$ comminuted through a $6 \mathrm{~mm}$ steel plate) were placed on each styrofoam tray and packaged similar to the steaks. The $1^{\text {st }}$ treatment represented traditional retail packaging and displayed conditions in which PVC-packaged steaks, stew meat and ground beef were exposed only to atmospheric oxygen. For the $2^{\text {nd }}$ packaging treatment, PVC-overwrapped product was placed in a barrier bag containing an oxygen scavenger ( $800 \mathrm{cc}$, FreshPax ${ }^{\circledR} \mathrm{CR}$ ) and flushed with a certified gas blend of $30 \% \mathrm{CO}_{2}$ and $70 \% \mathrm{~N}_{2}$ and sealed. After each storage time $(6,12$ and $15 \mathrm{~d})$, trays were removed from the barrier bag and displayed at $4^{\circ} \mathrm{C}$ up to $72 \mathrm{~h}$. Visual color and psychrotrophic aerobic bacterial were monitored during the display after each storage time (6,12 and $15 \mathrm{~d})$. The meat color surface was evaluated at $48 \mathrm{~h}$ after portioning in trays and at the end of each storage period in MAP (6,12 and $15 \mathrm{~d}$ ) after 2, 24 and $48 \mathrm{~h}$ of air exposure. A five-point color scale was used to evaluate the meat display color stability ( $1=$ very bright cherry-red, $2=$ bright cherry-red, $3=$ slightly dark-red to tannish-red, $4=$ moderately grayish-tan to brown, and $5=$ tan to brown). Surface discoloration was scored on a five-point scale, where $1=$ no discoloration $(0 \%) 2=$ light $(1-10 \%)$, $3=$ small $(11-20 \%), 4=$ moderate $(21-60 \%) ; 5=$ intense $(61-100 \%)$ and overall appearance was scored as $1=$ very pleasant; $2=$ slightly pleasant; $3=$ a little pleasant, $4=$ moderately unpleasant and $5=$ very unpleasant. A score of 4 was used to estimate the end of color life. All analysis was undertaken in triplicate. The means were calculated by ANOVA using Statistica. Significant differences between means $(p<0.05)$ were determined by the Tukey test.

Results: The oxygen scavenger reduced rapidly the residual oxygen to $0 \%$ and prevented transient discoloration on surface of the meat that arises from its reaction with the residual $\mathrm{O}_{2}$ initially present in master bag. Storage of steaks, stew meat and ground beef for up to $15 \mathrm{~d}$ in master bag system resulted in typical initial bloomed color similar or superior to fresh beef packaged only in PVC (control). The desirable red color of steaks remained stable over the $72 \mathrm{~h}$ of aerobic display at $4^{\circ} \mathrm{C}$, without discoloration, after all storage times. The red color of stew and ground meat remained stable up to $24 \mathrm{~h}$ of display. Visual discoloration $\geq 10 \%$ was detected on surface of stew and ground 
meat after 48h of display, leading to an overall appearance rating of "little pleasant" for stew meat and "moderately unpleasant" for ground meat. No steaks had spoilage levels of microbes (> $7 \log$ CFU.g- 1 ).

Conclusion: Master bag with anoxic atmosphere seems to offer an alternative for extending the shelf life of case-ready beef of Nellore bull.

Keywords: Oxygen scavenger 


\section{Meat and Poultry Processing, Ingredient Technology and Packaging}

35

\section{EFFECTS OF SOY HULL FIBERS AND SUNFLOWER OIL ON PHYSICOCHEMICAL AND TEXTURAL PROPERTIES OF REDUCED-SALT AND FAT MEAT EMULSIONS}

H.-W. Kim ${ }^{1, *}$, Y. J. Lee ${ }^{2}$, Y. H. B. Kim ${ }^{1}$

1Department of Animal Science, Purdue University, West Lafayett, 2Food Protein R\&D Center, Texas A\&M University, College Station, United States

Objectives: Various non-meat ingredients including dietary fiber have been applied to manufacture reduced-salt and fat meat products, while not compromising quality characteristics, such as water-holding capacity, emulsion stability and texture. Soy hulls, which are the seed coat of soybean, contain high amounts of pectin and insoluble fiber. Previous studies reported that the addition of soy hull pectin and insoluble fiber resulted in a decrease in cooking loss and an increase in texture of meat emulsion. Further, a vegetable oil pre-emulsion has been used to replace animal fat in meat products, as it can reduce saturated fatty acid and cholesterol of the final products. Therefore, our objective in this study was to evaluate effects of the addition of soy hull pectin and sunflower oil pre-emulsified with insoluble soy fiber on physicochemical and textural properties of emulsified meat products.

Materials and Methods: Soy hull pectin, which was extracted by two different systems - by-alcohol precipitation method (ASP) and microfiltration membrane (MSP), and insoluble fiber fraction (residue after pectin extraction) were used to prepare sunflower oil pre-emulsion (SO). The ratio of fiber, oil and water was 3:3.5:3.5. Control emulsion was formulated with $58 \%$ pork meat, $20 \%$ ice, $20 \%$ pork backfat and $2 \% \mathrm{NaCl}$. Reduced-salt and fat meat emulsions were prepared with $1 \% \mathrm{NaCl}, 10 \%$ pork backfat, and negative control was formulated with $10 \%$ additional water. Reduced-salt and fat treatments were individually prepared with $1 \%$ ASP and 10\% additional water (T1), $1 \%$ MSP and $10 \%$ additional water (T2), $1 \%$ ASP and $10 \%$ SO (T3) and $1 \% \mathrm{MSP}$ and $10 \%$ SO (T4). The pH, color (CIE $L^{*} a^{*} b^{*}$ ), cooking loss (core temperature of $71^{\circ} \mathrm{C}$ ) and texture profile analysis were measured. A total of three independent replicates were conducted $(n=3)$. The data were analyzed using general linear model (GLM) procedure of SPSS 18.0 software. Duncan's multiple range test $(P<0.05)$ was used to determine differences between treatment means.

Results: The addition of soy hull pectins and $\mathrm{SO}$ decreased the $\mathrm{pH}$ value of meat emulsions $(\mathrm{P}<0.05)$. Soy hull pectins and SO decreased lightness of meat emulsion but slightly increased redness and yellowness. Negative control showed the highest cooking loss (21.82\%), and the addition of ASP and MSP slightly decreased the cooking loss to $16.35 \%$ (T1) and $19.07 \%$ (T2), respectively. In addition, the combination of soy hull pectins and SO showed additional decrease in cooking loss to $16.13 \%$ (T3) and $15.36 \%$ (T4), which were still higher than control (12.19\%). ASP and MSP had no texture modifying effect, when compared to negative control. However, the combination of soy hull pectins and SO substantially increased hardness, gumminess and chewiness $(P<0.05)$. 
Conclusion: These results indicated that both pectins and sunflower oil pre-emulsion containing insoluble soy fiber can be an effective synergistic combination to decrease cooking loss and to improve textural properties of reduced-salt and fat meat emulsions. Further studies about the effects of soy hull fiber and sunflower oil on shelf stability (lipid oxidation and microbial safety) and sensory properties would be warranted.

Keywords: insoluble fiber, pectin, reduced-salt and fat, soy hull, sunflower oil 


\title{
Meat and Poultry Processing, Ingredient Technology and Packaging
}

36

\section{USE OF NATURAL DEHYDRATED PORK STOCK IN COMMINUTED MEAT PRODUCTS}

\author{
G. Prabhu 1, ${ }^{*}$, R. Husak ${ }^{1}$, K. Steffen ${ }^{2}$ \\ ${ }^{1}$ PHD Technologies LLC, Ames, IA, United States, ${ }^{2}$ Scanflavour AS, Moldrup, Denmark
}

Objectives: On March 1, 1990, FSIS published a final rule titled (FSIS Directive 7140.2) "Determination of Added Water in Cooked Sausages." The Federal meat inspection regulations limit the amount of added water which may be present in cooked sausages. Cooked sausages are those produced under 9CFR 319.140, 9CFR 319.180. 9CFR 319.181 or 9CFR 318.182. Added water in cooked sausages as defined in 9CFR 318.22 is water in excess of 4 times the Group 1 protein (ingredients of livestock and poultry origin) in addition of $1 \%$ of Group 2 protein. The final rule discontinues the practice whereby proteins contributed by mustard, spices, cereals, autolyzed yeast, and hydrolyzed milk protein were credited the same as protein from ingredients of livestock or poultry origins. These ingredients are now credited as protein from Group 2 Protein-Contributing Ingredients. The added water in cooked sausage cannot exceed $10 \%$, the fat content cannot exceed $30 \%$ and the fat + added water cannot exceed $40 \%$. Natural dehydrated pork stock is considered a Group 2 Protein-Contributing ingredient and has been approved as a "flavor" by USDA for use in standard of identity comminuted meat products at a level sufficient for purpose. When added to a meat system, this ingredient is capable of holding fat, water and other components, when cooked, imparts a meat like texture. Under normal thermal processing conditions, moisture and fat purging is reduced or eliminated.

The objective of this study was to maximize the added water in cooked sausage by the use of natural dehydrated pork stock.

Materials and Methods: Three treatments of smoked sausage were formulated: Trt.1:Control, Trt.2:1\% Dehydrated Pork Stock with 3.46\% additional water maintaining added water similar to the Control and Trt.3:1\% Dehydrated Pork Stock with $6 \%$ additional water maximizing added water to $10 \%$. Pork 72 s with $28 \%$ fat (1/2" grind), salt, phosphate, nitrite and erythorbate and half the water/ice were mixed in a paddle mixer for no more than 3 min. The pork $42 \mathrm{~s}$ with $58 \%$ fat (1/2" grind), mechanically deboned turkey, the rest of the dry ingredients and the remaining water were added and mixed for an additional 2 minutes. The mixture was re-ground through 3/16" plate, stuffed into $26 \mathrm{~mm}$ diameter cellulose casings and cooked in a smokehouse to an internal temperature of $161^{\circ} \mathrm{F}\left(71.66^{\circ} \mathrm{C}\right)$. Smoked sausages were evaluated for cook yields, texture profile analysis using a TAXT2 Texture Analyzer equipped with a 3" flat probe, color analysis (L, a and b values) using a hand-held Hunterlab colorimeter equipped with a D65 Optical Sensor and purge over 12 weeks of 
refrigerated storage. Statistical analysis was performed using ANOVA $(P<0.05)$ with StatView for Windows on three replications.

Results: Cook yields were significantly $(\mathrm{P}<0.05)$ higher for all test treatments compared to the control. The hardness, gumminess and chewiness values were not significantly $(P>0.05)$ different for Trt. 2 compared to the control. The interior color values $(L, a$, and $b)$ were not $(P>0.05)$ significantly different for any of the treatments. Purge was significantly $(P<0.05)$ lower for all test treatments compared to the control over 12 weeks of refrigerated storage.

Conclusion: Natural dehydrated pork stock is a functional allergen free ingredient that can increase cook yields and maintain texture in smoked sausage. This ingredient is not considered a "binder" by USDA hence meat processors are able to make "no binder/filler" claim.

Keywords: natural dehyrated pork stock, non allergen, no binder/filler, functional water-binder 


\section{Meat and Poultry Processing, Ingredient Technology and Packaging}

37

\section{INFLUENCE OF SORGHUM SYRUP AS A SWEETENER IN FRESH PORK SAUSAGE PATTIES ON OXIDATION DURING RETAIL DISPLAY COMPARED TO CORN SYRUP.}

T. D. Trevino ${ }^{1}$, H. Avila, Jr. ${ }^{1}$, T. J. Machado 1,*

${ }^{1}$ Animal, Rangeland and Wildlife Sciences, Texas A\&M University-Kingsville, Kingsville, United States

Objectives: The objective of this research was to determine if the inclusion of sorghum syrup into fresh pork sausage impacts oxidation during retail display.

Materials and Methods: Vacuum sealed picnic pork shoulders (IMPS 405) were purchased to generate pork trimmings for the study. The pork trimmings were ground through a $9.5 \mathrm{~mm}$ plate, mixed, ground through a $4.8 \mathrm{~mm}$ plate and divided into three $4.5 \mathrm{~kg}$ batches. Each batch was assigned to a treatment: 1.8\% 63DE corn syrup (control), $1.8 \%$ sorghum syrup, and $3.6 \%$ sorghum syrup. All batches were hand mixed with $1.26 \%$ salt, $0.12 \%$ ground black pepper, $0.05 \%$ ground white pepper, $0.05 \%$ ground nutmeg, $0.02 \%$ ground clove, and respective syrup. Final product was formed into $151 \mathrm{~g}$ patties (n = 54; 18 per treatment) using a $12 \mathrm{~cm}$ diameter die, placed on white Styrofoam trays and plastic over wrapped. Patties were randomly placed in a simulated retail storage environment $\left(2^{\circ} \mathrm{C}\right.$; continuous fluorescent light; bulb color temperature $3000 \mathrm{~K}$; color rendering index of 87; average light intensity of 1630 lux) with storage times of 2, 4, 7, 10, 12 and 14 d (3 patties/treatment/d). Oxidation was measured using a thiobarbituric acid reactive substance (TBARS) filtration method. The trial was replicated following the completion of the first trial. The data was analyzed using mixed model procedures of SAS with fixed effects of replication, treatment, day and treatment $x$ day interaction. Replication $x$ treatment was utilized as a random effect. Least square means were separated using PDIFF option with differences detected at the $P<0.05$ level.

Results: There was no difference $(P=0.87)$ in TBARS between treatments, and storage time influenced treatments similarly (treatment $x$ day; $P=0.46$ ). However, TBARS were influenced by day $(P<0.05)$. The TBARS values were similar $(P>0.05)$ between days 2,4 , and 7 , (absorbances $0.04 \pm 0.015,0.07 \pm 0.015$, and $0.06 \pm 0.015$, respectively) which were lower than days 10 (absorbance $0.12 \pm 0.015$ ) and 12 (absorbance $0.15 \pm 0.015$ ), with day 14 (absorbance $0.20 \pm 0.015)$ having the highest $(P<0.05)$ TBARS value.

Conclusion: The results of this study indicate that sorghum syrup is comparable to corn syrup with regards to oxidation during retail storage. Thus, sorghum syrup can be added to fresh pork sausages with no detrimental effects on oxidation.

Keywords: Retail display, Sausage, Sorghum syrup 



\title{
Meat and Poultry Processing, Ingredient Technology and Packaging
}

38

\section{EFFECTS OF PELLETING GROW-FINISH SWINE DIETS ON FRESH BELLY CHARACTERISTICS, FAT QUALITY, AND COMMERCIAL BACON SLICING YIELDS}

\author{
M. F. Overholt ${ }^{1,}{ }^{*}$, J. E. Lowell ${ }^{1}$, H. H. Stein ${ }^{1}$, A. C. Dilger ${ }^{1}$, D. D. Boler ${ }^{1}$ \\ ${ }^{1}$ Animal Science, University of Illinois, Urbana, United States
}

Objectives: Pigs are fed pelleted diets in order to improve growth rate and feed efficiency. However, it also increases iodine value (IV) of fat by 2 to 3 units. It is not known if this increase in iodine value decreases commercial bacon slicing yield. Therefore, objectives were to determine fresh belly characteristics, fat quality, and commercial bacon slicing yields of barrows and gilts fed a pelleted or meal diet, without or with $30 \%$ distillers dried grains with solubles (DDGS). Materials and Methods: A total of 192 pigs were used in 2 blocks. Each block consisted of 96 pigs that were randomly allotted to 1 of 4 dietary treatments, with 12 replicate pens per diet form and DDGS inclusion level. Each pen housed 2 barrows and 2 gilts. Pigs were fed $91 \mathrm{~d}$ on a 3-phase feeding program. Pigs were slaughtered $(B W=111.8 \mathrm{~kg})$ and fabricated at the University of Illinois Meat Science Laboratory. A fat sample for fatty acid analysis, consisting of all 3 fat layers was collected from the dorsal edge of the anterior end of each fresh belly. Belly length, width, thickness, and flop distance were also recorded. Bacon was manufactured at a commercial facility after fresh belly characteristics were collected. Data were analyzed as a $2 \times 2$ factorial arrangement in a randomized complete block design with main effects of diet form (pellet or meal) and DDGS inclusion (0 or 30\%) as fixed effects. Replication nested in block served as a random effect.

Results: Bellies from pigs fed pelleted diets had $5.3 \%$ heavier $(P<0.001)$ skin-on belly weight, but did not differ $(P=0.55)$ as a percentage of chilled side weight. Pigs fed pelleted diets were $1.7 \mathrm{~mm}$ fatter at the $10^{\text {th }}$ rib, but there was no effect $(P$ $\geq 0.11$ ) of diet form on belly length, width, thickness, or flop distance. However, IV of pigs fed pelleted diets was 3.1 units greater $(P<0.0001)$ than pigs fed meal diets.

Green weights of bellies from pigs fed pelleted diets were $6.6 \%$ heavier $(P<0.0001)$ and had 0.95 percentage units greater $(P<0.05)$ cook yield than bellies from meal-fed pigs. Bellies of pigs fed pelleted diets had $3.1 \%$ fewer $(P<0.01)$ slices $/ \mathrm{kg}$ of sliced belly weight, but were not different $(P \geq 0.30)$ from meal-fed pigs in slicing yield calculated from green or cooked weight, indicating that slice thickness may have been altered.

Inclusion of DDGS resulted in bellies that were $3.2 \mathrm{~mm}$ thinner $(P<0.0001)$, had 4.97 lesser $(P<0.0001)$ flop distance, $2.8 \%$ lesser $(P=0.04)$ green weights, a 7.1 unit greater IV, and a 2.33 percentage unit reduction $(P=0.01)$ in slicing yield calculated from green weight, but did not differ $(P=0.51)$ from corn-soy fed pigs in slicing yield calculated from cooked weight. 
Conclusion: Overall, bellies from pigs fed pelleted diets were heavier, had greater cooking yields and greater IV, but did not differ in slicing yield from bellies of meal-fed pigs. Pigs fed 30\% DDGS had bellies that were thinner, had lesser flop distance, greater IV, and a lesser slicing yield calculated from green weight. Though feeding a pelleted diet increased belly fat IV, this did not result in a difference in slicing yield. In conclusion, producers can take advantage of the improvements in growth performance offered by pelleting diets without concern about negative impacts on bacon slicing yield.

Keywords: Bacon, Commercial Slicing Yield, Fat Quality, lodine value, Pelleting 


\section{Meat and Poultry Processing, Ingredient Technology and Packaging}

39

\section{ALDEHYDE CONCENTRATION BY SPME- HRGC/MS AS A DISCRIMINATING FACTOR IN SALAMI FORMULATIONS WITH LOW NACL CONTENT CORRELATED WITH SENSORY ANALYSIS}

M. A. de Almeida ${ }^{1, *}$, J. S. S. Pinto ${ }^{1}$, E. Saldaña ${ }^{1}$, F. A. Ribeiro ${ }^{1}$, N. D. M. Villanueva ${ }^{2}$, C. J. Contreras Castillo ${ }^{1}$

${ }^{1}$ Agroindustry, Food and Nutriction, Sao Paulo University, Piracicaba, Brazil, 2Facultad de Ingeniería Agraria, Universidad Católica Sedes Sapientiae, Lima, Peru

Objectives: The amount of aldehyde is related to the formation of flavor characteristic of fermented products. Thus, this study aimed to correlation between aldehyde concentration and sensory analysis to discriminate better formulation in development of low-sodium salami

Materials and Methods: We used two production processes, using the following meat formulation: pork meat (60\%), beef $(20 \%)$, pork back fat $(20 \%)$, flavoring $(2.1 \%)$, sodium nitrate $(0.015 \%)$, sodium nitrite $(0.015 \%)$, and starter culture (Staphylococcus xylosus and Pediococcus pentosaceus), stuffed and subjected to fermentation $\left(23-25{ }^{\circ} \mathrm{C}, \mathrm{RH} 85-90 \%\right.$ for $48 \mathrm{~h}$ ) up to $\mathrm{pH} 5.0$, and drying/ripening process $\left(17-19{ }^{\circ} \mathrm{C}, \mathrm{RH} 85-75 \%\right.$ for $\left.26 \mathrm{~d}\right)$ until water activity (Aw) reached 0.90 (Brazilian law). All treatments contained $1.0 \%$ of $\mathrm{NaCl}$ and combinations of $\mathrm{KCl}$ and $\mathrm{CaCl}_{2}$ as follows: $\mathrm{T} 1(0.50 \%$ $\left.\mathrm{KCl}+0.50 \% \mathrm{CaCl}_{2}\right)$, T2 $(0.45 \%+0.45 \%)$, T3 $(0.40 \%+0.40 \%)$, T4 $(0.35 \%+0.35 \%)$, and T5 $(0.25 \%+0.25 \%)$. High control $(\mathrm{HC})$ and low control $(\mathrm{LC})$ contained only $\mathrm{NaCl}(\mathrm{HC}=2.5 \%$ and $\mathrm{LC}=1.0 \%)$. Both processes were similar and the quantification of aldehyde was based on the total ion chromatogram (TIC) and results were expressed in area units (AU) $\times 105 / \mathrm{g}$. The sensory characteristic of salami (flavor) was evaluated through a consumer's (sixty consumer's) acceptance analysis using a 9-point hedonic scale. Result of sensory test was statistically analyzed using SAS software (Tukey's test).

Results: Table1 shows quantification of all treatments with various aldehydes in different amounts of $\mathrm{NaCl}, \mathrm{KCl}$ and $\mathrm{CaCl}_{2}$. Aldehyde hexanal was usually present in greater quantities and could be used as group representative. We observe that treatment $\mathrm{HC}$, salami with similar characteristics to commercial, $(2.5 \% \mathrm{NaCl})$ produced higher amounts of hexanal than the others. T5 was closer $\left(1.0 \% \mathrm{NaCl}+0.25 \% \mathrm{KCl}+0.25 \% \mathrm{CaCl}_{2}\right)$. It can be inferred that least amount of salt substitutes $\left(0.25 \% \mathrm{KCl}+0.25 \% \mathrm{CaCl}_{2}\right)$ enhanced hexanal production. According to the literature, the sausage ripening process is related to significant increase of aldehydes. Straight chain aldehydes such as nonanal, hexanal, heptanal, octanal, pentanal, and decanal in excess are related to rancidity odor. But when we compare these data with the sensory analysis conducted with consumers, it appears that the most accepted treatment was $\mathrm{T} 5(1.0 \% \mathrm{NaCl}+0.25 \% \mathrm{KCl}+$ $\left.0.25 \% \mathrm{CaCl}_{2}\right)$ which obtained scores flavor near to $\mathrm{CH}\left(7.2^{\mathrm{a}}-\mathrm{CH}\right.$ and $\left.6.8^{\mathrm{a}}-\mathrm{T} 5\right)$ and hexanal value of $82 \%$ of the concentration value of $\mathrm{HC}$ and total aldehydes of $74 \%$ in $\mathrm{HC}$. The other treatments had low hexanal values and total aldehydes. 
Table 1 - Quantification of aldehydes IA/g x $10^{5} \mathrm{dry}$ basis, different formulations (treatments) salami after the drying/ripening stage (28 days) by SPME-HRGC/MS

\begin{tabular}{|c|c|c|c|c|c|c|c|}
\hline \multirow{2}{*}{ Aldehydes } & \multicolumn{7}{|c|}{ Treatments (expressed in $10^{5} \mathrm{IA} / \mathrm{g}^{*}$ ) } \\
\cline { 2 - 8 } & $\mathrm{T} 1$ & $\mathrm{~T} 2$ & $\mathrm{~T} 3$ & $\mathrm{~T} 4$ & $\mathrm{~T} 5$ & $\mathrm{LC}$ & $\mathrm{HC}$ \\
\hline Pentanal & 0 & 0 & 0 & 0 & 27.94 & 0 & 29.34 \\
\hline Hexanal & 24.3 & 8.1 & 15.0 & 14.8 & 87.23 & 34.6 & 105.8 \\
& 5 & 7 & 3 & 0 & & 9 & 3 \\
\hline Heptanal & 1.11 & 0.4 & 0.78 & 0.86 & 6.62 & 2.08 & 15.42 \\
& & 0 & & & & & \\
\hline Octanal & 0 & 0 & 0 & 0 & 3.23 & 1.45 & 11.81 \\
\hline Nonanal & 0.77 & 0.6 & 0.98 & 0.53 & 2.59 & 2.12 & 8.66 \\
& & 3 & & & & & \\
\hline Decanal & 0 & 0 & 0 & 0 & 0 & 0 & 1.47 \\
\hline Total & 26.2 & 9.2 & 16.7 & 16.2 & 127.6 & 40.3 & 172.5 \\
& 3 & 0 & 9 & 0 & 1 & 4 & 2 \\
\hline
\end{tabular}

\section{* Intensity Area.}

Conclusion: We conclude that the hexanal Although considered by the literature an "off flavor", lipid oxidation indicator for long periods, in our working conditions and with the data obtained it can be considered an indicator of good quality and a tool for discriminate different formulations which agrees fits with the results of the sensory analysis.

Keywords: Profile of volatiles, Ripening, Salami 


\title{
Meat and Poultry Processing, Ingredient Technology and Packaging
}

40

\section{EFFECTS OF SALTS OF VARYING PURITY ON LIPID OXIDATION, SENSORY CHARACTERISTICS, AND TEXTURAL PROPERTIES OF FRESH, GROUND PORK PATTIES}

\author{
M. F. Overholt ${ }^{1, *}$, S. Mancini ${ }^{2}$, H. O. Galloway ${ }^{1}$, G. Preziuso ${ }^{2}$, A. C. Dilger ${ }^{1}$, D. D. Boler ${ }^{1}$ \\ ${ }^{1}$ Animal Science, University of Illinois, Urbana, United States, ${ }^{2}$ Veterinary Sciences, University of Pisa, Pisa, Italy
}

Objectives: Objectives were to evaluate effects of salts containing varying amounts of impurites on lipid oxidation, sensory, and textural properties of ground pork patties.

Materials and Methods: Approximately $160 \mathrm{~kg}$ of fresh boneless pork trimmings were ground through a $1.32 \mathrm{~cm}$ plate, then a $0.32 \mathrm{~cm}$ plate and split into 30 independent bacthes. Batches were mixed in a bowl chopper for 5 revolutions with either a salt typical to industry (Salt A), 1 of 3 unrefined salts (Salts B, C, and D), or no added salt (control) and formed into patties. Salts were added at a $1.5 \%$ inclusion. Salts were analyzed for $\mathrm{Na}$ and $\mathrm{Cl}$ and metal impurities (Fe, $\mathrm{Cu}, \mathrm{Ca}$, $\mathrm{Mg}$, and Mn). Total impurity ranged from 101 ppm (Salt A) - 2644 ppm (Salt B). Meat block samples were collected from each batch for use in salt-soluble protein extractability determination. Patties were overwrapped in polystyrene trays and stored at $4^{\circ} \mathrm{C}$ for 1,6 , or 11 days. Treatments were replicated 6 times, for a total of 30 independent batches. Data were analyzed as repeated measures in a complete randomized design. At the conclusion of the allotted storage time, patties were removed from packaging to determine lipid oxidation, $L^{*}, a^{*}, b^{*}$, discoloration, break strength, and sensory characteristics. Sensory evaluation was conducted using 6 trained panelists.

Results: Salt $A$ and Salt $B$ extracted a greater $(P \leq 0.03)$ percentage of salt-soluble protein than Salt $C$ or Salt $D$, but were not different $(P=0.16)$ from one another. Salt $C$ and $D$ did not differ $(P=0.89)$ in extracted salt-soluble proteins. There was no effect $(P=0.53)$ of salt variety on break strength. Salt inclusion resulted in increased $(P<0.0001)$ extracted saltsoluble protein and break strength.

There was no effect $(P \geq 0.34)$ of salt variety on ${ }^{*} L$ or $b^{*}$ values. There was an interaction $(P=0.02)$ of salt variety and storage time on $a^{*}$ values. Salt $B$ patties stored did not differ $(P=0.40)$ in redness after $1 \mathrm{~d}$ or $6 \mathrm{~d}$, but a reduction $(P \leq$ $0.01)$ in redness was observed in patties formulated with with Salt $A, C$, and $D$. There was an interaction $(P<0.0001)$ of salt variety and storage time for browning discoloration. No differences $(P \geq 0.40)$ were among salt varieties after $1 \mathrm{~d}$ or 6 d. After $11 \mathrm{~d}$ Salt A patties were more discolored $(P=0.01)$ than Salt $C$, Salt $C$ patties was more discolored than Salt $D$ $(P<0.01)$, and Salt $\mathrm{D}$ patties were more discolored $(P=0.02)$ than Salt $\mathrm{B}$. Salt inclusion resulted in less $(P<0.0001)$ browning discoloration, $L^{*}, a^{*}$, and $b^{*}$ values compared with the control.

After $11 \mathrm{~d}$ of storage, there were no differences $(P \geq 0.15)$ in lipid oxidation among patties formulated with salts $\mathrm{A}, \mathrm{C}$, or $\mathrm{D}$, but salt $\mathrm{B}$ had less $(P \leq 0.04)$ lipid oxidation than salts $\mathrm{A}, \mathrm{C}$, or $\mathrm{D}$. However, no differences in oxidized flavor $(P=0.54)$ or oxidized odor $(P=0.95)$ were detected by a trained sensory panel. 
Conclusion: Differences in purity of the salts used in this study affected lipid oxidation, color, and extractable salt-soluble protein. Observed differences in lipid oxidation did not result in differences in sensory characteristics, and differences in extractable salt-soluble protein did not alter break strength. In conclusion, processors using salts with impurities should not expect differences in oxidized flavor, oxidized odor and texture of ground pork products, but may observe differences in discoloration during fresh storage.

Keywords: Lipid oxidation, Pork, Salt, Sensory, Sodium chloride 


\section{Meat and Poultry Processing, Ingredient Technology and Packaging}

41

\section{SALTY AND SAVORY ENHANCING PROPERTIES OF HYDROLYZED POULTRY PROTEIN GLYCATED WITH GLUCOSAMINE}

P. K. Hong ${ }^{1, *}$, M. Ndagijimana ${ }^{1}$, M. Betti ${ }^{1}$

1Department of Agricultural, Food and Nutritional Science, University of Alberta, Edmonton, Canada

Objectives: The utilization of the Maillard reaction (glycation) to produce food flavorings and taste enhancers is widely documented. Designed cocktails containing reducing monosaccharides, amino acids and peptides are reacted at specific temperatures to obtain a desired meat flavour. This study was conducted to investigate the perceived saltiness and savoriness of poultry protein hydrolysate glycated at moderate temperatures with glucosamine (GlcN), a reactive amino sugar obtained from the hydrolysis of chitin.

Materials and Methods: Poultry protein (PPI) was isolated from the mechanically deboned turkey meat with the acid-aided isoelectric solubilization and precipitation process. The PPI was then hydrolyzed with Alcalase (enzyme:PPI=1:10 v/w, pH $8,50^{\circ} \mathrm{C}, 3.5 \mathrm{~h}$ ) and it was pooled and treated as a hydrolysate stock solution. The hydrolysate was glycated with $\mathrm{GlcN}$ (GlcN:hydrolysate $=1: 4 \mathrm{w} / \mathrm{w}, \mathrm{pH} 7.0-7.5,3.5 \mathrm{~h}$ ) at moderate temperatures $\left(37^{\circ} \mathrm{C}, 50{ }^{\circ} \mathrm{C}\right.$, respectively) in the presence $(+)$ or absence (-) of transglutaminase (TGase); the process was replicated in three batches and pooled according to the respective sample treatment. Each of the glycated samples was compared against controls (native hydrolysate, GIcN and sodium solution, respectively) and commercial taste enhancers (Table 1) in two separate sessions of sensory evaluation held on two different days. A randomized complete design was used with sample treatment as experimental unit. In the first session of sensory evaluation, 64 consumers were asked to rank the saltiness intensity of the 10 samples served randomly; another 61 consumers were recruited in the second session to rank the savory intensity. Sample with the highest intensity was ranked with score 1 whilst score 10 was given to sample with the lowest intensity. All the mean rank scores were analyzed with Friedman's test and separated with Bonferroni adjustment. Means were considered statistically significant at $p \leq 0.05$.

Results: All the glycated PPI hydrolysates showed enhanced saltiness compared to the salty solution $(p<0.05)$.

Remarkable, PPI hydrolysate glycated at $37^{\circ} \mathrm{C}$ in the absence of TGase showed a higher perceived saltiness compared to the commercial taste enhancers $(p<0.05)$. A tendency towards significance in the perceived savory taste $(p=0.059)$ as a function of the treatments was also observed.

Table 1: Statistical analysis of sensory evaluation

\begin{tabular}{|l|l|l|}
\hline \multirow{2}{*}{ Treatments } & Mean Rank Scores & \multicolumn{2}{|c|}{ Savory $(\mathrm{N}=61)$} \\
\cline { 2 - 3 } & Salty $(\mathrm{N}=64)$ & 6.3 \\
\hline Hydrolysate $37^{\circ} \mathrm{C}$ & $4.8 \mathrm{abc}$ & 6.0 \\
\hline Hydrolysate $50^{\circ} \mathrm{C}$ & 4.9 abcd & \\
\hline
\end{tabular}




\begin{tabular}{|c|c|c|}
\hline $\begin{array}{l}\text { Glycated hydrolysate } 37^{\circ} \mathrm{C} \\
\text { (-TGase) }\end{array}$ & $4.5^{\text {a }}$ & 5.1 \\
\hline $\begin{array}{l}\text { Glycated hydrolysate } 37^{\circ} \mathrm{C} \\
\text { (+TGase) }\end{array}$ & $4.7 \mathrm{ab}$ & 5.0 \\
\hline $\begin{array}{l}\text { Glycated hydrolysate } 50^{\circ} \mathrm{C} \\
\text { (-TGase) }\end{array}$ & $4.9 \mathrm{abc}$ & 4.8 \\
\hline Glucosamine $50^{\circ} \mathrm{C}$ & $5.9 \mathrm{bcd}$ & 5.3 \\
\hline Salty solution (Sodium) & $6.5^{d}$ & 5.8 \\
\hline $\begin{array}{l}\text { Savory solution (Sodium+Monosodium } \\
\text { glutamate) }\end{array}$ & $6.4 \mathrm{~cd}$ & 6.2 \\
\hline Kokumi solution (Sodium+Glutathione) & $6.2 \mathrm{bcd}$ & 5.4 \\
\hline $\begin{array}{l}\text { Savory+ Kokumi solution } \\
\text { (Sodium+Monosodium } \\
\text { glutamate+Glutathione) }\end{array}$ & $6.2 \mathrm{bcd}$ & 5.2 \\
\hline$P$ value & $<0.001$ & 0.0593 \\
\hline
\end{tabular}

Low mean rank scores denote a higher perceived taste intensity.

Mean rank scores with different letters within the same column were significantly different $(p<0.05)$.

Conclusion: In conclusion, this study was able to demonstrate that the glycated hydrolyzed PPI possessed salt-enhancing properties. This study can benefit the salt reduction strategy in the meat industry through the addition of Alcalase hydrolyzed PPI and GlcN.

Keywords: glucosamine, glycation, poultry protein isolate, salty, savory 


\section{Meat and Poultry Processing, Ingredient Technology and Packaging}

42

\section{EFFECT OF VARIOUS DRYING TEMPERATURES OF OVEN-DRYING ON PHYSICOCHEMICAL PROPERTIES AND ANTIOXIDANT ACTIVITY OF PORK PATTIES DURING REFRIGERATED STORAGE}

H. $\operatorname{Kim}^{1, *}$, K. B. Chin ${ }^{1}$

${ }^{1}$ Animal Science and Functional Food Research Center, Chonnam National University, Buk-gu, Korea, Republic Of

Objectives: This study was performed to evaluate physicochemical properties and antioxidant activity of pork patties with oven-dried tomato powders as affected by different drying temperatures.

Materials and Methods: Fresh tomatoes were homogenized by food mixer and then, dried at 60,80 and $100^{\circ} \mathrm{C}$ in an oven. Control patties without dried tomato powder (DTP), reference patties with $0.1 \%$ of ascorbic acid (REF), and treatment patties with $1 \%$ powder of DTP in a 60 (TRT1), 80 (TRT2) and $100^{\circ} \mathrm{C}$ (TRT3) oven-drying were manufactured. The patties were packaged using a polystyrene case and stored at $4^{\circ} \mathrm{C}$. During storage, patties were analyzed at $0,3,7$ and 14 days of refrigerated storage. $\mathrm{pH}$, Hunter color values, lipid oxidation (2-thiobarbituric acid reactive substances, TBARS, malondialdehyde (MDA) mg/kg); peroxide value, POV), protein deterioration (volatile basic nitrogen, VBN, mg\%) and microbial counts (total bacterial count, TPC; Enterobacteriaceae count, VRB, log cfu/g) of pork patties were measured during 14 days of refrigerated storage. Data were analyzed using SPSS 21.0 program. Two-way analysis of variance was performed as factors for treatment and storage time. Significant differences among the means of treatments were analyzed by Duncan's multiple range test $(P<0.05)$.

Results: Addition of $1 \%$ DTP decreased $\mathrm{pH}$ values of pork patties $(P<0.05)$. Among the treatments, patties with $1 \%$ of DTP from $100^{\circ} \mathrm{C}$ oven-drying showed the lowest lightness value $(P<0.05)$. In contrast, incorporation of DTP into patties increased redness and yellowness values $(P<0.05)$. TBARS values of treatments were lower than those of control, but higher than those of REF until 7 days of storage $(P<0.05)$. POV values of patties with DTP with various drying temperatures showed lower than those of control until the end of storage time $(P<0.05)$. Patties with DTP with different drying temperatures were lower VBN than those of CTL. However, no antimicrobial activity was observed among the treatments $(P>0.05)$.

Conclusion: These results suggested that DTP could be used as a natural antioxidant in meat products during refrigerated storage.

Keywords: antioxidant activity, drying temperatures, pork patty, tomato 


\title{
Meat and Poultry Processing, Ingredient Technology and Packaging
}

44

\section{RETAIL SHELF-LIFE OF FRESH AND CURED MEAT PRODUCTS STORED UNDER FLUORESCENT AND LIGHT EMITTING DIODE (LED) ILLUMINATION SOURCES}

\author{
A. Lowder ${ }^{1, *}$, J. Killefer ${ }^{1}$
}

${ }^{1}$ Animal \& Rangeland Sciences, Oregon State University, Corvallis, United States

Objectives: Illumination emission spectrum and intensity are both known factors affecting the retail shelf-life of fresh and nitrite cured meat products. In fresh products, greater overall light intensity and increased interaction with certain wavelengths of light will speed the oxy- to metmyoglobin conversion and prematurely bring about discoloration that consumers select against at retail. The same factors in nitrite cured products hasten fading of the cured pink color, again causing rejection. As such, it is important to meat shelf life to consider lighting type, which determines emission spectrum, where meat products may be exposed to light for extended periods of time, such as grocery outlets. Currently, fluorescent lighting is heavily used in retail due to advantages in efficiency and longevity over older lighting types. However, the newer technology of light emitting diode (LED) sources has recently achieved commercial viability. As LED holds major advantages over fluorescent in energy efficiency, longevity and environmental friendliness, their adoption by many commercial retailers is inevitable. The current study sought to determine what impact, if any, LED lamps may have on fresh and nitrite cured meat products relative to fluorescent lamps.

Materials and Methods: Beef steaks were sliced to $2.54 \mathrm{~cm}$ thick from semitendinosus and overwrapped in $\mathrm{O}_{2}$ permeable film on polystyrene trays. Cured beef sausages were manufactured in a table top bowl chopper from round muscles (4-6\% fat) with $2 \%$ added salt, $10 \%$ added water and $156 \mathrm{ppm}$ sodium nitrite. Sausage samples $(\sim 100 \mathrm{~g})$ were placed in a vacuum package and flattened to $6 \mathrm{~mm}$ before sealing and cooking in a water bath to $71^{\circ} \mathrm{C}$. Packaged steaks and sausages were placed into a simulated retail display $\left(4^{\circ} \mathrm{C}\right)$ with either fluorescent or LED illumination; a control group was kept in dark storage. Both illumination sources were rated at $3500 \mathrm{~K}$ color temperature and light intensity was normalized to 1600-2200 lux. Instrumental color (400-700 nm reflectance spectra) was monitored daily and lipid oxidation at certain intervals was determined by thiobarbituric acid reactive substances (TBARS). Both studies were replicated three times.

Results: Spectra of both light sources showed heaviest emissions in the visible range $(400-700 \mathrm{~nm})$ with the fluorescents emitting some in the infrared range $(>700 \mathrm{~nm})$ as well. As such, the surface temperature of the fluorescent samples was $0.5-1.0^{\circ} \mathrm{C}$ greater than those under LED. This did not negatively affect shelf life of fresh beef steaks as there were no statistically significant differences in measured parameters $\left(L^{*}, a^{*}, b^{*}\right.$ or 630/580 $\mathrm{nm}$ ratio). Cured sausages, however, experienced marked decline in red color as determined by $a^{*}$ values when under LED light for at least $16 \mathrm{~d}$ as compared to fluorescent light and dark storage. Lipid oxidation (TBARS) and cured color intensity (650/570 nm ratio) were not different on any testing day between the light sources for cured sausage. 
Conclusion: In this study, it was observed that the redness of cured sausage declined faster under LED lighting than fluorescent but no other indicator of shelf-life was affected, while fresh beef steak shelf-life was unaffected by lighting type. Differential sensitivity to certain wavelengths may explain the dichotomy. Retailers eyeing adoption of LED should consider product type (cured vs uncured) and the specific emission spectra of the light source.

Keywords: Color stability, Lighting, Shelf-life 


\title{
Meat and Poultry Processing, Ingredient Technology and Packaging
}

45

\section{INHIBITION OF LIPID OXIDATION IN GROUND TURKEY BREASTS BY ENCAPSULATED POLYPHOSPHATES AS INFLUENCED BY POSTMORTEM PH}

\author{
J. Claus ${ }^{1,}$, , C. Du ${ }^{1}$, B. Kılıç ${ }^{2}$
}

${ }^{1}$ Animal Sciences, Univerisity of Wisconsin, Madison, United States, ${ }^{2}$ Department of Food Engineering, Suleyman Demirel University, Isparta, Turkey

Objectives: The objective of this research was to determine polyphosphate antioxidant abilities as influenced by meat $\mathrm{pH}$ (high, 6.4 to 6.7; low: 5.9 to 6.2), polyphosphate type (HMP=sodium hexameta phosphate, SPP=sodium acid pyrophosphate, STP=sodium tripolyphosphate), encapsulation (u=unencapsulated, e=encapsulated) and two different temperature release points (TRP: 60 and $68 \mathrm{C}$ ), by a replicated $(n=3)$ experiment using ground turkey breasts associated with pre-cook storage times $(3,6,24 \mathrm{~h})$, end-point cooking temperatures $(73.9 \mathrm{C}, 79.4 \mathrm{C})$ and post-cook storage times $(0$, $1,7 \mathrm{~d})$.

Materials and Methods: Nine batches of ground turkey were used to manufacture the polyphosphate treatments ( 3 unencapsulated polyphosphates; 3 encapsulated polyphosphates, each at two TRP). Regardless of being encapsulated or unencapsulated, $0.4 \%$ pure polyphosphate along with $10 \%$ water and $1 \%$ salt were delivered on a meat weight basis. Polyphosphates (PP) were commercially encapsulated with hydrogenated vegetable oil designed to achieve the two different temperature release points. Treated ground turkey was stuffed into plastic sausage casings $(7.4 \mathrm{~cm}$ diameter). After pre-cook storage, samples were water cooked. The encapsulated polyphosphates were coded as eHMP-60, eHMP68, eSPP-60, eSPP-68, eSTP-60, and eSTP-68. Unencapsulated polyphosphates were coded as uHMP, uSPP, and USTP. Dependent variables determined on cooked samples included: $\mathrm{pH}$, soluble orthophosphate (SOP; hydrolysis of PP), lipid hydroperoxides (LPH), and thiobarbituric acid reactive substances (TBARS). Statistical analysis was first performed to determine the most effective TRP (based on limiting PP hydrolysis and lipid oxidation), after which those encapsulated polyphosphates were compared to unencapsulated cohorts.

Results: TRP 68 was more effective $(P<0.05)$ than TRP 60 in limiting polyphosphate hydrolysis only for eSPP (SOP: eSPP-68, $4770 \mu \mathrm{g} / \mathrm{g}$; eSPP-60, $5076 \mu \mathrm{g} / \mathrm{g}$ ). TRP did not influence ( $>0.05)$ SOP accumulation for eSTP. However, TRP 68 resulted in higher $(P<0.05)$ SOP for eHMP (eHMP-68, $4814 \mu \mathrm{g} / \mathrm{g}$; eHMP-60, $4612 \mu \mathrm{g} / \mathrm{g})$. TRP 68 only influenced (lower, P<0.05) TBARS for eHMP (eHMP-68, $0.49 \mathrm{mg} / \mathrm{kg}$; e-HMP-60, $0.62 \mathrm{mg} / \mathrm{kg}$ ). At a given TRP, eSPP and eSTP were equally more effective at reducing TBARS ( $<<0.05 ; 55 \%$ at TRP $60,48 \%$ at TRP 68 , respectively) in comparison to eHMP. The difference in the $\mathrm{pH}$ between the two sets of turkey breasts had minimal effect on control of lipid oxidation by the encapsulated phosphates likely because the phosphates altered the $\mathrm{pH}$ upon cooking. Only a minor difference of about 0.05 of a pH unit was found in the cooked samples between the high $\mathrm{pH}$ group and low $\mathrm{pH}$ group. At the end of 
post-cooked storage (day 7) TRP 68 encapsulated PP had about 5 times lower $(P<0.05)$ LHP than unencapsulated PP (600 versus 2991, $\mu \mathrm{mol} / \mathrm{kg}$ ). eSTP-68 and eSPP-68 were more effective at limiting TBARS accumulation than e-HMP-68 and both had about 4 times lower TBARS than unencapsulated cohorts.

Conclusion: Encapsulating polyphosphates dramatically preserve their antioxidant functionality by limiting their exposure to active phosphatases prior to thermal processing. The higher temperature release point associated with the melting properties of the encapsulate likely provided the opportunity for more complete inactivation of the phosphatases prior to releasing the polyphosphate.

Keywords: encapsulated polyphosphates, lipid oxidation, turkey 


\section{Meat and Poultry Processing, Ingredient Technology and Packaging}

46

\section{DRY POTATO EXTRACT IMPROVES WATER HOLDING CAPACITY, SHELF LIFE, AND SENSORY CHARACTERISTICS OF BEEF PATTIES}

M. Colle 1, ${ }^{\star}$, R. P. Richard ${ }^{1}$, M. J. Colle ${ }^{1}$, W. I. Loucks ${ }^{1}$, S. J. Gray ${ }^{1}$, Z. J. Reynolds ${ }^{1}$, H. A. Sutton ${ }^{1}$, J. A. Nasados ${ }^{1}$, M. E. Doumit 1

${ }^{1}$ Animal and Veterinary Science, University of Idaho, Moscow, United States

Objectives: Binders are commonly incorporated into processed meat products to improve product yield, texture, and palatability. Our objective was to examine shelf stability, cooked product yield, and sensory characteristics of beef patties with no added binder (Control), soy flour (TVP), or dry potato extracts.

Materials and Methods: Potato extracts were provided by Basic American Foods (Blackfoot, ID) and included X-TEND ${ }^{\mathrm{TM}}$, $X-T_{E N D}{ }^{\mathrm{TM}} \mathrm{M}$, which is a potato extract containing mustard, and X-TEND ${ }^{\mathrm{TM}} \mathrm{S}$, which includes sodium acid pyrophosphate. USDA Choice beef shoulder clods (IMPS 114) were purchased from AB Foods (Toppenish, WA). The product was coarse ground through a $0.9525 \mathrm{~cm}$ plate and subsequently fine ground through a $0.3175 \mathrm{~cm}$ plate. Batches $(n=6)$ were mixed and formulated with $10 \mathrm{lbs}$ ground beef ( 15\% fat), and the following ingredients as a percentage of the meat block: $1 \%$ salt, $15 \%$ water, $0.2 \%$ onion granules, and $2 \%$ of the designated binder. Patties were mechanically formed to $151 \mathrm{~g}$ and were randomly assigned to four days of fresh retail display or to be cooked, frozen, and stored for 21 to 52 days at $-20^{\circ} \mathrm{C}$. Fresh patties were placed on white styrofoam trays, overwrapped with an oxygen permeable PVC film, and displayed in a glass-fronted retail display case at $2^{\circ} \mathrm{C}$. Two objective color measurements per patty were taken on day 0 using a Hunter MiniScan EZ. Subsequent color measurements were taken on days $1,2,3$, and 4 . The instrument was set to illuminant $A$ and $\mathrm{CIE} \mathrm{L*}{ }^{*} \mathrm{a}^{*}$, and $\mathrm{b}^{*}$ values were recorded. Discoloration was also visually scored by two evaluators each day. Thiobarbituric acid reactive substances were used to determine lipid oxidation on days 0 and 4 of retail display for fresh patties and days 0 and 21 of frozen storage for precooked patties. Patties were cooked to an internal temperature of $71^{\circ} \mathrm{C}$ on a clamshell grill on day 0 and cooking yield was determined as the percentage of initial product weight that remained after cooking. Patties designated for sensory analysis were cooked on day 0 , stored frozen for 51 or 52 days and then reheated in an oven to $71^{\circ} \mathrm{C}$ prior to serving. A consumer panel $(n=60)$ evaluated precooked patties for overall acceptability, texture, juiciness, and flavor. Data were analyzed using the Mixed Model procedure of the Statistical Analysis System (SAS Institute, Inc., Cary, NC) and significance was determined at $P<0.05$.

Results: In retail display patties, all binders decreased discoloration and lipid oxidation compared to Control, and XTEND $^{\text {TM }} \mathrm{M}$ was superior $(P<0.0001)$ to all other treatments. Cooking yield was higher $(P<0.0001)$ in patties containing potato extracts compared with patties containing TVP, which had higher yield than Control patties. All potato extract treatments were comparable for consumer acceptability, texture, and juiciness. Beef patties with potato extracts were juicier $(P<0.001)$ than Control and TVP patties, and had higher $(P<0.001)$ overall acceptability than Control patties. 
Conclusion: We conclude that potato extracts are effective binders for use in fresh or pre-cooked beef patties because they improve retail shelf life, cooked product yield, and sensory characteristics.

Keywords: Beef Patties, Potato Extract, Shelf Stability, Yield 


\title{
Meat and Poultry Processing, Ingredient Technology and Packaging
}

47

\section{EFFECTS OF BRINE TEMPERATURE ON HAM AND BACON PROCESSING CHARACTERISTICS}

\author{
B. C. Peterson ${ }^{1, *}{ }^{\star}$, E. K. Arkfeld ${ }^{1}$, S. F. Holmer ${ }^{2}$, F. K. McKeith ${ }^{1}$, A. C. Dilger ${ }^{1}$, D. D. Boler ${ }^{1}$
}

1 University of Illinois, Urbana, ${ }^{2}$ Smithfield Foods, Smithfield, United States

Objectives: Effects of brine temperature on processing yields, cured meat chemistry, and sensory characteristics are largely unknown. Therefore, the objective was to evaluate the effect of brine temperature on processed ham and bacon processing characteristics.

Materials and Methods: Pork knuckles (IMPS \#402H Pork Leg, Tip; N=51) and pork bellies (IMPS \#409 Pork Belly, Skinless; $\mathrm{N}=60$ ) were weighed and allotted to 1 of 3 treatment groups (brine temperature; $-1.1^{\circ} \mathrm{C}, 7.2^{\circ} \mathrm{C}, 15.5^{\circ} \mathrm{C}$ ). $\mathrm{A}$ master batch of curing solution was mixed to include all curing ingredients except sodium nitrite, divided into three aliquots of equal weight, and held overnight to manipulate brine temperature. Brine was formulated to deliver $1.52 \%$ sodium chloride, $0.11 \%$ sugar, $0.12 \%$ spices, $0.33 \%$ sodium tripolyphosphate, $0.05 \%$ sodium erythorbate and $0.014 \%$ nitrite in the final product. Nitrite was added just prior to injection of each treatment. Brines were agitated thoroughly during temperature manipulation to ensure accurate final temperature determinations. Knuckles were injected twice to a target of $130 \%$ of green weight and bellies were pumped to a target of $110 \%$ of green weight with a Wolf-Tec Inc. Model Number N50 injector. Knuckles were weighed immediately after injection and then allowed to drain for 30 minutes and weighed again. Bellies were weighed and immediately hung on a smoke cart. Knuckles were cooked and smoked until they reached an internal temperature of $66.6^{\circ} \mathrm{C}$ and bellies were cooked and smoked until they reached an internal temperature of 52.2 ${ }^{\circ} \mathrm{C}$. After thermal processing, hams (knuckles) and bellies were showered with cold water (15 min and $10 \mathrm{~min}$, respectively). Hams were weighed to determine hot cooked weight. Hams and bellies were chilled to $7.2^{\circ} \mathrm{C}$ and weighed to determine final cooked weight. Evaporative chilling loss of hams was calculated as the difference between hot and chilled cooked weights as a percentage of chilled weight. Cooked yield of hams and bellies was calculated from chilled cooked weight as a percentage of green weight. Two $2.54 \mathrm{~cm}$ ham steaks were collected from the middle of each ham for texture analysis, proximate composition, and sensory evaluation. Hams were evaluated for saltiness, juiciness and mouthfeel by a trained sensory panel.

Results: Brine temperature did not affect $(P \geq 0.18)$ pumped weight, drained weight, initial pump uptake, drained pump uptake, cooked yield, chilled weight, or evaporative chill loss of hams. Hams pumped with $15.5^{\circ} \mathrm{C}$ brine were lighter $(P=0.03)$ and redder $(P=0.01)$ compared with hams pumped with $-1.1^{\circ} \mathrm{C}$ and $7.2^{\circ} \mathrm{C}$ brine. Hams cured with $15.5^{\circ} \mathrm{C}$ brine were saltier $(P=0.06)$ than $-1.1^{\circ} \mathrm{C}$ and $7.2^{\circ} \mathrm{C}$ treatments. Brine temperature did not affect juiciness $(P=0.80)$ or mouthfeel $(P=0.40)$ of hams or any trait from texture analysis $(P \geq 0.08)$. Moisture and lipid content also did not differ $(P \geq 0.60)$ in hams among brine temperatures. Brine temperature did not affect pump uptake $(P=0.57)$ or cooked yield $(P=0.98)$ of bellies. 
Conclusion: Overall, though hams pumped with $15.5^{\circ} \mathrm{C}$ brine tended to be saltier, lighter and redder in color but, brine temperature did not affect processed ham cooked yields. Brine temperature did not affect processing yields of bellies.

Keywords: Bacon, Cured Meat, Ham 


\title{
Meat and Poultry Processing, Ingredient Technology and Packaging
}

48

\section{PALATABILITY ATTRIBUTES OF BEEF STRIPLOINS MECHANICALLY ENHANCED WITH PORK FAT}

\author{
D. D. Reed, Jr. 1, ${ }^{*}$, L.-A. J. Walter ${ }^{1}$, A. N. Schmitz ${ }^{1}$, D. E. Guadián-Garcia ${ }^{1}$, T. E. Lawrence ${ }^{1}$
}

1West Texas A\&M University, Canyon, United States

Objectives: An experiment was conducted to examine the palatability attributes of low quality beef striploin steaks mechanically enhanced with pork subcutaneous fat.

Materials and Methods: Beef subprimal strip loins (IMPS 180; $n=40$ ) were collected from USDA Standard steer carcasses, vacuum packaged and stored at $2^{\circ} \mathrm{C}$. Loins were longitudinally cut into halves and each half (lateral or medial) was randomly assigned to pork fat injection $(\mathrm{PFI})$ treatment or to non-injected control (CON). Loin halves assigned to the $\mathrm{PFI}$ treatment were injected $(12.61 \% \pm 2.45 \%)$ using a multi-needle mechanical injector with liquid $\left(60^{\circ} \mathrm{C}\right)$ pork fat (subcutaneous loin origin) that had been fully cooked $\left(>71^{\circ} \mathrm{C}\right)$. Loin halves from PFI and CON were frozen $\left(-28.9^{\circ} \mathrm{C}\right)$ before steaks $(2.54 \mathrm{~cm})$ were cut. Steaks for Warner Bratzler Shear Force (WBSF), trained and consumer sensory panels and proximate analysis (cooked and uncooked) were thawed at $1^{\circ} \mathrm{C}$ for $24 \mathrm{~h}$ before being cooked in a forced air convection oven set at $177^{\circ} \mathrm{C}$ until an internal endpoint temperature of $70^{\circ} \mathrm{C}$ was reached. Eighty ( $\left.80 \mathrm{CON} / 80 \mathrm{PFI}\right)$ pairs of steaks were evaluated for trained sensory panel attributes; panelists scored (1-extremely

tough/dry/bland/tough/intense, 8-extremely tender/juicy/intense/tender/none) steaks for myofibrillar tenderness, juiciness, beef flavor intensity, overall tenderness, and off-flavor intensity. Seventy (70 CON / $70 \mathrm{PFI}$ ) pairs of steaks were evaluated at West Texas A\&M by untrained consumers for sensory attributes; panelists scored (1-extremely dislike, 9extremely like) samples for tenderness, flavor, juiciness, and texture. In addition, panelists were asked to provide their overall preference. Steaks allocated to WBSF determinations were chilled for $24 \mathrm{~h}$ at $1^{\circ} \mathrm{C}$ before six $1.27 \mathrm{~cm}$ cores were randomly removed parallel to the muscle fiber orientation. Cores were immediately sheared using a V-shaped blade on the WBSF machine; peak shear force $(\mathrm{kg})$ values were recorded for each core, and averaged for each steak. Continuous data were analyzed as a completely randomized design using a mixed model; treatment was the fixed effect with random effects of animal and location (lateral or medial half). Ordinal data were analyzed using the Wilcoxon rank-sum test. Overall preference data were analyzed using a chi-square test.

Results: Uncooked steaks from the PFI treatment had less $(P<0.01)$ moisture $(-5.2 \%)$ and protein $(-1.9 \%)$ simultaneous with greater $(P<0.01)$ fat $(+7.3 \%)$ vs. CON uncooked steaks. Cooked PFI steaks had less $(P<0.01)$ moisture $(-1.0 \%)$ and more $(P<0.01)$ fat $(+1.3 \%)$ with no difference $(P=0.14)$ in the protein percentage vs. cooked CON steaks. Trained panelists denoted $(P=0.02)$ an off-flavor for the PFI treatment but were unable to discern $(P>0.14)$ other attribute differences. In contrast, consumer panelists denoted $(P=0.05)$ improved tenderness for the PFI treatment and reported preference $(P=0.01)$ for PFI treated steaks. Similarly, WBSF data demonstrated lower $(P<0.01)$ values for PFI treated steaks as compared to the CON treatment ( $2.50 \mathrm{vs} .4 .44 \mathrm{~kg}$, respectively). 
Conclusion: In conclusion, mechanically injecting low quality beef loins with pork subcutaneous fat altered proximate analysis and improved palatability. This processing method deserves further investigation and may offer an opportunity for new product development.

Keywords: Beef, Enhancement, palatability, strip loin 


\title{
Meat and Poultry Processing, Ingredient Technology and Packaging
}

49

\section{MEASURING OXIDATIVE STATUS OF GROUND BEEF TREATED WITH ROSMARINIC ACID}

\author{
A. McCain ${ }^{1}$, S. Menard ${ }^{1, *}$, B. Bounds ${ }^{1}$, T. Dinh ${ }^{1}$ \\ ${ }^{1}$ Animal and Dairy Sciences, Mississippi State University, Mississippi State , United States
}

Objectives: Antioxidants have been reported to improve the shelf life of meat products by preventing oxidation. Effectiveness of various concentrations of natural antioxidants has been evaluated using either ferric reducing antioxidant power (FRAP), Folin-Ciocalteu (FC), trolox equivalent antioxidant capacity (TEAC), or thiobarbituric acid reactive substances (TBARS) method. The objectives of this study were (1) to investigate different concentrations of rosmarinic acid in preventing oxidation of ground beef and (2) to compare four methods used to evaluate oxidative status of meat samples.

Materials and Methods: A single batch of ground beef (90\% lean) was divided into $72100-\mathrm{g}$ experimental units ( $\mathrm{N}=$ 72). They were randomly assigned to nine treatment combinations of a $3 \times 3$ factorial arrangement $(0,25$, or $50 \mathrm{ppm}$ rosmarinic acid; and room temperature exposure for 0,4 , or $8 \mathrm{~h} ; \mathrm{n}=8$ replicates per treatment combination). One milliliter of rosmarinic acid solution, Sigma Aldrich, St. Louis, MO, was applied to samples according to their assigned treatment, mixed, vacuum packaged, and stored at $2^{\circ} \mathrm{C}$ overnight. Samples were subsequently exposed to air and room temperature according to their time treatments. Samples were then frozen in liquid nitrogen, pulverized to fine powder, and stored at $-80^{\circ} \mathrm{C}$ for subsequent analysis. Oxidative status was evaluated by FC, FRAP, TEAC, and TBARS methods. Statistical analysis was performed using GLIMMIX procedure and mean separation was determined using protected t-test. Pearson correlations were also done to determine correlations among the four testing methods.

Results: Oxidative status of samples were significantly influenced by both rosmarinic acid concentration and exposure time when measured by FRAP, FC, and TBARS methods ( $P \leq 0.011$ ); except for TEAC having a concentration effect but not an exposure time effect ( $P<0.001$ for concentration; $P=0.292$ for exposure time). Values of FRAP, FC, and TEAC were increased by concentration (more than $18 \%$ increase from control to $50 \mathrm{ppm}$ ). Antioxidant power measured by FRAP and FC peaked at $4 \mathrm{~h}$ and decreased at $8 \mathrm{~h}$ of exposure $(P<0.001)$. The TBARS value increased 18.3 and $15.1 \%$ for control and $25 \mathrm{ppm}$, respectively $(P \leq 0.009)$, but remained similar for $50 \mathrm{ppm}(P=0.125)$ over 8-h exposure. There was no concentration $\times$ time interaction $(P>0.168)$. The TBARS was negatively correlated with FC, FRAP, and TEAC $(P \leq$ 0.050), whereas FC, FRAP, and TEAC were positively correlated $(P<0.001)$ with each other.

Conclusion: Results from this study indicated that the oxidative status of ground beef was influenced by added antioxidant concentration and storage condition. The concentration of $50 \mathrm{ppm}$ of rosmarinic acid is equivalent to $1000 \mathrm{ppm}$ of rosemary extract, which was proved most effective. The use of TBARS method and one of FC, FRAP, or TEAC methods is needed to characterize the oxidative status of meat samples. 
Keywords: Antioxidant Capacity, Beef, Meat Quality, Natural Antioxidant, Rosemary 


\title{
Meat and Poultry Processing, Ingredient Technology and Packaging
}

50

\section{PROCESSING YIELDS AND QUALITY CHARACTERISTICS OF HOTDOGS MADE WITH FUNCTIONALIZED MECHANICALLY SEPARATED CHICKEN SOLUTIONS.}

\author{
C. A. Frost ${ }^{1, *}$, H. L. Gilleland ${ }^{1}$, T. D. Pringle 1
}

1Animal and Dairy Science, University of Georgia, Athens, United States

Objectives: Mechanically separated chicken (MSC) is a paste-like and batter-like product used widely in emulsion sausages. Although MSC is a low cost raw material $(\$ 0.57 / \mathrm{kg})$, there are compositional, textural and functional differences that must be accounted for when using it as a meat ingredient. Therefore we conducted an experiment to determine the effect of adding Functionalized MSC solutions (FMSC) of varying $\mathrm{pH}$ in place of turkey thigh meat $(\$ 3.00 / \mathrm{kg})$ in a low-fat, low-cost, poultry hotdog.

Materials and Methods: The primary ingredients in the control (C) frankfurters were turkey thigh meat, MSC, chicken skin emulsion, and water. Additionally, sodium lactate(56\%)/diacetate(4\%), sodium acid pyrophosphate, soy concentrate, potato starch, and wheat flour were added as functional ingredients. In the test hotdogs, $6 \%$ of the turkey thigh meat and the water was replaced by the FMSC. The FMSC solutions were made by homogenizing the MSC and water while adding crystalline citric acid to lower the $\mathrm{pH}$ of the solution to 3.7. The pH was adjusted up to 6.3 (T1), 6.65 (T2), or 7.0 (T3) using sodium bicarbonate. Finally, the FMSC solutions were degassed and stored overnight at $4^{\circ} \mathrm{C}$. Hotdogs were manufactured by chopping the ingredients for $3 \mathrm{~min}$ and then passing the batter through a vertical emulsifier. The batter was placed under vacuum for $10 \mathrm{~min}$ before being stuffed and linked in fibrous casings. Samples of the batters were taken to determine $\mathrm{pH}$, temperature, instrumental color, and emulsion stability. The hotdogs were weighed and cooked to an internal temperature of $75^{\circ} \mathrm{C}$ (approximately $75 \mathrm{~min}$ ). Following cooking the hotdogs were weighed, stored at $4^{\circ} \mathrm{C}$ overnight, and reweighed to determine cook yields. Random samples of the cooked hotdogs were collected for measuring $\mathrm{pH}$, composition, and instrumental color and texture. The experiment was replicated three times. Data were analyzed using ANOVA for a replicated experiment and means were separated using the LSD procedures of SAS.

Results: Batter $\mathrm{pH}$ increased linearly from the control to $\mathrm{T} 3(6.18,6.38,6.67,6.88$, respectively). There were no differences in the $L^{*}$ values of the batter, however the $C$ batter was redder $(P<0.05)$ than the $T$ batters. Additionally, $T 3$ and T2 batters were bluer $(P<0.05)$ than $C$ and T1 batters. Although cook yields $(0 \mathrm{~h}$ and $24 \mathrm{~h})$ did not differ across the treatments, emulsion stability was higher in T1 compared to $\mathrm{C}, \mathrm{T} 2$ and $\mathrm{T} 3$. The $\mathrm{pH}$ of the cooked hotdogs, like the batters, increased linearly from C to T3 $(6.18,6.36,6.61,6.82$, respectively). For cooked color, T2 and T3 hotdogs were darker $(P<0.05)$ than $C$ hotdogs. T3 hotdogs were also less red $(P<0.05)$ but bluer $(P<0.05)$ than $C, T 1$ and T2 hotdogs. Compositionally, fat content was not different $(P=0.25)$ across the treatments; however, T2 hotdogs had a higher $(P<0.05)$ moisture content than T3 and $C$ hotdogs and $C$ hotdogs had a higher $(P<0.05)$ protein content than all other hotdogs. 
Control hotdogs were harder $(P<0.05)$ and chewier $(P<0.05)$ than all the $T$ hotdogs, which did not differ. Springiness and resilience did not differ across treatments; however, the cohesiveness of T1 hotdogs was great than T2 hotdogs.

Conclusion: Replacement of turkey thigh meat in hotdogs with FMSC solutions should produce a lower cost product with comparable or better quality and yields.

Keywords: Frankfurters, Functionalized Proteins, Mechanically Separated Chicken, Poultry, Quality 


\section{Meat and Poultry Processing, Ingredient Technology and Packaging}

52

\section{ESTABLISHING BEST PRACTICES FOR SOUS VIDE PREPARATION OF LARGER BONELESS BEEF \& PORK CUTS}

K. Madore ${ }^{1}$, D. Johnson ${ }^{1}$, C. Carr ${ }^{1,}$, , J. Neto ${ }^{2}$

1 University of Florida, Gainesville, United States, ${ }^{2}$ Federal Institute of Science, Education and Technology of Mato Grosso, Campo Grande, Brazil

Objectives: Determine best practices for sous vide preparation of larger boneless beef and pork cuts for foodservice. Materials and Methods: Paired pork shoulder butts, cellar trimmed, boneless (CT Butts, NAMP \# 407) and beef clod hearts, boneless (NAMP \# 114E) were selected from both sides of 10 industry standard pork and fed-beef carcasses at commercial processors. Pork and beef muscles were trimmed to $0.64 \mathrm{~cm}$ external fat, vacuum packaged and aged for 7 and $14 \mathrm{~d}$ postmortem, respectively prior to freezing and subsequent evaluation. Pairs of muscles from the same species were evaluated per run/day during evaluation. After aging and thawing at $2^{\circ} \mathrm{C}$, one muscle from one side of each carcass was browned in a non-stick skillet for up to $20 \mathrm{~min}$ (PRE), and then weighed. Both muscles from each side of each carcass were then individually vacuum sealed prior to being placed in a constant temperature water bath with a circulating water agitator at $57.2^{\circ} \mathrm{C}$ for $10 \mathrm{~h}$. When muscles were removed from the water bath, all were removed from vacuum packaging, reweighed, and the muscles not browned prior to sous vide cooking were browned as previously described (POST), and reweighed prior to initiating trained sensory panel evaluation. The serratus ventralis (SV) was segregated from the pork CT butt with the most medial $2.5 \mathrm{~cm}$ slice used for Warner-Bratzler shear force (WBS) assessment and the remainder used for sensory assessment. Three $2.5 \mathrm{~cm}$ slices were cut from the center of the beef clod heart/triceps brachii (TB), with the most medial used for WBS, with the remainder used for sensory. Care was taken not to include sensory samples or WBS cores with the heavy connective tissue of the TB for evaluation. A total of 20 beef and pork samples were evaluated over five or four sensory panel sessions, respectively. Data were analyzed using the mixed model procedure of SAS and carcass was the experimental unit.

Results: Pork SV browned PRE had a $20 \%$ lower cooking loss $(P=0.02)$ than the same cuts browned POST. Cooking loss between treatments trended similarly for beef $T B$, but did not differ $(P=0.12)$. Both pork $S V$ and beef TB browned PRE had improved trained panelist juiciness values $(P<0.002)$, compared to POST roasts. Slices of pork $S V$ and beef TB browned PRE tended $(P<0.14)$ to have lower WBS values, than slices from POST roasts. However, these differences were not deciphered by trained sensory panelist for tenderness and connective tissue. The timing of browning did not influence any other palatability traits.

Conclusion: These findings suggests that large boneless beef and pork cuts should be browned prior to, rather than after, sous vide cooking, to minimize cooking loss and to optimize juiciness and potentially have some improvement of tenderness. 
Keywords: Sous vide 


\title{
Meat and Poultry Quality
}

53

\section{INCIDENCE OF DFD MEAT ON BRAZILIAN BEEF CUTS}

\author{
A. Rosa ${ }^{1, *}$, R. Fonseca ${ }^{2}$, J. C. Balieiro ${ }^{3}$, M. D. Poleti ${ }^{4}$, K. Domenech-Pérez ${ }^{5}$, B. Farnetani ${ }^{2}$, J. Eler ${ }^{1}$ \\ ${ }^{1}$ Medicine Veterinary, ${ }^{2}$ Animal Production, ${ }^{3}$ Animal Nutrition, University of São Paulo, Pirassununga, ${ }^{4}$ Animal Production, \\ University of São Paulo, Piracicaba, Brazil, ${ }^{5}$ Animal Science, University of Nebraska - Lincoln, Lincoln, United States
}

Objectives: Dark, firm and dry meats (DFD) look unattractive and are discriminated against by consumers; they have poor processing characteristics when compared to non-DFD meat and are significant causes of financial loss. Therefore, the aim of this work was to evaluate the percentage of DFD beef meat and their possible effect on meat quality characteristics of Brazilian commercial crossbred cattle.

Materials and Methods: This study evaluated 485 F1 crossbred animals (Nellore x South African Simmental): 182 heifers and 303 imunocastrated steers aged $18.0 \pm 2.0$ months and live weights at slaughter of 450 and $500 \mathrm{~kg}$ for heifers and steers, respectively. After 24 hours post mortem, two $2.5 \mathrm{~cm}$ steaks were collected at the 12th and 13th ribs of the Longissimus muscle. The steaks were individually identified and vaccum packaged. The meat quality characteristics analyzed were: $\mathrm{pH}$ (48hs post mortem), colour (CIE Lab), \% Cooking Loss (CL) and Warner Bratzler Shear Force (WBSF), according AMSA (1995) at 2 and 14 days after slaughter. The steaks with 48 hour pH > 5.8 were classified as DFD and after those classifications were made, Statistical Analysis was done with the MIXED PROCEDURE of SAS, the model included the fixed effects of slaughter, gender and $\mathrm{pH}$ class, as well residual random effect.

\section{Results:}

From 485 carcass evaluated, $4.53 \%(\mathrm{n}=22)$ were considered DFD $(\mathrm{pH}>5.8)$. According to the results, $\mathrm{pH}$ affected meat colour characteristics at 48 hours post mortem where, greater $\mathrm{pH}$ resulted in lower $\mathrm{L}^{*}$ values (darker meat) and lower $\mathrm{b}^{*}$ values (less yellow). However, gender affected colour ( $L^{*}$ and $\left.a^{*}\right)$ and tenderness at 14 days of aging (Table 1) where, steers had more tender meat with lower $a^{*}$ values in comparison to heifers. No significant interactions between gender and $\mathrm{pH}$ were determined. Data from other countries such as the Australia and Canada have showed that the incidence of DFD is $5.4 \%$ and $3.4 \%$, respectively, and this represents losses around $U \$ 0.5 / \mathrm{kg}$ carcass weight. Thus, the incidence of DFD in Brazil is considerable and must be addressed.

Table 1 . Mean values of meat quality characteristics by gender and $\mathrm{pH}$

\begin{tabular}{|c|c|c|}
\hline Gender & pH class & P \\
& & val \\
& & ue \\
& & s \\
\hline
\end{tabular}




\begin{tabular}{|c|c|c|c|c|c|}
\hline & Steers & Heifers & $\leq 5,8$ & $>5,8$ & $\begin{array}{l}\mathrm{G} \\
\mathrm{e} \\
\mathrm{n} \\
\mathrm{d} \\
\mathrm{e} \\
\mathrm{r}\end{array}$ \\
\hline $\begin{array}{l}\mathrm{L}^{*} \\
- \\
4 \\
8 \\
\mathrm{~h} \\
\mathrm{~s}\end{array}$ & 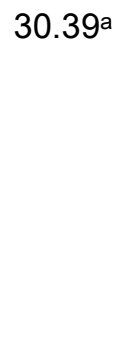 & $28.07^{b}$ & $30.84^{a}$ & $27.63^{b}$ & $\begin{array}{l}0 \\
. \\
0 \\
1 \\
0 \\
2\end{array}$ \\
\hline $\begin{array}{l}a^{*} \\
- \\
4 \\
8 \\
h \\
s\end{array}$ & $14.17^{b}$ & $15.86^{a}$ & 14.70 & 15.34 & $\begin{array}{l}0 \\
. \\
0 \\
2 \\
9 \\
4\end{array}$ \\
\hline $\begin{array}{l}b^{*} \\
- \\
4 \\
8 \\
h \\
s\end{array}$ & 10.31 & 10.54 & $11.27^{a}$ & $9.59 \mathrm{~b}$ & $\begin{array}{l}0 \\
. \\
6 \\
6 \\
5 \\
7\end{array}$ \\
\hline $\begin{array}{l}\text { C } \\
\text { o } \\
\text { o } \\
\text { ki } \\
\text { n } \\
\text { g } \\
\text { lo } \\
\text { ss } \\
( \\
\% \\
\text { ) - } \\
4 \\
8\end{array}$ & 25.66 & 24.37 & 25.78 & 24.24 & $\begin{array}{l}0 \\
. \\
1 \\
8 \\
2 \\
1\end{array}$ \\
\hline
\end{tabular}




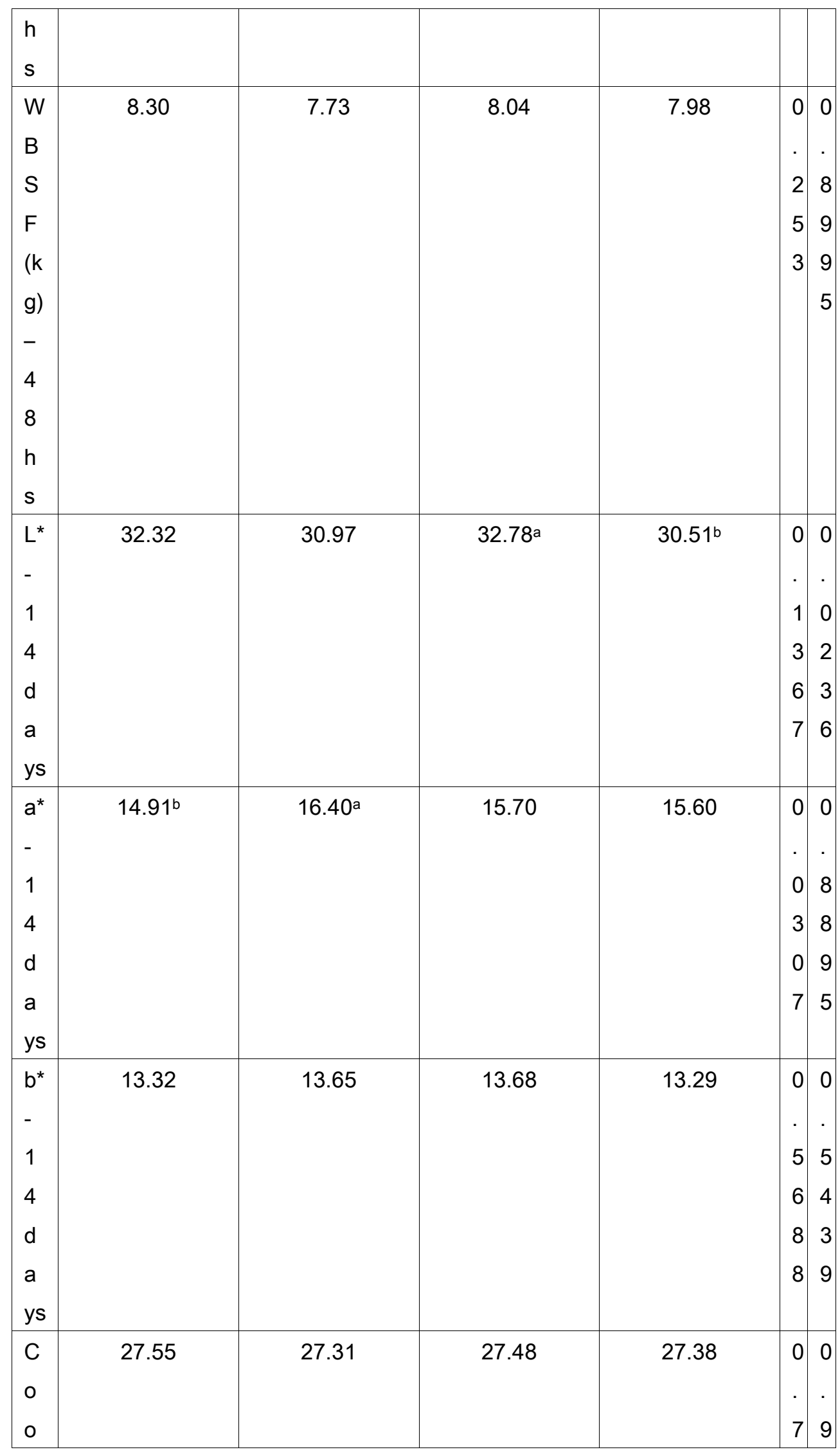




\begin{tabular}{|c|c|c|c|c|c|}
\hline $\begin{array}{l}\text { ki } \\
\mathrm{n} \\
\mathrm{g} \\
\text { lo } \\
\text { ss } \\
\text { ( } \\
\% \\
\text { ) - } \\
1 \\
4 \\
\text { d } \\
\text { a } \\
\text { ys }\end{array}$ & & & & & P \\
\hline $\begin{array}{l}\text { W } \\
B \\
S \\
F \\
(k \\
g) \\
- \\
1 \\
4 \\
d \\
a \\
\text { ys }\end{array}$ & $4.78^{b}$ & $5.60^{a}$ & 5.00 & 5.38 & $\begin{array}{l}0 \\
. \\
0 \\
1 \\
0 \\
3\end{array}$ \\
\hline
\end{tabular}

a,b Means within each row with different letter differed with $\mathrm{P}<0.05$

Conclusion: There was a considerable presence of DFD meat on Brazilian crossbred cattle and these anomalies affected principally meat colour and this can consequently negatively affect consumer purchasing decisions.

Keywords: Meat Quality Attributes, Nellore, Simmental 


\title{
Meat and Poultry Quality
}

54

\section{COLOR STABILITY OF THREE BLESBOK (DAMALISCUS PYGARGUS PHILLIPSI) MUSCLES}

\author{
N. E. Neethling 1,*, L. Hoffman ${ }^{2}$, S. P. Suman ${ }^{3}$ \\ ${ }^{1}$ Food Science, ${ }^{2}$ Animal Sciences, Stellenbosch University, Stellenbosch, South Africa, ${ }^{3}$ Animal and Food Sciences, \\ University of Kentucky, Lexington, United States
}

Objectives: Fresh meat color stability is a muscle-specific trait and critically influences the consumers' purchasing decisions. While muscle-specific color stability has been extensively studied in conventional livestock species, limited information is available on this phenomenon in game meat. Blesbok (Damaliscus pygargus phillipsi) is a popular and economically important game species in South Africa. The objective of the present study was to evaluate the color stability of three major blesbok muscles, namely infraspinatus (IS), longissimus lumborum (LL) and biceps femoris (BF), during refrigerated storage.

Materials and Methods: The IS, LL, and BF muscles were removed from twelve $(n=12)$ blesbok carcasses $24 \mathrm{~h}$ post mortem. The muscles were vacuum-packaged and stored at $2^{\circ} \mathrm{C}$. After $48 \mathrm{~h}$, the muscles were removed and fabricated into twelve $2.5 \mathrm{~cm}$ steaks. The steaks were placed in trays, aerobically overwrapped, and stored at $2^{\circ} \mathrm{C}$ for eight days. Instrumental color $\left(L^{*}, a^{*}, b^{*}\right.$, hue, and chroma), $\mathrm{pH}$, metmyoglobin reducing activity (MRA), oxygen consumption rate (OCR), and lipid oxidation were measured on $0,1,2,4,6$, and 8 days. Total iron and heme iron were measured on days 0 and 8. Data were analyzed using mixed model repeated measures ANOVA, with carcass as random effect and, muscle and time as fixed effects.

Results: $L^{*}$ values increased $(P<0.05)$ for IS from day 0 to day 8 , whereas no change $(P>0.05)$ was observed for LL and BF. IS had the highest $L^{*}$ values followed by BF and then LL. The $a^{*}$ values decreased $(P<0.05)$ in all muscles over time, with IS having higher $(P<0.05)$ values than LL and BF. The $b^{*}$ values increased $(P<0.05)$ in IS, but decreased $(P$ $<0.05)$ for $\mathrm{LL}$ and BF. The chroma decreased $(P<0.05)$ in LL and BF. On the other hand, chroma for IS increased $(P<$ $0.05)$ from day 0 to 4 and subsequently decreased $(P<0.05)$. Chroma was higher $(P<0.05)$ for IS than LL and BF. Hue increased $(P<0.05)$ for all muscles from day 0 to day 8 , with BF having the highest $(P<0.05)$ values followed by $L L$ and then IS. The IS exhibited higher $(P<0.05) \mathrm{pH}$ values than $\mathrm{LL}$ and BF. The $\mathrm{pH}$ increased $(P<0.05)$ in IS and $\mathrm{LL}$ over time, whereas no change $(P>0.05)$ was observed in BF. LL had the highest $(P<0.05)$ initial total iron followed by BF and then IS. Total iron decreased $(P<0.05)$ for $\mathrm{LL}$, whereas no changes $(P>0.05)$ were observed in IS and BF. Heme iron decreased $(P<0.05)$ for all muscles, with IS demonstrating higher $(P<0.05)$ values than $\mathrm{LL}$ and $\mathrm{BF}$. No change $(P>$ $0.05)$ in OCR was observed for BF and LL, while a decrease $(P<0.05)$ in OCR was observed for IS from day 0 to day 8. In addition, IS had a lower $(P<0.05)$ OCR on day 8 than LL and BF. Lipid oxidation increased $(P<0.05)$ for all muscles over time, with LL having higher $(P<0.05)$ values followed by BF and then IS. Moreover, IS exhibited higher $(P<0.05)$ MRA compared to LL and BF. 
Conclusion: The results indicated that blesbok IS muscle is more color-stable than its LL and BF counterparts. The game meat industry may employ muscle-specific processing strategies to improve retail marketability and to maximize the use of fresh blesbok meat.

Keywords: Blesbok, Color stability, Game meat 


\title{
Meat and Poultry Quality
}

55

\section{COMPARING EFFECTS OF WET AND DRY AGING ON INSTRUMENTAL TENDERNESS AND COLOR, SENSORY ANALYSIS AND PROCESSING YIELDS OF BEEF STRIPLOIN}

\author{
G. F. Vilella ${ }^{1}$, C. T. Battaglia ${ }^{1}$, C. L. Gomes ${ }^{1}$, P. E. de Felício ${ }^{1}$, S. B. Pflanzer 1,* \\ 1Department of Food Technology, State University of Campinas, Campinas, Brazil
}

Objectives: Aging of meat is a process usually done by vacuum packaging (wet aging) or, in a "gourmet-like" procedure, without packing (dry aging). Aging is expected to improve meat tenderness and flavor. Differences between flavor of wet and dry aged beef have been previously described. However, fewer studies discussed changes in tenderness between these processes. The purpose of this preliminary research was to compare sensory and instrumental texture traits, as well as aging losses of beef wet and dry aged for 14 and 21 days.

Materials and Methods: Beef striploin $(\mathrm{N}=12)$ of Nelore young bulls were collected 4 days post mortem. Each loin was cut in four parts, balanced by anatomical locations for treatments. The aging was performed in a chamber at $3^{\circ} \mathrm{C}$ and $63 \% \mathrm{RH}$ during 14 and 21 days. For wet ageing, samples were deboned before vacuum, while for dry aging, samples were kept fat up and deboned and trimmed in the end of each aging time. $\mathrm{pH}$, instrumental color $\left(L^{*}, a^{*}, b^{*}\right)$, cooking loss $(C L)$, slice shear force (SSF), and initial and sustained sensory tenderness and juiciness (IT, ST, IJ and SJ; eight point scale) at the end of each aging time were analyzed. Intramuscular fat and moisture factorial ANOVA (2 aging methods and 2 aging times), and means $( \pm S E M)$ were tested by Tukey test.were analyzed at 4 days post mortem. The statistical analyses were performed by a $2 \times 2$

Results: Average moisture and fat were $73.91 \pm 0.32 \%$ and $3.11 \pm 0.34 \%$, respectively. No difference $(P>0.05)$ was found for total weight loss (moisture, trimmings and bone) between aging times $(41.4 \pm 1.6 \%)$, however, dry aged samples $(51.2 \pm 0.9 \%)$ presented higher losses $(P<0.05)$ than wet aged $(31.6 \pm 0.9 \%)$. This difference occurred due to a greater drip and trimming losses of dry aged samples. There was an interaction $(\mathrm{P}<0.05)$ between aging times and methods for $\mathrm{pH}$. The initial $\mathrm{pH}$ (day 4) was 5.68. There was an increasing in dry aged samples (5.67 to 5.72), while wet aged decreased (5.57 to 5.42) from day 14 to 21 . Aging method had no effect $(P>0.05)$ on internal color ( $L^{*} 38.9 \pm 2.4 ; a^{*} 24.1 \pm 0.9 ; b^{*}$ $20.3 \pm 0.2)$, while samples aged for 21 days shown greater $(P<0.05) b^{*}$ value $(20.2 \pm 0.3)$ than samples aged for 14 days (19.8 \pm 0.2$)$. Aging method and time did not affect $C L(22.1 \pm 0.5 ; P>0.05)$, however, SSF was lower $(P<0.05)$ in samples aged for 21 day $(14.7 \pm 0.8)$ than 14 day (18.2 \pm 1.1$)$. Aging method had no effect $(P>0.05)$ on SSF values $(16.4 \pm 0.7)$. Trained panelists were not able to detect differences $(P>0.05)$ on sensory attributes among treatments $(I T-6.0 \pm 0.1$; ST $5.8 \pm 0.1$; IJ $-5.5 \pm 0.1$; SJ $-5.7 \pm 0.1)$, however, there was a trend $(P=0.12)$ to higher tenderness on samples aged for 21 days $(6.2 \pm 0.2)$ in comparison with samples aged for 14 days $(5.8 \pm 0.2)$. 
Conclusion: According to these data, there is an increase of $62 \%$ in processing losses of dry aged beef, with no beneficial effect for instrumental or sensory tenderness of meat when aged up to 21 days, however no flavor analysis were conducted in this study. More data is needed to suggest or not the dry aging process to the industry in Brazil.

Keywords: color, dry aging, sensory analysis, Wet aging 


\title{
Meat and Poultry Quality
}

56

\section{AGING IMPLICATIONS ON FRESH MUSCLE CHARACTERISTICS OF CERTIFIED ANGUS BEEF STEAKS}

\author{
L. A. Adcock ${ }^{1}$, J. T. Sawyer ${ }^{1}$, B. D. Lambert ${ }^{2}$, T. N. Jones ${ }^{1}$, J. J. Ball ${ }^{1}$, J. E. Jackson ${ }^{1}$, M. B. Mora García 1,*, R. P. Wyatt
} 1

1Department of Animal Sciences and Veterinary Technology, ${ }^{2}$ College of Graduate Studies, Tarleton State University, Stephenville, United States

Objectives: The demand for a more consistent and uniform product has resulted in the formation of countless branded beef programs. At the forefront of this initiative has been the first-established branded beef program, Certified Angus Beef. The current study focused on evaluating the influence of postmortem aging on fresh and cooked muscle characteristics of Certified Angus Beef muscles. The results from this study could provide a greater understanding of the aging parameters of premium beef products.

Materials and Methods: Vacuum packaged Certified Angus Beef (CAB) subprimals ( $N=72)$ Longissimus dorsi (LD), Longissimus lumborum (LL), Gluteus medius (GM), and Infraspinatus (INF) were purchased from a major beef packing facility. Subprimals from each muscle were allocated to one of three aging periods $(14,28$, and $42 \mathrm{~d})$ and wet-aged at $2 \mathrm{C}$ in the absence of light. After aging, five steaks were removed from the subprimals, and assigned to $\mathrm{pH}$, water-holding capacity (WHC), Warner-Bratzler shear force (WBSF), cooked color, cooking yield, or sensory panel analysis. Consumer sensory panelists $(N=67)$ evaluated samples for overall impression and tenderness on an hedonic scale and flavor, juiciness and purchase intent on a Just About Right scale. All data was analyzed using a completely randomized mixed model design procedure with individual steak as the experimental unit.

Results: WBSF values were more tender $(P<0.05)$ for INF steaks than all other steaks combined. Interestingly, subprimals aged for $14 \mathrm{~d}$ had greater WBSF values $(P<0.05)$ regardless of muscle than any other aging period. WHC was greater $(P<0.05)$ for $L L$ and LD steaks whereas purge loss was greatest $(P<0.05)$ for INF and GM steaks. Additionally, $L L$ and LD steaks had the greatest $(P<0.05)$ cook yield comparatively to steaks from the INF and GM across all aging periods. It is interesting to note, that $\mathrm{pH}$ declined for all muscle groups throughout the aging periods, with INF steaks having the greatest $\mathrm{pH}$ values $(\mathrm{P}<0.05)$. Sensory evaluations of INF reported no differences across aging periods in all attributes $(P>0.05)$. Consumers reported $14 \mathrm{~d}$ LD steaks offered the greatest overall impression and flavor scores $(P<0.05)$, compared to $28 d$ and $42 d$ LD steaks. There were no differences found across aging periods for tenderness $(P>0.05)$ in LD steaks. Additionally, there were no differences reported in LL steaks for overall sensory impression across all aging periods $(P>0.05)$. Consumer panelists rated $L L$ tenderness values to be different $(P<0.05)$ for steaks aged across all aging periods $(14,28$, and 42$)$. All other quality attributes (flavor, juiciness, and purchasing intent) remained unchanged $(P>0.05)$. Finally, aging $G M$ steaks for $28 \mathrm{~d}$ resulted in greater sensory ratings for all 
sensory panel anchors $(P<0.05)$ compared to GM steaks aged for $42 \mathrm{~d}$. Nonetheless, the least sensory panel ratings were for GM steaks regardless of aging periods $(P>0.05)$ when compared to the other muscles.

Conclusion: With these results it appears the consumer panelist struggles to identify the development of enhanced palatability in muscles aged for $42 \mathrm{~d}$, compared to those aged $28 \mathrm{~d}$. Additionally, the results from this study suggest that the perceived benefit of muscle aging of premium beef products does not offer a tremendous advantage for the consumer.

Keywords: Aging, Certified Angus Beef, Consumer Panel, Meat Quality Attributes, Tenderness 


\section{Meat and Poultry Quality}

57

\section{IMPROVING FRESH BEEF ROUND STEAK CHARACTERISTICS THROUGH MECHANICAL TENDERIZATIONAND SOLUTION ENHANCEMENT}

L. A. Adcock ${ }^{1}$, R. P. Wyatt ${ }^{1}$, J. T. Sawyer ${ }^{1}$, R. M. Harp ${ }^{1}$, J. J. Ball ${ }^{1}$, B. D. Lambert ${ }^{2}$, J. P. Sylvester 1,*

1Department of Animal Science and Veterinary Technology, ${ }^{2}$ College of Graduate Studies, Tarleton State University, Stephenville, United States

Objectives: Understanding the impact that mechanical tenderization and solution enhancement has on the characteristics of fresh beef may improve consumer demand for muscles from the round. With the advancements in research from the educational and private sectors, fully understanding the methods of improving fresh meat tenderness could be influential to the meat industry. The focus of the current study is based upon a solution enhancement of the beef top round (Semimembranousus) and multiple passes through a mechanical tenderizer to influence fresh and cooked sensory characteristics.

Materials and Methods: Subprimals ( $\mathrm{N}=18$ ) were purchased from a major beef packing facility (National Beef, Inc., Kansas City, MO, USA), aged for $14 \mathrm{~d}$ and randomly assigned to either a non-enhanced control (CNT) or an antioxidant treatment (TST) and then identified to a varying tenderization method (single; double; triple; double - folded; triple folded). All beef round subprimals were injected to $110 \%$ of green weight with a solution of: $97.1 \%$ water, $1.0 \%$ salt, $0.4 \%$ phosphate and $1.5 \%$ beef broth (B3307, Proliant Meat Ingredients, Ankeny, IA, USA). The water percentage for subprimals allocated to TST was reduced to account for the $1.0 \%$ added rosemary extract (Fortium R-WS 10 Kemin, Des Moines, IA, USA). Following injection, subprimals were cut into $1.27 \mathrm{~cm}$-thick steaks and passed through a mechanical tenderizer as per allocated tenderization method. Steaks were packaged individually using a styrofoam tray, overwrapped with a poly-vinyl chloride film (PVC), and placed into a display case set at $2 \mathrm{C}$ for $7 \mathrm{~d}$. Throughout the $7 \mathrm{~d}$ simulated retail display period, steaks were assessed for sensory and instrumental color, and thiobarbituric acid reactive substance assay (TBARS) on D 0, 3, 5, and 7 of display. Steaks allocated to Allo-Kramer Shear Force (AKSF) and a trained sensory evaluation were placed into a vacuum package and frozen at $-20 \mathrm{C}$ until analysis could be completed. $\mathrm{A}$ trained sensory panel $(\mathrm{N}=11)$ evaluated samples for tenderness, juiciness, and flavor on an 8-point scale. All data was analyzed using a completely randomized mixed model design procedure with individual steak as the experimental unit. Results: Results from the study suggest that the addition of rosemary at $1 \%$ within the solution did limit surface color deterioration of tenderized round steaks when compared to CNT steaks $(P<0.05)$. AKSF values improved with a greater number of passes through the tenderizer $(P<0.05)$, including the added folding method. Moreover, sensory taste panelist noted only slight differences in the flavor profile of enhanced tenderized steak with the addition of rosemary $(P<0.05)$. It is positive to note that the overall flavor of the tenderized steaks was not perceived as objectionable by sensory panelist. 
Additionally, when comparing lipid oxidation values, rosemary treated steaks were less than CNT steaks $(P<0.05)$ at all time points measured.

Conclusion: The results from this study suggest that rosemary can be used in concert with varying tenderization methods without significantly altering palatability traits noted by trained consumer panelists, could aid in prolonging surface color during retail display. Furthermore, these results suggest mechanical tenderization could improve industry applications of manufactured tenderized cuts resulting in greater consumer appeal.

Keywords: Antioxidant, Beef, Instrumental Tenderness, Sensory Taste, Solution Enhancement 


\section{Meat and Poultry Quality}

58

\section{EVALUATION OF CLAM-SHELL GRILL, CONVECTION OVEN AND BROILER COOKERY METHODS ON PORK AND LAMB CHOPS}

H. C. Brietzke 1,,, L. A. Weinheimer ${ }^{1}$, A. A. Reyes ${ }^{1}$, L. A. Branham ${ }^{1}$, R. P. Cope ${ }^{1}$, M. W. Boenig ${ }^{1}$, K. W. Braden ${ }^{1}$

1Department of Agriculture, Angelo State University, San Angelo, United States

Objectives: Since its validation as a cookery method for beef research, the clam-shell grill has become a useful tool due to its cost effectiveness and availability. However, the use of the clam-shell grill has yet to be validated for use in species other than beef. Therefore, the objectives of this study were 1) to compare the clam-shell grill (CLAM) to conventional convection (CONV) and oven broiling (BROL) methods for pork and lamb LM chops and 2) determine the cook time for pork and lamb LM chops.

Materials and Methods: Center-cut pork loins (IMPS 412B; $n=16$ ) and block ready lamb loins (IMPS 232A; $n=16$ ) were cut into $2.54 \mathrm{~cm}$ chops starting from the anterior end. Pork and lamb chops ( $n=9 / /$ oin) were then separated into three loin sections: anterior, middle and posterior. One chop from each loin section was randomly assigned to one of three cookery methods: CLAM, CONV and BROL. Chops were subsequently cooked to an internal $71^{\circ} \mathrm{C}$ in the geometric center. Each chop was weighed pre- and post-cooking to determine percent cook loss. Cook time necessary to reach $71^{\circ} \mathrm{C}$ was also recorded. After cooking, chops were covered with polyvinyl chloride film and chilled at $4^{\circ} \mathrm{C}$ for 12 hours. Six $1.3 \mathrm{~cm}$ cores were obtained parallel to muscle fiber orientation, then sheared once with a Warner-Bratzler shear (WBS) force machine. The mean WBS force for each chop was used for analysis. Data were analyzed using the MIXED procedures of SAS for a completely randomized design with cookery method and loin section as fixed effects. Significant $(P \leq 0.05)$ cookery method, loin section and interaction means were separated using Fischer's protected LSD.

Results: When evaluating pork loins, loin section had no impact on WBS $(P=0.39)$, cook time $(P=0.79)$ or cook loss $(P=0.56)$. WBS was dependent upon cookery method $(P<0.01)$ as CLAM chops had lower WBS values $(3.13 \mathrm{~kg})$ when compared to both BROL $(3.67 \mathrm{~kg})$ and CONV $(3.62 \mathrm{~kg})$. Cooking method significantly impacted cook time $(\mathrm{P}<0.01)$ with CLAM taking 7.54 min., CONV taking $14.74 \mathrm{~min}$. and BROL taking $26.67 \mathrm{~min}$. Similarly, cook loss was dependent on cookery method $(P<0.01)$, as CLAM lost the least weight at $10.38 \%$, followed by CONV $(12.75 \%)$ and then BROL (19.53\%). When evaluating lamb chops, Warner-Bratzler shear force was dependent on a cookery method by loin section interaction $(P<0.01)$, as WBS values ranged from $2.17 \mathrm{~kg}$ to $2.83 \mathrm{~kg}$. When evaluating cook time, loin section had no impact $(P=0.24)$. However, cookery method affected cook time $(P<0.01)$ as CLAM chops took 7.21 min., followed by CONV (14.15 min.) and BROL (21.22 min.). Lamb cook loss was dependent on loin section ( $\mathrm{P}=0.04)$, as posterior sections had higher cook loss values $(17.86 \%)$ when compared to both anterior $(16.09 \%)$ and middle $(16.36 \%)$ sections. Additionally, cookery method impacted cook loss $(P<0.01)$, as CLAM lost the least at $10.51 \%$, followed by CONV (15.64\%) and then BROL (24.16\%). 
Conclusion: While clam-shell grills remain a common tool in beef research due to decreased cooking loss and reduced shear force values, the results of the current study suggest further evaluation of their use in pork and lamb studies is needed to validate their dependability in providing consistent results. This study serves as preliminary data to establish cook times needed to reach a medium degree of doneness $\left(71^{\circ} \mathrm{C}\right)$ for each controlled cookery method.

Keywords: Cooking, Lamb Quality, Pork Quality, Warner-Bratzler shear force 


\section{Meat and Poultry Quality}

59

\section{EFFECTS OF ZILPATEROL HYDROCHLORIDE SUPPLEMENTATION ON CARCASS CHARACTERISTICS AND MEAT QUALITY CHARACTERISTICS OF STEERS DIFFERING IN BREED TYPE}

J. O. Fulton 1, ${ }^{*}$, K. N. Kerns ${ }^{1}$, A. A. Harty ${ }^{1}$, J. J. Kincheloe ${ }^{1}$, M. K. Luebbe ${ }^{2}$, K. C. Olson ${ }^{1}$, K. R. Underwood ${ }^{1}$, S. M. S. Zuelly ${ }^{1}$, A. D. Blair 1

${ }^{1}$ Animal Science, South Dakota State University, Brookings, ${ }^{2}$ Animal Science, University of Nebraska, Panhandle Research Station, Scottsbluff, United States

Objectives: The $\beta$-adrenergic agonist zilpaterol hydrochloride $(\mathrm{ZH})$ enhances skeletal muscle growth in beef cattle resulting in a shift in composition of gain. This results in improvements to feedlot performance and carcass yield, but decreases product tenderness. Further, British (B) and British $\times$ Continental (BC) cattle possess inherent differences in muscle and adipose composition and may respond differently to the growth promoting mechanism of $\mathrm{ZH}$. Therefore the objective of this study was to determine the effects of $\mathrm{ZH}$ on feedlot performance, carcass characteristics and meat quality of $B$ and $B C$ steers.

Materials and Methods: Steers of $B(n=76)$ or $B C(n=57)$ background were allocated to a randomized incomplete block design with a $2 \times 2$ treatment structure. Pens within each block $\times$ breed type were randomly assigned to either ZH ( 8.3 $\mathrm{mg} / \mathrm{kg}$ of DM; fed for $20 \mathrm{~d}$ before slaughter, followed by a $3 \mathrm{~d}$ withdrawal) or control (CON; $0 \mathrm{mg} / \mathrm{kg} \mathrm{ZH}$ ). Steers were ultrasounded immediately before $\mathrm{ZH}$ inclusion and following withdrawal to determine the influence of $\mathrm{ZH}$ on change in longissimus muscle area (LMA), fat thickness and percent intramuscular fat (IMF). Carcass data were collected and striploins were removed for analysis of objective color, WBSF, percent moisture and crude fat content. Data were analyzed as a 2 breed type $\times 2 \mathrm{ZH}$ level factorial treatment structure in a randomized incomplete block design using replicate pens of each treatment combination as experimental units.

Results: The breed type $\times \mathrm{ZH}$ supplementation interaction was not detected $(P \geq 0.05)$ for live performance or carcass traits evaluated. Breed type did not influence $(P>0.05)$ change in ultrasound measurements during the $\mathrm{ZH}$ feeding period. Carcasses from BC steers had larger LMA $(P<0.05)$ and improved $Y G(P<0.05)$ compared to $B$, while $B$ steers had increased marbling scores $(P<0.01)$. A greater proportion of $B C$ carcasses were classified as $Y G 2(P<0.05)$ and fewer were classified as $Y G 3(P<0.05)$ than B steers. A greater proportion of B carcasses were classified as upper $2 / 3$ Choice $(P<0.01)$ while more BC carcasses tended to be included in the lower $1 / 3$ Choice designation $(P<0.10)$. Steaks from $\mathrm{B}$ carcasses had increased Minolta $\mathrm{L}^{*}$ and $\mathrm{b}^{*}$ color values $(P<0.05)$ compared to $\mathrm{BC}$ steaks. Steaks from $\mathrm{BC}$ carcasses had increased percent moisture $(P<0.001)$ and decreased fat content $(P<0.01)$ compared to steaks from $\mathrm{B}$ carcasses. Breed type did not influence WBSF or $a^{*}$ values $(P>0.05)$. Feeding ZH improved ADG $(P<0.05)$, YG $(P<$ $0.05)$, and LMA $(P<0.001)$ and tended to increase the proportion of carcasses classified as YG $2(P<0.10)$. Control steers had increased IMF $(P<0.05)$ during ZH feeding; however, this did not manifest into differences in Quality Grade. 
Supplementing cattle with ZH increased WBSF values $(P<0.0001)$ and percent cook loss $(P<0.001)$. An interaction was observed for breed type $\times \mathrm{ZH}$ level for steak percent moisture. Steaks from the $\mathrm{BC} \times \mathrm{CON}$ treatment had a greater percent moisture compared to $\mathrm{B} \times \mathrm{CON}$ group $(P<0.05)$.

Conclusion: Collectively these data indicate there was not a differential response to $\mathrm{ZH}$ among the breed types of cattle included in this study. Responses among breed types were as expected for B vs. BC cattle types. ZH influenced growth and carcass traits as expected, adding value to carcasses primarily by increasing HCW, and influenced meat quality as expected by increasing WBSF values.

Keywords: Beef Cattle, Breed Type, Growth Performance, Meat Quality , Zilpaterol Hydrochloride 


\section{Meat and Poultry Quality}

60

\section{EXTENDED AGING IMPROVES TENDERNESS OF THE SEMITENDINOSUS FROM STEERS FED RACTOPAMINE- HCL AND ZINC BY INCREASED MYOFIBRILLAR PROTEOLYSIS}

K. J. Phelps ${ }^{1,}{ }^{*}$, M. B. Silva ${ }^{1}$, L. D. F. Miranda ${ }^{1}$, S. M. Ebarb ${ }^{1}$, C. L. Van Bibber-Krueger ${ }^{1}$, T. G. O'Quinn ${ }^{1}$, J. S. Drouillard 1, J. M. Gonzalez 1

${ }^{1}$ Animal Science and Industry, Kansas State University, Manhattan, United States

Objectives: Beef tenderness is the most important trait affecting consumer beef eating satisfaction. Ractopamine- $\mathrm{HCl}$ (RH; Optaflexx, Elanco Animal Health) and Zinc (ZN) can reduce proteolysis by altering the calpain system. The Semitendinosus (ST) often is undervalued due to its inherent toughness and is aged an average of $17 \mathrm{~d}$. The objective of this study was to examine effects of extended aging and steak location (LOC) on myofibrillar proteolysis and tenderness of Semitendinosus steaks from steers that had been supplemented organic zinc alone or in combination with $\mathrm{RH}$ for the final $28 \mathrm{~d}$ of feeding.

Materials and Methods: Crossbred steers ( $n=60$; initial body weight $643 \pm 20 \mathrm{~kg}$ ) were blocked by body weight and used in a randomized complete block experiment with a $2 \times 2 \times 5 \times 10$ factorial treatment arrangement with supplemental zinc $(0$ or 360 mg/animal daily as zinc methionine; Zinpro 120; Zinpro Corporation, Eden Prairie, MN), RH at 0 or 400 mg/animal daily during the last $28 \mathrm{~d}$ of feeding, day of aging (DOA; 7, 14, 21, 42, or $70 \mathrm{~d}$ ), and LOC as main effects. After dietary treatment administration, harvesting, and $6 \mathrm{~d}$ postmortem aging, the ST from the left side of each carcass were removed and fabricated, extending from proximal to distal end of the muscle, into ten $2.54-\mathrm{cm}$ thick steaks. Steaks cut adjacent to one another were paired, vacuum-packaged, and aged at $2 \pm 1^{\circ} \mathrm{C}$. After each aging period, paired steaks were randomly assigned to Warner-Bratzler shear force (WBSF) or myofibrillar proteolysis analysis (calpain-1 activity and desmin and troponin-T degradation). Data were analyzed using the Proc MIXED procedure of SAS with RH, ZN, DOA, LOC, and all possible interactions as fixed effects.

Results: Zinc and RH had no two-, three-, or four-way interactions with DOA and LOC for WBSF and proteolysis $(P>0.12)$, no LOC $\times D O A$ interactions ( $P>0.08$ ), nor did main effects of $Z N$ or RH affect measures of WBSF or proteolysis $(P>0.38)$. Steak LOC affected (quadratic, $P<0.01$ ) WBSF, with steaks originating closer to proximal and distal ends being tougher than steaks from the middle. Increasing DOA improved WBSF (quadratic, $P<0.01$ ) for the duration of the 70-d postmortem period. Calpain-1 activity and desmin and troponin-T proteolysis were unaffected by steak LOC (P>0.18). As DOA increased, calpain-1 activity decreased (quadratic $P<0.01$ ), with activity detected through $\mathrm{d} 42$. Proteolysis of desmin increased with DOA, indicated by a decrease (linear, $P<0.01$ ) in intensity of intact $55 \mathrm{kDa}$ band and an increase (linear, $P<0.01)$ in the $38 \mathrm{kDa}$ band through d 70 . Similarly, DOA increased troponin-T proteolysis through $\mathrm{d} 70$, indicated by a decrease (quadratic, $P<0.01$ ) in intensity of the intact $40 \mathrm{kDa}$ band and an increase (linear, $P<0.01$ ) in the $30 \mathrm{kDA}$ band. 
Conclusion: Dietary supplementation of RH and ZN did not influence tenderness of the ST. Location differences in tenderness were not explained by calpain-1 activity or desmin and troponin-T proteolysis, which may indicate that collagen or muscle fiber size has a larger influence on location tenderness differences across the ST. Semitendinosus steaks continued to increase in tenderness through d 70 postmortem due to continued degradation of desmin and troponin-T, but calpain-1 activity was not detected on $\mathrm{d} 70$. This indicates another active enzyme system may be involved in extended postmortem cytoskeletal protein proteolysis.

Keywords: Extended aging, Ractopamine-HCL, Semitendinosus, Tenderness, Zinc 


\section{Meat and Poultry Quality}

61

EFFECTS OF STEPWISE DRYMET AGING ON PHYSICAL, CHEMICAL AND QUALITY ATTRIBUTES OF BEEF LOINS.

B. Meyers ${ }^{1, *}$, Y. H. B. Kim ${ }^{1}$, A. Liceaga ${ }^{2}$, R. P. Lemenager ${ }^{1}$

${ }^{1}$ Animal Sciences, ${ }^{2}$ Food Science, Purdue University, West Lafayette, United States

Objectives: Currently many small meat processors use a traditional dry-aging system whereby beef carcasses are hung in a cooler, without protective packaging, for 10-21 days. This method is perceived by both processors and consumers to greatly impact flavor and tenderness, but incurs considerable cost due to excessive surface drying, trim losses, and slow throughput which translates to a more expensive retail product. Conversely, most large meat processors have adopted wet-aging (storing sub-primal cuts in vacuum sealed packaging), which allows for faster product flow and less trim loss thereby reducing cost. Wet aging, however, may result in a metallic taste. The objective of this study is to examine the effects of a combination dry/wet-aging system on the quality attributes of beef loins and to re-evaluate the aging process used by small meat processors.

Materials and Methods: Pairs of loins ( $M$. Longissimus) from 8 Angus $x$ Simmental steers (16 months of age, average USDA quality grade $\mathrm{Ch}+$ ) were assigned 2 aging treatments: traditional carcass dry aging and stepwise dry/wet aging. The dry-aging treatment consisted of half of each railed carcass being left with the loin ( $M$. Longissimus) intact for 17 days at $1^{\circ} \mathrm{C}$ before removal. Stepwise dry/wet-aging was accomplished through 10 days of traditional dry-aging then the loin was separated, vacuum packaged and stored at $1^{\circ} \mathrm{C}$ for the remaining 7 days. The Warner-Bratzler shear force value (WBSF), samples prepared by cooking $1.5-2 \mathrm{~cm}$ strip steaks at $\left(135^{\circ} \mathrm{C}\right)$ to an internal temperature of $71^{\circ} \mathrm{C}$ and held at $2.5^{\circ} \mathrm{C}$ for 24 hours before analysis on a Stable Microsystems TA-XT Plus, color stability ( $\mathrm{L}^{*} \mathrm{a}^{*} \mathrm{~b}^{*}$, Hunter MiniScan EZ 4500L), water-holding capacity (drip and cook loss), and consumer ( $n=192)$ sensory characteristics (overall liking on a 9point hedonic scale) as well as flavor, tenderness, and juiciness (on a 5-point intensity scale) were measured. The experimental design was split-plot. Data were analyzed by mixed procedure of SAS. Means were separated (F-test, $\mathrm{P}<$ $0.05)$ by using least significant differences.

Results: There were no differences in overall liking, flavor, tenderness or juiciness between stepwise dry/wet-aging and the dry-aged only counterpart $(P>0.05)$. There was a slight trend observed $(P=0.076)$ in WBSF values, where dry/wetaged steaks had lower values $(28.8 \mathrm{~N})$ compared to the dry-aged only steaks $(33.3 \mathrm{~N})$. A difference was observed in drip loss $(P=0.01)$, with dry/wet-aged loin steaks losing less $(2.1 \%)$ water compared to dry-aged only steaks $(3.8 \%)$, but there were no differences in cooking losses $(P>0.05)$. Pooled together to encompass total water loss, drip and cooking loss yielded no difference as well $(P>0.05)$. Additionally, examination of display color stability yielded no difference $(P>0.05)$. 
Conclusion: These findings indicate that stepwise dry/wet-aging will yield equivalent or more desirable quality attributes than traditional whole carcass dry-aging, while concurrently reducing the time and space needed to obtain the consumer desired quality characteristics of traditionally dry-aged beef carcasses. This would allow small meat processors to decrease their operating costs, as well as allow them more throughput due to the decrease in cooler time and space needed for the aging process. An appropriate follow-up would be required to determine the optimal combination of dryand wet-aging times to maximize economic impacts while not compromising meat quality attributes.

Keywords: dry aging, Meat Quality Attributes, Wet aging 


\section{Meat and Poultry Quality}

62

\section{GLUTAMINE AND SUCCINATE STABILIZE SHELF-LIFE COLOR OF FROZEN AND THAWED MEAT BY STIMULATION OF MITOCHONDRIAL RESPIRATION}

\section{B. T. Egelandsdal 1,*, P. Berg ${ }^{2}$, M. Wahlgren ${ }^{2}$, E. Slinde 1}

1Department of Chemistry, Biotechnology and Food Science, Norwegian University of Life Sciences, AAS, ${ }^{2}$ Nortura, Oslo, Norway

Objectives: Freezing of meat is a necessity in order to regulate the meat market and secure that fluctuating seasonal demands for specific meat cuts or trimmings are maintained. Frozen (at $-18^{\circ} \mathrm{C}$ ) and thawed meat has reduced display life. Investigations aimed to stabilize the color of frozen and thawed meat are largely missing.

Thus the objectives were to:

- Determine the color stability of frozen and thawed ground beef added glutamine and succinate (GS) and packaged in $40 \%$ $\mathrm{N}_{2}$ and $60 \% \mathrm{CO}_{2}$.

- Investigate the method of how to add glutamine and succinate to ground meat.

\section{Materials and Methods:}

Fresh (4 days post mortem) and frozen and thawed ground beef were split into three raw material groups: 1) fresh; 2) $70 \%$ fresh and $30 \%(\mathrm{w} / \mathrm{w})$ frozen; 3) $50 \%$ fresh and $50 \%(\mathrm{w} / \mathrm{w})$ frozen ground meat. These groups were added glutamine and succinate brine (GS-B) (molar ratio 1:1) having pH 5.8, to stabilize color (Slinde et al., 2012). This was done by adding $5 \%$ (by weight) of GS-B to give an average molar concentration in the ground meat of $0.03 \mathrm{~mol} \mathrm{GS} / \mathrm{kg}$ ground meat and by spraying the ground meat surface to give an average GS concentration of $0.003 \mathrm{~mol} / \mathrm{kg}$ ground meat. In addition, ground meat with no additives, with $10 \mathrm{~g} \mathrm{NaCl} / \mathrm{kg}$ added as $5 \%$ brine and with $1 \mathrm{~g} \mathrm{NaCl} / \mathrm{kg}$ obtained by spraying the surface of ground meat, were prepared. This gave 5 samples with or without additives within the 3 raw material groups. Ten replicates were made for the 15 different samples. The samples were kept in a dark cold room $\left(4^{\circ} \mathrm{C}\right)$ but removed for surface color measurements ( $\mathrm{L}^{*} \mathrm{a}^{*} \mathrm{~b}^{*}$ using Minolta Chromameter CR-410) at 15 degrees. Color measurements was on day 1, 2, 7 and day 13. On day 13 the packages were opened and a blooming test was carried out. Sensory analysis was carried out on the $10^{\text {th }}$ day by 6 trained sensory panelists. Multiple triangle tests were done in order to identify if the added compounds gave detectable flavor changes.

\section{Results:}

The largest difference was between the salted and the control group (nothing added). Adding $10 \mathrm{~g} \mathrm{NaCl} / \mathrm{kg}$ ground meat as a brine gave a brownish color (lower $a^{*}$ and higher $b^{*}$ ). Using $50 \%$ frozen ground meat with added GS gave a higher $a^{*}$ and a nominally lower $\mathrm{b}^{*}$ compared to both $10 \mathrm{~g} \mathrm{NaCl} / \mathrm{kg}$ ground meat and the control (nothing added) samples. The color 
difference was easy to detect visually. Spraying tended to be less effective than brining in changing color. The blooming test highly favored GS-B and GS-S (glutamine and succinate sprayed) relative to the other three systems.

Sensory test: The judges detected ( $P<0.05)$ GS-B versus control in one triangle test, but not in a repeated test. The judges detected $(P<0.05) 10 \mathrm{~g} \mathrm{NaCl} / \mathrm{kg}$ ground meat samples when compared with control, but did not detect $(P>0.05) 10 \mathrm{~g} \mathrm{NaCl} / \mathrm{kg}$ ground meat samples when compared with GS-B. GS-S was not tested.

Conclusion: Spraying $0.003 \mathrm{~mol} / \mathrm{kg}$ of glutamine and succinate on the surface of ground meat will make ground beef consisting of $50 \%$ frozen and $50 \%$ fresh (by weight) appear redder and bloom better than fresh meat due to increased availability of mitochondrial substrates on meat surface. Consumers would not detect this low concentration of GS.

Keywords: color, frozen meat, krebs cycle compounds, mitochondria 


\title{
Meat and Poultry Quality
}

63

\section{EFFECTS OF DOCOSAHEXAENOIC ACID (DHA) RICH MICROALGAE MEAL AND ORGANIC TRACE MINERALS IN DIETS CONTAINING THERMALLY OXIDIZED OIL ON THE SHELF-LIFE STABILITY OF DHA-ENRICHED PORK MEAT}

\author{
R. M. Delles ${ }^{1, *}$, M. D. Lindemann ${ }^{2}$, R. S. Samuel ${ }^{1}$ \\ ${ }^{1}$ Alltech, Inc., Nicholasville, ${ }^{2}$ Animal and Food Sciences, University of Kentucky, Lexington, United States
}

Objectives: Numerous health benefits are associated with increased dietary consumption of docosahexaenoic acid (DHA). Including a DHA rich microalgae meal (MM-DHA; All-G-Rich ${ }^{\mathrm{TM}}$, CCAP 4087/2, Alltech, Inc.) in finishing swine diets can increase the polyunsaturated fatty acids (PUFA) content of pork, but this may predispose the meat to oxidation. The objective of this study was to investigate the inclusion of MM-DHA with organic trace minerals (Sel-Plex® and Bioplex®, Alltech, Inc.) in diets containing $5 \%$ thermally oxidized oil on the oxidative stability of pork loin.

Materials and Methods: Six barrows, each as a replicate, were selected and randomly allocated to 6 pens assigned one of two dietary treatments: 1) control diet with $0.1 \%$ inorganic trace mineral premix and $5 \%$ oxidized oil or 2) $0.5 \% \mathrm{MM}-\mathrm{DHA}$ diet, $0.1 \%$ organic mineral premix and $5 \%$ oxidized oil. Barrows $(101 \pm 1 \mathrm{~kg})$ were fed their respective diets for $24 \mathrm{~d}$ before slaughter. Carcasses were chilled at $4{ }^{\circ} \mathrm{C}$ for $24 \mathrm{~h}$ and boneless loin and backfat samples were removed, vacuum packaged, and frozen at $-30{ }^{\circ} \mathrm{C}$ until use. Each loin was thawed at $4{ }^{\circ} \mathrm{C}$ in the dark for $36 \mathrm{~h}$, then cut into nine $2.54 \mathrm{~cm}$ chops for triplicate sample analysis per display time and overwrapped with an air-permeable polyvinylchloride film. Samples were placed in a retail display cooler at $2-4{ }^{\circ} \mathrm{C}$ for up to 7 days display days 0,4 , and 7 . Meat quality was evaluated with purge loss, cooking loss, and shear force. Data were subjected to analysis of variance (ANOVA) to determine the significance of main treatment factors (diet and storage time). Least Significant Differences (LSD) allpairwise multiple comparisons were performed to separate the means when a treatment effect was found significant $(P<$ 0.05).

Results: Fatty acid analysis revealed pigs fed MM-DHA contained more DHA in backfat $(0.10$ vs. $0.01 \% ; P<0.01)$ compared with control. In both treatments, lipid oxidation in the meat increased throughout the first $4 \mathrm{~d}$ of storage then decreased by $d 7$. MM-DHA meat samples had higher $(P<0.05)$ TBARS formation on $d 0$, but there were no significant differences between dietary treatments throughout retail display. On d 0, MM-DHA samples had reduced protein carbonyl formation $(P<0.05)$ and tended to have reduced sulfhydryl disappearance $(P<0.10)$ compared with control samples. Gel electrophoretic patterns of samples from both control and MM-DHA appeared similar for the first $4 \mathrm{~d}$ of retail display. By $\mathrm{d}$ 7 there was a notable reduction of the myosin heavy chain in control samples compared with MM-DHA, indicating a 
greater degree of oxidation. Water-holding capacity was similar between dietary treatments. However, shear force was $17 \%$ lower $(P=0.03)$ in MM-DHA samples compared to control for the first $4 \mathrm{~d}$ of retail display.

Conclusion: Dietary supplementation with 0.5\% MM-DHA and total replacement by organic trace minerals resulted in similar or improved meat quality attributes versus control samples and did not negatively influence protein oxidation in boneless pork loin chops throughout retail display. Therefore, dietary inclusion of MM-DHA can provide a source of PUFA for the enrichment of meat that does not decrease juiciness and tenderness of boneless pork loins.

Keywords: algae, DHA, oxidation, pork 


\section{Meat and Poultry Quality}

64

\section{PREFERENCES ASSOCIATED WITH AMERICAN LAMB QUALITY IN RETAIL \& FOODSERVICE MARKETS}

T. W. Hoffman 1, ${ }^{*}$, K. E. Belk ${ }^{1}$, D. R. Woerner ${ }^{1}$, J. D. Tatum ${ }^{1}$, R. J. Delmore ${ }^{1}$, R. K. Peel ${ }^{1}$, S. B. LeValley ${ }^{1}$, D. L. Pendell ${ }^{1}$, H. N. Zerby ${ }^{2}$, L. F. English ${ }^{2}$, S. J. Moeller ${ }^{2}$, F. L. Fluharty ${ }^{2}$

${ }^{1}$ Animal Sciences, Colorado State University, Fort Collins, CO, ${ }^{2}$ Animal Sciences, The Ohio State University, Columbus, $\mathrm{OH}$, United States

Objectives: Lamb Quality is an accumulation of quality attributes that are necessary to provide lamb that satisfies customer preferences and expectations. The objectives of this study, funded by the American Lamb Board, were to determine U.S. lamb retail and foodservice rank, definition, and relative preference for seven quality attributes including: 1) Origin (ORG); 2) Sheep Raising Practices (SRP); 3) Eating Satisfaction (ES); 4) Weight/Size (WS); 5) Product Appearance/Composition (PAC); 6) Product Convenience/Form (PCF); and 7) Nutrition/Wholesomeness (NW). Bestworst scaling, shares of preference computation, and a willingness-to-pay (WTP) assessment provided a rank and quantification of attribute preference, the likelihood of "must have" quality attributes for purchase, and an estimate of percent increased value of lamb products when a quality attribute was guaranteed for lamb.

Materials and Methods: Structured interviews were conducted by researchers asking questions either by face-to-face or telephone interview, and recorded using an interactive computer software program (Qualtrics $\left.{ }^{\circledR}\right)$. Interviews $(N=120)$ were conducted (May 2014 to March 2015) with lamb/protein purchaser representatives of retail $(n=60)$, foodservice $(n=45)$, and purveyor $(n=15)$ sectors. Interview respondents ranked the most and least important traits defining lamb quality using choice rank sets of three attributes. Multinomial logit models in SAS ${ }^{\circledR}$ MDC were used to estimate shares of preference. Open-ended definitions for each quality attribute were qualitatively aggregated to central themes, and WTP probabilities were estimated using the PROC GLIMMIX function in $\mathrm{SAS}^{\circledR}$. Lamb shoulder chops $(\mathrm{N}=148)$ purchased at retail from 46 stores in 11 states were evaluated for price and quality attribute label claim comparisons. Least squares means were calculated and separated at $\alpha=0.05$.

Results: Shares of preference for all participants $(N=120)$ indicated that ES was the most important quality attribute (38.90\%; most commonly defined as flavor/taste) when purchasing lamb. All seven attributes were statistically different from each other in rank of preference $(P<0.05)$. Two credence attributes, ORG (17.22\%; most commonly defined as locally raised, and subsequently American) and SRP (13.55\%; most commonly defined as grass-fed) were second and third in rank, respectively. Product Appearance/Composition (10.51\%) and WS (8.45\%) ranked fourth and fifth, respectively, and were of greater importance to purveyors than either retail or foodservice purchasers $(P<0.05)$. Nutrition/Wholesomeness (7.13\%) ranked sixth, and PCF (4.22\%) was seventh in relative importance. Origin (25.8\%) and SRP $(20.0 \%)$ had the greatest likelihood of being a non-negotiable requirement for lamb purchasers. Eating Satisfaction 
was most likely to return a premium $(71.7 \%)$, and product assurance of ES generated the greatest average WTP premium $(18.6 \%)$.

Conclusion: This research indicated that, across all sectors, Eating Satisfaction, defined as lamb flavor/taste, was the most imperative quality trait to those who purchase lamb. While ES is difficult to visually ascertain, retailers and foodservice representatives identified that credence attributes can be monetarily beneficial. Also, label claims of lamb shoulder chops at U.S. retail markets reinforced that source branded $(+\$ 1.94 / \mathrm{lb})$, locally raised $(+\$ 1.69 / \mathrm{lb})$, and grass-fed lamb $(+\$ 1.12 / \mathrm{lb})$ label claims were worth premiums $(P<0.05)$ for American consumers.

Keywords: Foodservice, Lamb Quality, Retail Market, Sheep, Willingness-to-Pay 


\section{Meat and Poultry Quality}

66

\section{U.S. CONSUMER EVALUATION OF HONDURAN AND U.S BEEF FROM DIFFERENT PRODUCTION AND PROCESSING SYSTEMS}

A. Gomez ${ }^{1, *}$, A. J. Garmyn ${ }^{1}$, K. S. Spivey ${ }^{1}$, T. G. O'Quinn ${ }^{2}$, C. Brooks ${ }^{1}$, M. F. Miller ${ }^{1}$

${ }^{1}$ Animal and Food science, Texas Tech, Lubbock, ${ }^{2}$ Animal Sciences and Industry, Kansas State University, Manhattan, United States

Objectives: The United States is the largest producer of high quality grain-fed beef in the world, with Bos taurus cattle representing a significant proportion of breeds used for beef production. Central American countries rely more heavily on grass-finishing systems and Bos indicus breeds are more suitable for the climate in these countries, generally resulting in lower quality beef. Enhancement is a process that has been implemented in these countries for improving meat quality. Therefore, the objective of this study was to evaluate the effects of different cattle production systems, processing systems and country of origin on palatability of the longissimus dorsias determined by U.S. consumers $(n=240)$.

Materials and Methods: U.S sourced strip loins from grain-finished cattle were selected to represent: USDA Select (SE; $\mathrm{n}=10$ ) and Top (upper 2/3) Choice (TC; $\mathrm{n}=10$ ). Strip loins collected in Honduras included dual-purpose cattle [HDP (milk and beef production); $n=10$ ], grain-finished (HGF; $n=10$ ) and sugar cane finished (HSC; $n=10$ ). Additional strip loins ( $n$ $=10$ /treatment) were selected and enhanced with water, salt and phosphates solution to $12 \%$ of green weight from dualpurpose cattle (EHDP), grain-finished cattle (EHGF) and sugar cane finished cattle (EHSC). Strip loins were aged for 21 days at 0 to $4^{\circ} \mathrm{C}$, fabricated into $2.5 \mathrm{~cm}$ thick steaks and frozen $\left(-20^{\circ} \mathrm{C}\right)$. Steaks were thawed for $24 \mathrm{~h}$ at $2-4^{\circ} \mathrm{C}$ prior to consumer evaluation, were cooked on clamshell grills to a well-done $\left(77^{\circ} \mathrm{C}\right)$ degree of doneness and portioned into eight uniform pieces to serve to panelists. Samples were evaluated on 8-point hedonic scales for tenderness, flavor, juiciness and overall liking, and each trait was classified as acceptable or unacceptable. Willingness to pay for each sample was rated in U.S. dollars $\$ 0, \$ 3, \$ 6$ or $\$ 10$ per pound. Data were analyzed using the GLIMMIX procedure of SAS as a completely randomized design with an alpha level of 0.05 .

Results: EHGF samples received greater scores $(P<0.05)$ for all palatability traits and were considered more acceptable for each of the traits compared to all other treatments, including TC. Additionally, consumers were willing to pay the most for EHGF samples $(P<0.05)$. When examining the three Honduran treatments, their enhanced counterparts were preferred as evidenced by greater scores for each of the palatability traits as well as greater acceptability when compared to the non-enhanced version of samples from those three finishing diets. In general, Honduran samples were scored as follows: HGF $>$ HSC $\geq$ HDP. Enhancing HSC produced palatability scores similar $(P>0.05)$ to those of HGF. Similarly, EHDP were not scored differently compared to HSC $(P>0.05)$. Without enhancement, none of the Honduran samples 
rated as well as either SE or TC $(P<0.05)$. However, EHSC samples were similar to SE $(P<0.05)$ for juiciness, flavor, overall liking and consumer's willingness to pay.

Conclusion: EHGF samples were ranked greater than both U.S treatments for all palatability traits showing that enhancement is functional for improving palatability traits; however, US consumers detected differences in steak samples from different Honduran finishing diets, preferring HGF over HSC or HDP, indicating enhancement did not completely overcome deficiencies in tenderness, juiciness, and flavor of HSC and HDP.

Keywords: Beef, Consumer Panel, Honduras 


\title{
Meat and Poultry Quality
}

67

\section{EFFECTS OF DIETARY ANTIOXIDANT SUPPLEMENTATION OF CATTLE FINISHED WITH $30 \%$ WET DISTILLERS GRAINS PLUS SOLUBLES ON FATTY ACID PROFILES AND DISPLAY LIFE}

\author{
M. Chao ${ }^{1, *}$, C. Calkins ${ }^{1}$, K. Domenech-Perez ${ }^{1}$, H. Voegele ${ }^{1}$, E. Kunze ${ }^{1}$
}

${ }^{1}$ Animal Science, University of Nebraska-Lincoln, Lincoln, United States

Objectives: Feeding wet distillers grains plus solubles (WDGS) in beef feedlot diets increases muscle tissue polyunsaturated fatty acids (PUFA) concentration and decreases beef display life, while antioxidants like vitamin $E(E)$ and Agrado Plus (AG; Novus International) have shown to mitigate such effects. The objective of this study was to evaluate the effects of finishing diets containing WDGS and different antioxidants on muscle tissue fatty acid profiles, discoloration and lipid oxidation of retailed-displayed beef.

Materials and Methods: One hundred and sixty cross-bred cattle were finished on either corn or a corn-based diet with $30 \%$ WDGS with 4 antioxidant treatments [E at $22.5 \mathrm{mg}(50 \mathrm{lU}) / \mathrm{hd} / \mathrm{d}-$ control; $E$ at $450 \mathrm{mg}(1,000 \mathrm{lU}) / \mathrm{hd} / \mathrm{d} ; A G$ at $3 \mathrm{~g} / \mathrm{hd} / \mathrm{d}$ ( $215 \mathrm{mg} / \mathrm{kg}$ of feed); a combination of $225 \mathrm{mg}(500 \mathrm{IU}) / \mathrm{hd} / \mathrm{d}$ of $E$ and $3 \mathrm{~g} / \mathrm{hd} / \mathrm{d}$ ( $215 \mathrm{mg} / \mathrm{kg}$ of feed) of AG] with 2 pens per treatment. Eighty out of 160 designated carcasses (10 carcasses per treatment) with 5 carcasses from each pen were selected based on quality grade (Choice). Strip loins from selected carcasses were collected and cut into steaks which were aged for 2, 7, and $14 \mathrm{~d}$ and placed under retail display conditions for $7 \mathrm{~d}$. During the display period, steaks were evaluated daily for objective and subjective (panel of 5 trained panelists) color scores. Lipid oxidation, muscle tissue fatty acid profile, and E and ethoxyquin concentrations were measured. Data were analyzed by GLIMMIX procedure of SAS (version 9.2, Cary, NC, 2009) as a split-split-plot repeated measures design with dietary treatments as the whole-plot, aging period as the sub-plot and retail display days as the repeated measures. Separation of means was conducted using LSMEANS procedure with PDIFF or SLICEDIFF options at $P \leq 0.05$.

Results: Feeding WDGS decreased $(P<0.05)$ the proportions of 14:0, 14:1 and 16:1, but increased $(P<0.05)$ 15:0, 17:0, 17:1, 18:1 trans, 18:2, 20:1 and total PUFA in muscle when compared to the fatty acid profiles of beef from cattle fed corn-only. In addition, steaks from the Corn+E treatment tended $(P<0.10)$ to have less $18: 1$ trans fatty acid when compared to the corn-only treatment. Supplementing $E+A G$ or $E$ alone was effective in reducing $(P<0.01)$ lipid oxidation for 0,4 and $7 \mathrm{~d}$ of retail display in beef from cattle fed corn-only and was effective in maintaining color stability after $6 \mathrm{~d}$ of retail display $(P<0.01)$ in beef from both corn-only and WDGS diets. Supplementation of $\mathrm{E}$ or AG significantly increased $(P<0.01)$ muscle tissue $E$ or ethoxyquin levels compared to the diets without $E$ or $A G$ supplementation. It was interesting to note that WDGS+AG samples had higher $(P<0.05)$ muscle tissue $E$ level compared to samples from Corn+AG.

Conclusion: The inclusion of $30 \%$ WDGS altered fatty acid profiles of muscle tissue, but did not promote lipid and myoglobin oxidation compared to the corn-only diet. Feeding $E$ alone was effective in reducing myoglobin and lipid oxidation in both diets, while supplementing AG showed a minor E-sparing effect when fed with $E$. 
Keywords: antioxidants, beef, discoloration, distillers grains, fatty acids 


\section{Meat and Poultry Quality}

68

\section{HONDURAN AND U.S. CONSUMER ASSESSMENT OF BEEF STRIP LOIN STEAKS FROM GRASS AND GRAIN FINISHED CATTLE}

M. E. Bueso 1,*, T. G. O'Quinn ${ }^{2}$, A. J. Garmyn ${ }^{1}$, J. C. Brooks ${ }^{1}$, M. F. Miller ${ }^{1}$

${ }^{1}$ Animal and Science, Texas Tech University, Lubbock, ${ }^{2}$ Animal Science and Industry, Kansas State University, Manhattan, United States

Objectives: The objective of this study was to characterize beef from U.S. and Honduras feeding regimes (grain vs. forage based diets) on palatability traits and to assess the willingness of Honduran and U.S. consumers to pay for these products.

Materials and Methods: All U.S. sourced strip loins from grain-finished cattle, aged $21 \mathrm{~d}$, were selected to equally represent Select (USS) (USDA Select; $n=6$ ) and Top Choice (USTC) (upper 2/3 USDA Choice; $n=6$ ) quality grades. Additionally, strip loins $(n=6)$ from Honduran grass-finished (HGrass) cattle and grain-finished (HGrain) cattle $(n=6)$ were collected from a packing plant in Siguatepeque, Honduras and aged $21 \mathrm{~d}$. Sub-primals were fabricated into $2.5 \mathrm{~cm}-$ thick steaks and frozen $\left(-20^{\circ} \mathrm{C}\right)$. A steak from each striploin was selected to conduct proximate analysis where fat, collagen, moisture and protein percentages were determined. Steaks were thawed for $24 \mathrm{~h}$ at 2 to $4^{\circ} \mathrm{C}$ prior to consumer evaluation and were cooked on clamshell grills to $77^{\circ} \mathrm{C}$. Each steak was portioned into 10 uniform pieces and served warm to panelists. A consumer $(n=240)$ panel was conducted during the yearly Pan-American Fair at Zamorano University in Honduras and a second consumer $(n=240)$ panel was conducted at Texas Tech University. Samples were evaluated on an 8-point hedonic scale for flavor, tenderness, juiciness, overall liking and acceptability. Willingness to pay for each sample was rated in U.S dollars: $\$ 0, \$ 3, \$ 6, \$ 10$ per pound, for the panel conducted in Honduras the equivalent of Lempiras was used.

Results: Results from proximate analysis demonstrate that protein percentages for the two U.S. treatments (USTC and USS) and the HGrass treatments were similar $(P=0.37$ and $P=0.94$, respectively). There were no statistical differences $(P=0.11)$ in fat percentage between USTC and HGrain treatments. USS and HGrass demonstrated greater moisture percentages. The two U.S treatments were scored higher $(P<0.05)$ for tenderness, flavor, and overall liking compared to both Honduran treatments; however, consumers rated USTC higher $(P<0.05)$ than USS for all traits. Consumers scored HGrass greater $(P<0.05)$ than HGrain for each trait. Honduran consumers gave higher ratings $(P<0.05)$ for all traits compared to U.S consumers. A greater $(P<0.05)$ percentage of U.S. samples were acceptable for tenderness compared to either Honduran treatment. For all traits, Honduran consumers ranked acceptability greater than U.S. consumers. Consumers were willing to pay $\$ 4.05$ per pound for USTC samples, but were only willing to pay $\$ 1.75$ per pound for HGrain samples. Results indicate consumers prefer U.S. beef strip loin steaks compared to Honduran domestic beef 
finished by grain or grass feeding. Changes may be needed to improve domestic beef production practices in Honduran beef.

Conclusion: Results indicate both U.S. and Honduran consumers prefer U.S. sourced beef compared to Honduran beef. Similarly, consumer acceptability percentages for Honduran treatments demonstrate a need to improve grain based feeding systems to improve palatability of Honduran beef. Top Choice treatment was more liked than any other U.S. or Honduran sourced beef. Consumers are willing to pay premium for products with greater palatability

Keywords: Beef, consumers, Honduras, grain-finished, grass-fed 


\section{Meat and Poultry Quality}

69

\section{EFFECTS OF FINISHING DIET ON CONSUMER ASSESSMENT OF BEEF FROM MATURE CULL COWS}

D. A. Gredell 1,*, T. G. O'Quinn ${ }^{2}$, J. C. Brooks ${ }^{1}$, M. F. Miller ${ }^{1}$

${ }^{1}$ Animal and Food Sciences, Texas Tech University, Lubbock, ${ }^{2}$ Animal Sciences and Industry, Kansas State University, Manhattan, United States

Objectives: Cull beef cows can be finished on a high-energy grain diet prior to harvest as a way to offset negative palatability traits typically associated with beef from mature cow carcasses that have been on a forage-based maintenance diet. Therefore, the objective of this study was to compare consumer sensory scores of beef from grainfinished cull cows and unfed cull cows to beef from grain-finished young cattle.

Materials and Methods: Beef strip loins ( $n=15$ per treatment) from two marbling score groups [slight (SL) and traces/practically devoid (TR/PD)] across three beef types [young fed (YF), mature fed (MF), and mature unfed (MU)] were collected in commercial processing facilities. Mature unfed strip loins were selected from mature cows that were perceived to be fed a maintenance diet prior to harvest. Subprimals were fabricated into $2.5 \mathrm{~cm}$ thick steaks, vacuum packaged, and aged for 21 days before freezing at $-20^{\circ} \mathrm{C}$ until further evaluation. Proximate analysis was performed on 1 steak from each subprimal to determine fat, protein, and moisture values. Consumer panelists $(n=120)$ were used to determine palatability of cooked steaks. Steaks were cooked to an internal temperature of $71^{\circ} \mathrm{C}$ using a gas radiant broiler. After cooking, each steak was cut into $2 \mathrm{~cm}^{2}$ cubes with each consumer receiving 1 piece. A $100 \mathrm{~mm}$ line scale verbally anchored at both ends was used to evaluate samples for tenderness, juiciness, beef flavor liking, overall liking, and off-flavor intensity. Data were analyzed using the GLIMMIX procedure of SAS. The experiment was designed as a $2 \times$ 3 factorial with marbling score and beef type as the fixed effects.

Results: Proximate analysis showed SL steaks had higher $(P<0.05)$ fat content than TR/PD steaks. Consumer ratings for tenderness, juiciness, flavor liking and overall liking were higher $(P<0.05)$ for steaks from SL carcasses. Beef type had no effect $(P>0.05)$ on consumer ratings. Neither marbling score $(P>0.05)$ nor carcass type $(P>0.05)$ had an effect on off-flavor intensity scores. Consumers scored MF-TR/PD and MU-TR/PD steaks lowest $(P<0.05)$ of all treatments for overall liking. Consumer acceptance of SL steaks was higher $(P<0.05)$ for tenderness, juiciness, flavor liking, and overall liking than TR/PD samples. Beef type had an effect on consumer acceptance for tenderness and juiciness. Tenderness acceptance was highest $(P<0.05)$ in YF steaks and lowest $(P<0.05)$ for MU steaks. Juiciness acceptance $(P<0.05)$ was highest in MU steaks followed by YF and MF steaks, respectively. Marbling score by beef type interactions were observed $(P<0.05)$ for flavor liking and overall liking acceptance. Flavor liking and overall liking acceptance were not affected by beef type within SL steaks; however, flavor liking and overall liking acceptance scores were lower $(P<0.05)$ for MF and MU steaks with TR/PD marbling scores. 
Conclusion: In conclusion, marbling score had the largest influence on consumer sensory scores and acceptance of steaks from varying beef types. Consumers rated steaks with SL marbling scores higher and more acceptable for tenderness, juiciness, flavor liking, and overall liking than steaks with TR/PD marbling scores. Nevertheless, MF and MU steaks with TR/PD marbling scores had the lowest percentage of samples rated as acceptable for flavor and overall liking.

Keywords: beef quality, carcass maturity, cull-cow, grain-finished, palatability 


\title{
Meat and Poultry Quality
}

70

\section{VARIATION AND UNIFORMITY IN COOKED MEAT SPOILING BACTERIA}

\author{
O. Sliekers ${ }^{1, *}$, N. de Rooij ${ }^{1}$, R. Zumbrink ${ }^{1}$ \\ ${ }^{1}$ Corbion, Gorinchem, Netherlands
}

Objectives: The objective was to investigate the variation in cooked meat spoilage in different regions in the world and the variation in growth and lactic acid sensitivity between individual spoilage strains and species.

Materials and Methods: More than 200 dominant meat spoilage isolates (60 from the US) were obtained from 11 different countries (e.g. US, Brasil, The Netherlands, Spain, The Phillipines, Japan) from different regions in the world (US, Latin America, Asia and Europe), and their $16 \mathrm{~S} \mathrm{r}$ DNA sequenced to determine the identity. By counting the frequency of isolation of a species, the top 5 list per region was established. A considerable part $(>50)$ of the strains isolated from the cooked meat was grown in MRS broth. Growth was measured using the optical density (turbidity) in broth and using plating in meat. The growth rate was calculated by the logistic growth equation. Different species were also grown in cooked meat at $4{ }^{\circ} \mathrm{C}$ in absence and presence of $3 \%$ Purasal S. Purasal S contains lactic acid, and does not only provide protection against Listeria but also elongates shelf life by slowing down growth of cooked meat spoilage bacteria.

Results: The isolated species per region show some variability with respect to the most frequently isolated species, but a breakdown to the top 3 per region show obvious similarities. Lactobacillus sakei, Leuconostoc mesentroides, Leuconostoc carnosum and Lactobacillus plantarum were the most dominant. In the US, the most frequently isolated species was Lactobacillus sakei (40\%). In Europe both Lactobacillus sakeias well as Leuconostoc carnosum was found equally often (18\% each). In Latin America, Leuconostoc mesentroides (29\%) was the most common and in Asia, Lactobacillus plantarum (21\%).

More striking was the variability in growth rates (in broth) between the species and especially between different strains of the same species. L.plantarum grew the slowest in broth, whereas slow and fast growers could be found within the L.sakei, Lc. mesentroides and Lc. carnosum strains. The growth rate of all species was diminished with almost the same factor by Purasal S.

It is tempting to hypothesize that it is a matter of chance what species from the top 5 becomes dominant during shelf life of a cooked meat product. It probably depends on the individual growth rate of all the competing species that attach to the meat and as shown, the growth rate can vary from strain to strain. Luckily, in all cases lactic acid will slow down growth, independent of who is winning the competition.

Conclusion: The biological variation between meat spoilage strains is considerable, as shown by the variation in growth rates in broth. This in sharp contrast to the uniformity of the dominant flora that spoils cooked meat in different regions in the world. All species found to be dominant in cooked meat were sensitive to lactic acid, so lactic acid will slow down growth in cooked meat products all over the world. 
Keywords: cooked meat, spoilage 


\title{
Meat and Poultry Quality
}

71

\section{EFFECTS OF ASCORBIC ACID AND ROSEMARY EXTRACT ON QUALITY CHARACTERISTICS AND SENSORY PERCEPTION OF EXTENDED AGED BEEF}

\author{
M. J. Colle ${ }^{1, *}$, R. P. Richard ${ }^{1}$, M. C. Colle ${ }^{1}$, W. I. Loucks ${ }^{1}$, M. E. Doumit ${ }^{1}$ \\ University of Idaho, Moscow, United States
}

Objectives: Our objective was to determine the effects of ascorbic acid and rosemary extract on color, microbial growth, lipid oxidation, and sensory perception of extended aged beef top loin and top round steaks.

Materials and Methods: Carcasses were fabricated at $24 \mathrm{~h}(\mathrm{~d} \mathrm{0})$ post mortem. At $48 \mathrm{~h}$ post mortem (d 1), strip loin (IMPS 180 ) and top (inside) round (IMPS 168) from USDA Choice carcasses $(n=12)$ were purchased from AB Foods (Toppenish, WA) and transported to the University of Idaho Meat Science Laboratory. The longissimus lumborum (LL) and semimembranosus (SM) were removed from their respective wholesale cuts for aging and subsequent analysis. On day 1 , muscles were cut into three sections and assigned to one of three aging periods $(14,28$, and 42 days postfabrication). Sections were vacuum shrink packaged and aged for the pre-determined time period at $0^{\circ} \mathrm{C}$. At the end of each aging period, four $2.54 \mathrm{~cm}$-thick steaks were cut from designated sections. Two steaks were sprayed $(\sim 2 \mathrm{ml})$ with a $0.05 \%$ ascorbic acid $+0.1 \%$ rosemary extract solution (treated) and two were untreated (control). One steak in each group was assigned to shelf-life, while the other steak was designated to consumer panel analysis. Steaks assigned to shelf-life were sampled for microbial growth (MG), thiobarbituric acid reactive substances (TBARS), metmyoglobin reducing activity (MRA), and oxygen consumption (OC). Steaks were then placed in white styrofoam trays, and overwrapped with an oxygen permeable PVC film before being displayed in a glass-fronted retail display case for 4 days at $3^{\circ} \mathrm{C}$. Steaks were allowed to bloom for at least $60 \mathrm{~min}$ before visual and instrumental color measurements were taken. This represented day 0 of retail display, and subsequent color measurements were taken on days 1, 2, 3, and 4. The Hunter MiniScan EZ was set to illuminant $A$ and $(\mathrm{CIE}) L^{*}, a^{*}$, and $b^{*}$ values were recorded. Following retail display, steaks were sampled for MG, TBARS, and MRA. Steaks designated for consumer panels were exposed to retail display conditions for 2 days, then sampled for $M G$ and TBARS, and vacuum packaged and frozen at $-20^{\circ} \mathrm{C}$ until completion of all aging periods. A panel of consumers ( $n=60$ per muscle) evaluated cooked steaks for overall acceptability, tenderness, juiciness, and flavor. Data were analyzed using the Mixed Model procedure of the Statistical Analysis System (SAS Institute, Inc., Cary, NC) and significance was determined at $P<0.05$.

Results: Treated LL steaks had higher $(P<0.05) L^{*}$ values, but lower $(P<0.05) a^{*}$ and $b^{*}$ values than control steaks. Additionally, there was a day by treatment interaction $(P<0.05)$ for $L L$ amount of browning. Treated LL steaks were less brown than control steaks on day 4 of retail display. A treatment by day of retail display interaction $(P<0.001)$ was observed for SM MRA. MRA of treated SM steaks was greater than control steaks on day 0 of retail display, but did not 
differ between treated and control steaks on day 4 of retail display. Treatment did not affect MG, TBARS, OC, or consumer panel flavor scores for either muscle.

Conclusion: The current study revealed only a slight improvement in color when using ascorbic acid and rosemary extract to improve the shelf-life of aged beef.

Keywords: Aging, Ascorbic acid, Beef, Rosemary 


\section{Meat and Poultry Quality}

72

\section{WHAT CAUSES SHELF LIFE DETERIORATION IN GROUND BEEF?}

Z. Callahan 1, ${ }^{\star}$, C. Lorenzen ${ }^{1}$, K. Shircliff ${ }^{1}$, D. Reynolds ${ }^{1}$, A. Mustapha ${ }^{2}$, B. Wiegand 1

${ }^{1}$ Animal Sciences, ${ }^{2}$ Food Science, University of Missouri, Columbia, United States

Objectives: This research was performed to determine causes of shelf life deterioration during retail storage of ground beef patties formulated at 5 and $25 \%$ fat from two fat depots. The objectives were to evaluate the color stability, degree of fat oxidation, and microbial load during retail storage of ground beef patties.

Materials and Methods: Beef carcasses $(n=20)$ were chilled for two days and then fabricated. Top round muscles (IMPS \#168) were removed and closely trimmed. Within each carcass, two sources of fat, kidney and pelvic (KP) and subcutaneous (SQ), were sourced to blend with the top round to achieve either 75:25 or 95:5 ground beef. Trim and fat blocks were individually ground through a coarse 10 $\mathrm{mm}$ plate. Final meat blocks (969.6 g of meat and $51.0 \mathrm{~g}$ of fat) for $95 \%$ lean product and $(765.4 \mathrm{~g} \mathrm{of}$ meat and $255.2 \mathrm{~g}$ of fat) for $75 \%$ lean product were blended and finely ground through a $4.5 \mathrm{~mm}$ plate. The $1020.6 \mathrm{~g}$ of product from each treatment within animal was then used to create eight, $113.4 \mathrm{~g}$ patties to be used for the shelf study. Patties were placed on Styrofoam trays and overwrapped with oxygen permeable, polyvinyl chloride and placed in refrigerated retail storage $\left(4^{\circ}\right.$ C) where an instrumental measurement of color $\left(L^{*}, a^{*}, b^{*}\right)$, myoglobin concentration, thiobarbituric acid reactive substances (TBA), and aerobic plate counts were collected on their designated days of the study. The additional $113.4 \mathrm{~g}$ of sample was placed in a whirl-pack bag, stored at $4^{\circ} \mathrm{C}$, and used for fat determination, fatty acid analysis, and calculated iodine value (IV).

Results: Data analysis indicated oxymyoglobin $(\mathrm{OMb})$ to have a source $x$ fat \% interaction $(P=0.011)$ where KP25 > SQ25 > KP5 > SQ5 with means of 54.70, 54.2, 50.0, and 49.5, respectively, and a difference for day $(P=<0.0001)$ where $d 1>d 3>d 5>d 7$ with means of 55.0, 52.6, 50.8, and 50.0, respectively. Inversely, results showed metmyoglobin $(\mathrm{MMb})$ to have a difference for day $(\mathrm{P}=$ $<0.0001$ ) where $\mathrm{d} 1<\mathrm{d} 3<\mathrm{d} 5<\mathrm{d} 7$ with means of 35.9, 39.4, 41.2, and 42.2, respectively. These changes in myoglobin concentration contributed to changes in $a^{*}$ values $(P<0.0001)$ over time where d $0>$ d $1>$ d $3>$ d $5>$ d 7 with means of 20.9, 19.6, 16.6, 15.6, and 15.0, respectively. There was also a trend $(P=0.071)$ for day where TBA values increased up to $d 5$ but then decreased from $d 5$ to d 7. However, aerobic plate counts did not differ $(P>0.05)$ for any of the main effects.

Conclusion: This data refutes our hypothesis of aerobic microbial spoilage being a main contributor of discoloration in ground round over time. Discoloration in ground round over seven days of retail display was more a function of muscle pigment oxidation (OMb to MMb) and lipid oxidation.

Keywords: Beef color stability, Ground beef patties, Lipid oxidation 



\title{
Meat and Poultry Quality
}

73

\section{AGING EFFECTS ON SELECTED BEEF MUSCLES FROM CARCASSES CLASSIFIED INTO TENDERNESS GROUPS BASED ON LONGISSIMUS MUSCLE TENDERNESS}

\author{
A. Rosa ${ }^{1,}{ }^{*}$, K. Domenech-Perez ${ }^{1}$, M. Chao ${ }^{1}$, H. Voegele ${ }^{1}$, K. Nubiato ${ }^{1}$, E. Kunze ${ }^{1}$, C. Calkins ${ }^{1}$ \\ ${ }^{1}$ Animal Science, University of Nebraska, Lincoln, United States
}

Objectives: The objective of this research was to evaluate aging effects on tenderness of beef muscles from carcasses classified into tenderness groups based on Longissimus muscle tenderness.

Materials and Methods: Carcasses $(n=120)$ were selected from the following grades: upper 2/3 Choice, low Choice and Select (40 per grade). Beef tenderness was assessed on three different muscles: Longissimus (LD), Gluteus medius (GM) and Infraspinatus (IS) of each carcass. Every muscle was cut into five steaks, individually identified, skin tight vacuum packaged and aged for $7,14,21,28$ or $35 \mathrm{~d}$, after which they were frozen. Steaks were thawed $24 \mathrm{hr}$ before cooking. Slice shear force values were determined for LM, GM and IS steaks. Data were collected from a total of 1800 steaks. Data were analyzed using GLIMMIX procedures of SAS, LS MEANS statement and the TUKEY adjustment were used for mean separation with an alpha level of 0.05 (Version 9.2, Cary, N.C., $2002-2008$ ). The model contained muscle, aging time, and grade.

Results: In general, upper 2/3 Choice carcasses were more tender than those from low Choice and Select carcasses (data not shown) and aging period significantly improved tenderness until $28 \mathrm{~d}$. At $14 \mathrm{~d}$ of aging, 28\% of LD steaks were classified as Very Tender ( $<15.3 \mathrm{~kg}), 36 \%$ were Tender $(15.4-19.9 \mathrm{~kg})$ and $36 \%$ were considered Not Certified (>20.0 $\mathrm{kg}$ ). Carcasses were grouped by the LD categories at $14 \mathrm{~d}$ of aging to identify possible aging patterns for the GM and IS. Although all IS muscles responded to aging in a similar manner, there were no differences in tenderness among IS groups when groups were defined by $14 \mathrm{~d}$ LD tenderness. The GM from carcasses classified as Not Certified were significantly less tender than the Tender and Very Tender groups, which were similar (Table 1). No discernible differences in aging patterns were observed for GM and IS muscles. In each tenderness category, the aging response was similar between the LD, GM, and IS except in the Not Certified group. Tenderness of the LD within the Not Certified group significantly dropped in SSF between 21 and $28 \mathrm{~d}$ of aging while the other muscles within that group continued their gradual SSF decline.

Image: 
Table 1. Slice shear force (SSF) values of muscles from carcasses classified as Very Tender, Tender or Not Certified based on the Longissimus dorsi SSF at d 14.

\begin{tabular}{|c|c|c|c|c|c|c|c|c|c|}
\hline \multirow[b]{2}{*}{$\begin{array}{l}\text { Aging } \\
\text { (Days) }^{1}\end{array}$} & \multicolumn{3}{|c|}{ Very Tender $(<15.3 \mathrm{~kg})$} & \multicolumn{3}{|c|}{ Tender $(15.4-19.9 \mathrm{~kg})$} & \multicolumn{3}{|c|}{ Not Certified $(>20.0 \mathrm{~kg})$} \\
\hline & $L D^{2}$ & $G M$ & IS & $L D$ & $G M$ & IS & $L D$ & $G M$ & IS \\
\hline 7 & $16.06^{b}$ & $19.78^{x}$ & $16.20^{b}$ & $20.81^{*}$ & $20.20^{s}$ & $15.91^{b}$ & $27.17^{8}$ & $21.63^{b}$ & $16.04^{\varepsilon}$ \\
\hline 14 & $12.95^{\mathrm{c}}$ & $17.62^{a}$ & $15.37 \mathrm{~b}$ & $17.64^{a}$ & $17.77^{\mathrm{a}}$ & $15.26^{b}$ & $24.94^{\mathrm{a}}$ & $20.35^{b}$ & $15.63^{\circ}$ \\
\hline 21 & $13.25^{\mathrm{b}}$ & $16.88^{2}$ & $13.83^{b}$ & $16.08^{2}$ & $17.06^{\circ}$ & $13.38^{b}$ & $23.09^{8}$ & $19.37^{2}$ & $14.20^{b}$ \\
\hline 28 & $12.43^{b}$ & $15.70^{a}$ & $12.21^{\mathrm{b}}$ & $14.77^{b}$ & $16.17^{\mathrm{a}}$ & $12.41^{\circ}$ & $17.45^{\mathrm{a}}$ & $17.78^{a}$ & $12.63^{\mathrm{b}}$ \\
\hline 35 & $12.38^{b}$ & $14.33^{2}$ & $12.06^{b}$ & $14.41^{2}$ & $13.74^{2}$ & $11.90^{\mathrm{b}}$ & $16.97^{\mathrm{a}}$ & $16.37^{2}$ & $12.42^{\mathrm{b}}$ \\
\hline
\end{tabular}

'Data from 120 carcasses of Upper $2 / 3$ choice, Low choice and Select grades ( 40 carcasses /grade)

${ }^{2}$ LD: Longissimus dorsi / GM: Gluteus medius / IS: Infraspinatus

${ }^{\mathrm{D}}$ Different superscripts within row and tenderness category indicate differences $(\mathrm{P}<0.05)$

Conclusion: It seems that sorting carcasses based on the USDA tenderness categories of LD at $14 \mathrm{~d}$ of aging does not clearly provide a guide for aging strategies in other muscles.

Keywords: Aging, Gluteus medius, Infraspinatus, Longissimus, Tenderness 


\title{
Meat and Poultry Quality
}

74

\section{EFFECTS OF IMPLANTING STRATEGY AND ZILPATEROL HYDROCHLORIDE ON THE CALPAIN PROTEOLYTIC SYSTEM IN SECTIONED BEEF STEAKS AGED FOR TWO TIME PERIODS}

\author{
B. Howard 1,*, J. Gonzalez 2, W. Keller ${ }^{1}$, J. Drouillard ${ }^{2}$, K. Phelps ${ }^{2}$, S. Ebarb ${ }^{2}$, K. Maddock-Carlin ${ }^{1}$ \\ ${ }^{1}$ North Dakota State University, Fargo, ${ }^{2}$ Kansas State University, Manhattan, United States
}

Objectives: The objective of this study was to evaluate the impact of a $200 \mathrm{mg}$ trenbolone acetate and $20 \mathrm{mg}$ estradiol implant and its use with zilpaterol hydrochloride $(\mathrm{ZH})$ on calpain proteolytic system activity across specific areas of the beef strip steak aged for two time periods.

Materials and Methods: Yearling crossbred heifers $(n=15$, starting weight $463.78 \pm 1.59 \mathrm{~kg})$ were blocked by weight and randomly assigned to one of three treatments: 1) no implant or ZH (CON), 2) implant, no ZH (IMP), and 3) implant and ZH $(\mathrm{IMP}+\mathrm{ZH})$. On d 0, heifers were given an implant. On $\mathrm{d} 50,8.3 \mathrm{ppm} \mathrm{ZH}$ was included in the finishing ration for $21 \mathrm{~d}$ with a 3 -d withdrawal prior to slaughter. Heifers were slaughtered in a commercial plant on $d 75$. Strip steaks were collected and aged for 3 and $14 \mathrm{~d}$ at $4^{\circ} \mathrm{C}$. Samples were cut into lateral, lateral/medial, and medial sections. Protein was extracted from each section, and casein zymograms were conducted to evaluate calpain 1 and 2 activity (d 3), as well as troponin- $T$ Western blots, and heated calpastatin assays ( 3 and d 14). Six immunoreactive bands (bands 1 through 6 ) corresponding to the approximate molecular weights $40,38,36,34,30$, and $27 \mathrm{kDa}$, respectively, were analyzed in the troponin-T Western blots. Data were analyzed using a split plot design with repeated measures for aging day. Pairwise comparisons were made between least squares means when main effects or interactions were significant at $P \leq 0.05$. Results: Calpastatin and calpain 1 activities did not differ $(P>0.05)$ among treatment, aging days, or section. There was a treatment by section interaction $(P=0.027)$ in calpain 2 clear zone zymography measurements where the lateral/medial section of IMP+ZH had a smaller clear zone than the lateral/medial sections of both CON and IMP. Additionally, the lateral section of CON had a larger calpain 2 clear zone than the medial section of CON and lateral section of IMP+ZH. An effect $(P<0.0002)$ of aging day was observed in all analyzed troponin-T bands where bands 1 and 2 as a percentage of total lane density decreased and bands $3,4,5$, and 6 percentage increased with days. Troponin-T bands 5 and 6 had treatment by aging day interactions $(P<0.05)$ where percentage of total lane density increased during aging in $C O N$ and IMP but not in IMP+ZH. Also troponin-T band 6 had a day by section interaction $(P=0.042)$ where on $\mathrm{d} 3$ the sections did not differ, but on $\mathrm{d} 14$, the medial section had a larger percentage of total lane density than the lateral or lateral/medial sections.

Conclusion: Although measurements of calpastatin and calpain 1 activity were not affected by growth promotant technologies used in this study, the lesser accumulation of troponin- $T$ degradation products in beef from cattle fed $\mathrm{ZH}$ indicate a mechanism for a decrease in protein degradation that may affect beef tenderness. Interestingly, the measured 
differences in calpain 2 activity indicate a possible role in post-mortem aging. Additionally, changes in protein degradation across a retail cut indicate that variation does occur across a single muscle that may impact overall quality factors.

Keywords: Aging, Beef, Calpain, Implants, Zilpaterol Hydrochloride 


\section{Meat and Poultry Quality}

75

\section{EFFECTS OF POSTMORTEM AGE AND FREEZING ON WARNER-BRATZLER SHEAR FORCE OF SIX MUSCLES FROM THE BEEF HINDQUARTER.}

R. Mcewan 1,*, J. Unruh 1, T. Houser ${ }^{1}$, T. O'Quinn ${ }^{1}$, N. Bloedow ${ }^{2}$, C. Vahl ${ }^{2}$, S. Stroda ${ }^{1}$

${ }^{1}$ Animal Science and Industry, ${ }^{2}$ Statistics, Kansas State University, Manhattan, United States

Objectives: When designing research protocols, samples for Warner-Bratzler shear force (WBSF) are often frozen for later analysis. Previous research has been inconclusive as to the effect of freezing on WBSF of beef steaks. Therefore, the objective of this experiment was to determine the effects of postmortem aging time and freezing on WBSF of six muscles from the beef hindquarter.

Materials and Methods: Choice strip loin (IMPS \# 180), tenderloin (IMPS \# 189A), top sirloin butt (IMPS \# 184), inside round (IMPS \# 168), eye of round (IMPS \# 171C), and round flat (IMPS \# 171B) subprimals ( $n=18$ / muscle) with a common slaughter date were purchased from a commercial processing facility. Longissimus dorsi (LD), psoas major (PM), gluteus medius (GM), semimembranosis (SM), semitendenosis (ST), and biceps femoris (BF) muscles from the respective subprimals were fabricated into four $2.54-\mathrm{cm}$ steaks from the center of the muscle, vacuum packaged, and randomly assigned to treatments of status (fresh or frozen), and 7 or $21 \mathrm{~d}$ of aging. At the end of the designated aging time $\left(7\right.$ or $21 \mathrm{~d}$ ), fresh treatment steaks were cooked and frozen treatment steaks were blast frozen at $-40^{\circ} \mathrm{C}$ for one week, and thawed for $12 \mathrm{~h}$ in refrigerated $\left(3 \pm 1^{\circ} \mathrm{C}\right)$ storage prior to cooking. All steaks were cooked in a convection oven $\left(163^{\circ} \mathrm{C}\right)$ to an internal temperature of $70^{\circ} \mathrm{C}$. Cooked steaks were stored overnight in refrigerated storage $\left(0 \pm 1^{\circ} \mathrm{C}\right)$ before eight core samples were taken parallel to the muscle fiber orientation from each steak. Cores were sheared using an Instron model 5569 Universal Testing Machine fitted with a WBSF blade attachment. Purge and cooking losses were measured to calculate total moisture losses. Data were analyzed using a completely randomized design, where the whole plot was muscle, and the split plots were aging time and status, using the MIXED (total moisture loss) and GLIMMIX (WBSF) procedures of SAS 9.4 .

Results: Steaks aged $21 \mathrm{~d}$ had $(P<0.05)$ lower WBSF than steaks aged $7 \mathrm{~d}$. In a muscle $\times$ status interaction $(P=0.02)$, previously frozen LD steaks tended to have lower $(P=0.07)$ WBSF than fresh LD steaks. For fresh steaks, PM steaks had $(P<0.05)$ the lowest WBSF, LD steaks had $(P<0.05)$ lower WBSF than ST, SM, and BF steaks, and GM steaks had $(P<0.05)$ lower WBSF than BF steaks. For previously frozen steaks, PM steaks had $(P<0.05)$ the lowest WBSF. In addition, LD steaks had $(P<0.05)$ lower WBSF than GM, SM, ST, and BF steaks; and GM steaks had $(P<0.05)$ lower WBSF than ST and BF steaks. Steaks aged $7 \mathrm{~d}$ had $(P<0.05)$ lower total moisture losses than steaks aged $21 \mathrm{~d}$. In a muscle $\times$ status interaction $(P=0.002)$, previously frozen steaks from the $\mathrm{GM}, \mathrm{PM}$, and $\mathrm{ST}$ had $(P<0.05)$ greater moisture losses than fresh GM, PM, and ST steaks. For fresh steaks LD and PM steaks had $(P<0.05)$ the lowest total moisture losses; and fresh GM steaks had $(P<0.05)$ lower total moisture losses than fresh $\mathrm{BF}$ steaks. For previously 
frozen steaks, LD steaks had $(P<0.05)$ the lowest total moisture losses; and PM steaks had $(P<0.05)$ lower total moisture losses than ST, GM, and BF steaks.

Conclusion: Extended aging (21 vs $7 \mathrm{~d}$ ) of steaks improves tenderness (lower WBSF), but increases total moisture losses. Freezing steaks has minimal impact on WBSF for hindquarter muscles. Therefore, when designing research protocols, it is acceptable to freeze samples prior to analysis.

Keywords: Aging, Beef, Freezing , Fresh, Shear force 


\title{
Meat and Poultry Quality
}

76

\section{TRAINED PANEL EVALUATION OF GRILLED STRIP LOIN STEAKS FROM GRAIN-FINISHED CULL COWS}

\author{
R. D. Crownover 1, ${ }^{\star}$, D. A. Cashman 1, T. G. O'Quinn ${ }^{2}$, R. J. Rathmann ${ }^{1}$, J. C. Brooks ${ }^{1}$, M. F. Miller ${ }^{1}$ \\ ${ }^{1}$ Animal and Food Sciences, Texas Tech University, Lubbock, ${ }^{2}$ Animal Sciences and Industry, Kansas State University, \\ Manhattan, United States
}

Objectives: A trained sensory panel was conducted to compare the palatability traits of beef strip loins with similar marbling scores from A-maturity carcasses and mature, grain-finished cull cows.

Materials and Methods: Treatments included strip loins with USDA marbling scores of Slightly Abundant and greater $\left(\mathrm{SLAB}^{+}\right)$, Modest and Moderate (MT/MD), Small (SM), Slight (SL), and Traces and Practically Devoid (TR/PD) of youthful, "A" maturity carcasses $(Y)$ and carcasses from mature $(M)$ cattle (C or greater maturity). Fifteen subprimals from each treatment were selected by Texas Tech University personnel, and were aged $21 \mathrm{~d}$ under vacuum at 2 to $4^{\circ} \mathrm{C}$. Strip loins were cut into $2.5 \mathrm{~cm}$ thick steaks, frozen and stored at $-20^{\circ} \mathrm{C}$ until sensory evaluation. Steaks were thawed for $24 \mathrm{~h}$ at 2 to $4^{\circ} \mathrm{C}$ and cooked on a gas radiant broiler (model IRB-36, Imperial Commercial Cooking Equipment, Corona, CA) to a medium degree of doneness $\left(71^{\circ} \mathrm{C}\right)$ monitored by a digital meat thermometer (Digi-Sense Type J, Cole-Parmer Instrument Company Vernon Hills, IL). Following a 3 min rest period, steaks were portioned into cubes $\left(1 \mathrm{~cm}^{3}\right)$ and served to panelists. Samples were evaluated by a seven member trained panel for initial juiciness, sustained juiciness, initial tenderness, sustained tenderness, beef flavor, and flavor intensity on a $10 \mathrm{~cm}$, verbally anchored line-scale $(0=$ extremely dry/tough/unbeef-like; 100 = extremely juicy/tender/beef-like). Seven samples were served in each of the 15 panel sessions.

Results: Samples from Y-SLAB ${ }^{+}$rated greatest $(P<0.05)$ for initial juiciness, sustained juiciness, initial tenderness, sustained tenderness, beef flavor, and flavor intensity. Also, M-TR/PD rated lowest $(P<0.05)$ for initial juiciness, initial tenderness, sustained tenderness, beef flavor, and flavor intensity. Young cattle rated more desirable $(P<0.05)$ for both initial tenderness and sustained tenderness when compared to mature cattle with the same marbling score. Strips from $Y$ $\mathrm{SLAB}^{+}$and $\mathrm{M}-\mathrm{SLAB}{ }^{+}$rated greatest $(P<0.05)$ in beef flavor and flavor intensity. Furthermore, M-SLAB ${ }^{+}$rated greater $(P<$ $0.05)$ for initial juiciness and sustained juiciness when compared to samples from all lower marbling scores regardless of maturity. Initial juiciness, initial tenderness, sustained tenderness, beef flavor, and flavor intensity were rated greater $(P<$ 0.05) for strips from Y-TR/PD when compared to M-TR/PD. Moreover, M-MT/MD rated greater $(P<0.05)$ in initial juiciness and sustained juiciness when compared to $Y-S M$. In addition, between M-MT/MD and Y-SM values were rated similar $(P<0.05)$ for sustained tenderness and flavor intensity. Finally, sustained juiciness, beef flavor, and flavor intensity were rated similar $(P<0.05)$ between $\mathrm{Y}-\mathrm{SL}$ and $\mathrm{M}-\mathrm{SL}$. 
Conclusion: These results indicate cull cows fed a high concentrate diet prior to harvest with carcasses possessing SLAB ${ }^{+}$ marbling scores could provide a similar eating experience to "A" maturity carcasses of lower marbling scores. Therefore, these results indicate the opportunity to market these beef items with higher premiums than are currently received.

Keywords: Beef, Maturity, palatability, trained panel, USDA quality grades 


\title{
Meat and Poultry Quality
}

77

\section{CHARACTERISTICS OF TOP LOIN STEAKS PURCHASED AT MULTIPLE RETAIL GROCERY STORE OUTLETS}

\author{
A. Collins ${ }^{1, *}$, J. Unruh ${ }^{1}$, T. Houser ${ }^{1}, \mathrm{~S}$. Stroda ${ }^{1}$ \\ ${ }^{1}$ Kansas State University, Manhattan, United States
}

Objectives: Consumers have the opportunity to purchase steaks consisting of different quality grades from different retail outlets that may vary in tenderness. Therefore, the purpose of this study was to determine Warner-Bratzler shear force (WBSF) and cooking characteristics of top loin (strip) steaks available for purchase from self-serve display cases in grocery store outlets throughout the year.

Materials and Methods: Self-serve display steaks $(n=311)$ were purchased from four local grocery stores. Six steak types were purchased weekly from March, 2014 through February, 2015. They included branded Premium Choice (BPC1), branded Premium Choice from a second store (BPC2), Premium Choice steaks from a third store (PC), Choice steaks (C), non-grade specified steaks (NS), and branded natural (BN) steaks. The Premium Choice specifications required modest or higher marbling. The fifty-two weekly observations for each steak type were divided into four seasons of spring (March-May), summer (June-August), fall (September-November), or winter (December-February) for analysis. The day following the purchase, steaks were cooked using a Blodgett (model DFC-102 CH3) convection oven preheated to $163^{\circ} \mathrm{C}$. Steak temperatures were monitored using a Doric temperature recorder attached to copper-constantan thermocouples. Thermocouples were placed in the geometric center of the steak, and steaks were removed from the oven once they reached an internal temperature of $70^{\circ} \mathrm{C}$. Steaks were then held at a refrigerated temperature $\left(2-4^{\circ} \mathrm{C}\right)$ for at least 12 hours prior to coring ( 8 cores per steak) and shearing. Steaks were cored parallel to the muscle fiber orientation using a $1.27-\mathrm{cm}$ corer, and sheared using an Instron Universal Testing Machine (model 5569) with a Warner-Bratzler shear force Vshaped blade attachment. Cooking losses and time were recorded for each steak. Data were analyzed as a completely randomized design with a 6 (steak type) $\times 4$ (season) factorial arrangement of treatments using the Mixed procedure of SAS 9.3.

Results: As expected, top loin steaks with higher quality classifications generally had more observed marbling than those with lower quality classifications (PC and BPC1 $>\mathrm{BPC} 2>\mathrm{C}>\mathrm{NS}>\mathrm{BN}, P<0.05)$. In a steak type $\mathrm{x}$ season interaction $(P$ $=0.03)$ for WBSF, $C$ steaks during the winter had lower $(P<0.05)$ WBSF values than those during summer and fall. For NS steaks, winter steaks had lower $(P<0.05)$ WBSF values than spring steaks. For BN steaks, summer steaks had lower $(P<0.05)$ WBSF values than spring and winter steaks. During the spring, PC and BPC1 had lower $(P<0.05)$ WBSF values than NS and BN; and BPC2 had lower $(P<0.05)$ WBSF values than NS. For summer, PC, BN, and BPC1 had lower $(P<0.05)$ WBSF values than C. For fall, BPC2 had lower $(P<0.05)$ WBSF values than NS, BN, and C; and BPC1 had lower $(P<0.05)$ WBSF values than $C$ steaks. For winter, PC, BPC1, BPC2, and C steaks had lower WBSF values than BN steaks. Percentages of cooking loss were lower $(P<0.05)$ for PC, BPC1, BPC2, and NS steaks than C steaks; 
and PC steaks had lower $(P<0.05)$ cooking losses than BN steaks. Summer steaks had lower $(P<0.05)$ cooking losses than spring steaks.

Conclusion: Higher quality top loin steaks generally have greater amounts of marbling, are more tender (lower WBSF) and are more consistent in tenderness throughout the year than lower quality steaks.

Keywords: beef, retail, season, shear force, steak 


\section{Meat and Poultry Quality}

78

\section{EFFECTS OF VARYING CORN OR SOYBEAN CO-PRODUCT INCLUSION IN FINISHING DIETS OF FEEDLOT HEIFERS ON CARCASS CHARACTERISTICS, FRESH AND PROCESSED MEAT QUALITY}

M. Nelson ${ }^{1, *}$, J. Johnston ${ }^{1}$, A. DiCostanzo ${ }^{1}$, R. Cox ${ }^{1}$

${ }^{1}$ Animal Science, University of Minnesota - Twin Cities, St. Paul, United States

Objectives: The impact of using corn or soybean co-product in high or low corn grain finishing diets of feedlot heifers was evaluated using forty-four purebred Limousin heifers.

Materials and Methods: Heifers were randomly assigned to one of four dietary treatments (11 per treatment) that included: $65 \%$ corn grain diet with $20 \%$ modified distillers grains with solubles (HI+MDGS); $65 \%$ corn grain diet with a combination of $15.2 \%$ soy glycerin and soybean hulls (HI+SOY); $25 \%$ corn grain diet with $60 \%$ MDGS (LO+MDGS); or $25 \%$ corn grain diet with 40\% MDGS and 15.2\% SOY (LO+MDGS+SOY). All heifers received melengestrol acetate and Rumensin. Experimental unit was individual heifer, as all animals were fed individually using a Calan gate system. Heifers were fed finishing diets for $129 \mathrm{~d}$ and were humanely harvested at a commercial facility. Hot carcass weight $(\mathrm{HCW})$; 12th rib back fat (BF); rib eye area (REA); percent kidney, pelvic, and heart fat (KPH); and marbling score were collected $48 \mathrm{~h}$ postmortem by trained plant personnel. Strip loins (IMPS \#180) were collected and fabricated into $2.54 \mathrm{~cm}$ steaks for evaluation of drip loss, Warner-Bratzler shear force, retail shelf life evaluation (subjective and objective), and sensory evaluation. Shoulder clods (IMPS \#114) were collected and ground twice $(0.375 \mathrm{~cm}$ plate) to create ground beef and bologna, both of which were evaluated for retail shelf life (subjective and objective).

Results: There was no treatment effect for HCW $(P=0.37)$, BF $(P=0.10), \operatorname{REA}(P=0.63), \mathrm{KPH}(P=0.67)$, or marbling score $(P=0.18)$. Drip loss did not differ among treatments $(P=0.85)$. Warner-Bratzler shear force values of steaks from $\mathrm{HI}+\mathrm{SOY}$ were lower $(3.17 \mathrm{~kg})$ than LO+MDGS+SOY $(3.79 \mathrm{~kg} ; \mathrm{P}=0.02)$. Treatment did not affect subjective scores for lean color $(P=0.06)$, surface discoloration $(P=0.19)$, and overall appearance $(P=0.52)$ or objective scores for $L^{*}(P=$ $0.32), a^{*}(P=0.41)$, and $b^{*}(P=0.25)$ of steaks. Treatment did not affect overall liking $(P=0.59)$, flavor liking $(P=0.78)$, texture liking $(P=0.38)$, juiciness $(P=0.56)$, or off flavor $(P=0.89)$ of steaks. Subjective toughness ratings of steaks from $\mathrm{HI}+$ MDGS were higher than LO+MDGS (10.54 and 9.11 respectively; $P=0.02$ ). $L^{*}$ values for $25 \%$ corn diets were higher than $65 \%$ corn diets $(P<0.01)$ in ground beef. Treatment did affect surface discoloration $(P<0.01)$ in ground beef, with $\mathrm{HI}+\mathrm{SOY}$ having the highest subjective value (6.21). Treatment affected surface discoloration $(P=0.01)$ in ground beef, with $\mathrm{HI}+\mathrm{SOY}$ having the highest mean subjective value (6.21). Treatment did have an effect on overall appearance $(\mathrm{P}=<.01)$ in ground beef, with $\mathrm{HI}+\mathrm{SOY}$ having the highest mean subjective value (4.20). Treatment had no effect on $a^{*}(P=0.62)$ or $b^{*}(P=0.43)$ in ground beef. Treatment did not affect lean color $(P=1.00)$ or overall appearance $(P=1.00)$ subjective mean values or $a^{*}(P=0.89)$ or $b^{*}(P=0.82)$ in bologna. LO+MDGS had a higher mean subjective 
surface discoloration value (9.38) and $L^{*}$ (55.22) compared to all other dietary treatments $(P<0.01$ and 0.01 , respectively) in bologna.

Conclusion: Results indicate feeding $40 \%$ MDGS had no effect on carcass traits and fresh meat quality. However, feeding $60 \%$ MDGS detrimentally affected processed meat quality, but $15.2 \%$ soy co-product inclusion decreased these negative effects.

Keywords: beef, modified distillers grains, quality, soy co-product 


\title{
Meat and Poultry Quality
}

79

\section{EFFECTS OF FINISHING METHOD ON TRAINED PANEL ASSESSMENT OF BEEF FROM MATURE CULL COWS}

\author{
B. C. Hutto ${ }^{1, *}$, D. A. Gredell ${ }^{1}$, T. G. O'Quinn ${ }^{2}$, J. C. Brooks ${ }^{1}$, M. F. Miller ${ }^{1}$
}

${ }^{1}$ Texas Tech University, Lubbock, ${ }^{2}$ Kansas State University, Manhattan , United States

Objectives: Beef steaks from mature cow carcasses finished on a forage-based maintenance diet prior to harvest are associated with negative palatability attributes. The objective of this study was to evaluate the potential mitigation of these negative factors by finishing mature cows on a high-energy diet post-production and prior to harvest.

Materials and Methods: Beef strip loins from two marbling score groups [Slight (SL) and Traces/Practically Devoid (TR/PD)] across three beef types [young fed (YF), mature fed (MF), and mature un-fed (MU)] were collected in commercial processing facilities. MF cattle were fed a high-energy diet for 100 to 120 days and young fed cattle were selected as commercially available. The maturity of the carcasses, as well as the quality grade data were collected by trained personnel from Texas Tech University at the time of product selection. Strip loins were fabricated into $2.5 \mathrm{~cm}$ thick steaks, vacuum packaged, and aged 21 days prior to being frozen at $-20^{\circ} \mathrm{C}$. Samples were evaluated for tenderness, juiciness, flavor and off-flavor presence by a trained descriptive panel (AMSA, 1995). Steaks were cooked to an internal temperature of $71^{\circ} \mathrm{C}$ using a gas radiant broiler and cut into $1 \mathrm{~cm}$ cubes, with each panelist receiving 2 to 3 pieces. The panelists were asked to evaluate each sample using a verbally anchored $100 \mathrm{~mm}$ line scale $(0=$ extremely dry/tough/unbeef-like; 100 = Extremely juicy/tender/beef-like) for the following attributes: initial juiciness, sustained juiciness, initial tenderness, sustained tenderness, beef flavor, beef flavor intensity, and off flavor intensity. Data were analyzed using the GLIMMIX procedure of SAS as a $2 \times 3$ factorial design with marbling score group and beef type as the fixed effects and panel time as a random effect.

Results: There was no interaction between marbling score and beef type for juiciness or tenderness ratings $(P>0.05)$. However, marbling score impacted juiciness and tenderness ratings $(P \leq 0.05)$, where beef type influenced tenderness scores $(P<0.05)$. Trained panelists rated SL steaks greater for both initial and sustained juiciness $(P<0.05)$ as well as initial and sustained tenderness $(P<0.05)$ compared to TR/PD steaks. Trained panelists detected a difference $(P<0.05)$ across all three maturity groups for both initial and sustained tenderness, with YF rated most tender, MF rated intermediate, and MU rated least tender. An interaction between marbling score and beef type was detected for both beef flavor and off-flavor intensity $(P<0.05)$. Steaks from MU cattle with TR/PD marbling had the least beef-like flavor $(P<$ $0.05)$ with the greatest off-flavor intensity $(P<0.05)$ compared to all other treatment group combinations. Trained panelists rated SL steaks greater for beef-like flavor intensity compared to TR/PD $(P<0.05)$.

Conclusion: In conclusion, marbling score had the largest effect on trained panel scores. Panelists scored SL steaks higher than TR/PD steaks for all palatability traits. Additionally, finishing mature cows on a high-energy diet increased 
panelist scores for tenderness; however, steaks from both mature beef types were still rated less tender than steaks from young cattle.

Keywords: beef quality, carcass maturity, cull-cow, grain-finished, palatability 


\section{Meat and Poultry Quality}

80

\section{EFFECT OF FREEZING ON WARNER-BRATZLER SHEAR FORCE OF TOP LOIN STEAKS PURCHASED AT RETAIL GROCERY STORES}

A. Collins ${ }^{1, *}$, J. Unruh ${ }^{1}$, T. Houser ${ }^{1}$, S. Stroda ${ }^{1}$

${ }^{1}$ Kansas State University, Manhattan, United States

Objectives: The objective of this study was to determine the impact of freezing on Warner-Bratzler shear force (WBSF) and cooking characteristics of top loin steaks purchased from grocery store outlets.

Materials and Methods: Packages $(n=125)$ containing two top loin (strip) steaks were purchased in different weeks between March, 2014 to February, 2015 from self-serve display cases in local grocery store outlets. Steak treatments included Premium Choice (modest marbling or higher, PC), Choice (C), and non-grade specified (NS) steaks. After purchase, marbling scores for each steak were estimated by experienced panelists. One steak was randomly selected from each package and cooked the following day (fresh, non-frozen) while the other steak was vacuum-packaged and frozen at $-20^{\circ} \mathrm{C}$ for two weeks. These frozen steaks were thawed at $2-4^{\circ} \mathrm{C}$ for $24 \mathrm{~h}$ prior to cooking. Fresh (non-frozen) and previously frozen steaks were cooked using a Blodgett (model DFC-102 CH3) convection oven preheated to $163^{\circ} \mathrm{C}$. Steak temperatures were monitored using a Doric temperature recorder attached to copper-constantan thermocouples. Thermocouples were placed in the geometric center of the steak, and steaks were removed from the oven once they reached an internal temperature of $70^{\circ} \mathrm{C}$. The steaks were then held at a refrigerated temperature $\left(2-4^{\circ} \mathrm{C}\right)$ for 12 hours prior to coring (8 cores per steak) and shearing. Steaks were cored using a 1.27-cm corer, and sheared using an Instron Universal Testing Machine (model 5569) with a Warner-Bratzler shear force blade attachment. Data were analyzed using a completely randomized design with steak type serving as the whole plot and condition as the split-plot using the Mixed procedure of SAS 9.3.

Results: A greater $(P<0.05)$ amount of marbling was observed for $\mathrm{PC}$ steaks than $\mathrm{C}$ steaks; and $\mathrm{C}$ steaks exhibited a greater $(P<0.05)$ amount of marbling than NS steaks. Warner-Bratzler shear force values were lower $(P<0.05)$ for PC steaks than NS and C steaks. Percentages of cooking loss were higher $(P<0.05)$ for $\mathrm{C}$ steaks than PC steaks. Cooking time was longer $(P<0.05)$ for $C$ steaks than PC and NS steaks. Previously frozen steaks $(3.16 \mathrm{~kg})$ had lower $(P<0.05)$ WBSF values than fresh (non-frozen) steaks $(3.35 \mathrm{~kg})$. However, frozen steaks had higher $(P<0.05)$ cooking losses and longer cooking times than fresh steaks.

Conclusion: Previously-frozen top loin steaks are more tender (lower WBSF) than fresh (non-frozen) steaks. Additionally, steaks that are frozen for two weeks have higher cooking losses and take longer to cook than fresh steaks. 
Keywords: Beef, Freezing, retail, shear force, steaks 


\title{
Meat and Poultry Quality
}

81

\section{CULL HAZELNUTS AS A LIPID SOURCE IN HOG FINISHING RATIONS: EFFECTS ON PORK SHELF-LIFE AND FATTY ACID COMPOSITION}

\author{
A. Lowder ${ }^{1, *}$, N. B. Parker ${ }^{1}$, M. Kennedy ${ }^{1}$, D. Keys ${ }^{2}$, C. Mireles DeWitt ${ }^{2}$, J. Killefer ${ }^{1}$
}

${ }^{1}$ Animal \& Rangeland Sciences, Oregon State University, Corvallis, ${ }^{2}$ Seafood Research and Education Center, Oregon

State University, Astoria, United States

Objectives: It is common for hog diets in the United States to contain lipid sources high in polyunsaturated fatty acids, especially linoleic acid (18:2). This can result in greater deposits of linoleic acid in pork fat depots, contributing to increased lipid oxidation potential, high n-6/n-3 fatty acid ratio and increased fat softness. These factors lead to detrimental effects on shelf life, nutritional impact on humans and decreased yields. The hazelnut is a crop rich in nutritionally beneficial oleic acid (18:1) and $\alpha$-tocopherol. A cull segment of this crop comes from hazelnuts considered to be unmarketable to humans represents a relatively low-cost potential feedstuff for livestock. Altering the fatty acid profile of pork to reduce proportions of linoleic acid and increase oleic acid could allow for improved shelf life and a beneficial nutritional profile. To this end, we sought to explore the effects of adding cull hazelnuts as a lipid source to hog diets on pork shelf-life and fatty acid composition.

Materials and Methods: Cull hazelnuts ( $95 \%$ kernel/5\% shell) were ground and used to replace a commercial pork finishing ration at 0,15 or $30 \%(\mathrm{H0}, \mathrm{H} 15$ or $\mathrm{H} 30$, respectively) of the diet. Hogs (5/diet, avg. $97 \mathrm{Kg})$ were fed $a d$ libitum individually for $42 \mathrm{~d}$, then slaughtered. Loins were removed $72 \mathrm{hr}$ postmortem and held at $3^{\circ} \mathrm{C}$ in vacuum packaging for $4 \mathrm{~d}$, then sliced into $2.54 \mathrm{~cm}$ thick chops. Chops were overwrapped with $\mathrm{O}_{2}$ permeable film and placed into a simulated retail display with continuous fluorescent lighting (3500K CCT, 1600-2200 lux) and held at $3{ }^{\circ} \mathrm{C}$. Color was monitored daily with a portable spectrophotometer and samples were pulled at days $0,2,4$ and 6 for determination of lipid oxidation by thiobarbituric acid reactive substances (TBARS). Additional samples were taken to determine fatty acid composition, $\alpha$-tocopherol content and total phenols. Data were analyzed as a completely randomized design with individual hog serving as the experimental unit. Diet treatment was the main effect with analysis day serving as a repeated effect in the case of shelf-life analyses.

Results: Redness (CIE $a^{*}$ ) declined over storage time for all treatments, but rate of decline was not different between treatments. Lipid oxidation (TBARS) was suppressed ( $P<0.05$ ) by $44-59 \%$ at $\mathrm{d} 4$ and 6 by both $\mathrm{H} 15$ and $\mathrm{H} 30$ compared to $\mathrm{H} 0$. Total phenols were not different ( $P>0.05$ between diet treatments but $\alpha$-tocopherol levels were 83 and $132 \%$ higher $(P<0.05)$ in $\mathrm{H} 15$ and $\mathrm{H} 30$, respectively, than $\mathrm{H} 0$. Levels of palmitic acid (16:0) were reduced $(P<0.05)$ in $\mathrm{H} 30$ pork while oleic acid (18:1) was increased $(P<0.05)$ from $43.7 \%$ to $48.2 \%$ and $50.4 \%$ in $\mathrm{H} 15$ and $\mathrm{H} 30$, respectively. No significant changes $(P>0.05)$ in linoleic acid (18:2) or $n-6 / n-3$ ratio were detected. 
Conclusion: Overall, pork fatty acid composition was improved nutritionally through increases in oleic acid (18:1) by hazelnut feeding, but no other concrete benefits were found in this study. The suppression of TBARS was likely due to increased $\alpha$-tocopherol levels in muscle but was not sufficient to produce noticeable effects on shelf life when measured by color change alone.

Keywords: Alternative feedstuff, Color stability, Hazelnut, Pork 


\section{Meat and Poultry Quality}

82

\section{EFFECTS OF USDA QUALITY GRADE AND DEGREE-OF-DONENESS ON VOLATILE COMPOUNDS FROM BEEF STRIP STEAKS}

K. Gardner ${ }^{1, *}$, J. Legako ${ }^{1}$

${ }^{1}$ Nutrition, Dietetics, and Food Science, Utah State University, Logan, United States

Objectives: Flavor is one of the primary palatability traits of importance to beef. Volatile compounds are known to influence flavor perception and to develop with cooking, however, little data is available regarding the development of volatile compounds related to beef degree-of-doneness (DOD). Furthermore, USDA quality grade (QG) or intramuscular fat content is known to impact beef flavor. Therefore, the objective of this study was to determine any interacting or main effects of quality grade and degree of doneness on flavor related volatile compounds.

Materials and Methods: Paired strip loins were collected from three QG (Prime, Low Choice, Standard; $n=8 / Q G$ ). On day 21 post-mortem, $2.54 \mathrm{~cm}$ thick steaks were cut from each loin. Steaks were then randomly assigned to six degrees of doneness $\left(4,25,5560,71\right.$, and $\left.77^{\circ} \mathrm{C}\right)$. Volatile compounds (picograms per gram) were collected by head space solid phase microextraction from samples tempered in refrigerated temperatures (3$\left.5^{\circ} \mathrm{C}\right)$, room temperature $\left(24-26^{\circ} \mathrm{C}\right)$, or cooked on an electric clamshell-style grill. Collected samples were subsequently determined by gas chromatography mass spectrometry. Prominent compounds known to be the result of the Maillard reaction or lipid degradation were retained for comparison.

Results: Differences between QG, DOD, or their interaction were determined by analysis of variance using a sub-plot design, where QG was the whole plot and DOD was the sub-plot. Effects were considered different at $\alpha=0.05$. An interaction was determined for compounds of both the Maillard reaction and lipid degradation pathways. Maillard reaction compounds (methyl pyrazine, 2,5-dimethyl pyrazine, and trimethyl-pyrazine) were greatest $(P<0.05)$ in prime steaks at higher DOD, in comparison with Low Choice and Standard steaks having common, lower concentrations $(P<0.05)$ at each DOD. Therefore, the abundance of each of these compounds at a particular DOD depended on the quality grade of a particular steak. Lipid degradation compounds differed by QG dependent on DOD $(P<0.05)$. Acetic acid methyl ester and butanoic acid methyl ester were greatest $(P<0.05)$ in Low Choice and Standard steaks at $4^{\circ}$. Meanwhile, butanoic acid and hexanoic acid were greatest $(P<0.05)$ in Prime steaks at $77^{\circ}$.

Maillard reaction compounds (acetaldehyde, dimethyl disulfide, and benzaldehyde) were also influenced by QG independent of DOD, where higher $(P<0.05)$ quantities were determined in prime steaks. Hexanal, a lipid degradation compound, was highest $(P<0.05)$ in standard steaks. Maillard reaction compounds also varied across DOD. Acetaldehyde was highest $(P<0.05)$ in $4^{\circ} \mathrm{C}$ steaks. Dimethyl disulfide and benzaldehyde were greatest $(P<0.05)$ in $77^{\circ} \mathrm{C}$ steaks. Lipid degradation compounds (butanoic acid, methyl ester; butanoic acid; 1-octen-3-ol; and octanoic acid) also varied according to DOD. These compounds were greatest $(P<0.05)$ in $4^{\circ} \mathrm{C}$ steaks, while other lipid degradation compounds were highest in $55^{\circ}$ steaks or $25^{\circ}$ steaks. 
Conclusion: Previous work has primarily utilized model systems to study the development of volatile flavor compounds from beef. This data set reveals that basic understanding of flavor development may be attained from beef steaks.

Furthermore, these data reveal that both quality grade and degree of doneness impact important volatile compounds.

Therefore, these data have potential for management of important flavor contributing compounds as a function of cooking and QG.

Keywords: degree of doneness, quality grade, Volatile 


\section{Meat and Poultry Quality}

83

\section{EFFECT OF BEEF FINISHING DIET AND RETAIL DISPLAY ON OXIDATIVE VOLATILE COMPOUNDS AND THEIR RELATIONSHIP WITH BEEF COLOR}

T. Gardner 1,* and J. Legako, T. Murphy, K. Yardley, A. Chail, J. MacAdam

${ }_{1}^{1}$ Nutrion and Food Science, Utah State University, Logan, United States

Objectives: Beef volatiles compounds, associated with oxidation, were determined from beef ribeye steaks (Longissimus thoracis) from cattle finished on three different diets having had undergone simulated retail display for seven days.

Materials and Methods: Beef steaks originated from cattle of three finishing diets, conventional feedlot (FL), perennial legume birdsfoot trefoil (Lotus corniculatus, BFT), and a grass, meadow brome (Bromus riparius Rehmann, GF). Six cattle per finishing diet were fed diets for 18 months prior to harvest. Ribeye steaks (2.5-cm thick) were produced from ribeye rolls, (IMPS \# 1112, n=6) aged 14 days postmortem and packaged on foam trays overwrapped with gas permeable polyvinyl-chloride. Packages were placed in a refrigerated cooler $\left(2-4^{\circ} \mathrm{C}\right)$ under continuous fluorescent lighting $(1920 \mathrm{Im})$ and monitored for seven days with daily rotation. Samples were taken on days 0, 3 and 7 and frozen and homogenized for analysis of thiobarbituric acid reactive substances (TBAR, $\mathrm{mg} / \mathrm{g}$ ) and volatile compounds (HS-SPME GC-MS). Prior to steak homogenization, steak surface color was monitored by instrumental measurement $\left(L^{*}, a^{*}, b^{*}\right)$ and trained panelists $(n \geq 8)$ which evaluated steaks for redness (8-point hedonic scale, $1=$ bright red and $8=$ brown) and discoloration (6-point hedonic scale, 1 = none, $0 \%$ and $6=$ extensive discoloration, $81-100 \%)$. The simulated retail display, instrumental and subjective color analysis, and TBAR analysis were determined and reported in previous studies. Volatile analysis was done to compare the oxidative compounds to the previously reported data to determine significance and correlation to product oxidation. Volatile compounds were compared by one-way ANOVA. The correlations were determined using Pearson Correlations.

Results: Diet was determined to affect several volatile compounds associated with lipid degradation (octane, hexanal, 1 octen-3-ol, hexanoic acid, 1-heptanol, octanal, nonanal, 1-hexanol, 1-pentyl-furan and heptanal ( $\leq 50.05)$. Greater quantities were found in feedlot samples as compared to the BFT and GF. Two compounds [1-penten-3-ol $(P<0.05)$ and 3-hydroxy-2-butanone $(P<0.01)$ ] showed a change over the seven days of display. Interestingly, 1-penten-3-ol showed a decrease $(P<0.05)$ from day 0 to day 7 while 3-hydroxy-2-butanone showed an increase $(P<0.05)$. Correlations were found between multiple compounds (see Table 1) and the TBARS, $L^{*}$ and $a^{*}$ values ( $r$-values indicated in Table 1). Image: 
Table 1.

\begin{tabular}{|c|ccc|}
\hline \multicolumn{2}{|c}{ TBARS } & $\mathrm{L}^{*}$ & $\mathrm{a}^{*}$ \\
\hline Octare & $0.47^{* * *}$ & $0.44^{* *}$ & $-0.30^{*}$ \\
rexanal & $0.52^{* * *}$ & $0.43^{* *}$ & $-0.37^{*}$ \\
1-texanol & $0.32^{*}$ & $0.33^{*}$ & -0.20 \\
Heptanal & $0.40^{* *}$ & $0.40^{* *}$ & $-0.35^{*}$ \\
1-Octen-3-ol & $0.64^{\cdots *}$ & $0.46^{\cdots *}$ & $-0.42^{* *}$ \\
1-Heptenol & $0.39^{* *}$ & $0.41^{* *}$ & -0.21 \\
Furan,1-penty|- & $0.51^{\cdots *}$ & $0.46^{\cdots *}$ & -0.34 \\
Octanal & $0.53^{\cdots *}$ & $0.54^{* *}$ & $-0.41^{* *}$ \\
Noranal & $0.50^{* *}$ & $0.49^{* *}$ & $-0.35^{*}$ \\
\hline
\end{tabular}

(level of significance: ${ }^{*}<0.05,{ }^{\wedge *}<0.01,{ }^{* \star}<0.001$ )

Conclusion: Concentration of TBARS has long been used as a measurement of lipid oxidation of meat products.

Previously hexanal has been suggested to be a good indicator of oxidation. These results support this sentiment and suggest that alternative compounds may be utilized as measures of oxidation. These results also revealed that diet was highly impactful to development of oxidative compounds. It has previously been suggested that forage finishing diets provide greater residual antioxidants in beef. While these results are in agreement with that conclusion further measures are required to determine any antioxidant capacity differences between diets.

Keywords: Beef color, Finishing Diet, oxidation 


\title{
Meat and Poultry Quality
}

84

\section{COMPARISON OF PROXIMATE COMPOSITION, PH AND FATTY ACIDS OF BEEF RIBEYE STEAKS FROM FORAGE AND CONVENTIONAL FEEDLOT FINISHED CATTLE}

\author{
A. Chail ${ }^{1, *}$, J. F. Legako ${ }^{1}$, S. Martini ${ }^{1}$, B. Ward ${ }^{1}$, J. MacAdam ${ }^{2}$ \\ ${ }^{1}$ Nutrition, Dietetics and Food Science, 2Department of Plant, soild and climate, Utah State University, Logan, United \\ States
}

Objectives: To study the effects of dietary treatments on the chemical properties of beef. Proximate data and fatty acids (FA; $\mathrm{mg} / \mathrm{g}$ ) were determined for ribeye steaks (Longissimus thoracis) from forage and conventional feedlot (FL) finished cattle.

Materials and Methods: Forage diets included a perennial legume, birdsfoot trefoil (Lotus corniculatus, BFT), and a grass, meadow brome (Bromus riparius Rehmann, GF). Eighteen steers were divided among these three diets, six in each group. All the animals were slaughtered at the same age, 18 months. Additionally, six each from representative retail forage (USDA Certified Organic Grass-fed, COGF) and conventional beef (USDA Top Choice, TC) were studied. Ribeye steaks of 2.5-cm thickness were produced from ribeye rolls (IMPS \# 112, $n=6$ ) aged 14 days postmortem. Diet effects were determined by one-way analysis of variance with a significance level of 0.05 .

Results: Dietary treatments affected moisture percent $(P<0.001)$, percentage of ash $(P=0.009)$, intramuscular fat (IMF) $(P<0.001)$ and protein percentages $(P=0.008)$. The IMF percentage was highest $(P<0.05)$ in TC $(7.94)$ followed by $\mathrm{FL}$ (5.84) which was similar $(P>0.05)$ but greater $(P>0.05)$ than BFT (4.43). The lowest IMF percentages were observed in GF (2.91) and COGF (2.21). However, BFT was similar $(P>0.05)$ to GF though greater $(P<0.05)$ than COGF. There was no difference in $\mathrm{pH}(P=0.080)$ between treatments. Saturated fatty acids $(\mathrm{SFA})$ and monounsaturated fatty acids (MUFA) concentrations were found to be similar $(P>0.05)$ in TC and FL but greater $(P<0.05)$ than GF and COGF. For BFT, concentrations were found to be intermediate to FL and GF. Polyunsaturated fatty acid (PUFA) concentrations were similar $(P>0.05)$ in BFT(2.25), FL(2.04), GF(1.67) and COGF(1.41) but were lower $(P<0.05)$ than TC (4.05). Generally all FA concentrations increased along with increases in percentage of IMF fat of conventional feedlot beef. When FA proportions were explored the percentages of PUFA and MUFA were dependent on diet $(P<0.001)$. Where the PUFA percentage was observed to be higher $(P<0.05)$ in forage finished beef, including conjugated linoleic acid (CLA). The ratio of PUFA to SFA (P:S) was found to be highest in COGF (0.19) followed by GF (0.12).

Conclusion: The P:S ratio has been concluded to have important nutritional implications. In this study diet regimen of cattle greatly impacted P:S ratio. These results are in agreement with many past studies comparing feedlot finished beef with forage finished beef. However, beef finished on BFT possessed a chemical composition more similar to feedlot beef. This implies that specific forages impact final beef composition and quality. 
Keywords: Beef, birdsfoot trefoil, fatty acids, proximate, ribeye 


\section{Meat and Poultry Quality and Composition - Measurement and Prediction}

85

\section{ARE SARCOMERE LENGTH AND MIOFIBRILAR FRAGMENTATION INDEX PREDICTORS FOR SENSORY AND INSTRUMENTAL TENDERNESS OF AGED BEEF?}

C. T. Battaglia ${ }^{1}$, G. F. Vilella ${ }^{1}$, B. I. Sousa ${ }^{1}$, C. L. Gomes ${ }^{1}$, P. E. de Felicio ${ }^{1}$, S. B. Pflanzer 1,*

1Department of Food Technology, State University of Campinas, Campinas, Brazil

Objectives: Previous studies have shown miofibrilar structure may affect meat tenderness. Miofibrilar fragmentation index (MFI) is a consequence of meat proteolysis, while sarcomere length (SL) is associated with chilling conditions during the development of rigor mortis. Therefore, both measurements may be associated with meat tenderness. This work aim to evaluate how MFI and SL can predict instrumental and sensory tenderness of beef aged for up to 21 days post mortem. Materials and Methods: Beef striploin ( $\mathrm{N}=10)$ of Nellore young bulls were collected 4 days post mortem. Each loin was cut in three parts, one for initial aging time (4 days aging), and the other two were vacuum packed and aged for 14 and 21 days after slaughter $\left(3^{\circ} \mathrm{C}\right)$. Steaks were analyzed for $\mathrm{pH}$, MFI and WBSF (Warner Bratzler shear force) in all samples. Initial and sustained sensory tenderness and juiciness (IT, ST, IJ and SJ; eight point scale) were carried out in samples aged 14 and 21 days. Meat aged 4 days was analyzed for SL. The statistical analyses were performed by ANOVA one way, and the results were expressed as mean \pm SEM. Means were tested by Tukey test. Simple correlation coefficients were estimated.

Results: SL ranged from 1.31 to $1.85 \mu \mathrm{m}(1.67 \pm 0.05 \mu \mathrm{m})$. There was no difference $(P>0.05)$ on sensory attributes between 14 and 21 day aged samples (IJ - 5.5 \pm 0.1 , SJ $-5.3 \pm 0.1$, IT $-6.1 \pm 0.2$ e ST $-5.9 \pm 0.2$ ). During aging, pH decreased linearly from 4 to 21 days $(5.7,5.6$ and $5.5 ; P>0.05)$. $A$ trend $(P=0.12)$ for increasing MFI was found during aging from 4 to 21 days $(66.2 \pm 6.1,72.0 \pm 4.9$ and $81.5 \pm 5.2)$. There was a decreasing $(P<0.05)$ of WBSF from $4(4.9 \pm 0.6 \mathrm{~kg})$ to 14 days $(3.6 \pm 0.3 \mathrm{~kg})$, and to 21 days $(2.9 \pm 0.2 \mathrm{~kg} ; \mathrm{P}=0.07)$. Correlations between MFI, SL and sensory attributes were not significant $(P>0.05)$, but it was observed a negative correlation between WBSF and MFI (-0.60; $P<0.01 ; 4$, pooled 14 and 21 days), as well as between WBSF and sensory tenderness (IT: -0.79 and ST: -0.73 ; P<0.01; pooled 14 and 21 days) when analyzing only samples aged 14 and 21 days. When evaluating the correlation between SL, measured at day 4 , the following coefficients with WBSF were found for samples aged $4(-0.58 P>0.05 ; n=10), 14(-0.73 P<0.05 ; n=10)$ and 21 ($0.16 ; \mathrm{P}>0.05 ; \mathrm{n}=10$ ).

Conclusion: These data suggest SL, at 4 days of aging, can be a good predictor of instrumental tenderness of samples aged 14 days, while MFI is associated with instrumental tenderness at each evaluation time.

Keywords: Myofibrilar fragmentation index, sarcomere length, Warner Bratzler shear force 


\title{
Meat and Poultry Quality and Composition - Measurement and Prediction
}

86

\section{BENCHMARKING VENEZUELAN GRADE STANDARDS OF GRASS-FED BRAHMAN-INFLUENCED BULLS, HEIFERS AND COWS IN CARCASS PERFORMANCE AND BEEF PALATABILITY}

\author{
A. R. Rodas-Gonzalez ${ }^{1, *}$, N. Huerta-Leidenz ${ }^{2}$, N. Jerez-Timaure ${ }^{3}$
}

${ }^{1}$ Animal Science, University of Manitoba, Winnipeg, Canada, 2U.S. Meat Export Federation-México, Mexico DF, Mexico, ${ }^{3}$ Facultad de Agronomia, Universidad del Zulia, Maracaibo, Venezuela, Bolivarian Republic Of

Objectives: To benchmark A/B-graded heifers $(n=21)$ and C-graded cows $(n=18)$ with respect to B-graded bull $(n=17)$ carcasses on carcass traits, cutability and palatability of longissimus thoracis.

Materials and Methods: Purebred Brahman cull heifer and cows (2.5 and 4.5 years old; respectively) and crossbred Brahman bulls (unknown age) were finished on native grass pasture (savannah), slaughtered (average live weight $437 \mathrm{~kg}$ ) and graded according to Venezuelan grading system (A, B and C; based on maturity, marbling and subcutaneous fat cover scores). At $48 \mathrm{~h}$ postmortem, four ribeye steaks (2.54-cm thick) were removed from the longissimus thoracis muscle (posterior end) from the right side of each carcass, vacuum-packaged and immediately frozen at $-30^{\circ} \mathrm{C}$ for WarnerBratzler shear force (WBSF) and sensory evaluation (8 trained panelists). The study was conducted as a completely randomized design in an incomplete factorial structure.

Results: Subcutaneous fat cover (i.e., moderate amount and even distribution over shoulder, ribs, back and legs) and marbling (i.e., slight) scores did not differ $(P>0.05)$ among sex class graded carcasses. As expected, B-graded bulls dressed heavier carcasses, with a more convex leg muscle profile and larger ribeye area (REA), and yielded the greatest $(P<0.05)$ proportion of total subprimal cuts $(78 \%)$, as compared to their female counterparts (average $76 \% ; P<0.05)$. Cgraded cows ranked second after the B-graded bulls in carcass weight and REA $(P<0.05)$; however, A/B graded heifers and C-graded cows were similar in cutout yield for most individual cuts $(P>0.05$; particularly those from the loin and round). Cookery traits (cooking loss/time) did not vary among sex class graded carcasses $(P>0.05)$. A/B heifers and $\mathrm{C}$ cows yielded a greater proportion of "tender" (WBSF $<40.13 \mathrm{~N}$; average $85 \%)$ steaks as compared to B bulls $(41 \%$; $P<$ 0.05), which were in agreement with the higher mean scores for muscle fiber tenderness, overall tenderness and connective tissue amount given by the trained panelists.

Conclusion: The superior palatability of Brahman purebred female classes indicates a marketing opportunity for adding value to their carcasses if fed under these savannah feeding conditions.

Keywords: beef, carcass grade, cull cow, eatability, shear force 


\section{Meat and Poultry Quality and Composition - Measurement and Prediction}

87

\section{USDA PROVIDES NEW AND UPDATED MEAT NUTRIENT DATA AND APPLICATIONS, THROUGH UNIVERSITY AND INDUSTRY COLLABORATIONS}

J. M. Roseland 1, ${ }^{\text {, }}$, J. R. Williams ${ }^{1}$, Q. V. Nguyen ${ }^{1}$, P. R. Pehrsson ${ }^{1}$, K. Y. Patterson ${ }^{1}$, L. D. Thompson ${ }^{2}$, D. R. Woerner ${ }^{3}$, J. C. Brooks ${ }^{2}$, J. W. Savell ${ }^{4}$, A. M. Cifelli 5 , K. B. Gehring ${ }^{4}$

${ }^{1}$ Agricultural Research Service, US Department of Agriculture, Beltsville, MD, ${ }^{2}$ Animal and Food Sciences, Texas Tech University, Lubbock, TX, ${ }^{3}$ Animal Sciences, Colorado State University, Fort Collins, CO, ${ }^{4}$ Animal Science, Texas A\&M University, College Station, TX, ${ }^{5}$ National Cattlemen's Beef Association, Centennial, CO, United States

Objectives: To present meat research and data applications released by USDA/Nutrient Data Laboratory (NDL) between 2013 and 2015 as a result of collaborations between US and international governments and university and industry scientists, demonstrating the value of scientific partnerships.

Materials and Methods: Meat composition studies were conducted by NDL scientists with industry and university collaborators, based on statistical sampling plans to obtain nationally representative samples. Chemical analyses were done by validated laboratories using approved methods and quality control procedures. Data were released in USDA's National Nutrient Database for Standard Reference (SR).

Results: 1) Vitamin $D$ and 25(OH)D data along with analytical methods information were obtained for 5 animal-based foods and a dietary supplement in a study with 4 international and US labs and the National Institutes of Health/Office of Dietary Supplements.

2) Other nutrients of public health interest were reported in studies with the Centers for Disease Control and Prevention. Sodium and other nutrients were updated for 11 highly-consumed meats [sentinel foods (SF)], and monitored for 164 other processed meats, including cured, enhanced, and lunch meats. Among 11 SF over a 3-year period, recent analytical sodium values were within $10 \%$ of previous SR values for most meats, but sodium increased by $16 \%$ and $20 \%$ for bologna and enhanced pork, respectively.

3) Nutrient data profiles for imported cuts (25 beef, $25 \mathrm{lamb}$ ) were provided in a Beef + Lamb New Zealand study. Meat and Livestock Australia, in collaboration with Texas Tech University (TTU), provided data for 8 imported lamb cuts.

4) A nationwide veal study with Colorado State University (CSU) and North American Meat Association resulted in full nutrient profiles for 7 cuts.

5) A nationwide beef study with National Cattlemen's Beef Association (NCBA), Texas A\&M University, TTU, and CSU resulted in full nutrient profiles for 32 beef cuts. Data for selected cuts were compared, showing that some combinations of cooking methods and cuts had significant effects $(p<0.05)$ on percent cooking yield, percent fat and moisture change, and protein, fat, and moisture concentrations. Furthermore, retail beef cuts from three recent NDL analytical studies were identified which met the federal "lean" criteria ( $<10 \mathrm{~g}$ total fat, $\leq 4.5 \mathrm{~g}$ saturated fat, and $<95 \mathrm{mg}$ cholesterol $/ 114 \mathrm{~g} \mathrm{raw})$. 
6) Canadian goose and ruffed grouse nutrient data resulted from a study with Cornell Cooperative Extension.

7) User-friendly on-line tools to access data were created or updated, in partnership with NCBA and others. Applications included: a) calculator generating nutrient values for ground beef products at 3 to $30 \%$ fat; b) veal and beef tables supporting on-pack nutrient label requirements; and c) cooking yield data tables for $>175$ meat and poultry items.

Conclusions: New and updated meat data from USDA/NDL have been released, the culmination of collaborations with university and industry scientists. On-line tools are available at www.ars.usda.gov/ba/bhnrc/ndl. These resources are applicable for meat scientists, dietitians and other health professionals, researchers, and government representatives for labeling, data trend evaluation, surveys, nutrition monitoring, and policy development.

\section{Conclusion:}

Keywords: Beef, Lamb, Nutrient data, Pork, Veal 


\section{Meat and Poultry Quality and Composition - Measurement and Prediction}

88

\section{TENDERNESS OF PASTURE VERSUS GRAIN FED BEEF AGED 14 AND 28 DAYS}

K. Pfeiffer 1, , , G. Mafi ${ }^{1}$, R. Ramanathan ${ }^{1}$, J. Neel ${ }^{2}$, D. VanOverbeke 1

${ }^{1}$ Animal Science, Oklahoma State University, Stillwater, ${ }^{2}$ Grazinglands Research Laboratory, ATS-USDA, EI Reno, United States

Objectives: Consumer interest in pasture versus grain fed beef has been on the rise in recent years. This interest could be sparked by the public's concerns of beef management techniques and processing impacts on the nutrition and safety of their food, as well as the environmental impact of each management type. Peaked interest in pasture versus grain fed beef has also brought into question if palatability differences exist between the two types of beef. The objective of this study was to evaluate the difference in tenderness between pasture and grain fed beef, and the effects different aging times would have.

Materials and Methods: All cattle were on forage diets during the entire stocking period. For finishing, cattle were randomly assigned to either a conventional grain based diet or pasture finished on alfalfa. Conventionally finished cattle were fed for $94 \mathrm{~d}$, and alfalfa cattle were on pasture for either 88 or $130 \mathrm{~d}$. Average age of animals at slaughter was 18.2 mon for concentrate fed and 18.9 mon for alfalfa finished. Strip loins $(n=107)$ were cut $2.54 \mathrm{~cm}$ thick and vacuumed packaged. From the loin end, the second steak was used for Warner-Bratzler (WBS) $14 \mathrm{~d}$, the fourth steak was used for Slice Shear (SS) $14 \mathrm{~d}$, the seventh steak was used for SS $28 \mathrm{~d}$, and the eighth steak was used for WBS $28 \mathrm{~d}$. The steaks were aged 14 or $28 \mathrm{~d}$ at $4^{\circ} \mathrm{C}$. At the end of each aging time, steaks were frozen at $-20^{\circ} \mathrm{C}$. Steaks were thawed at $4^{\circ} \mathrm{C} 24 \mathrm{~h}$ prior to cooking. The steaks used for WBS and SS were cooked in an impingement oven at $200^{\circ} \mathrm{C}$ to an internal temperature of $68^{\circ} \mathrm{C}$. Temperatures were measured as the steaks exited the oven, if they had not yet reached $68^{\circ} \mathrm{C}$ they were returned to the conveyor until they reached $68^{\circ} \mathrm{C}$. WBS steaks were cooled overnight at $4^{\circ} \mathrm{C}$. WBS steaks were allowed to reach room temperature prior to coring. The cores were done by hand and $1.27 \mathrm{~cm}$ in diameter cores were taken from the middle of the steak parallel to longitudinal orientation of muscle fibers so shearing action was perpendicular to the longitudinal orientation of muscle fibers. There were six cores collected per sample. For SS, the final temperature of steaks was recorded. The lateral of each steak was removed, a $1 \mathrm{~cm}$ thick, $5 \mathrm{~cm}$ long slice was cut parallel to the muscle fibers. A Warner-Bratzler Meat Shear fixture was used for WBS and a Flat Shear Blade was used for SS, these blades were attached to an Instron Universal Testing Machine (Model 5943, Instron Corporation, Norwood, MA). The crosshead speed was $200 \mathrm{~mm} / \mathrm{min}$ and software utilized was Bluehill 3. The data were analyzed using the Mixed Procedure of SAS. The aging by feeding regime interaction was tested, and no interaction was observed.

Results: For WBS, $14 \mathrm{~d}$ steaks were more tender $(\mathrm{P}<0.05)$ than $28 \mathrm{~d}$ aged steaks. However, WBS values for both treatments were well below the typically considered steak tenderness threshold of $3.5 \mathrm{~kg}, 2.04 \mathrm{~kg}$ for $14 \mathrm{~d}$ and $2.65 \mathrm{~kg}$ for $28 \mathrm{~d}$. No differences $(\mathrm{P}>0.05)$ were found between the two finishing types. For $\mathrm{SS}$, there was no significant difference 
between aging times $(P>0.05)$.

Conclusion: The results indicate there is no difference in tenderness of grass fed versus grain fed steaks. Additional research will be conducted to evaluate subjective tenderness, as well as flavor and juiciness.

Conclusion:

Keywords: Aging, Grain Fed, Grass Fed, Tenderness 


\title{
Meat and Poultry Quality and Composition - Measurement and Prediction
}

89

\section{IDENTIFYING THE INFLUENCE OF CATTLE PRODUCTION HISTORY AND LEAN MUSCLE CHARACTERISTICS ON SPECIFIC BEEF FLAVOR ATTRIBUTES.}

\author{
T. S. Adams ${ }^{1, *}$, D. R. Woerner ${ }^{1}$, J. F. Legako ${ }^{2}$, T. E. Engle ${ }^{1}$, J. D. Tatum ${ }^{1}$, R. J. Delmore ${ }^{1}$, K. E. Belk ${ }^{1}$ \\ ${ }^{1}$ Animal Science, Colorado State University, Fort Collins, 2Nutrition and Food Science, Utah State University, Logan, \\ United States
}

Objectives: Identify and characterize specific beef flavors associated with differences in cattle production history and lean muscle characteristics.

Materials and Methods: Three lean sources representing variation in collagen content, heme iron content, and muscle fiber type and 5 fat sources representing differences in animal type (F1 Wagyu-Angus, Long-Fed Holstein, Short-Fed Holstein, Long-Fed Beef Type, Short-Fed Beef Type) and a varying number of days on feed (DOF; >500d, 330-370d, 230260d, 170-200d, 90-100d respectively) were collected for this experiment. USDA Select strip loins, tenderloins, and brisket flats were collected as lean sources, and the primary muscle of each cut (Longissimus dorsi, Psoas major, Pectorales Profundl) was isolated. Fat sources were collected from a common location (subcutaneous brisket fat) from carcasses with a known type and production history. Each lean source and fat source was used in combination with oneanother in a factorial arrangement. For each lean/fat source combination, 3 separate, 10-pound batches were formulated to 70,80 , and $90 \%$ lean, respectively. Products were ground through a grinding plate with holes that were $3 \mathrm{~mm}$ in diameter. Each 10-pound batch was replicated 5 times $(n=5 ; N=225)$. Ground samples representing each batch were then formed into $30 \mathrm{~g}$ patties for analysis. Trained panelist quantified the intensity of the following flavor attributes using an unstructured $10 \mathrm{~cm}$ line scale: beefy/brothy, browned/grilled, buttery/beef fat, bloody/metallic, grassy/fishy, earthy/mushroom, nutlike/roasted, and livery/organy.

Results: Least square means were evaluated for all flavor attributes and differences among fat source, lean source, and lean percentages. Short-fed Holstein had less $(P<0.05)$ buttery flavor and nutlike flavor when compared to all 4 other cattle types. Long-fed beef has less $(P<0.05)$ buttery flavor when compared to Wagyu, Long-Fed Holstein, and ShortFed Beef cattle types. Both long-fed and short-fed beef had higher $(P<0.05)$ bloody flavors than Wagyu and short-fed Holstein cattle types. Long-fed Holstein had higher $(P<0.05)$ bloody flavors than short-fed Holstein. Long-fed beef had higher $(P<0.05)$ earthy flavors than long-fed Holstein and short-fed beef. Wagyu had higher $(P<0.05)$ nutlike flavors than long-fed Holstein and long-fed Beef. Short-fed beef and Wagyu cattle type had greater $(P<0.05)$ incidences of livery flavor versus long-fed beef, long-fed Holstein, and short-fed Holstein. For individual muscle attributes Longissimus dorsi and Pectorales profundi had higher $(P<0.05)$ beefy, browned, buttery, and nutlike flavors than Psoas major. Psoas major had higher $(P<0.05)$ bloody and livery flavors than Longissimus dorsi and Pectorales profundi. Pectorales profundi had higher $(P<0.05)$ buttery and grassy flavor compared to Longissimus dorsi. For lean percentage attributes $90 \%$ lean 
samples had higher $(P<0.05)$ bloody, grassy, earthy, and livery flavors than $80 \%$ and $70 \%$ samples. $70 \%$ samples had higher $(P<0.05)$ beefy, buttery, and nutlike flavors than the $90 \%$ and $80 \%$ samples and higher $(P<0.05)$ browned flavor than $90 \%$ samples. $80 \%$ samples had higher $(P<0.05)$ beefy, browned, buttery, and nutlike flavors than $90 \%$ samples as well as higher $(P<0.05)$ bloody, earthy, and livery flavors than $70 \%$ samples.

Conclusion: Variances in breed-type and DOF, muscle type, and lean percentage influence the flavor profile of beef.

Keywords: Beef flavor, Breed, Days on feed, Lean percentage, Muscle type 


\section{Meat and Poultry Quality and Composition - Measurement and Prediction}

90

\section{USE OF PORK LOIN QUALITY ATTRIBUTES TO DETERMINE SUBSEQUENT FRESH AND PROCESSED HAM QUALITY}

D. N. Burton ${ }^{1, *}$, D. A. Mohrhauser ${ }^{2}$, A. D. Blair ${ }^{1}$, K. R. Underwood ${ }^{1}$, R. C. Johnson ${ }^{2}$, S. M. S. Zuelly ${ }^{1}$

${ }_{1}^{1}$ Animal and Range Sciences, South Dakota State University, Brookings, ${ }^{2}$ Smithfield Foods, Denison, United States

Objectives: Product consistency is a major driver in consumer purchasing habits. While there are several quality attributes that pork consumers evaluate at the retail display case, color tends to be of great importance. Two-toned color in ham slices has been a major issue for processors and retailers for several decades, with little progress made in a way to prevent or predict this issue during the production process. The objective of this study was to determine if fresh and processed ham quality could be predicted by carcass traits and fresh loin quality attributes.

Materials and Methods: Pork carcasses $(n=163)$ were selected at a commercial processing facility to fit within a predetermined hot carcass weight (HCW), gender and backfat thickness (BF) criteria. The following data were collected from each loin: loin circumference (LCF); $1 \mathrm{hr}$ and $22 \mathrm{hr}$ loin (longissimus thoracis) pH; subjective color, marbling and firmness scores; proximate analysis; and Minolta $\mathrm{L}^{*}, \mathrm{a}^{*}$ and $\mathrm{b}^{*}$ values. Minolta $\mathrm{L}^{*}, \mathrm{a}^{*}$, and $\mathrm{b}^{*}$ on the loin (longissimus thoracis). Fresh ham measurements included: $1 \mathrm{hr}$ and $22 \mathrm{hr}$ ham (semimembranosus) $\mathrm{pH}$; and $\mathrm{L}^{*}, \mathrm{a}^{*}$ and $\mathrm{b}^{*}$ color on the buttface (gluteus medius, psoas major, iliacus, gluteus profundus, gluteus accessories, rectus femoris, and vastus lateralis), inside (gracillis and semimembranosus), outside (biceps femoris and semitendonosus), and knuckle (vastus lateralis and rectus femoris). Fresh muscles were then transported back to the South Dakota State University meat lab where three-piece boneless hams were manufactured. Processing yield, two-toned color evaluation, sensory panels, objective $L^{*}, a^{*}$ and $b^{*}$ and proximate analysis was collected for processed hams. Stepwise regression, within SAS, was used to determine predictive models for fresh and processed ham measurements using a pre-determined significance level of $P<0.05$.

Results: Fresh ham buttface and individual muscle $L^{*}, a^{*}$ and $b^{*}$ values as well at $1 \mathrm{hr}$ and $22 \mathrm{hr} \mathrm{pH}$ could be predicted from fresh loin quality attributes. Processing yield could be predicted $\left(R^{2}=0.3666\right)$ for fresh loin measurements of firmness, color, circumference, marbling, loin weight and BF. A predictive model $\left(R^{2}=0.4235\right)$ to predict processed ham $\mathrm{pH}$ was determined that consisted of gender, loin circumference, color, weight, and the categories of HCW and BF. Separate predictive models were developed for processed ham $L^{*}, a^{*}$ and $b^{*}$. The $L^{*}$ model was constructed using the variables of: loin $L^{*}, a^{*}$ and $b^{*}$; loin color score, and $B F\left(R^{2}=.4868\right)$. For $a^{*}$, loin circumference, loin color score, loin $L^{*}, a^{*}$ and $b^{*}$ values, $B F$ category, percent moisture and marbling score were used to develop the predictive model $\left(R^{2}=0.4072\right)$. The predictive model for $\mathrm{b}^{*}$ consisted of HCW and BF category, loin color score, weight, $\mathrm{L}^{*}$ and $\mathrm{a}^{*}$ values and $1 \mathrm{hr}$ and 22 $\mathrm{hr}$ loin $\mathrm{pH}\left(\mathrm{R}^{2}=0.4285\right)$. The percent fat in processed ham could be predicted from gender, loin $\mathrm{L}^{*}$, weight, $22 \mathrm{hr}$ loin $\mathrm{pH}$, 
$B F$, fat percentage of loin and marbling score $\left(R^{2}=0.4285\right)$. There was no significant model present for the prediction on two-toning in processed ham.

Conclusion: From this data it can be concluded that carcass and fresh loin measurements could be used to develop a model that is predictive of fresh and processed ham quality.

Keywords: ham, loin, processing, quality, two-toned 


\section{Meat and Poultry Quality and Composition - Measurement and Prediction}

91

\section{CARCASS TRAITS OF BOER- AND SAVANNAH-CROSS KID BUCKLING GOATS FED DRIED DISTILLERS GRAIN WITH SOLUBLES}

J. N. Maynard ${ }^{1, *}$, K. McMillin ${ }^{1}$, M. Persica III ${ }^{1}$

${ }^{1}$ Louisiana State University, Baton Rouge, United States

Objectives: Determine the carcass and meat characteristics of Boer- and Savannah-cross buckling goats less than one year of age fed $0,15,30$, and $45 \%$ dried distillers grain with solubles (DDGS).

Materials and Methods: Savannah bucklings $(n=31)$ and Boer bucklings $(n=28)$ were stratified by weight and breed to allocate the two heaviest goats from each breed to pens $(n=16)$ in descending weight order. Each pen (11 pens of 4 goats and 5 pens of 3 goats) was randomly assigned a treatment of $0 \%$ (T1), 15\% (T2), 30\% (T3), or 45\% (T4) DDGS. Feed was provided once daily at $4 \%$ of the total goat weight in each pen. On day 0 , one goat from each pen was harvested ( $\mathrm{H} 1)$ to establish a baseline and one goat from each pen was harvested every 21 days $(\mathrm{H} 2, \mathrm{H} 3, \mathrm{H} 4)$ so that equal numbers of goats from each breed were sacrificed each time. After humane harvest, temperature and $\mathrm{pH}$ of the $M$.

Semimembranosus were measured at hide removal and at $1 \mathrm{hr}, 3 \mathrm{hr}$ and $24 \mathrm{hr}$ after stunning. Carcasses were evaluated for conformation score, flank lean color, $\mathrm{KPH}$, and external fat over the ribs before ribbing carcasses between the $12^{\text {th }}$ and $13^{\text {th }}$ ribs. Ribeye area (REA) was traced on an acetate sheet and later measured with a digital planimeter. Color values $\left(\mathrm{L}^{*}, \mathrm{a}^{*}, \mathrm{~b}^{*}\right)$ were recorded for M. Longissimus dorsi and Rectus abdominis. Right sides were fabricated into the USDA Fresh Goat Series 11 IMPS food service style with an additional transverse cut between the $4^{\text {th }}$ and $5^{\text {th }}$ ribs. Each $M$. Semimembranosus muscle was cooked in a broiler oven to $70^{\circ} \mathrm{C}$ internal temperature and then chilled at $3^{\circ} \mathrm{C}$ overnight. Three $12.5 \mathrm{~mm}$ cores were removed parallel to muscle fibers for Warner-Bratzler shear force. Data were analyzed with SAS 9.4 Proc Mixed for comparison of Least Squares Means.

Results: Breed did not affect $(P>0.05)$ any carcass or cut characteristics. $\mathrm{H} 4$ had highest $(P<0.05) 1$ and 3-hour temperatures and $\mathrm{H} 1$ had lowest $(\mathrm{P}<0.05) 1$ and 3-hour $\mathrm{pH}$. $\mathrm{H} 1$ goats had higher $(\mathrm{P}<0.05) \mathrm{L}^{*}$ and $\mathrm{a}^{*}$ values for the Rectus abdominis than $\mathrm{H} 3$ and $\mathrm{H} 4$. $\mathrm{KPH} \%$, body wall thickness, and REA were increased with harvest time. $\mathrm{H} 4$ carcass weights and most primal and retail cuts were heavier than at other harvest dates. Carcass weights, most primal cut weights, and REA of T4 goats were less $(P<0.05)$ than those from T1 and T3. Percentages of primal cuts in relation to the cold carcass did not differ $(P>0.05)$ for treatments, but were influenced by harvest time. Boneless lean yields increased $(P<0.05)$ with harvest time. Warner-Bratzler shear force did not differ $(P>0.05)$ among treatments and harvest times.

Conclusion: Level and length of time feeding DDGS can affect kid goat carcass characteristics, but no differences in carcass characteristics were found between Boer- and Savannah-cross kid buckling goats. 
Keywords: breed, carcass traits, DDGS, goat 


\title{
Meat and Poultry Quality and Composition - Measurement and Prediction
}

92

\section{PREDICTION OF OXIDATION IN GROUND BEEF MEATBALLS MADE WITH CITRUS FIBER BY FOURIER TRANSFORM INFRARED SPECTROSCOPY}

\author{
A. Gedikoglu 1,*, M. Lin ${ }^{1}$, A. D. Clarke ${ }^{1}$ \\ ${ }^{1}$ Food Science Department, University of Missouri, Columbia, United States
}

Objectives: Fourier transform infrared spectroscopy (FTIR) is a rapid and non-invasive technique that provides vibrational information about the compounds that absorb light in the mid infrared region. The FTIR spectral features are unique for each compound and provide fingerprint-like information of the compound. Lipids are organic molecules that give absorbance at $4000-500 \mathrm{~cm}^{-1}$. Citrus fiber has been known to have flavonoid compounds. These compounds are associated with providing antioxidant potential. Therefore, objective of this study was to determine the oxidative stability of ground beef made with different levels of $(0,1,3$, and $5 \%)$ citrus fiber during $1,3,5,7$ days of refrigerated storage. In addition to FTIR analysis, moisture and fat content of all the treatments were determined.

Materials and Methods: Shank muscles were collected from three carcasses to provide three replications. After grinding, weighing, mixing and forming, meatballs of each treatment were placed on their Styrofoam ${ }^{\circledR}$ tray, were wrapped with plastic film, were labeled for replication, treatment level and day of testing and were stored in a refrigerator. Each treatment was extracted for fat in duplication using chloroform: methanol: water (2:2:1, v/v/v) as solvents. Chloroform-fat layer was collected for FTIR analysis. Solvent extracted fat samples were measured between 4,000 and $500 \mathrm{~cm}^{-1}$ at a resolution of $4 \mathrm{~cm}^{-1}$ with 128 scan using a Nicolet 380 spectrometer (Thermo Scientific, U.S.A.). The spectrum of each sample was corrected against the background spectrum of air to present the spectra in absorbance units. Measurements were done in triplicate. Delight software (D-Squared Development Inc., LaGrande, OR, USA) is used for analysis of the FTIR data. Trend analysis with fixed block mean, polynomial subtract (first order) and smoothing $\left(8 \mathrm{~cm}^{-1}\right)$ options were chosen to analyze all the data. For monitoring lipid oxidation, peaks at 2924, 2853, and $1743 \mathrm{~cm}^{-1}$ were used. The moisture and fat content of the meat samples was determined based on the CEM SMART Trac system (CEM Corp., North Carolina, U.S.A.).

Results: Results show that the addition of citrus fiber (CF) caused more decrease in absorbance in comparison to the control (CF 0\%) at bands $2924 \mathrm{~cm}^{-1}$ and $2853 \mathrm{~cm}^{-1}$ due to the production of oxidation products. The band at $1743 \mathrm{~cm}^{-1}$ was also a useful indicator. By day 3 , weak band appeared around $1728 \mathrm{~cm}^{-1}$ indicating the presence of oxidation products such as aldehydes and ketones, and spectra of CF $3 \%$ and CF $5 \%$ show more apparent band than the control and CF $1 \%$. Moisture content of ground beef was significantly different $(P<0.05)$ between control and CF $3 \%$ and CF $5 \%$. Control had the highest moisture content and followed by CF $1 \%$, CF $3 \%$ and CF $5 \%$, respectively. There was no significant difference $(\mathrm{P}>0.05)$ between treatments for fat content, control having the highest fat content with $4.7 \%$ and $\mathrm{CF}$ $5 \%$ having the lowest fat content with $4.18 \%$. 
Conclusion: Results of this study demonstrate that the addition of citrus fiber caused oxidation in ground beef. Fourier transform infrared spectroscopy was a useful tool for determination of oxidative stability of ground beef made with different levels of citrus fiber.

Keywords: Citrus fiber, FTIR, Ground beef, Lipid oxidation 


\section{Meat and Poultry Quality and Composition - Measurement and Prediction}

93

\section{A COMPARISON OF THE FOSS FOODSCAN AND CHEMICAL ANALYSES FOR PROXIMATE COMPOSITION IN FRESH BEEF}

L. D. Woolley ${ }^{1, *}$, K. S. Spivey ${ }^{1}$, J. N. Martin ${ }^{1}$, J. E. Johnston ${ }^{1}$, R. N. Carmichael ${ }^{1}$, D. A. Gredell ${ }^{1}$, R. D. Crownover ${ }^{1}$, J. C. Brooks ${ }^{1}$, M. F. Miller ${ }^{1}$

${ }^{1}$ Animal and Food Sciences, Texas Tech University, Lubbock, United States

Objectives: The FOSS FoodScan near-infrared spectrophotometer is used in the meat industry as a real-time alternative to traditional chemical analyses for determining the fat, moisture and protein content of raw meat. The objective of this study was to determine level of agreement between measures of protein, fat and moisture derived from the FOSS FoodScan versus those obtained using traditional chemical analyses.

Materials and Methods: Fresh USDA No Roll inside rounds (peeled and denuded) and $50 \%$ lean, 50\% fat beef trimmings were ground and mixed to formulate ten targeted lean:fat formulations. Formulations ranged from 95:5 (lean:fat) to 50:50 (lean:fat), using increasing increments of $5 \%$ fat. After formation, each mixture was vacuum packaged and stored ( 2 to $\left.4^{\circ} \mathrm{C}\right)$ until analysis. Each formulation $(n=10)$ was split into quadruplicate and analyzed by four separate individuals for a total of 16 analyses per formulation. Each quadruplicate sample was first analyzed using the FOSS FoodScan according to AOAC (2007.04) protocols. Following FOSS analyses, the ground sample was frozen in liquid nitrogen and powdered for determination of moisture, protein and fat using traditional analytical methods. Moisture determination was conducted using an AOAC-approved oven drying method (950.46). Crude protein determination was performed using a combustion method (AOAC 992.15). Chemical fat was determined using a variation of the chloroform:methanol method described by Folch, Lees, and Stanley (1957). A standard reference material (SRM 1546-Meat Homogenate) obtained from the National Institute of Standards and Technology (NIST) was used for quality control in traditional chemical analyses. Correlation and regression analyses were used to identify and quantify relationships among chemical fat, moisture and protein and FOSS fat, moisture and protein.

Results: Generally, fat and protein values were greater and moisture values lower when derived from the FOSS FoodScan versus those obtained from traditional chemical analysis. Of analyses evaluated, the strongest correlation $(P<$ $0.05)$ occurred between FOSS moisture and chemical moisture $(r=0.993)$. Also, fat values obtained from the FOSS FoodScan were positively correlated $(P<0.05)$ with values obtained from fat content determined using a chloroform:methanol-based procedure $(r=0.961)$. Moreover, a positive correlation $(P<0.05)$ was observed between FOSS evaluated protein content and chemically determined protein $(r=0.978)$. Regression analysis indicated the strongest $(P<0.05)$ likeness of fit for moisture determined by the FOSS FoodScan and chemical moisture $\left(r^{2}=0.986\right)$. Additionally, FOSS protein fit closely $(P<0.05)$ in the model with respective chemical protein $\left(r^{2}=0.955\right)$. Lastly, a strong $(P<0.05)$ similarity of fit between FOSS fat and chemical fat was observed $\left(r^{2}=0.922\right)$. 
Conclusion: The results from the current study indicate the FOSS FoodScan is a suitable method to use for quick determination of fat, moisture and protein composition in fresh beef.

Keywords: Beef, fat, method, moisture, protein 


\title{
Meat and Poultry Quality and Composition - Measurement and Prediction
}

94

\section{EVALUATION OF THE SIGNIFICANCE OF THE MAILLARD BROWNING REACTION, CARAMELIZATION, AND FLAVOR DEVELOPMENT IN BEEF STEAKS}

\author{
H. R. Rode ${ }^{1,{ }^{*}}$, C. E. Fehrman ${ }^{1}$, A. D. Blair ${ }^{1}$, K. R. Underwood ${ }^{1}$, S. M. S. Zuelly ${ }^{1}$
}

1South Dakota State University, Brookings, United States

Objectives: Tenderness is the most important trait influencing consumer acceptance of beef. However, this is only true when flavor is acceptable. Beef flavor research has primarily focused on the amount and type of intramuscular fat in steaks. Very few studies have looked at cookery method and it's effect on beef flavor. Most beef is cooked using a direct heat source leading to either the Maillard browning reaction or caramelization, which have unique flavors. Therefore, our objective was to determine the significance of the browning reaction and caramelization on sensory evaluation of beef flavor.

Materials and Methods: Strip loins were selected from a commercial packing facility to obtain USDA Prime (PR; $n=8)$, Low Choice $(\mathrm{CH} ; \mathrm{n}=8)$, and Standard $(\mathrm{ST} ; \mathrm{n}=5)$ quality grades. Strips loins were then transported to the South Dakota State University Meat Lab and aged for 14 days from slaughter date. Two steaks $(2.54 \mathrm{~cm})$ were removed from the anterior end of each strip loin for direct heat cookery or indirect heat cookery. Steaks designated for direct heat cookery were cooked on electric clam-shell grills, and a conventional oven was used to cook the steaks designated for indirect heat cookery method. All steaks were cooked to a target internal temperature of $71^{\circ} \mathrm{C}$, with peak internal temperature recorded. Minolta colorimeter $L^{*}, a^{*}$, and $b^{*}$ values were measured for cooked steaks to verify the cookery methods produced differences in browning. A trained sensory panel was used to assess beef flavor $(1=$ non detectable; $8=$ extremely intense), tenderness ( 1 = extremely tough; 8 = extremely tender $)$, juiciness $(1=$ extremely dry; $8=$ extremely juicy), off-flavor $(1=$ non detectable; 8 = extremely intense) and overall acceptability ( 1 = extremely unacceptable; 8 = extremely acceptable) for each steak.

Results: Direct heat cookery steaks had decreased $\mathrm{L}^{*}$ values $(P<0.05)$, increased $\mathrm{a}^{*}$ and $\mathrm{b}^{*}$ values $(P<0.05)$ compared to indirect heat cookery. Panelist found direct heat steaks had more beef flavor versus indirect heat steaks $(P<0.05)$. Also, PR steaks had more beef flavor $(P<0.05)$ than $\mathrm{CH}$, while $\mathrm{CH}$ had more beef flavor $(P<0.05)$ than ST. Panelists detected $\mathrm{PR}$ steaks to be more tender $(P<0.05)$ than $\mathrm{CH}$ and $\mathrm{ST}$, but there was no difference between $\mathrm{CH}$ and $\mathrm{ST}(P>$ $0.05)$ or direct versus indirect heat $(P>0.05)$. There was a linear decline in juiciness among quality grades. Prime steaks were the juiciest $(P<0.05)$, followed by $\mathrm{CH}(P<0.05)$, and then $\mathrm{ST}(P<0.05)$. Additionally, direct heat steaks had more perceived juiciness $(P<0.05)$ than indirect heat. There was no difference in off flavor between direct and indirect heat cookery $(P>0.05)$, but PR steaks had less off flavor $(P<0.05)$ compared to ST. Prime steaks had the greatest overall acceptability $(P<0.05)$, followed by $\mathrm{CH}(P<0.05)$, and then ST $(P<0.05)$. However, there was no difference in acceptability $(P>0.05)$ between direct or indirect heat cookery methods. 
Conclusion: Direct heat cookery increased sensory beef flavor and juiciness, however increased quality grades positively influenced all sensory attributes. Therefore, future research should account for browning, caramelization, and cookery method when analyzing beef flavor.

Keywords: Beef flavor, Maillard browning, Sensory Evaluation 


\title{
Meat and Poultry Quality and Composition - Measurement and Prediction
}

95

\section{INFLUENCE OF CANOLA OIL, SELENIUM AND VITAMIN E ON LIPID METABOLISM IN FEEDLOT CATTLE}

\author{
Z. A. Marcus ${ }^{1}$, L. B. Correa ${ }^{1}$, A. Saran Netto ${ }^{1}$, A. F. Rosa 2,", D. P. Lanna ${ }^{3}$
}

${ }^{1}$ Animal Science, ${ }^{2}$ Medicine Veterinary, University of Sao Paulo, Pirassununga, ${ }^{3}$ Animal Science, University of Sao Paulo, Piracicaba, Brazil

Objectives: The objective of this study was to determine the effect of canola oil as fat source and the selenium and vitamin $E$ in the diet, on fatty acid profile in Nellore beef cattle.

Materials and Methods: The experiment was conducted in the Faculty of Animal Science and Food Engineering of University of São Paulo (FZEA/USP), Pirassununga Campus, State of São Paulo, Brazil, for a period of 84 days. Forty eight Nellore bulls approximately 2 years-old, in the finishing phase, were used. The animals were placed in Calan Gate feed system, with individual feeding and were divided into four groups: 1) Control (C): Basal diet without supplementation; 2) Antioxidants (CA): Control diet with $2.5 \mathrm{mg} \mathrm{Se} / \mathrm{kg}$ of dry matter (DM) (as organic selenium) and 500Ul of vitamin E/kg DM; 3) Oil (CO): Control diet with 3\% of canola oil/kg DM; 4) Oil + Antioxidants (CAO): Control diet with $2.5 \mathrm{mg}$ of Se/kg DM (as organic selenium), $500 \mathrm{Ul}$ of vitamin E and $3 \%$ of canola oil $/ \mathrm{kg}$ DM. All animals received diet with $30 \%$ corn silage and $70 \%$ concentrate. The slaughter was performed following humanely standard procedures at a local slaughterhouse. At 24 hours post-mortem, Longissimus dorsi muscle (13th through the 10th rib) from right carcasses were removed, cut into $2.5 \mathrm{~cm}$ thick steaks and immediately frozen for posterior fatty acid profile analysis. The fatty acids qualitative determination was made by gas chromatography .Statistical analyses were performed by ANOVA within a completely randomized design, using the PROC GLM procedure of SAS (3). Means were compared by contrasts. Differences were considered significant when $\mathrm{p}<0.05$.

Results: Canola oil supplementation ( $\mathrm{CO}$ and $\mathrm{CAO})$ changed the meat fatty acid profile $(p<0.05)$, with increase in unsaturated fatty acids proportion in detriment of saturated fatty acids compared with the other groups. Considering omega 3 in muscle, there was a greater percentage of omega 3 for the animals supplemented with oil $(p<0.05)$, when compared with the other groups. The production of meat with higher unsaturated fatty acids would benefit both marketing and public health.

Authors thank to FAPESP (Grant 2010/20689-5) for the financial support.

Conclusion: In conclusion, there was influence of oil supplementation in cattle diet on fatty acid profile in Nellore's meat, with reduction of the percentage of saturated acids, increase of unsaturated ones and omega 3 in L. dorsi muscle.

Keywords: minerals, omega 3, unsaturated fat 



\title{
Meat and Poultry Quality and Composition - Measurement and Prediction
}

96

\section{MEAT TENDERNESS ASSESSMENT USING TISSUE ANISOTROPY IMAGING ANALYSIS}

\author{
Y. H. B. Kim 1, ${ }^{*}$, D. Setyabrata ${ }^{1}$, T. Kim ${ }^{2}$, Y. L. Kim ${ }^{2}$
}

1Department of Animal Sciences, ${ }^{2}$ Weldon School of Biomedical Engineering, Purdue University, West Lafayette, United States

Objectives: Providing consistently high eating quality of meat products to consumers is crucial for the meat industry. Inconsistent meat tenderness has been identified as one of major quality-related challenges to the meat industry. Thus, development of precise and consistent methods for predicting meat tenderness will be expected to greatly benefit the meat industry by supplying quality ensured/guaranteed meat products to consumers. In this respect, we have recently developed a novel non-invasive optical imaging method to evaluate and predict the spatiotemporal extent of microstructural and physicochemical changes in fresh muscle. Our imaging method takes advantage of the scattering anisotropy properties in tissue to provide a novel image contrast of subtle alterations in tissue microstructures and arrangements. The main hypothesis is that the meat tenderization process is sensitively captured by reflectance intensity images obtained from our imaging system nondestructively. The objective of this study is to evaluate the efficacy of the non-invasive anisotropy imaging analysis for assessing the tenderness of beef loins with various postmortem aging periods.

Materials and Methods: At $7 \mathrm{~d}$ postmortem, beef strip loins ( $M$. longissimus dorsl) from one side of each beef carcass $(n=3 ; 24$ months old steers) were removed. Each muscle was equally divided into 4 sections and randomly allocated to 4 different aging times $(7,14,21$ and $28 \mathrm{~d})$. Samples excluding $7 \mathrm{~d}$ were individually vacuum-packaged and aged at $2^{\circ} \mathrm{C}$. At each aging time, two steak cuts $\left(2.4-\mathrm{cm}\right.$ thick; $\left.10 \times 8 \mathrm{~cm}^{2}\right)$ were made for the Warner-Bratlzer shear force (WBSF) measurement and the non-invasive anisotropy imaging analysis. For WBSF, a steak was immediately cooked on an electrical grill and cooled at $2^{\circ} \mathrm{C}$ for 24 hours. The average peak shear force of the six cores using the TA-XT texture analyzer was calculated. Images of the steak were captured using the anisotropy imaging system and the average cosine values of the scattering angle were calculated. The meat specimens were imaged using the imaging system and the reflectance intensity images were averaged over the entire area. The averaged intensity data from three animals were correlated with WBSF. Data were analyzed by using SAS. Means were separated $(P<0.05)$ by least significant differences.

Results: As the postmortem aging time increased, a significant decrease in WBSF of loins was observed as expected ( $P$ $<0.05)$, indicating an improvement in meat tenderness with aging. The meat tenderization process with aging was correlated with the anisotropy images, showing an excellent linear correlation of both averaged reflectance and shear force with a $R^{2}$ of $0.995(P=0.003)$. In addition, the averaged reflectance also decreased as the aging period increased 
$(P<0.05)$. This result suggests that meat tenderness can be assessed by imaging the tissue anisotropy factor, which can be sensitively captured by our imaging system.

Conclusion: The results from the current pilot study indicate that the tissue anisotropy imaging method could potentially be used as a viable non-invasive prediction tool for determining the extent of meat tenderization. Further studies focusing on the efficacy of our imaging analysis method in determining meat tenderness under various baseline factors including different muscle cuts, fat contents, and amount of connective tissues will be warranted. The U.S. provisional patent application for this method and apparatus has been submitted.

Keywords: Beef, Tenderness, Anisotropy image analysis, Quality 


\section{Meat and Poultry Quality and Composition - Measurement and Prediction}

97

\section{THE RELATIONSHIP BETWEEN PHYSICAL AND CHEMICAL COMPOSITION OF 9-10-11 RIB AND CARCASS OF BEEF STEERS}

L.-A. J. Walter 1, ${ }^{\star}$, A. N. Schmitz ${ }^{1}$, W. T. Nichols ${ }^{2}$, J. P. Hutcheson ${ }^{2}$, T. E. Lawrence 1

${ }^{1}$ West Texas A\&M University, Canyon, ${ }^{2}$ Merck Animal Health, Summit, United States

Objectives: A trial was conducted to examine the linear relationship between composition of the 9-10-11 rib and the carcass.

Materials and Methods: Single-sired, beef steers $(n=56 ; 574 \pm 36 \mathrm{~kg})$ blocked $(n=2)$ by weight and terminal implant were further sorted into pairs ( $n=28)$ by weight. Pairs of steers were assigned to 0,28 or $56 \mathrm{~d}$ (DOF) and fed individually to maintenance (M) or ad libitum (A) intake (DIET). Within $56 \mathrm{~d}$ of feeding, steers within a pair were randomly assigned to $20 \mathrm{~d}$ of zilpaterol hydrochloride (ZH) supplementation ( $90 \mathrm{mg} / \mathrm{hd} / \mathrm{d}$ ) plus a $4 \mathrm{~d}$ withdrawal $(\mathrm{Z})$ or to no $\mathrm{ZH}(\mathrm{C})$. Carcasses were graded $24 \mathrm{~h}$ after harvest and sides fabricated after a $48 \mathrm{~h}$ chill. Carcass subprimals and fat were ground and sampled, long bones sliced and sampled and 9-10-11 ribs dissected into lean, fat, and bone with lean and fat ground and sampled. The relationship between individual 9-10-11 rib and carcass parameters were evaluated via correlation and simple linear regression. Multiple-linear regression was used to evaluate the predictive ability of 9-10-11 rib composition, $\mathrm{HCW}$, LM area (LMA), $12^{\text {th }}$ rib s.c. fat depth $(F T)$, percent KPH fat, marbling score $(Q G), T R T(C=0, Z=1)$, and DIET (M=0, $A=1)$ to estimate edible carcass chemical composition.

Results: Separable fat of the carcass (SFC) was strongly correlated (r=0.89; $P<0.01$ ) to 9-10-11 rib separable fat (SFR) and estimated using the equation $\left\{(\mathrm{SFC}=16.30+0.39 * \mathrm{SFR}) ; P<0.01\right.$, Adj. $\mathrm{R}^{2}=0.49$, RMSE 2.362$\}$. Separable lean of the carcass (SLC) was strongly correlated ( $\mathrm{r}=0.83 ; P<0.01)$ to separable lean of the 9-10-11 rib (SLR) and estimated with $\{(\mathrm{SLC}=20.86+0.24 * \mathrm{SLR})$; $P<0.01$, Adj. $\mathrm{R}^{2}=0.68$, RMSE 1.446\}. Separable bone of the carcass (SBC) was correlated ( $\left.\mathrm{r}=0.59 ; P<0.01\right)$ to separable bone of the 9-10-11 rib (SBR) and was estimated with $\left\{(\mathrm{SBC}=-0.17+1.13 * \mathrm{SBR}) ; P<0.01\right.$, Adj. $\mathrm{R}^{2}=0.33$, RMSE 1.761). Ether extract of the edible carcass (EEC) exhibited a correlation ( $\mathrm{r}=0.40, P<0.01)$ to ether extract of the edible 9-10-11 rib (EER) and was estimated as $\left\{(\right.$ EEC $=21.31+0.23 * E E R) ; P<0.01$, Adj. $\mathrm{R}^{2}=0.16$, RMSE 3.660 $\}$. Edible carcass moisture $(\mathrm{MC})$ was correlated $(\mathrm{r}=0.49, P<0.01)$ to 9-10-11 edible rib moisture (MR) and estimated from the equation $\left\{(\mathrm{CM}=37.76+0.30 * \mathrm{RM}) ; P<0.01\right.$, Adj. $\mathrm{R}^{2}=0.23$, RMSE 3.012 . Protein of the edible carcass (PC) was not estimable $(P=0.18)$ from 9-10-11 edible rib protein $(\mathrm{PR})$ but was correlated to EER $(\mathrm{r}=-0.42, P<0.01)$ and estimated by EER $\left\{(\mathrm{PC}=19.84-0.09 *\right.$ EER $) ; P<0.01$, Adj. $\mathrm{R}^{2}=0.16$, RMSE 1.375$\}$ as well as to MC $(\mathrm{r}=0.41, P<0.01)$ and $\left\{\left(\mathrm{PC}=11.64+0.11^{*} \mathrm{MC}\right) ; P<0.01\right.$, Adj. $\mathrm{R}^{2}=0.15$, RMSE 1.379 $\}$. An equation to predict EEC was developed $\left\{P<0.01\right.$; Adj. $\mathrm{R}^{2}=0.51$, RMSE 2.791; EEC = 35.60-(2.25*TRT)+(1.86*FT)+(0.017*QG)-(0.33*SLR) $\}$. Carcass protein $(\mathrm{CP})$ was estimated $\left\{P<0.01\right.$, Adj. $\mathrm{R}^{2}=0.54$, RMSE 1.025; $\left.\mathrm{CP}=2.56+(0.019 * \mathrm{HCW})-(0.083 * \mathrm{LMA})+(0.297 * \mathrm{SLR})\right\}$. Prediction of CM was estimable $\left\{P<0.01\right.$, Adj. $\mathrm{R}^{2}=0.58$, RMSE 2.246; $\left.\mathrm{CM}=50.64+(2.74 * \mathrm{TRT})-(0.03 * \mathrm{HCW})-(0.01 * \mathrm{QG})-(0.31 * \mathrm{SLR})\right\}$.

Conclusion: Results indicate strong correlations $(r>0.80, P<0.01)$ between separable lean and fat of the 9-10-11 rib to separable lean and fat of the carcass, however chemical composition of the carcass was moderately correlated to 9-10-11 rib chemical composition $(r<0.50, P<0.01)$. Models were developed that moderately predict $\left(\right.$ Adj. $\left.\mathrm{R}^{2}>0.50, P<0.01\right)$ carcass chemical composition by 9-10-11 rib physical and chemical composition, using carcass grading traits. 
Keywords: 9-10-11 rib, beef, carcass composition, Zilpaterol Hydrochloride 


\title{
Meat and Poultry Quality and Composition - Measurement and Prediction
}

98

\section{DETERMINING THE RELATIONSHIP BETWEEN PH AND INSTRUMENTAL COLOR MEASUREMENTS TO PREDICT WATER-HOLDING CAPACITY AND SENSORY JUICINESS}

\author{
K. N. Kerns ${ }^{1, *}{ }^{*}$, J. O. Fulton ${ }^{1}$, K. R. Underwood ${ }^{1}$, A. D. Blair ${ }^{1}$, S. M. S. Zuelly ${ }^{1}$ \\ ${ }^{1}$ Animal Science, South Dakota State University, Brookings, United States
}

Objectives: Beef palatability is impacted by tenderness, flavor and juiciness. Previous beef palatability research has focused heavily on tenderness and flavor attributes; however, limited research has been conducted on juiciness which has been shown to impact both tenderness and flavor. Therefore, the objective of this study was to determine if a relationship exists between color, $\mathrm{pH}$, and water-holding capacity and determine if color and $\mathrm{pH}$ can predict sensory perceived juiciness.

Materials and Methods: Beef strip loins $(n=427)$ were obtained from a commercial packing plant. Strip steaks $(2.54 \mathrm{~cm})$ were analyzed for $\mathrm{pH}$ and Minolta $\mathrm{L}^{*}, \mathrm{a}^{*}$, and $\mathrm{b}^{*}$. Steaks were wet aged in vacuum packaged bags for varying aging time periods to determine purge loss $(3,7,14,21 \mathrm{~d})$. Steaks were cooked to a target end-point temperature of $71^{\circ} \mathrm{C}$, with actual peak internal temperature recorded. Cook loss, Warner-Bratzler shear force (WBSF), moisture and fat content were determined for each steak. A sub set of steaks $(n=101)$ were selected for sensory analysis based on the initial regression analysis with a spectrum of cook loss and moisture differences. Sensory steaks were cooked to a target end-point temperature of $71^{\circ} \mathrm{C}$ and evaluated for juiciness, tenderness, beef flavor, off flavor, and overall acceptability using trained panelists and an eight point hedonic scale. Step-wise regression equations were used to predict moisture content, purge loss, cook loss, and sensory perceived juiciness with all models considered significant at $P<0.05$.

Results: Several individual color and pH measurements showed significant correlations to moisture content, purge loss, cook loss and sensory juiciness. A step-wise regression determined variables used to predict moisture content were $\mathrm{a}^{*}$, $\mathrm{b}^{*}$, and marbling score $\left(\mathrm{R}^{2}=0.6808 ; P<0.0001\right)$. Purge loss was predicted using steak age, $\mathrm{a}^{*}, \mathrm{pH}$, and marbling score $\left(\mathrm{R}^{2}=0.3591 ; P<0.0001\right)$. Cook loss was predicted using peak internal temperature, $L^{*}, a^{*}$, and $b^{*}\left(R^{2}=0.2988 ; P\right.$ $<0.0001)$. Lastly, sensory juiciness could be predicted using marbling, $\mathrm{b}^{*}$ and end-point temperature $\left(\mathrm{R}^{2}=0.2849 ; P\right.$ $<0.0001)$.

Conclusion: Minolta $b^{*}$ was significant for predicting moisture content, cook loss, and sensory juiciness; however, there has been limited investigation on the major factors influencing $b^{*}$ of beef and beef products. Therefore, further investigation of $b^{*}$ is necessary to determine the mechanisms of $b^{*}$ in relation to beef palatability. Furthermore, these data indicate that moisture content and purge loss may be predicted using instrumental color, marbling score, and $\mathrm{pH}$. Thus, it may be possible to predict moisture and purge loss using current industry technologies. Regression analysis for both cook 
loss and sensory juiciness determined a model which contains peak internal temperature; therefore it is still critical for researchers and consumers to monitor peak internal temperature to improve juiciness and palatability.

Keywords: Beef, Color, Juiciness, $\mathrm{pH}$, sensory 


\section{Meat and Poultry Quality and Composition - Measurement and Prediction}

99

\section{PREDICTING PORK TWO TONE COLOR GRADE USING IMAGE COLOR FEATURES AND SUPPORT VECTOR}

\section{MACHINE}

X. Sun ${ }^{1}$, D. Newman 1,*, J. H. Liu ${ }^{1}$, J. Young ${ }^{1}$, L. Bachmeier ${ }^{1}$

${ }^{1}$ Animal Science Department, North Dakota State University, FARGO, United States

Objectives: Pork quality has been shown to impact consumer eating satisfaction. Pork quality is usually evaluated subjectively based on color, texture, and exudative characteristics of the meat. Two-tone coloring is a color defect that affects both quality and consumer intent to purchase. The objective of this study was to determine if pork loin two-tone color image features could be used to predict color grade according to objective $L^{*}$ value.

Materials and Methods: Nine image two tone ratio color features, means for two tone ratios of R, G B, L*, $a^{*}, b^{*}, H, S$, and I, were extracted from 3 different color spaces (RGB [red, green, and blue], CIE LAB [ $L^{*}$, luminance; $a^{*}$, green to red; and $\mathrm{b}^{*}$, blue to yellow], and HIS [hue, saturation, and intensity]). Color features were extracted from a laboratory-based highquality CCD camera imaging system. Objective color (CIE $L^{*}$, $a^{*}$, and $b^{*}$ color space values) was measured using a Minolta Colorimeter (CR-410, 50 mm diameter head, 10 standard observer, D65 light source; Minolta Co., Ramsey, NJ), calibrated using both white and black tiles. Boneless, 2.54-cm thick loin chops (enhanced, $n=541$; non-enhanced, $n=232$ ) were collected from National Pork Board project (ID \# 11-163). K-means clustering technique was used for grouping pork color grade based on Minolta $L^{*}$ value. Pork was separated into 2 grades (Grade $1=$ lighter, Grade $2=$ darker) according to the K-means clustering method. The image color features were used as predictors for multivariate classification of the samples using machine learning method (Support Vector Machine, SVM). Image data was separated into 3 different sets in order to test the model robustness (enhanced, non-enhanced, and combined). For establishing the model, each data set was separated into training $(70 \%)$ and testing (30\%) sets. Ten-fold cross validation method was used to set up the model and test the best model parameters.

Results: The results showed that, for the enhanced chops, the SVM machine method correctly predicted $98.4 \%$ of the grade 1 color score and $99.0 \%$ correct for grade 2 . For non-enhanced samples, the SVM machine predicted $95.5 \%$ correct for grade 1 and $100 \%$ correct for grade 2 . When pooling enhanced and non-enhanced to determine the model, the prediction results were $100 \%$ correct for both grades.

Conclusion: Therefore, color image features can be used to correctly classify pork chops by Minolta $\mathrm{L}^{*}$.

Keywords: color grade, image processing, pork loin, SVM 


\section{Meat and Poultry Quality and Composition - Measurement and Prediction}

100

\section{ESTIMATION OF THE RELATIONSHIP BETWEEN DENTITION AND SKELETAL MATURITY TO CHRONOLOGICAL AGE AND THE DEVELOPMENT OF AN OBJECTIVE MEASURE OF SKELETAL MATURITY}

R. Carmichael ${ }^{1,{ }^{*},}$, K. Spivey ${ }^{1}$, J. C. Brooks ${ }^{1}$, B. Johnson ${ }^{1}$, T. Lawrence ${ }^{2}$, M. Miller ${ }^{1}$

${ }^{1}$ Animal and Food Science, Texas Tech University, Lubbock, ${ }^{2}$ Animal Science, West Texas A \& M University, Canyon, United States

Objectives: The current study evaluated the relationship between dentition (DENT), subjective assessment of thoracic ossification (TOSS), and percent thoracic ossification (TTP) with chronological age.

Materials and Methods: Cattle $(n=580)$ with a variety of genders and known age ranging from 15-109 mo were sampled. At harvest animals were evaluated on a moving chain for DENT. Approximately $28 \mathrm{~h}$ post-mortem all carcasses were subjectively evaluated on a moving chain for the amount of ossification present in the vertebral column and images were captured to determine TTP. TTP was evaluated by uploading pictures and analyzing them using a commercially available program APS Assess (American Phytopathological Society Press St. Paul, MN). Each image was evaluated for the overall area of the cartilaginous tip of the spinous process as well as the area of ossification in that tip. All variables were correlated to age in mo using PROC CORR of SAS.

Results: Age $(\mathrm{mo})$ was highly correlated $(P<0.05)$ to DENT $(r=0.83)$ and TTP $(r=0.67)$, but weakly associated to TOSS $(r=0.20)$. Subsequently, all variables were then correlated to DENT resulting in coefficients of $0.80(P=0.0001)$ for TTP and $-0.02(P=0.70)$ for TOSS. Results showed no difference in dentition scores of cattle $\leq 20 \mathrm{mo}$, but dentition score increased $(P<0.05)$ as cattle age increased from 21 to 51 mo. Cattle from 15 to 20 mo of age had no permanent incisors while cattle in the 21-30 mo group exhibited 3.43 permanent incisors, 31 to 40 mo displayed 5.80 incisors, and 41 to 50 mo had 7.15 incisors. No differences $(P>0.05)$ were observed in dentition scores between the 51 to $60 \mathrm{mo}(7.82), 61$ to $76 \mathrm{mo}$ (7.90), and the $\geq 77 \mathrm{mo}$ group (8.00). Results for cattle less than $21 \mathrm{mo}$ of age agree with previous research which found that permanent incisors begin to erupt at the age of $22.5 \mathrm{mo}$. Data indicated that as animals age TTP increases as well as TOSS, with animals in the 15 mo category exhibiting the lowest values (TTP $=0.17 \%$, TOSS $=141.79$ ) and cattle $\geq 77$ mo exhibiting the highest values (TTP $=71.47 \%$, TOSS $=532.86$ ).

Conclusion: Once animals passed 20 mo of age and before they reached 51 mo of age it appears that increases in thoracic ossification occur from posterior to anterior. Results indicate that both DENT and TTP may be viable factors in determining animal age and that increases in TTP may occur from posterior to anterior.

Keywords: Chronological Age, Dentition, Ossification, Skeletal Maturity, Thoracic 


\title{
Meat and Poultry Quality and Composition - Measurement and Prediction
}

101

\section{EVALUATION OF CARCASS QUALITY AND YIELD ATTRIBUTES USING THREE GRADING SYSTEMS ON CARCASSES FROM STEERS THAT WERE FED MAINTENANCE OR AD LIBITUM DIETS WITH OR WITHOUT ZILPATEROL HYDROCHLORIDE SUPPLEMENTATION}

\author{
A. Schmitz ${ }^{1,}{ }^{*}$, L.-A. J. Walter ${ }^{1}$, W. T. Nichols ${ }^{2}$, J. P. Hutcheson ${ }^{2}$, T. E. Lawrence ${ }^{1}$ \\ ${ }^{1}$ West Texas A\&M University, Canyon, ${ }^{2}$ Merck Animal Health, Summit, United States
}

Objectives: An experiment was performed to evaluate the ability of three separate beef grading systems $\{$ United States Department of Agriculture (USDA), Canadian Beef Grading Agency (CBGA) and Japanese Meat Grading (JMG)\} to estimate the red meat yield of carcasses from over-finished beef steers supplemented zilpaterol hydrochloride $(\mathrm{ZH})$ and fed at maintenance $(\mathrm{M})$ or ad libitum $(\mathrm{AL})$ intake levels.

Materials and Methods: Single-sired beef steers $(n=56)$ were blocked $(n=28$ per block) by implant status and sorted into pairs by weight. Harvest day $(0,28$, or 56$)$ and diet level $(M$ or $A L)$ was randomly assigned to each pair. Supplementation of $\mathrm{ZH}$ was randomly applied within a pair for steers harvested at 56 days. Steers were individually weighed on $\mathrm{d} 0,1,27$, 28, 55, and 56 following feed and water withdrawal for $9 \mathrm{~h}$. Adjustments for DMI on M diet level were performed accordingly by weighing steers on d 11 and 21 with AL bunk calls adjusted daily; ZH was fed continuously at $90 \mathrm{mg}$ for 20 $\mathrm{d}$ prior to a $4 \mathrm{~d}$ withdrawal period. Steers were harvested at a commercial processing facility. After a $24 \mathrm{~h}$ chill, left carcasses sides were cut between the $12^{\text {th }}$ and $13^{\text {th }}$ ribs to expose the longissimus dorsi muscle where USDA and CBGA grading procedures were implemented. Standard USDA grading procedures were used to derive a calculated yield grade $(3.7 \pm 0.3)$ and percentage of boneless closely trimmed cuts from the round, loin, rib and chuck (BCTRLRC; $48.1 \pm 0.7 \%$ ) from hot carcass weight (HCW, $381.0 \pm 11.2 \mathrm{~kg}), 12^{\text {th }}$ rib s.c. fat depth $(2.0 \pm 0.2 \mathrm{~cm})$, LM area $\left(88.5 \pm 2.9 \mathrm{~cm}^{2}\right)$, and percentage of kidney-pelvic-heart fat (KPH\%, $2.1 \pm 0.2 \%)$. Similarly, standard CBGA grading procedures were used to determine the calculated yield grade $(2.3 \pm 0.2)$ and estimated lean yield $(54.2 \pm 0.02 \%)$ from the CBGA yield ruler measures of LM width (2.0 \pm 0.0$)$, LM length $(3.0 \pm 0.2)$, CBGA muscle score $(2.9 \pm 0.2)$, and fat class $(7.7 \pm 0.6)$. Following USDA and CBGA grading procedures, all carcasses were cut between the $6^{\text {th }}$ and $7^{\text {th }}$ ribs for JMG beef grading measurements. A calculated yield estimation $(72.3 \pm 0.01 \%)$ was derived from measurements that included LM area $\left(48.0 \pm 1.86 \mathrm{~cm}^{2}\right)$, rib thickness $(7.8 \pm 0.3 \mathrm{~cm})$, cold left side weight $(186.0 \pm 5.9 \mathrm{~kg})$, and subcutaneous fat thickness $(3.1$ $\pm 0.3 \mathrm{~cm}$ ). After grading, the left side of each carcass was fabricated into subprimals to determine individual red meat yield (RMY; $63.4 \pm 0.01 \%)$, trimmable fat yield $(21.1 \pm 0.03 \%)$, and bone yield $(15.3 \pm 0.01 \%)$. Correlation and linear regression was used to quantify linear relationships between estimates of red meat yield from each grading system and actual RMY from the carcasses. 
Results: Pearson correlation coefficients indicated that RMY was correlated $(P<0.01)$ to BCTRLRC $(r=0.72)$, CBGA lean yield $(r=0.57)$, and JMG yield estimation ( $r=0.37)$. Similarly, when each yield estimate was used in a regression model to predict RMY, adjusted $\mathrm{R}^{2}$ were 0.51 for USDA, 0.32 for CBGA, and 0.12 for JMG.

Conclusion: These results provide insight into the ability of current yield estimates to predict the percentage of RMY of over-finished beef carcasses.

Keywords: Beef, carcass composition, carcass traits, Zilpaterol Hydrochloride 


\section{Meat and Poultry Quality and Composition - Measurement and Prediction}

102

\section{EFFECT OF FEEDING DISTILLERS GRAINS AND SUPPLEMENTING ANTIOXIDANTS ON LIPID OXIDATION OF GROUND BEEF}

B. Cleveland ${ }^{1, *}$, C. Bower ${ }^{1}$, T. Jones ${ }^{1}$, J. MacDonald ${ }^{1}$, G. Sullivan ${ }^{1}$

1 University of Nebraska-Lincoln, Lincoln, United States

Objectives: The objective of this trial was to evaluate the effect of vitamin E or Ethoxyquin/TBHQ (Agrado Plus, Novus International, St. Louis, MO) supplementation on lipid oxidation of ground beef from cattle fed distillers grains during the finishing phase.

Materials and Methods: Cattle $(n=100)$ were randomly assigned to one of five finishing diets; corn (control), wet distillers grains (WDGS, 30\% DM basis), WDGS and $1000 \mathrm{IU} / \mathrm{hd} / \mathrm{d}$ vitamin E, WDGS and $150 \mathrm{ppm} / \mathrm{hd} / \mathrm{d}$ Agrado Plus, or WDGS with $500 \mathrm{IU} / \mathrm{hd} / \mathrm{d}$ vitamin $\mathrm{E}$ and $150 \mathrm{ppm} / \mathrm{hd} / \mathrm{d}$ Agrado Plus. At the conclusion of the finishing phase, cattle were harvested at a commercial abattoir. Forty-eight h post-harvest, seven USDA Choice beef shoulder clods (IMPS \# 114) from each dietary treatment group were collected from the right side of carcasses and vacuum packaged. On d 14 postmortem, each shoulder clod was independently ground and lean, fat and composite samples were collected for fatty acid analysis. Patties were manufactured (hand operated hamburger press) and overwrapped with permeable oxygen wrap and placed under simulated retail display for $7 d$ to measure lipid oxidation (TBARS; $d$ 0, 1, 2, 3, 5 and 7, where $d 0$ represents the day of grinding). Additionally, a $2.27 \mathrm{~kg}$ ground beef sample was taken from each shoulder clod to manufacture cooked beef links. All beef link treatments contained $0.75 \%$ salt and $0.25 \%$ sodium phosphate. Beef and non-meat ingredients were mixed for $1 \mathrm{~min}$ and the mixture was stuffed into skinless links using a hydraulic piston stuffer. Links were placed in individual foil trays for each shoulder clod and cooked to an internal temperature of $71^{\circ} \mathrm{C}$. Cooked links were placed in zip-top bags and placed in either dark refrigerated storage at $2^{\circ} \mathrm{C}$ or dark frozen storage at $-20^{\circ} \mathrm{C}$. Thiobarbituric acid reactive substances (TBARS) were analyzed beginning on $0 \mathrm{~d}$ and then every $3 \mathrm{~d}$ until $18 \mathrm{~d}$ of refrigerated storage and every $28 \mathrm{~d}$ until $252 \mathrm{~d}$ of frozen storage. Day 0 represents the day of cooking. Data were analyzed with repeated measures (day) utilizing the PROC GLIMMIX procedures of SAS.

Results: Raw patties had a day $\times$ treatment interaction $(P=0.027)$ for lipid oxidation. Patties from the corn control had greater TBARS values on $\mathrm{d} 2,3,5$ and 7 than patties from cattle supplemented vitamin $E$, with other dietary treatments having intermediate values. Additionally, WDGS and WDGS plus Agrado were similar at all days of simulated retail display $(P \geq 0.34)$. For both refrigerated and frozen beef link lipid oxidation, TBARS values increased over time $(P=$ 0.001 and $<0.0001$, respectively), and no dietary effects were observed $(P \geq 0.10)$.

Conclusion: Therefore, cooked beef links (refrigerated and frozen) TBARS increased over time. For raw patties, any supplementation of vitamin E sustained lower TBARS values than the corn control after $2 \mathrm{~d}$ of simulated retail display, with Agrado containing intermediate values between corn and vitamin $\mathrm{E}$ supplemented cattle. 
Keywords: Agrado, Distillers Grains, Ground Beef, TBARS, Vitamin E 


\section{Meat and Poultry Quality and Composition - Measurement and Prediction}

103

\section{EVALUATION OF POSTMORTEM BEEF AGE DETERMINATION SYSTEMS IN RELATION TO CHRONOLOGICAL AGE}

N. C. Hardcastle ${ }^{1,}{ }^{*}$, K. S. Spivi ${ }^{1}$, M. F. Miller ${ }^{1}$, J. C. Brooks ${ }^{1}$, B. J. Johnson ${ }^{1}$, T. E. Lawrence ${ }^{2}$

${ }^{1}$ Animal and Food Sciences, Texas Tech University, Lubbock, ${ }^{2}$ Department of Agriculture, West Texas A\&M University, Canyon, United States

Objectives: Current methods of age classification in beef carcasses used in commercial beef processing facilities are dentition (DENT; number of permanent incisors) or skeletal maturity (OSS; the subjective evaluation of ossification of the vertebral column cartilages).

Materials and Methods: Dentition and OSS were measured to evaluate the accuracy of age measurements compared to documented chronological age in both young beef cattle ( $\leq 20 \mathrm{mo}$ of age) and older beef cattle ( $\geq 21 \mathrm{mo}$ of age). After harvest at a commercial beef processing facility, DENT was recorded. Experiment 1 consisted of 4,087 hd of young beef cattle, and experiment 2 consisted of 3,805 hd of older beef cattle. Identification of each carcass was maintained into the chill cooler, in order to maintain individuality. Approximately $28 \mathrm{~h}$ post-mortem, carcasses were evaluated for the amount of OSS present in the vertebral column in accordance to USDA standards. Upon completion of carcass evaluation, documented age of the live animal and post-mortem records, such as DENT and OSS, were associated with individual identification. Young cattle were further categorized into six age groups (15 mo, $16 \mathrm{mo}, 17 \mathrm{mo}, 18 \mathrm{mo}, 19 \mathrm{mo}$, and $20 \mathrm{mo}$ of age) and old cattle were further categorized into four age groups (21 - $30 \mathrm{mo}, 31-40 \mathrm{mo}, 41-50 \mathrm{mo}$ and $\geq 51 \mathrm{mo}$ of age) verified by validated age. Data were analyzed using the mixed procedure of SAS.

Results: Results for cattle $\leq 20$ mo of age showed an increase $(P<0.05)$ in DENT scores as animals reached 20 mo of age (0.05 incisors) when compared to animals $15-19$ mo of age (0.01 incisors). However, this only reinsured that beef cattle $\leq 20$ mo of age do not have a full permanent incisor. Cattle $\geq 21$ mo of age showed an increase $(P<0.05)$ in DENT scores as the animals increased in age (21 - $30 \mathrm{mo}, 1.15 ; 31$ - $40 \mathrm{mo}, 3.58 ; 41$ - $50 \mathrm{mo}$ 5.68; and $\geq 51 \mathrm{mo}$, 8.00). Skeletal maturity increased in cattle $\leq 20 \mathrm{mo}$ in age (16 mo, 138.89; $17 \mathrm{mo}, 141.84 ; 18 \mathrm{mo}, 143.71 ; 19 \mathrm{mo}, 145.83$; $20 \mathrm{mo}, 155.24)$, with the exception of cattle $15-16$ mo who showed a slight reduction in ossification (141.29 and 138.89 , respectively). OSS of beef cattle $\geq 21$ mo of age increased from $21-40$ mo of age (164. 63 and 223.27, respectively) and to $\geq 51 \mathrm{mo}(550.00)$. Concurrently, cattle $31-40 \mathrm{mo}$ of age were more mature $(P<0.05)$ according to OSS compared to cattle $41-50$ mo of age (223.27 and 189.59, respectively).

Conclusion: Data from these experiments demonstrate that OSS would be more useful in determining the chronological age of cattle $\leq 20$ mo of age, while DENT would be more accurate to determine the age of beef cattle $\geq 21$ mo of age. 
Keywords: Beef, Chronological Age, Dentition, Maturity, Ossification 


\title{
Meat and Poultry Quality and Composition - Measurement and Prediction
}

104

\author{
TENDERNESS AND MUSCLE AREA DIFFERENCES BY VERTEBRAL LOCATION FOR LONGISSIMUS DORSI FROM \\ HOLSTEIN STEER CARCASSES \\ D. E. Guadian Garcia ${ }^{1, *}$, L.-A. J. Walter ${ }^{1}$, D. D. Reed Jr. ${ }^{1}$, C. L. Rogers ${ }^{1}$, T. E. Lawrence ${ }^{1}$ \\ ${ }^{1}$ Beef Carcass Research Center, West Texas A \& M University, Canyon, United States
}

Objectives: An experiment was conducted to examine the objective tenderness of M. longissimus dorsi (LD) from Holstein steer carcasses.

Materials and Methods: Thoracic and lumbar vertebrae from the left side of each carcass $(n=11)$ were numbered from the $5^{\text {th }}$ thoracic vertebrae to the $6^{\text {th }}$ lumbar vertebrae (T5 through T13 and L1 through L6). Primal beef rib (IMPS \#103) and short loins (IMPS \#173) were removed from each carcass side, vacuum packaged, and aged for 28 days $\left(2^{\circ} \mathrm{C}\right)$ before being frozen $\left(-28.9^{\circ} \mathrm{C}\right)$. Frozen primals were band-sawed into steaks $(2.54 \mathrm{~cm})$ perpendicular to each of the 15 numbered vertebrae. Steaks $(n=165)$ were individually identified to carcass and vertebral location, vacuumed packaged and stored at $-28.9^{\circ} \mathrm{C}$. Steaks were thawed at $1^{\circ} \mathrm{C}$ for $24 \mathrm{~h}$ before being cooked in a forced-air convection oven set at $177^{\circ} \mathrm{C}$ until an internal endpoint temperature of $70^{\circ} \mathrm{C}$. Uncooked LD area was also determined for each steak. Cooked steaks were chilled for $24 \mathrm{~h}$ at $1{ }^{\circ} \mathrm{C}$ before six-1.27 cm cores were randomly removed parallel to the muscle fiber orientation of each steak. Cores were immediately sheared using a V-shaped blade on the Warner-Bratzler Shear Force (WBSF) machine; peak shear force values were recorded for each core, which were averaged for each steak. Data were analyzed as a completely randomized design using a mixed model; fixed effect was vertebral location with the random effect of carcass. Results: Steaks adjacent to lumbar vertebrae exhibited a lower $(P<0.02)$ WBSF as compared to those adjacent to thoracic vertebrae (30.8 vs. $34.8 \mathrm{~N}$, respectively). Furthermore, WBSF data illustrated the lowest shear values in the L4 $(27.7 \mathrm{~N})$ location and highest values in the T5 $(41.4 \mathrm{~N})$ location. In the anterior portion of the LD, the T6 steak exhibited the smallest area $\left(29.2 \mathrm{~cm}^{2}\right)$. Muscle area progressively increased to a maximum at the $T 12$ steak $\left(64.0 \mathrm{~cm}^{2}\right)$, and then reduced to a minimum at the posterior end at the L6 steak $\left(44.2 \mathrm{~cm}^{2}\right)$. However, average LD area was greater $(P<0.04)$ for steaks adjacent to lumbar vertebrae $\left(57.4 \mathrm{~cm}^{2}\right)$ vs. thoracic vertebrae $\left(49.1 \mathrm{~cm}^{2}\right)$.

Conclusion: Overall, the largest LD area was detected between the T12 and T13 junction, which is consistent with measurement of that location for yield grading. These results also support greater objective tenderness from the loin subprimal relative to the rib primal, however overall tenderness varied throughout the entire LD.

Keywords: Beef, Holstein, Lumbar, Tenderness, Thoracic 


\section{Meat and Poultry Quality and Composition - Measurement and Prediction}

105

\section{CARCASS CHARACTERISTICS OF BEEF CATTLE FINISHED ON CONTINUOUSLY STOCKED PASTURES OF WHEAT, TRITICALE AND RYEGRASS MIXTURES}

C. Weissend ${ }^{1, *}$, C. Holland ${ }^{1}$, K. Marchant ${ }^{1}$, C. Bratcher ${ }^{1}$

${ }^{1}$ Auburn University, Auburn, United States

Objectives: An experiment was conducted to evaluate the carcass characteristics of growing-finishing beef cattle from continuously stocked mixed pastures of triticale (Triticale secale), wheat (Triticum aestivum) and ryegrass (Lolium multiflorum).

Materials and Methods: Twenty-four yearling Angus cross steers in year one (mean initial BW, $391 \pm 98 \mathrm{~kg}$ ) and 18 Angus cross steers in year two (mean initial BW, $315 \pm 44 \mathrm{~kg}$ ) were randomly assigned to six 1.42-ha pastures ( 3 steers/pasture) planted with mixtures of wheat \& ryegrass (WR), triticale \& ryegrass (TR), or wheat, triticale \& ryegrass (WTR). There were 2 pasture replicates per treatment. Pastures were grazed 116 d from January 29, 2013 to May 24, 2013 in year one and $161 \mathrm{~d}$ from December 16, 2013 to May 26, 2014 in year two. Additional put-and-take steers were used as necessary to maintain forage allowance at $1 \mathrm{~kg} \mathrm{DM} / \mathrm{kg}$ steer BW. Forages were sampled biweekly throughout each grazing season and steer weights were recorded every $28 \mathrm{~d}$. Grazing was discontinued when forage quality and availability were no longer adequate to support satisfactory steer ADG. Steers were humanely harvested each year at a commercial processing facility. Carcasses were measured for skeletal maturity, lean maturity, average maturity, marbling, quality grade, hot carcass weight, back-fat thickness, Longissimus muscle area, kidney pelvic and heart fat, yield grade, and dressing percent. Lean color ( $L^{*}, a^{*}$ and $b^{*}$-values) and fat color $\left(L^{*}, a^{*}\right.$, and $b^{*}$-values) were measured using a Hunter Miniscan XE Plus colorimeter. Data were analyzed separately for each year as a completely randomized design by the PROC GLM procedure of SAS with treatment as the experimental unit.

Results: In year one, differences were only observed $(P<0.05)$ in fat color $b^{*}$ values when analyzed across treatments. Fat color $b^{*}$ values were 28.9, 30.1 and 33.0 for WTR, WR and TR, respectively. In year two, differences were only observed $(P<0.05)$ in fat color $a^{*}$ values when analyzed across treatments. Fat color $a^{*}$ values were 6.9, 10.0, and 12.7 for TR, WTR and WR, respectively.

Conclusion: Therefore, fat color in steers finished on continuously stocked pastures of triticale and ryegrass mixtures will have the potential to be more yellow and less red than steers finished on continuously stocked pastures of wheat and ryegrass or wheat, triticale, ryegrass mixtures. With no observed differences in other measured variables the decision for which forage combination to utilize for winter forage feeding is largely dependent upon which forages produce better growth performances for a particular geographic region and on consumer perception of differences in fat color. 
Keywords: Carcass Traits, Grass Fed 


\section{Meat and Poultry Quality and Composition - Measurement and Prediction}

106

\section{UTILIZATION OF CARCASS MEASUREMENTS TO PREDICT FABRICATION OUTCOMES OF CALF-FED HOLSTEIN STEERS.}

T. J. McEvers ${ }^{1, *}$, N. D. May ${ }^{1}$, L.-A. J. Walter ${ }^{1}$, J. A. Reed ${ }^{1}$, J. P. Hutcheson ${ }^{2}$, T. E. Lawrence ${ }^{1}$

${ }^{1}$ Beef Carcass Research Center, West Texas A\&M University, Canyon, ${ }^{2}$ Merck Animal Health, Summit, United States

Objectives: Grading and fabrication characteristics obtained during a serial harvest trial of 115 steers (BW $=449.2$ $\pm 19.9 \mathrm{~kg}$ ) were utilized to build predictive models for primal weights \{round (RND,kg), loin (LN,kg), flank (FK,kg), rib

$(\mathrm{RIB}, \mathrm{kg})$, plate $(\mathrm{PT}, \mathrm{kg})$, chuck $(\mathrm{CK}, \mathrm{kg})$, and brisket $(\mathrm{BK}, \mathrm{kg})\}$ and fabrication characteristics (saleable yield (SL, \%), trimmable fat $(\mathrm{TF}, \%)$, and bone (BN,\%) percentage, respectively).

Materials and Methods: Five steers were randomly harvested on d 226 for modeling purposes. Remaining cattle ( $n=$ 110 ) were randomly allocated to diet treatment (one-half were fed zilpaterol hydrochloride $(\mathrm{ZH} ; 8.33 \mathrm{mg} / \mathrm{kg} 100 \% \mathrm{DM}$ basis) during the final 23 days on feed (DOF) including a $3 \mathrm{~d} Z \mathrm{ZH}$ withdrawal prior to harvest with the remainder fed a control diet) and harvest endpoint (254, 282, 310, 338, 366, 394, 422, 450, 478, 506, and 534 DOF). Models were developed using the REG procedure of SAS for prediction of fabrication characteristics. Additionally, collinearity diagnostics were performed using calculated variance inflation factors (VIF). A VIF of 10 or greater for any variable was considered an indicator of multicollinearity. Cattle feeding history including DOF and ZH supplementation $(0=$ control; $1=$ fed $\mathrm{ZH})$ were included in development of all models. Grading data included subcutaneous fat thickness $(\mathrm{FT}, \mathrm{cm})$, longissimus muscle area (LMA, $\left.\mathrm{cm}^{2}\right)$, kidney-pelvic-heart fat percentage $(\mathrm{KPH}, \%)$, cold carcass weight $(\mathrm{CCW}, \mathrm{kg})$, and estimated marbling score (MARB).

Results: For prediction of RND, a four variable equation was developed with an $\mathrm{R}^{2}$ of 0.9273 and root mean square error (RMSE) of $3.6\{\mathrm{RND}=21.145+(2.59951 * \mathrm{ZH})-(0.02388 * \mathrm{DOF})-(4.30196 * \mathrm{FT})+(0.20753 * \mathrm{CCW})\}$. For prediction of LN, a three variable equation with an $\mathrm{R}^{2}$ of 0.9166 and RMSE of 3.3 was calculated $\{\mathrm{LN}=4.81029+(3.56553 * \mathrm{FT})-(0.08253 * \mathrm{MARB})+$ $(0.13287 * \mathrm{CCW})\}$. For prediction of RIB, a three variable equation with an $\mathrm{R}^{2}$ of 0.8707 and RMSE of 2.3 was calculated $\{\mathrm{RIB}=-$ $3.33023+(0.06017 * \mathrm{LMA})+(0.13802 * \mathrm{MARB})+(0.06199 * \mathrm{CCW})\}$. For prediction of CK, a three variable equation with an $\mathrm{R}^{2}$ of 0.9550 and RMSE of 4.8 was developed $\{\mathrm{CK}=-7.12505+(0.03329 * \mathrm{DOF})-(2.92430 * \mathrm{FT})+(0.27031 * \mathrm{CCW})\}$. For prediction of $\mathrm{FK}$, a two variable equation with an $\mathrm{R}^{2}$ of 0.7677 and RMSE of 3.2 was calculated $\{\mathrm{FK}=-4.86814+(2.34441 * \mathrm{FT})+$ $(0.0674 * \mathrm{CCW})\}$. For prediction of PT, a four variable equation with an $\mathrm{R}^{2}$ of 0.9073 and RMSE of 3.8 was calculated $\{\mathrm{PT}=-$ $14.95495-(1.88461 * \mathrm{ZH})-(0.07082 * \mathrm{LMA})+(0.12267 * \mathrm{MARB})+(0.15723 * \mathrm{CCW})\}$. For prediction of BK, a two variable equation was developed with an $\mathrm{R}^{2}$ of 0.7600 and RMSE of $3.6\left\{\mathrm{BK}=2.80383-\left(0.08453^{*} \mathrm{MARB}\right)+\left(0.09147^{*} \mathrm{CCW}\right)\right\}$. Saleable lean prediction included a four variable equation with an $\mathrm{R}^{2}$ of 0.5514 and RMSE of $1.9\{\mathrm{SL}=69.27871+(2.21042 * \mathrm{ZH})-(1.54976 * \mathrm{FT})$ $+(0.04310 * \mathrm{LMA})-(0.02034 * \mathrm{CCW})\}$. Prediction of TF included a four variable equation with an $\mathrm{R}^{2}$ of 0.7059 and RMSE of 2.1 $\{\mathrm{TF}=3.30172-(1.44886 * \mathrm{ZH})+(2.24286 * \mathrm{FT})+(0.47415 * \mathrm{KPH})+(0.02585 * \mathrm{CCW})\}$. Prediction of BN included a seven variable equation with an R2 of 0.6640 and RMSE of $0.98(\mathrm{BN}=26.27455-(0.56384 * \mathrm{ZH})+(0.00896 * \mathrm{DOF})-(0.56125 * \mathrm{FT})-$ $(0.02363 * \mathrm{LMA})-(0.21955 * \mathrm{KPH})-(0.02343 * \mathrm{MARB})-(0.01721 * \mathrm{CCW})\}$.

Conclusion: Equations developed utilizing readily available data to beef processors may add to the knowledge of fabrication characteristics of calf-fed Holstein steers. 
Keywords: Beef, Carcass, Holstein, Yield 


\section{Meat and Poultry Quality and Composition - Measurement and Prediction}

107

\section{EFFECTS OF USDA BEEF QUALITY GRADE, MUSCLE, AND WET-AGING ON RAW PROXIMATE COMPOSITION AND LIPID OXIDATION BY-PRODUCTS}

C. N. Kirby 1,,, J. C. Brooks ${ }^{1}$, J. N. Martin ${ }^{2}$, M. F. Miller ${ }^{1}$

${ }^{1}$ Animal and Food Sciences, Texas Tech University, Lubbock, TX, ${ }^{2}$ Animal Science, Colorado State University, Fort Collins, CO, United States

Objectives: The objective of this study was to assess the raw proximate composition and formation of lipid oxidation byproducts in ground beef patties prepared from three denuded beef muscles (Gluteus medius (GM), Biceps femoris (BF), Serratus ventralis (SV) representing three USDA beef quality grades (Prime, Low Choice, Standard) and two wet-aging periods (21d and $42 \mathrm{~d})$.

Materials and Methods: A maturity carcasses representing USDA Low Choice, Prime, and Standard ( $n=6 /$ Quality Grade) were identified for procurement of the top sirloin, bottom round, and chuck roll from the left and right sides of each carcass. The paired subprimals from each carcass were vacuum packaged and randomly assigned to wet-aging for 21 or $42 \mathrm{~d}$ before transportation to Texas Tech University and storage ( 2 to $4{ }^{\circ} \mathrm{C}$ ) for their designated aging periods. At each aging period, subprimals were fabricated into individual muscles and denuded before grinding. The ground meat from each muscle were hand stuffed into chub packages and frozen at $\left(-20^{\circ} \mathrm{C}\right)$. Five weeks after freezing, chub packages were portioned into patties, individually identified, randomly and evenly assigned to analysis of proximate composition (moisture, protein, ash and fat) or lipid oxidation (TBARs; mg malonaldehyde/ kg meat) vacuum packaged, and stored at $\left(-20^{\circ} \mathrm{C}\right)$ for subsequent analyses . Homogenized patties were maintained at $\left(-80^{\circ} \mathrm{C}\right)$ until analysis. Data were analyzed using a mixed model with USDA quality grade, muscle and aging period serving as the fixed effects of interest while carcass identification was a random variable. The resulting least square means were separated using an $\alpha$ of 0.05 . Results: As expected, total fat content varied among USDA quality grades, with USDA Prime samples containing the greatest amount of fat and USDA Standard samples the least. Among the three muscles, SV contained the most fat $(P<$ $0.05)$, while the GM contained the least $(P<0.05)$. Muscle age had no influence $(P=0.72)$ on the fat content of ground beef patties derived from individual beef muscles. Moisture content was influenced by USDA quality grades and muscle. Muscles derived from USDA Low Choice and USDA Standard carcasses had greater moisture content $(P<$ $0.001)$ than muscles from USDA Prime carcasses. Similarly, ground beef derived from BF and GM had more moisture ( $P$ $<0.001)$ than SV samples. Samples aged for $21 \mathrm{~d}$ before grinding had more ash than samples aged for $42 \mathrm{~d}(P<0.05)$. Likewise, protein content was greater $(P=0.005)$ in samples aged for $42 \mathrm{~d}$ versus those aged for $21 \mathrm{~d}$. Among muscles, the SV contained less protein $(P<0.001)$ than either the BF or GM. Neither USDA quality grade nor muscle source or age had an effect on the amount of lipid oxidation by-products present in samples. 
Conclusion: These data indicate that USDA quality grade and muscle source influence the proximate composition of ground beef, while it did not influence lipid oxidation by-products. Interestingly, although muscle age influenced the moisture and protein content of ground beef samples, it had no effect on total fat content. This information will provide valuable insight into the development of quality and palatability characteristics associated with individual muscles.

Keywords: beef, fat, ground, muscle, quality 


\section{Meat and Poultry Quality and Composition - Measurement and Prediction}

108

\section{THE PHYSICAL AND THERMAL PROPERTIES OF PRIME, LOW CHOICE, AND STANDARD BEEF STRIP STEAKS AT REFRIGERATED TEMPERATURES.}

J. McClellan 1, ${ }^{*}$, J. Legako ${ }^{1}$, S. Martini ${ }^{1}$, K. Allen ${ }^{1}$, H. Ban ${ }^{2}$

${ }^{1}$ NDFS, 2 Mechanical and Aerospace Engineering, Utah State University, Logan, United States

Objectives: The physical properties of beef influence consumer perception of tenderness. Furthermore, intramuscular fat (IMF) content has been related with tenderness in numerous studies. However, the effects of varying IMF levels on physical and thermal properties of beef steaks have not been established.

Materials and Methods: In this study, 24 strip loins were selected representing USDA quality grades (QG) of Prime, Low Choice, and Standard ( $n=8$ per quality grade). At 21 days post-mortem, strip steaks were produced at a thickness of 2.54 $\mathrm{cm}$ and frozen $\left(-20^{\circ} \mathrm{C}\right)$ until analysis. Prior to analysis $(23 \pm 3$ hours $)$, steaks were thawed at $3-5^{\circ} \mathrm{C}$. Samples were held in the $3-5^{\circ} \mathrm{C}$ environment during sample preparation and testing. Quality grade effects were determined by one-way anaylsis of variance with a significance level of 0.05 .

Results: Thermodynamic property measurements $(P \geq 0.403)$, viscoelasticity measurements $(P \geq 0.207)$, water activity $(P$ $=0.127)$, expressible moisture $(P=0.107)$, water holding capacity $(P=0.107)$, and shear force $(P=0.600)$ were determined to not differ between QG. Textural properties such as adhesion, chewiness, and cohesiveness $(P \geq 0.077)$ did not differ, however, hardness $(P<0.032)$, springiness $(P<0.012)$, and resilience $(P<0.047)$ were affected by $Q G$. Prime steaks had greater $(P<0.05)$ hardness and resilience when compared to Low Choice and Standard steaks. Alternatively, Standard steaks had greater $(P<0.05)$ springiness. Protein degradation was determined through the measurement of steak surface and steak center enthalpy of actin, myosin and sarcoplasmic proteins. Actin did not differ due to QG, regardless of location $(P \geq 0.568)$. However, the enthalpy of center steak myosin and sarcoplasmic proteins was affected by $Q G(P=0.001)$, where Standard steaks were lower $(P<0.05)$ when compared to Prime and Low Choice.

Conclusion: Overall, these findings indicate that $Q G$ has moderate effects on the thermal and physical properties of steaks at refrigerated temperatures $\left(3-5^{\circ} \mathrm{C}\right)$. It is recognized that a divergence in physical properties, such as shear force, occurs between quality grades after cooking. Therefore, further data at progressive cooked internal temperatures will be collected to elucidate the effects of quality grade on the thermal and physical properties of beef.

Keywords: quality grade, strip steak, thermophysical 


\section{Meat and Poultry Quality and Composition - Measurement and Prediction}

109

\section{COMPARISON OF NIX COLOR SENSOR AND NIX COLOR SENSOR PRO TO STANDARD MEAT SCIENCE RESEARCH COLORIMETERS}

J. Hodgen $1, *$

${ }^{1}$ Merck Animal Health, DeSoto, United States

Objectives: Color is a key attribute in consumers buying fresh meat. Monitoring of color to maximize shelf life and consumer acceptability can be cumbersome due to restrictions of typical lab scale colorimeters such as the Minolta and Hunter systems. While these are high performance devices that deliver very precise measurements, their expense and portability may possibly limit the amount of data that could be collected in everyday application. Therefore, the objective of this research was to comparatively test a colorimeter with a smartphone app originally developed for the paint industry with the Minolta and Hunter systems to determine if a smaller, more affordable device would have application in the meat industry.

Materials and Methods: A Konica Minolta Chroma Meter CR-410 (MIN; Konica Minolta Sensing Americas, Inc, New Jersey, USA), a Hunter MiniScan EZ (HMS; Hunter Associates Laboratory, Reston, VA), Nix Color Sensor (NIX; Nix Sensor, Ltd, Burlington, Ontario, Canada) and Nix Color Sensor Pro (NPRO; Nix Sensor, Ltd, Burlington, Ontario, Canada) were tested by averaging 3 scans against colored paper (white, red, pink, grey, and brown) and multiple cuts of meat from chicken, pork, and beef with various stages of visually determined myoglobin development.

Results: All of the sensors recorded similar results for the paper samples $(P>0.05)$. Deoxymyoglobin and oxymyoglobin samples had less than 2 units difference for each $L^{*}, a^{*}$, and $b^{*}$ between the 4 devices. The difference seen between the NIX and NPRO versus the MIN and HMS is in-part due to significant digits reported by each device. Metmyoglobin samples saw more color difference $(P<0.05)$ between the NIX and NPRO compared to the MIN and HMS. This difference may be due to the optic view size, so while each scan was in the same place on the sample for each device, the NIX and NPRO scanned a smaller area. The smaller area does allow for easier avoidance of connective tissue or fat bands, and two tone areas, but more research should be conducted as the optimal number of scans might be 4-6 rather than 3 as with the standard colorimeters.

Conclusion: As the app continues to be updated and offer more features, ease and quickness of use has been improved for the NIX and NPRO. A feature of the NIX and NPRO that has the potential to increase consumer acceptability research is the instant generation of visual color panels. The affordability of the Nix Color Sensors might allow for more concurrent and timely research over various locations. Overall the NIX and the NPRO seem to be viable options for color research in meat science. 
Keywords: Color, Hunter Miniscan, Minolta CR-410, Nix Color Sensor 


\title{
Meat and Poultry Quality and Composition - Measurement and Prediction
}

110

\section{EFFECT OF ZILPATEROL HYDROCHLORIDE SUPPLEMENTATION AND DIETARY INTAKE LEVEL ON BEEF CARCASS FABRICATION YIELDS}

\author{
A. N. Schmitz ${ }^{1, *}$, L.-A. J. Walter ${ }^{1}$, W. T. Nichols ${ }^{2}$, J. P. Hutcheson ${ }^{2}$, T. E. Lawrence ${ }^{1}$ \\ 1West Texas A\&M University, Canyon, ${ }^{2}$ Merck Animal Health, Summit, United States
}

Objectives: An experiment was performed to evaluate the fabrication yields of carcasses from over-finished beef steers supplemented zilpaterol hydrochloride $(\mathrm{ZH})$ and fed at maintenance $(\mathrm{M})$ or ad libitum $(\mathrm{AL})$ intake levels.

Materials and Methods: Single-sired beef steers $(n=56)$ were blocked ( $n=28$ per block) by implant status and sorted into pairs by weight. A harvest $d$ of 0,28 , or 56 and a $M$ or $A L$ diet level within $d 28$ and 56 was randomly assigned to each pair. Additionally, supplementation of $\mathrm{ZH}$ was randomly applied within a pair for each of $\mathrm{M}$ and $\mathrm{AL}$ diet levels. Steers were individually weighed on $\mathrm{d} 0,1,27,28,55$, and 56 following feed and water withdrawal for a $9 \mathrm{~h}$ period. Adjustments for DMI on M diet level were performed accordingly by weighing steers on $\mathrm{d} 11$ and 21 with AL bunk calls adjusted daily depending on feed refusal. ZH was fed continuously at $90 \mathrm{mg}$ for $20 \mathrm{~d}$ followed by a withdrawal period of $4 \mathrm{~d}$. Steers were finished to above typical slaughter weights $(B W=603.5 \pm 48.1 \mathrm{~kg})$ prior to harvest at a commercial processing facility. After a $24 \mathrm{~h}$ chill period, standard USDA grading procedures were used to derive a calculated yield grade ( $3.7 \pm$ 0.3). Following grading procedures, the left side of each carcass was transported to the West Texas A\&M University Meat Laboratory for fabrication processes. Each side was fabricated into subprimals to determine individual red meat yield (RMY), trimmable fat yield (TFY), and bone yield (BY). A mixed model was used for analysis; fixed effects included treatment combinations and random effects included block and pairs. Single df contrasts tested d 0 vs. 28 , d 0 vs. 56 , d 28 vs. $56, \mathrm{M}$ vs. AL, and Control (CON) vs. ZH. Differences were considered significant at a $P$-value $\leq 0.05$ and trends at a $P$-value $\geq 0.05$ and $\leq 0.10$.

Results: Yield of chuck eye roll differed $(P<0.05)$ by harvest day $(0=4.1,28=4.1,56=4.6 \%)$, intake $(\mathrm{M}=4.41, \mathrm{AL}=$ $4.40 \%)$, and treatment $(\mathrm{CON}=4.6, \mathrm{ZH}=4.5 \%)$. Similarly, eye of round yield was impacted $(P<0.05)$ by harvest day $(0$ $=1.5,28=1.4,56=1.4 \%)$, intake $(\mathrm{M}=1.4, \mathrm{AL}=1.3 \%)$, and treatment $(\mathrm{CON}=1.3, \mathrm{ZH}=1.4 \%)$. Additionally, brisket yield was altered $(P<0.01)$ by harvest day $(0=4.1,28=3.6,56=3.5 \%)$, intake $(\mathrm{M}=3.47, \mathrm{AL}=3.54 \%)$, and treatment $(\mathrm{CON}=3.4, \mathrm{ZH}=3.6 \%)$. Days on feed, intake and treatment tended $(P<0.09)$ to alter shoulder clod yield $(0=2.2,28=$ $2.0,56=2.0 \% ; \mathrm{M}=2.0, \mathrm{AL}=1.9 \% ; \mathrm{CON}=1.9, \mathrm{ZH}=2.1 \%)$. For remaining subprimals, no differences $(P \geq 0.15)$ were detected. Furthermore, results indicated that RMY tended $(P<0.07)$ to differ by harvest day $(0=64.0,28=63.3,56=$ $62.5 \%)$, intake $(\mathrm{M}=63.4, \mathrm{AL}=62.1 \%)$, and treatment $(\mathrm{CON}=61.4, \mathrm{ZH}=63.7 \%)$. Comparatively, TFY was impacted $(P$ $<0.04)$ by harvest day $(0=20.9,28=21.0,56=22.4 \%)$, intake $(\mathrm{M}=20.5, \mathrm{AL}=23.3 \%)$, and treatment $(\mathrm{CON}=23.5, \mathrm{ZH}$ $=21.3 \%)$. No difference $(P=0.80)$ was detected for BY $(15.7 \pm 0.01 \%)$. 
Conclusion: The results from this study indicate that intake level during the last 56 days of finishing and $\mathrm{ZH}$ supplementation affect subprimal yield of chuck eye roll, eye of round, brisket, and shoulder clod as well as carcass RMY and FY of beef steers.

Keywords: Beef, carcass composition, Zilpaterol Hydrochloride 


\title{
Meat and Poultry Quality and Composition - Measurement and Prediction
}

111

\section{MEASURING THE QUALITY OF, AND ADDING VALUE TO HAMS BY ASSESSING THE LOIN}

\author{
H. Shetters ${ }^{1, *}$, D. Johnson ${ }^{1}$, C. Carr ${ }^{1}$, J. Neto ${ }^{2}$ \\ 1 University of Florida, Gainesville, United States, ${ }^{2}$ Federal Institute of Science, Education and Technology of Mato \\ Grosso, Campo Grande, Brazil
}

Objectives: The bulk of lean pork yield is generated by the ham, however little information is known about associations between the extensively studied loin and ham quality. The purpose of this research was to determine if quantifying loin quality is an effective means to stratify ham quality differences and ultimately optimize quality for both processors and consumers.

Materials and Methods: Pigs $(n=12)$ were slaughtered on three days with the goal being to maximize lean quality variation by varying feed withdrawal and time of comingling prior to transportation, lairage, and slaughter. All procedures received IACUC approval (UF \# 201408407). Time from stunning until arriving in the carcass cooler was varied to result in the three treatments, with the intent to produce a normal $(N)$, fast $(F)$, and incomplete (I) early postmortem $\mathrm{pH}$ decline. Carcasses were fabricated at $24 \mathrm{~h}$ postmortem into primal cuts according to the National Association of Meat Purveyors (NAMP) guidelines (NAMP, 2007) and left sides were used to assess all $24 \mathrm{~h}$ meat quality data. Objective lean color $\left(L^{*}, a^{*}, b^{*}\right)$ were evaluated using a Hunter Labscan with an illuminant setting of D65/10 with a $2.54 \mathrm{~cm}$ aperture and $\mathrm{pH}$ was evaluated on the serratus ventralis (SV) of the blade face and gluteus medius (GM) of the sirloin face from the rough cut 413 loin. Loins were then cut into boneless $412 \mathrm{~B}$ loins, where objective color and pH were evaluated from the longissimus muscle (LM) at the blade end, sirloin end and the marked $10^{\text {th }}$ rib location on the boned side of the boneless loin. Hams were further fabricated into individual muscles (biceps femoris, adductor, semimembranosus, semitendinosus, GM, gracilis, vastus lateralis, and rectus femoris) then denuded prior to objective color and $\mathrm{pH}$ being measured in duplicate on the external surface of the muscle. Samples were frozen after $7 \mathrm{~d}$ of postmortem storage for cooking and trained sensory assessment. Animal was the experimental unit, with muscle, treatment, and their interactions as fixed effects, and slaughter date was a random effect, in the mixed model analysis of SAS.

Results: Ultimately, $10^{\text {th }}$ rib $L M$ pH ranged from 5.29-5.67, Hunter $L^{*}$ from 50.1-63.0, and $7 \mathrm{~d}$ vacuum sealed loin purge loss ranged from $0-19.1 \%$. Semitendinosus muscle samples rated the highest for cooked juiciness and flavor $(P<0.05)$ compared with other muscles assessed. However, the ability to predict semitendinosus eating quality from other quality parameters seems challenging as no measured fresh lean quality variable had Pearson correlation coefficient $\{R\}$ at a Pvalue less than 0.05 .

Conclusion: The semitendinosus holds promise as an additional pork cut to be marketed as fresh, rather than processed, due to its consistent shape, size, and desirable palatability. 
Keywords: ham, Pork Quality 


\section{Meat and Poultry Safety}

112

\section{DISTRIBUTION OF SALMONELLA OF LYMPH NODE ORIGIN THROUGHOUT GROUND BEEF}

K. Malin 1,*, T. Brown ${ }^{2}$, T. Edrington ${ }^{2}$, G. Loneragan ${ }^{1}$

${ }^{1}$ Animal and Food Science, Texas Tech University, Lubbock, ${ }^{2}$ USDA-ARS, College Station, United States

Objectives: This study was conducted to investigate the distribution of Salmonella, introduced via lymph nodes, throughout coarse ground beef product.

Materials and Methods: Peripheral lymph nodes were collected from steers challenged with Salmonella via a transdermal method. This study consisted of two models. Both Model 1 and Model 2 consisted of six replicates each. In each replicate of Model 1, six PLN i.e. the pre-scapular, subiliac and popliteal lymph nodes collected from both sides of the animal were mixed into 10 kilograms of $85 / 15$ beef trim and ground using a 3/8-inch grinder plate to simulate a coarse grind. The ground product passed through a loafing attachment and onto wax paper. The continuous ground beef loaf was portioned into approximately 100-gram samples and kept in chronological order resulting in approximately 100 samples per replicate. All of the ground product was sampled from each replicate. Ground beef samples were individually placed into filtered bags. Each sample was cultured both qualitatively and quantitatively. In each replicate of Model 2, one LN was added to $10 \mathrm{~kg}$ of trim. One $\mathrm{kg}$ of trim was ground first, the $\mathrm{LN}$ was added, then the remaining $9 \mathrm{~kg}$ was ground. The trim was ground and samples were processed as described for Model 1.

Results: The distribution of qualitative and quantitative Salmonella recovery from coarse GB of Model 1 is presented in Figure 1. For each of the 6 replicates, the adipose tissue surrounding the lymph node was left to better reflect how lymph nodes are incorporated into trim for ground beef production. The six replicatess of Model 1 (labeled REP 1-6) yielded very different results. Figure 1 shows the distribution of positive samples from each replicate. A blue bar indicates a positive sample, while a red bar indicates a quantifiable sample. The percentage of Salmonella positive samples in reps $1-6$ were $87.4 \%, 56.7 \%, 50.9 \%, 28.4 \%, 68.6 \%$, and $49.5 \%$, respectively. The distribution of Salmonella appears to be hightly clustered and clearly associated with the entry of a lymph node into the grinder head. Enumeration analysis of each sample resulted in a mean concentration of $2.27 \log 10$ CFU per 100-g ground beef sample (GB). In Model 2, there was also variation in the number of Salmonella-positive samples. In Reps 1-6, 3.9\%, 15.8\%, 6\%, 13.7\%, 19.8\%, and $8.8 \%$ of samples were positive, respectively. There were no quantifiable samples in Model 2. Similar to Model 1, Salmonella appears to be clustered and was rarely recovered once the lymph node had passed through the grinder plate.

Image: 


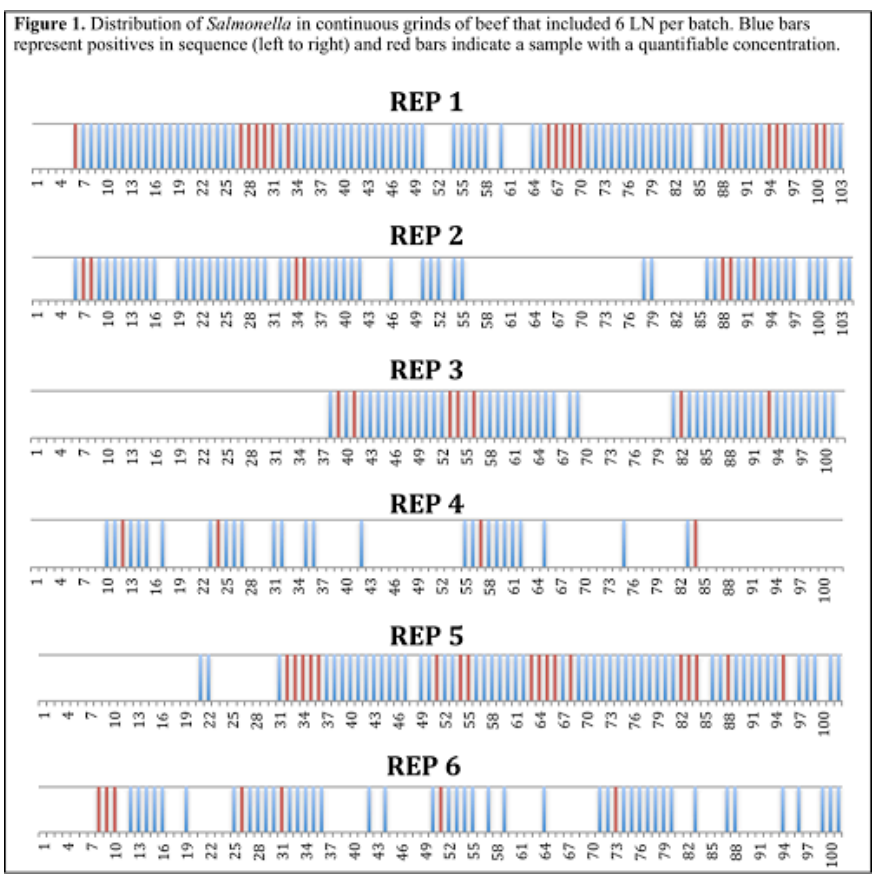

Conclusion: The improved understanding of the distribution of Salmonella within the lymph nodes of harvest-ready cattle can provide information to beef processors about the risk associated with these tissues during carcass fabrication and further processing. As lymph nodes are often encased in fat, current intervention strategies do not reach Salmonella harbored within the lymph node. The continued investigation of the inclusion of Salmonella-positive lymph nodes into ground beef can aid in the development of practical interventions to reduce Salmonella contamination of ground beef product. An example of a potential mitigation strategy would be the application of an intervention prior to regrinding of coarse ground beef to a fine ground beef product.

Keywords: Ground beef, Lymph nodes, Salmonella 


\section{Meat and Poultry Safety}

113

\section{EFFECT OF CHILLING, FREEZING AND COOKING ON SURVIVABILITY OF CLOSTRIDIUM DIFFICILE SPORES IN GROUND BEEF}

G. Flock ${ }^{1,}{ }^{\star}$, C.-H. Chen ${ }^{1}$, H.-B. Yin ${ }^{1}$, S. Fancher ${ }^{1}$, S. Mooyottu ${ }^{1}$, K. Venkitanarayanan ${ }^{1}$

${ }^{1}$ Animal Science, University of Connecticut, Storrs, United States

Objectives: Clostridium difficle is a major cause of enteric disease in humans, and has been isolated from a variety of foods, including beef. Genotypically identical $C$. difficile strains implicated in human infections have been isolated from food animals and foods, thereby further strengthening the role of food in the transmission of $C$. difficle to humans.

However, no information currently exists on the viability characteristics of $C$. difficile in foods, or the effect of various food processing treatments on $C$. difficile spores. This study investigated the effect of chilling, freezing and USDA recommended cooking temperature on $C$. difficile spore viability in ground beef.

Materials and Methods: A three-strain C. difficile spore mixture suspension was inoculated at two levels ( 3 log CFU/g and $5 \log \mathrm{CFU} / \mathrm{g})$ to ground beef. The inoculated samples were separately subjected to freezing storage $\left(-18^{\circ} \mathrm{C}\right)$ for 12 weeks, refrigerated storage $\left(4^{\circ} \mathrm{C}\right)$ for 1 week, and cooking $\left(71.1^{\circ} \mathrm{C}\right.$ internal temperature), after which viable spores were enumerated. In addition, total bacterial load in refrigerated and frozen ground beef was determined at each sampling time point.

Results: Freezing of ground beef for 12 weeks or refrigeration for 1 week did not affect the viability of $C$. difficile spores at both levels of inoculation ( $p>0.05$ ). In addition, cooking ground beef to the USDA recommended temperature of $71.1^{\circ} \mathrm{C}$ decreased $C$. difficile spores only by 1 log CFU/g compared to uncooked controls $(p<0.05)$.

Conclusion: The results suggest that $C$. difficile spores can survive chilling, freezing and the USDA recommended cooking temperature in ground beef, thereby warranting the development of suitable intervention strategies for controlling the pathogen.

Keywords: Chilling, Clostridium difficile, Cooking , Freezing, Spore viability 


\section{Meat and Poultry Safety}

114

\section{COMPARISON OF ANTIMICROBIAL INTERVENTIONS SPRAYED ONTO BEEF RIB CAP SECTION INOCULATED WITH E. COLI O157:H7}

S. Kumar ${ }^{1, *}$, M. Husman ${ }^{1}$, O. Sliekers ${ }^{2}$

${ }^{1}$ Corbion, Lenexa, United States, ${ }^{2}$ Corbion, Gorinchem, Netherlands

Objectives: To compare the antimicrobial effectiveness of various intervention solutions when sprayed onto $E$. coli O157:H7 inoculated beef rib cap sections.

Materials and Methods: Four E. coli $\mathrm{O} 157: \mathrm{H} 7$ strains that are resistant to gentamycin, novobiocin, and rifamycin SV (all at $25 \mu \mathrm{g} / \mathrm{ml}$; i.e., ' $25 \mathrm{GNR}$ ') were used in this study. Fresh beef rib caps were held at $4{ }^{\circ} \mathrm{C}$ until use. The beef rib caps were inoculated in triplicate sets on the dorsal side at $1 \times 10^{6} \mathrm{CFU} / \mathrm{cm}^{2}$, and were held for attachment for $25-30 \mathrm{~min}$ at $10^{\circ} \mathrm{C}$ before spray treatments. The spraying was done using a Ross TC700MC blade tenderizer with built-in spray system (the tenderizing capability was not used).

The following antimicrobial interventions were used to spray for the study: Beefxide and Purac®CL21/80 (2.5\% each) at 43$55^{\circ} \mathrm{C}$, Purac® FCC88 (4.54\%) at $43-55^{\circ} \mathrm{C}$, Aftec 3000 (no dilution) at room temperature and Peroxy Acetic Acid (PAA) at $200 \mathrm{ppm}$ concentration at room temperature. Water treatment at room temperature was used as control treatment. Microbiological analysis was done by plating after agitating sample bags in a stomacher for $60 \mathrm{sec}(540 \mathrm{rpm})$. The contents of the bags were diluted with $0.1 \%$ buffered peptone water and plated on tryptone soy agar plates with added antibiotics and incubated at $37^{\circ} \mathrm{C}$ for 24 hours. Untreated samples were plated to determine the background microflora.

Results: The most effective antimicrobial to reduce E. coli O157:H7 count on beef rib caps was the lactic acid based product, Purac $®$ FCC88 at $4.54 \%$. There was a 1.13 log reduction in E. coli $0157: H 7$ immediately after spraying Purac $®$ FCC88 compared to the water spray treatment. The spray treatments of beef rib caps with BeefXide, Purac $\circledast$ CL21/80, Aftec 3000 and PAA resulted in 0.58, 0.59, 0.59 and 0.35 log reductions in E. coli $\mathrm{O} 157: \mathrm{H} 7$ counts compared to water treatment, respectively.

Conclusion: The research substantiates the performance of lactic acid treatment to provide food safety solution for beef carcasses.

Keywords: Carcasses, E. coli, Harvest Treatment 


\title{
Meat and Poultry Safety
}

115

\section{EFFICACY OF CLEAN LABEL ANTIMICROBIALS AGAINST LISTERIA MONOCYTOGENES IN DELI-STYLE TURKEY FORMULATIONS}

\author{
S. Perumalla 1, ${ }^{\star}$, V. Sheehan 1, R. Cooper ${ }^{1}$, P. Ludtke 1, M. McGough 1, M. C. Golden ${ }^{2}$, B. J. Wanless ${ }^{2}$, K. Glass ${ }^{2}$ \\ ${ }^{1}$ Kerry, Inc, Beloit, ${ }^{2}$ Food Research Institute, University of Wisconsin-Madison, Madison, United States
}

Objectives: To compare the inhibitory properties of antimicrobials against Listeria monocytogenes in ready-to-eat cured and uncured deli-style turkey.

Materials and Methods: Five deli-style turkey formulations were prepared and sliced using Good Manufacturing Practices, each containing $\sim 1.6$ salt, $\sim 75 \%$ moisture, $\sim \mathrm{pH} 6.15$. Antimicrobial treatments included in the individual formulations consisted of: (i) control with no antimicrobials, (ii) commercial control consisting of a cured formulation (156 ppm ingoing sodium nitrite) with $3.8 \%$ of a potassium lactate and sodium diacetate blend, (iii) $1.5 \%$ liquid buffered vinegar, (iv) $2.0 \%$ and (v) $2.7 \%$ of liquid buffered vinegar and cultured dextrose blend. Cooked slices were surface inoculated with 3 log $\mathrm{CFU} / \mathrm{g}$ of a five-strain mixture of $L$. monocytogenes, vacuum packed (100 g/package), and stored for up to 14 weeks at $4{ }^{\circ} \mathrm{C}$. Populations of $L$. monocytogenes were enumerated in triplicate by plating samples onto modified oxford agar (35C, $48 \mathrm{~h})$ at weeks $0,4,6,7,8,9,10,11,12$, and 14 .

Results: The control formulation without antimicrobials supported the growth of $L$. monocytogenes resulting in an increase of $\sim 5.0$ log following 4 weeks storage at $4^{\circ} \mathrm{C}$. The commercial control inhibited L. monocytogenes growth throughout the duration of the study with an overall decrease of $0.6 \mathrm{log}$. Growth of L. monocytogenes was not observed over 14 weeks in uncured turkey formulations prepared with either 2.0 or $2.7 \%$ buffered vinegar-cultured dextrose blend. Moreover, a 1-log reduction of $L$. monocytogenes was observed in the formulation containing the $2.7 \%$ buffered vinegar-cultured dextrose blend. At 12 weeks, listerial growth was undetected in the treatment containing buffered vinegar alone, however, populations increased by $0.70 \log$ at 14 weeks.

Conclusion: The results presented here suggest that uncured deli-style turkey formulated with buffered vinegar when applied at levels delivering sufficient functional acids is effective at controlling the outgrowth of L. monocytogenes for 12 weeks of storage at $4^{\circ} \mathrm{C}$. Additional L. monocytogenes protection was achieved when products were formulated with a combination of buffered vinegar and cultured dextrose when compared with buffered vinegar alone. Furthermore, these results suggest that the buffered vinegar -cultured dextrose blends demonstrated anti-listerial efficacy comparable to the commercial control (cure and lactate-diacetate blend). Overall, the study demonstrates the efficacy of various clean-label antimicrobial interventions for use in the manufacture of uncured meat and poultry products. 
Keywords: Cultured Dextrose, Deli-style turkey, Liquid buffered vinegar, Listeria monocytogenes 


\title{
Meat and Poultry Safety
}

116

\section{REDUCED BURDEN OF SALMONELLA ENTERICA IN BOVINE SUBILIAC LYMPH NODES ASSOCIATED WITH ADMINISTRATION OF A DIRECT-FED MICROBIAL}

\author{
J. L. Vipham 1,*, G. Loneragan ${ }^{1}$, L. Guillen 2 , J. C. Brooks ${ }^{2}$, B. Johnson ${ }^{2}$, A. Pond ${ }^{3}$, N. Pond ${ }^{4}$, M. Brashears ${ }^{2}$

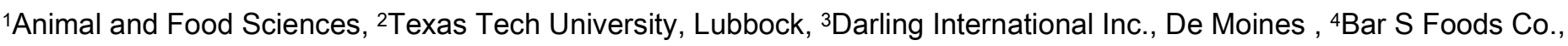 \\ Elk City, United States
}

Objectives: Despite effective food safety interventions within abattoirs, Salmonella enterica remains a common contaminant of raw ground beef. Research has implicated peripheral lymph nodes (PLNs) as a potential route by which Salmonella enterica contaminates ground beef. This study examined the efficacy of using Lactobacillus animalis (NP51) and Propionibacterium freudenreichii (NP24), at $10^{9} \mathrm{cfu} / \mathrm{head} /$ day, as a direct-fed microbial (DFM) in feedlot cattle diets to control Salmonella within PLNs.

Materials and Methods: Two studies were conducted in which cattle were randomly allocated into either control or DFM treatment groups. Diets of treated cattle were supplemented with $10^{9} \mathrm{cfu} / \mathrm{head} /$ day of the DFM, while control groups received no DFM supplementation. The cattle in the first study were slaughtered on three different dates (slaughter day 1 , 2, 3), which resulted in cattled being adminstered DFM for varying amounts of time (129, 142, 151 days, respectively). During slaughter at abattoirs, one subiliac lymph node (SLN) per carcass was collected from 627 carcasses from one study and 99 carcasses from the second study. Lymph nodes underwent microbial analysis and subsequent culture in order to estimate the presence and concentration of Salmonella enterica. Statistical analysis was conducted using the SAS System version 9.3, and alpha was set at 0.1. Binomial response variables for qualitative data were created where $r$ is the number of positives and $n$ is the number of nodes assayed. Generalized-linear mixed models using a log-link function were constructed, with block considered a random variable. Quantitative data were $\log _{10}$ transformed and analysed using a mixed linear model.

Results: In the first study, effects of DFM supplementation varied across slaughter days. On the first and second slaughter days, prevalence was reduced by $50 \%(p=0.0072)$ and $31 \%(p=0.0093)$, respectively. No significant difference was observed on slaughter day three $(p=0.1766)$. In the second study, Salmonella enterica was $82 \%$ less likely $(p=0.008)$ to be recovered from SLNs of treatment cattle. While a greater relative risk reduction was observed in the latter study, absolute risk reductions were similar across studies. A significant reduction in concentration of Salmonella enterica in SLNs $(p<0.0001)$ on a cfu/g and cfu/node basis was also observed in cattle administered NP51 and NP24 in the first study; in the second study, too few quantifiable SLNs were observed to facilitate meaningful comparisons.

Conclusion: The results indicate that NP51 and NP24 supplementation may aid in reducing the prevalence and concentration of Salmonella enterica in SLNs and, therefore, serve as an effective control measure to reduce Salmonella 
enterica in ground beef products. Further research is necessary in order to develop an understanding of the interaction between treatment and time observed in this study.

Keywords: Direct-fed microbial, Lymph nodes, Salmonella 


\section{Meat and Poultry Safety}

117

\section{PREVALENCE OF SALMONELLA FOUND ON THE SURFACE OF SMALL-RUMINANT CARCASSES}

K. E. Hanlon 1, ${ }^{*}$, M. F. Miller ${ }^{1}$, L. M. Guillen ${ }^{1}$, A. Echeverry ${ }^{1}$, S. Sanders ${ }^{2}$, L. A. Branham ${ }^{2}$, K. S. Spivey ${ }^{1}$, M. M. Brashears ${ }^{1}$

1Department of Animal and Food Sciences, Texas Tech University, Lubbock, 2Department of Agriculture, Angelo State University, San Angelo, United States

Objectives: Salmonella is a potentially serious food safety concern with a known presence in ruminants. In the literature Salmonella in beef cattle has been shown to be as high as $26.7 \%$ during pre-evisceration, with carcass interventions shown to be an effective to reduce this load. Information is known about the baseline of this organism in cattle, but less research has been published about the prevalence in small-ruminants. The objective of this study was to determine the prevalence of Salmonella found on the surface of lamb and goat carcasses processed within the United States.

Materials and Methods: Carcass swabs $(\mathrm{N}=596)$ were taken at three time-points during the harvest process, preevisceration $(\mathrm{N}=195)$, post-evisceration $(\mathrm{N}=201)$ and post-intervention $(\mathrm{N}=200)$. Sampling was done at small abattoir facilities in New Mexico and throughout Texas during the span of one calendar year. Interventions used varied by processing location in type and concentration of acid.

Carcass swabs were enriched and analyzed using a multiplex real-time polymerase chain reaction (PCR) system, cultured for confirmation of presumptive positives, and confirmed using latex agglutination.

Results: Salmonella was detected in $4.10 \%(n=8)$ of pre-evisceration swabs, $7.46 \%(n=15)$ of post-evisceration swabs and $3.00 \%(n=6)$ of post-intervention swabs.

Conclusion: Previously Salmonella has been reported at $1.5 \%$ in sheep carcasses post-intervention within the United States. These results indicate that Salmonella can be found on small ruminant carcasses at a higher prevalence during the harvest process, most notably after evisceration. The reduction of Salmonella detected indicates effectiveness of intervention techniques in the small-ruminant harvest process. These results demonstrate a need for further studies to be done to determine if organism prevalence could fluctuate by season, region or production practices.

Keywords: Goat, Intervention, Lamb, Salmonella, Small-ruminants 


\section{Meat and Poultry Safety}

118

\section{ENHANCING THE THERMAL DESTRUCTION OF ESCHERICHIA COLI 0157:H7 IN GROUND BEEF PATTIES BY NATURAL ANTIMICROBIALS}

M. Surendran Nair 1, ${ }^{*}$, P. Lau ${ }^{1}$, K. Belskie ${ }^{1}$, S. Fancher ${ }^{1}$, C.-H. Chen ${ }^{1}$, D. Karumathil ${ }^{1}$, H.-B. Yin ${ }^{1}$, F. Ma ${ }^{1}$, Y. Liu ${ }^{1}$, I. Upadhyaya $^{1}$, A. Upadhyay ${ }^{1}$, R. Mancini ${ }^{1}$, K. Venkitanarayanan ${ }^{1}$

${ }^{1}$ Department of Animal Science, University of Connecticut, Storrs, United States

Objectives: Escherichia coli O157:H7 (EHEC) is a major foodborne pathogen largely transmitted to humans due to the consumption of undercooked hamburger patties. The USDA has established zero tolerance for EHEC in ground beef, and recommends an internal cooking temperature of $71.1^{\circ} \mathrm{C}$ for patties. However, due to the lack of homogeneity in patty composition, and temperature monitoring difficulties, the recommended temperature may not be uniformly attained. Therefore, effective methods that kill EHEC in undercooked patties would reduce the likelihood of EHEC outbreaks. This study investigated the efficacy of two food-grade, plant-derived compounds, namely rutin hydrate $(\mathrm{RH})$, and $\mathrm{mega}$ resveratrol (MR) either alone or in combination with chitosan, in enhancing the thermal inactivation of EHEC in undercooked ground beef patties (medium rare cooked to $65^{\circ} \mathrm{C}$ ).

Materials and Methods: Fresh, fine ground beef ( $80 \%$ lean) purchased locally was divided into patties (25 g) and inoculated with a 5 -strain mixture of EHEC ( $7.0 \mathrm{log}$ CFU/g), followed by addition of RH $(0.05 \%, 0.1 \% \mathrm{w} / \mathrm{w})$ and MR $(0.1$, $0.2 \% \mathrm{w} / \mathrm{w})$ with or without $\mathrm{CH}(0.01 \%)$. The patties were packaged on styrofoam trays, wrapped with oxygen-permeable PVC film and stored at $4^{\circ} \mathrm{C}$ for 5 days. On days 1,3 and 5, patties were cooked to an internal temperature of $65^{\circ} \mathrm{C}$ and surviving EHEC were enumerated. The effect of treatments on meat color using MiniScan XE Plus colorimeter and lipid oxidation during storage was determined according to AMSA guidelines. In addition, scanning electron microscopy (SEM) was conducted to elucidate the antibacterial mechanism of action of RH and MR on EHEC.

The experimental design of the study was a completely randomized design with factorial treatment structure. Factors included antimicrobial treatments and storage days. Each batch of ground beef was divided into 160 patties of $25 \mathrm{~g}$ and randomly assigned to 1 of 80 , treatments $x$ storage time. Each patty served as an experimental unit and the entire study was repeated three times with duplicate samples per treatment. The data was analyzed using Mixed Procedure of SAS 9.4 and significance was tested at $P<0.05$.

Results: Both RH and MR enhanced thermal destruction of EHEC and reduced pathogen load by at least 3 log CFU/g compared with control $(\mathrm{P}<0.05)$. The combination of $\mathrm{RH}$ and $\mathrm{MR}$ with $\mathrm{CH}$ was more effective, and reduced EHEC by 5 log CFU/g $(P<0.05)$. However, the EHEC counts in uncooked patties did not decline during storage $(P>0.05)$. In addition, the treatments did not alter lipid oxidation compared with controls $(P>0.05)$, whereas there was an increased redness $\left(a^{*}\right.$ 
value) in patties treated with $\mathrm{MR}$ and $\mathrm{CH}(\mathrm{P}<0.05)$. In $\mathrm{SEM}$, a complete destruction of treated bacterial cells with blebs (small spheres of membrane coming off of bacteria) and pores was observed compared to unheated controls.

Conclusion: Results suggest that RH and MR could be used to inactivate EHEC in undercooked patties; however, detailed sensory studies are warranted.

Keywords: E.coli O157:H7, Ground beef patties, resveratrol, rutin 


\title{
Meat and Poultry Safety
}

119

\section{SURVIVAL OF SPOILAGE MICROORGANISMS ASSOCIATED WITH PICKLED SAUSAGE USING A COLD FILL PROCESS}

\author{
N. Gaydos 1,*, H. Gourama ${ }^{2}$, C. Cutter ${ }^{3}$, J. Campbell ${ }^{1}$
}

${ }^{1}$ Animal Sciences, The Pennsylvania State University, University Park, ${ }^{2}$ Food Science, The Pennsylvania State University, Reading, ${ }^{3}$ Food Science, The Pennsylvania State University, University Park, United States

Objectives: The pickling of sausages to preserve and extend shelf life is a process that has long been regarded as safe and until recently, has received little attention from regulators. However, incidences of spoilage contamination involving pickled meat products have occurred, prompting the USDA-FSIS to reconsider product stability. When cooked sausages are pickled with a heated solution of vinegar, salt and spices, it is called a "hot fill" process, resulting in a shelf stable product. Unfortunately, hot filling can result in fat leaching out of the sausages, causing the brine to become turbid and unappealing to consumers. The use of room temperature brine, known as "cold fill" pickling, does not cause the quality defects described above. However, little information exists as to whether this process will reduce spoilage microorganisms and prevent outgrowth of various microbial populations over time. The objective of this study was to investigate the effect of cold fill pickling on the survival of spoilage microorganisms: lactic acid bacteria (LAB), yeast $(Y)$ and mold (M) during processing and storage.

Materials and Methods: Strains of LAB, $Y$ and $M$ were chosen to represent microorganisms associated with spoilage of RTE sausages. Previous work indicated the need to segregate the microorganisms to prevent inhibition by the LAB. In addition, parameters such as the diameter of the sausages, casing type (collagen), and brine concentration were chosen in order to implement a "worst case scenario" for the experiments. In the current study, a room temperature brine solution $\left(5 \%\right.$ acetic acid $[\mathrm{v} / \mathrm{v}]$ and $5 \%$ salt $[\mathrm{wt} / \mathrm{v}], \mathrm{pH} \sim 2.70$ at $25^{\circ} \mathrm{C}$ ) was used to pickle fully cooked beef and pork sausages that were experimentally inoculated with $\mathrm{LAB}$ or $\mathrm{Y}$ and $\mathrm{M}$, as well as uninoculated, cold fill processed negative control sausages. Sausages were evaluated at various time points up to 28 days during pickling and storage $\left(25^{\circ} \mathrm{C}\right)$ for microbial populations, $\mathrm{pH}$, water activity $\left(\mathrm{a}_{\mathrm{w}}\right)$, and \% salt.

Results: Results showed that $L A B, Y$ and $M$ decreased significantly $(p \leq 0.05)$ as an effect of the cold fill pickling process within 7 days. Additionally, the pickled sausages experienced significant $(p \leq 0.05)$ decreases in $\mathrm{pH}$ over the length of the study while no significant $(p \leq 0.05)$ differences were observed in $a_{w}$ or $\%$ salt of the sausages or brine. Sausages inoculated only with LAB were reduced $\sim 5.34 \log _{10} \mathrm{CFU} / \mathrm{g}$ in 24 hours, with a total reduction of $6.58 \log _{10} \mathrm{CFU} / \mathrm{g}$ in 7 days. $Y$ were reduced $\sim 3.89 \log _{10} \mathrm{CFU} / g$ in 48 hours, while $\mathrm{M}$ were reduced $\sim 4.09 \log _{10} \mathrm{CFU} / \mathrm{g}$ in 24 hours. Furthermore, enrichments of both the brine and sausages were negative for $\mathrm{Y} \& \mathrm{M}$ after $72 \mathrm{~h}$. 
Conclusion: The results of this experiment demonstrate that cold fill processing can effectively reduce and inhibit spoilage microorganisms. Based on these findings, meat processors who utilize a cold fill process can use this research to validate their process in their HACCP plan. Processors may experience an even more effective inhibition of spoilage organisms by the use of higher concentrations of salt or acid, pickle smaller diameter sausages or use natural or skinless casings.

Keywords: cold fill , pickled sausage, spoilage microorganisms 


\section{Meat and Poultry Safety}

121

\section{THERMAL INACTIVATION OF SALMONELLA IN HIGH-FAT FRANKFURTERS}

R. Mcminn ${ }^{1, *}$, J. J. Sindelar ${ }^{1}$, K. A. Glass ${ }^{2}$, R. Hanson ${ }^{3}$

1University of Wisconsin - Madison, ${ }^{2}$ Food Research Institute, Madison, ${ }^{3 H a n s o n T e c h, ~ H u d s o n, ~ U n i t e d ~ S t a t e s ~}$

Objectives: USDA, FSIS Appendix A is widely used as validation support for thermal processes, but its time-temperature tables and humidity requirements were originally developed and validated only for Salmonella in roast, cooked, and corned beef. Appendix A however, is routinely applied to a much wider array of products than those examined in the original study. Furthermore the humidity requirements are limited in scope and difficult to apply to certain processes. Product-specific, time-temperature tables along with more flexible and robust humidity requirements are needed to improve validation of thermal processes

Purpose: To determine the temperature-death times of Salmonella in high-fat frankfurter batter at four different temperatures and validate these findings using commercial product and cooking processes.

Materials and Methods: Mechanically-separated turkey, 50\% lean pork trimmings, and all non-meat ingredients were chopped in a vertical cutter mixer, under vacuum, until a temperature of $12.7^{\circ} \mathrm{C}$ was reached. The batter was then inoculated with 8-log cfu/g Salmonella (5-strain mixture) and mixed for 1.5 minutes.

D-value determination: One-g samples of inoculated batter were flattened into a thin film (0.5-1.0 mm thickness) in moisture-impermeable pouches and vacuum-packaged. Samples were heated at one of four temperatures $\left(54.4^{\circ} \mathrm{C}\right.$, $60^{\circ} \mathrm{C}, 65.6^{\circ} \mathrm{C}, 71.1^{\circ} \mathrm{C}$ ) in a water bath. Triplicate samples were removed at predetermined time points and immediately chilled to $\leq 4^{\circ} \mathrm{C}$ by immersion in an ice water bath. Samples were then enumerated for the survival of Salmonella using XLD agar with a thin layer overlay of nonselective media to enhance recovery of injured cells. D-values were calculated from the linear regression on log reduction of Salmonella versus time. This experiment was replicated three times.

Validation: Inoculated batter was stuffed into size 28 cellulose casings and linked manually in 6-inch increments. Links were then transferred to a combination steam/convection oven and thermally processed following one of two cook schedules until an internal temperature of $71.1^{\circ} \mathrm{C}$ was achieved. The control cycle maintained a relative humidity $\geq 50 \%$ for half the duration of the cook cycle. The test cycle only applied steam during the final step of the process to investigate the efficacy of a surface lethality step. For both processes, triplicate links were removed when product internal temperature reached $54.4^{\circ} \mathrm{C}, 62.7^{\circ} \mathrm{C}$, and $71.1^{\circ} \mathrm{C}$. Casings were removed aseptically and $2.5 \mathrm{~cm}$ was removed from each end of the links. The central portion of each link was enumerated for the survival of Salmonella using the methods described above. This experiment was repeated twice. 
Results: D-values for $54.4^{\circ} \mathrm{C}, 60^{\circ} \mathrm{C}, 65.6^{\circ} \mathrm{C}$, and $71.1^{\circ} \mathrm{C}$ were $20.48 \pm 6.54,1.74 \pm 0.10,0.26 \pm 0.06$, and $0.06 \pm 0.01$ minutes, respectively. The control cycle produced an average log reduction of $-0.01 \pm 0.04,6.86 \pm 0.11$, and $6.86 \pm 0.11$ for the $54.4^{\circ} \mathrm{C}, 62.7^{\circ} \mathrm{C}$, and $71.1^{\circ} \mathrm{C}$ target temperatures, respectively. The test cycle achieved an average log reduction of $0.07 \pm 0.11,5.94 \pm 1.30$, and $6.91 \pm 0.18$ for the $54.4^{\circ} \mathrm{C}, 62.7^{\circ} \mathrm{C}$, and $71.1^{\circ} \mathrm{C}$ target temperatures, respectively. The test cycle achieved lethality comparable to that seen with the control cycle.

Conclusion: Appendix A time-temperature recommendations are adequate for controlling Salmonella in high-fat, small diameter products. Wet-bulb time-temperature may be sufficient as a replacement for relative humidity requirements.

Keywords: food safety, Salmonella, thermal processing, validation 


\section{Meat and Poultry Safety}

124

\section{BASELINE STUDY FOR PREVALENCE OF RESISTANT AND SUSCEPTIBLE CAMPYLOBACTER IN RETAIL GROUND BEEF}

K. A. Ortega ${ }^{1,}{ }^{*}$, G. H. Loneragan ${ }^{1}$, P. M. Ortega ${ }^{1}$, L. S. Guillen ${ }^{1}$, J. L. Vipham ${ }^{1}$, J. C. Brooks ${ }^{1}$, M. M. Brashears ${ }^{1}$

${ }^{1}$ Animal and Food Sciences, Texas Tech University, Lubbock, United States

Objectives: The objective of this study was to determine the prevalence of resistant and susceptible Campylobacter spp. across various protein to fat ratios and packaging types of ground beef during the spring in retail markets in Lubbock, Texas.

Materials and Methods: During the spring of 2013, a total of 178 ground beef samples were collected from seven stores in Lubbock, Texas. Samples were processed and subjected to detection of Campylobacter using a commercially available PCR-based system. Positive samples were confirmed by plating samples onto Modified Charcoal Cefoperazone Deoxycholate Agar and R\&F® Campylobacter chromogenic plating media as well as with Schimdex Campy agglutination. A total of 162 isolates were selected and frozen at $-80 \mathrm{C}$ until further use. Isolates were resuscitated on blood agar and subjected to National Antimicrobial Resistance Monitoring System (NARMS) testing methods to determine resistance patterns. Resistant profiles were determined using the SWIN software system with clinical breakpoints. A multiple sample proportions test was performed in $\mathrm{R}$ to determine differences in prevalence of resistant Campylobacterisolates to the four antibiotics across package type and fat content.

Results: An overall prevalence of $30.5 \%(n=54)$ of 178 raw ground beef samples was observed. A total of 162 isolates from 54 positive samples were selected, and $54.3 \%(n=88)$ were successfully recovered from frozen stocks. According to the results determined using the SWIN software, there were four out of the nine antibiotics (erythromycin, gentamicin, ciprofloxacin, and tetracycline) with results for susceptibility or resistance. Campylobacter isolates expressed resistance to specific antibiotics as follows: $4.54 \%(n=4)$ for ciprofloxacin, $91.9 \%(n=68)$ for erythromycin, $15.3 \%(n=13)$ for gentamicin, and $4.60 \%(n=4)$ tetracycline. There was a significant difference $(P<0.05)$ in the prevalence of resistant Campylobacter observed among the four antibiotics. Only $3.41 \%(n=3)$ of the isolates were multidrug resistant as defined by the isolate exhibiting resistance to three or more classes of antibiotics. Campylobacter isolates expressed resistance based on packaging type as follows: $52.0 \%(n=64)$ for overwrap, $27.8 \%(n=10)$ for chub, and $33.3 \%(n=1)$ for over-the-counter packaging $(P=0.03)$. The resistance of Campylobacter isolates varied across protein to fat ratios as follows: $61.9 \%(n=13)$ for $73: 27,47.2 \%(n=34)$ for $85: 15,6.67(n=1)$ for $80: 20,100 \%(n=12)$ for $90: 10,77.8 \%(n=21)$ for $93: 7$, and $46.7 \%(\mathrm{n}=7)$ for 96:4 $(P<0.05)$.

Conclusion: A high prevalence of resistant Campylobacterwas observed in raw ground beef in this study. Prevalence of antibiotic resistant Campylobactervaried greatly among both package type and fat content. 
Keywords: Antibiotic resistant, Campylobacter, Ground beef 


\title{
Meat and Poultry Safety
}

125

\section{COMPARISON OF CONVENTIONAL CULTURE METHODS WITH MULTIPLEX REAL-TIME PCR FOR SALMONELLA SPP. DETECTION IN FECAL AND HIDE SAMPLES FROM SMALL RUMINANTS.}

\author{
S. G. Sanders ${ }^{1, *}$, K. W. Braden ${ }^{1}$, K. E. Hanlon ${ }^{2}$, M. M. Brashears ${ }^{2}$, L. A. Branham ${ }^{1}$
}

1Department of Agriculture, Angelo State University, San Angelo, ${ }^{2 D e p a r t m e n t ~ o f ~ A n i m a l ~ a n d ~ F o o d ~ S c i e n c e s, ~ T e x a s ~ T e c h ~}$ University, Lubbock, United States

Objectives: Detection of pathogens in livestock samples containing significant background flora such as fecal and hide samples can be a challenging component of pre-harvest food safety research. Even though real time PCR pathogen detection is available in several commercial formats, approved protocols tend to focus on retail and carcass samples, and do not readily exist for hide and fecal samples. While traditional culture methods are still considered the standard for pathogen detection in these types of samples, application of PCR detection would shorten associated labor and time inputs. The objective of this study was to determine the utility of a commercial, multiplex real-time polymerase chain reaction (PCR) system in the detection of Salmonella spp. from fecal samples and hide swabs from small ruminants when compared to traditional culture methods.

Materials and Methods: Fecal and hide swab samples were taken at a small scale university abattoir in West Texas over the course of 13 collection dates between July 2014 and March 2015. Hide swabs ( $n=103)$ were collected postexsanguination while fecal samples $(n=102)$ were aseptically retrieved post-evisceration. Samples were analyzed for presence of Salmonella using both traditional culture methods and real-time PCR detection methods. The traditional culture method included selective enrichment in Tetrathionate and Rappaport Vassiliadis broths and differential plating using Xylose Lysine Tergitol 4 agar. Isolates were confirmed using a commercially available latex agglutination kit. For PCR detection, samples were diluted using a sterile dilution buffer and processed according to manufacturer recommendations. Descriptive statistics and McNemar's test were conducted using the frequency procedure of SAS. Agreement beyond chance between tests was assessed using Cohen's kappa statistic.

Results: There were no detectable differences in the number of samples testing positive for Salmonella when comparing the two detection methods for either hide $(P=0.65)$ or fecal $(P=0.76)$ samples. Salmonella was detected in $18.45 \%(n=19)$ of hide swabs and $18.63 \%(n=19)$ of fecal samples when analyzed using the PCR system. Traditional methods detected Salmonella spp. in $17.48 \%(n=18)$ of hide swabs and $19.61 \%(n=20)$ of fecal samples. An analysis of concordance showed a substantial agreement beyond chance between the two methods when analyzing fecal samples (Kappa value $0.65 ; 95 \%$ confidence interval $0.46-0.84)$. Additionally, an almost perfect agreement beyond chance between the two methods was detected when analyzing hide samples (Kappa value 0.84; 95\%; confidence interval $0.69-0.97$ ). 
Conclusion: The time and labor required for detection of Salmonella using traditional culture methods can be extensive. Preliminary results show that real-time polymerase chain reaction systems are as reliable as traditional culture methods and can be used in the processing of fecal and hide samples to detect Salmonella spp.

Keywords: Goat, Multiplex PCR, Salmonella, Sheep 


\section{Meat and Poultry Safety}

126

\section{EFFICACY OF BETA-RESORCYLIC ACID SPRAY IN REDUCING ESCHERICHIA COLI 0157:H7 ON FLAT CUT BEEF STEAKS}

C.-H. Chen ${ }^{1,}{ }^{*}$, H.-B. Yin ${ }^{1}$, A. Upadhyay ${ }^{1}$, S. Fancher ${ }^{1}$, K. Belskie ${ }^{1}$, R. Mancini ${ }^{1}$, K. Venkitanarayanan ${ }^{1}$

${ }^{1}$ Animal Science, University of Connecticut, Storrs, United States

Objectives: This study investigated the efficacy of a novel, generally-regarded as safe (GRAS) plant-derived antimicrobial, namely Beta-resorcylic acid (BR) as an antimicrobial spray for reducing EHEC on circular, flat cut beef steak, for potential future application on carcasses.

Materials and Methods: A five-strain mixture of nalidixic acid-resistant EHEC was inoculated on beef steaks ( 5 log $\mathrm{CFU} / \mathrm{cm}^{2}$ ), followed by a spray treatment at $72^{\circ} \mathrm{C}$ for $30 \mathrm{sec}$ with sterile water $(20 \mathrm{ml}$ ) or water containing $2 \%$ LA (industry control) or $0.5 \%, 1 \%$ and $2 \% \mathrm{BR}$. The treated steak samples were stored aerobically at $4{ }^{\circ} \mathrm{C}$ for 3 days in sterile whirlpak TM bags, and surviving E. coli $\mathrm{O} 157: \mathrm{H} 7$ was determined on day 0,1 , and 3 . In addition, effect of spray treatments on meat $\mathrm{pH}$ and color ( $\mathrm{a}^{*}$ value) of beef was investigated on Longissimus dorsi muscle.

A completely randomized design was used for the study. All experiments had duplicate samples, and were replicated two times. For each treatment, the data from independent trials were pooled and analyzed using the PROC MIXED subroutine of the SAS 9.2. Differences were considered significant at $P<0.05$.

Results: On day zero, $2 \%$ BR reduced EHEC counts on steaks by $\sim 2 \log \mathrm{CFU} / \mathrm{cm}^{2}$ compared to control $(\mathrm{P}<0.05)$. From day 1 to day 3, EHEC counts on BR-treated steaks were consistently lower and after 3 days of storage, 2\% BR decreased EHEC by $\sim 4 \log \mathrm{CFU} / \mathrm{cm}^{2}$ compared to control $(\mathrm{P}<0.05)$. The $\mathrm{pH}$ of beef was not affected by spray treatment $(P>0.05)$ except for LA, which had minimal reduction ( 0.5) on day 0 and 1 of storage as compared to control. In addition, there was no significant difference in the color of beef sprayed with BR/LA as compared with control at the end of 5 days of storage.

Conclusion: Results suggest that BR could potentially be used as an antimicrobial spray to reduce EHEC on beef carcass, although follow up studies on the sensory and quality characteristics of BR-treated steaks are warranted.

Keywords: beef steak, Beta-resorcylic acid, Escherichia coli O157:H7 


\section{Meat and Poultry Safety}

127

\section{GLUCOSAMINE-DERIVED ANTIMICROBIAL COMPOUNDS AGAINST HEAT RESISTANT E. COLI AW 1.7 ISOLATED FROM BEEF}

D. J. Hincapie Martinez ${ }^{1, *}$, M. Ndagijimana ${ }^{1}$, M. Gänzle ${ }^{1}$, M. Betti ${ }^{1}$

${ }^{1}$ Agricultural, Food and Nutritional Science, University of alberta, Edmonton, Canada

Objectives: Pathogenic strains of $E$. coli are of main concern in the meat industry, particularly due to their resistance against heat treatments and antimicrobial agents. Novel, food-derived and affordable antimicrobial compounds are an interesting alternative to reduce the risk of bacterial food contamination. The objective of this study was to generate antimicrobial products (i.e. $\alpha$-dicarbonyls) by non-enzymatic modification of glucosamine at mild temperatures in presence of iron $\left(\mathrm{Fe}^{2+}\right)$, and to evaluate their antimicrobial activity against the heat resistant E. coli AW 1.7.

Materials and Methods: Non-enzymatic modification of glucosamine (GlcN) in phosphate buffer was induced over 3, 12, 24 or $48 \mathrm{~h}$ at $50^{\circ} \mathrm{C}$ in the absence $(\mathrm{GlcN})$ and presence of iron ( GlcN/Fe $\left.{ }^{2+}\right)$ at five different concentrations $(15,30,50,75$, 100 and $150 \mathrm{~g} / \mathrm{L})$. UV absorbance profiles were monitored overtime and used to select the best conditions for the antimicrobial analysis performed by critical dilution assay. E.coli AW 1.7 isolated from beef carcass was grown at $37^{\circ} \mathrm{C}$ for 16h in Luria-Bertani (LB) broth. Aliquots of each sample were incubated with the strain to a cell counts approximately of $10^{6} \mathrm{CFU} / \mathrm{mL}$. The bacterial growth was measured by optical density (OD630nm). Identification and quantification of $\alpha-$ dicarbonyls were performed by derivatization with $O$-phenylenediamine, followed by UHPLC-RP/UV and Orbitrap mass spectrometry analyses. Analyses of the different treatments were performed in triplicate and were subjected to analysis of variance (ANOVA). Tukey's multiple range test $(p<0.05)$ was conducted to determine differences between means.

Results: Samples obtained by treatment of $150 \mathrm{~g} / \mathrm{L}$ of GlcN after $3 \mathrm{~h}$ of incubation showed antimicrobial activity; the percentage of inhibition by these samples increased overtime in GlcN and GlcN/Fe ${ }^{2+}$ samples from $6 \%$ to $29 \%$ and $10 \%$ to $50 \%$, respectively. In particular, the sample GlcN/Fe ${ }^{2+}$ incubated for 48 hours inhibited the bacterial growth by $50 \%$ (IC50) at a concentration of $5 \%(\mathrm{w} / \mathrm{v})$ while the sample GlcN incubated for the same time did not show activity. These results might be attributed to the production of Maillard reaction compounds such as $\alpha$-dicarbonyls. Indeed, $\mathrm{GlcN} / \mathrm{Fe}^{2+}$ contained two major a-dicarbonyl compounds: glucosone and 3-deoxyglucosone. The amount of 3-deoxyglucosone found in our most effective treatment was $0.89 \pm 0.01 \mathrm{~g} / \mathrm{L}$, which was close to the IC50 of the pure standard $(1 \mathrm{~g} / \mathrm{L})$. Other $\alpha$-dicarbonyls compounds such us glyoxal, methylglyoxal and diacetyl were identified at much more lower concentration.

Conclusion: Non-enzymatically modified GIcN at a concentration of $5 \%$ inhibited the growth of thermo resistant E. coli AW 1.7 in vitro, which opens the possibility of using this amino-sugar as an antimicrobial compound directly in meat products. Compounds contributing to such inhibitory property are $\alpha$-dicarbonyls. Hence, GlcN might be a valuable food ingredient for the meat processing industry. 
Keywords: antimicrobial activity, E. coli, glucosamine, iron, $\alpha$-dicarbonyls 


\section{Meat and Poultry Safety}

128

\section{THE PREVALENCE OF ESCHERICHIA COLI 0157:H7 AND SALMONELLA SPP. ON BEEF HEADS AND VARIETY} MEAT

S. Pokharel ${ }^{1, *}$, M. F. Miller ${ }^{1}$, A. R. Parks ${ }^{1}$, M. M. Brashears ${ }^{1}$

${ }^{1}$ Animal and Food Sciences, Texas Tech University, Lubbock, United States

Objectives: Escherichia coli and Salmonella are synonymous to many food borne diseases in humans. Cattle are major contributor and harbor these bacteria in their guts and hide. This study was conducted in a beef processing facility to determine the prevalence of E. coli O157:H7 and Salmonella spp. on beef head (check meat) and variety meat (heart) before they are processed into ground beef.

Materials and Methods: For this study, 60 swabs were collected ( $n=30 /$ meat) randomly (in $25 \mathrm{ml} \mathrm{BPW}$ ) throughout a day that covered early, mid, and end shifts of the beef processing facility. Swabs were collected from beef head (check meat) and variety meat (heart) before they were processed into ground beef. Collected swabs were enriched in modified Tryptic Soy Broth (mTSB) for $24 \mathrm{~h}$ at $37^{\circ} \mathrm{C}$ then sampled for $\mathrm{BAX} \otimes$ analysis.

Results: After PCR analysis, E. coli O157:H7 was not detected in the samples, however only one Salmonella spp. was detected which was later confirmed by latex agglutination test.

Conclusion: In this beef processing facility, the prevalence of E. coliO157:H7 and Salmonella spp. in beef heads and variety meat is very low which conclude that the intervention programs are being effective; however consumer should take special care to cook ground beef products.

Keywords: BAX®, Escherichia coli O157:H7, Ground Beef, Salmonella 


\section{Meat and Poultry Safety}

129

\section{PERACETIC ACID AS AN ANTIMICROBIAL IN BEEF}

C. Davenport ${ }^{1}{ }^{*}$, G. Hill ${ }^{1}$, C. Bratcher 1

${ }^{1}$ Auburn University, Auburn, United States

Objectives: Peracetic acid, also known as PAA, has been used successfully in the poultry industry to reduce the bacterial load of Salmonella and Campylobacter. The objective of this study was to evaluate the effectiveness of PAA in reducing Escherichia coli O157:H7 in beef.

Materials and Methods: In this study, 150 slices of beef ball tips weighing $100 \mathrm{~g}$ each were inoculated with either a high $\left(10^{6}\right)$ or a low $\left(10^{2}\right)$ concentration of five strains of E. coli $\mathrm{O} 157: \mathrm{H} 7$. After a 30 minute attachment time, the inoculated samples were treated with either 0.012\% (120ppm) PAA, 0.04\% (400ppm) PAA, or were left untreated as a positive control. After a 5 minute treatment time, the samples were sprayed with sodium thiosulfate to neutralize the reaction. The neutralized samples were stomached for $2 \mathrm{~min}$ and plated onto CT-SMAC plates and incubated for 24 hours before being counted. This process was repeated 3 times on different days.

Results: For the low $\left(10^{2}\right)$ concentration of $E$. coli O157:H7, the 120ppm treatment of PAA reduced bacterial growth by $0.067 \mathrm{log}$, which was not different $(P>0.05)$ than the control. The $400 \mathrm{ppm}$ treatment for the low concentration of $E$. coli O157: $\mathrm{H} 7$ was different $(\mathrm{P}<0.05)$, reducing the bacterial growth by $0.568 \mathrm{log}$. When treatment was applied to the high $\left(10^{6}\right)$ concentration of $E$. coli $0157: \mathrm{H} 7$, both the 120ppm treatment and the 400ppm treatment of PAA reduced $(\mathrm{P}<0.05)$ the bacterial growth (reductions were $0.12 \mathrm{log}$ and $0.19 \mathrm{log}$, respectively). While both 120ppm PAA and 400ppm PAA reduced the overall amount of $E$. coli $\mathrm{O} 157: \mathrm{H} 7$ when compared to the positive controls, not all reductions were significant, and treatment with 400ppm PAA was the most effective at reducing E. coli O157:H7 on the samples.

Conclusion: Results from this study suggest that at low levels of contamination, applying 400ppm PAA as an antimicrobial in beef could be effective in reducing E. coliO157:H7. However, with zero tolerance of E. coliO157:H7 in beef, these results do not show enough reduction in bacterial growth to use PAA as the sole method of controlling $E$. coli O157:H7. Processors may consider PAA as a hurdle strategy in combination with other hurdles tailored to individual processes.

Keywords: Antimicrobial, Beef, E. coli O157:H7, Peracetic acid 


\section{Meat and Poultry Safety}

130

\section{THERMAL INACTIVATION OF SALMONELLA SPP. IN HIGH FAT GROUND BEEF}

B. Inestroza 1, ${ }^{*}$ A. Ramirez ${ }^{1}$, M. X. Sanchez-Plata ${ }^{1}$, A. R. Parks ${ }^{1}$, A. Echeverry ${ }^{1}$, M. M. Brashears ${ }^{1}$

1Department of Animal and Food Sciences, Texas Tech University, Lubbock, United States

Objectives: To determine the $D$ and $z$ values to inactivate a Salmonella cocktail in a high fat beef processing by-product subjected to rendering-like conditions at pre-determined temperatures from 55 to $125^{\circ} \mathrm{C}$ at $5^{\circ}$ increments in a circulating bath.

Materials and Methods: A 12-h culture of 5 Salmonella strains isolated from animals or associated with human illness ( $S$. Senftenberg, $S$. Enteritidis, $S$. Newport, $S$. Typhimurium, and $S$. Heidelberg) was used to prepare a cocktail (8 log $\mathrm{CFU} / \mathrm{mL})$ to challenge $(250 \mu \mathrm{l})$ a high fat ground beef by-product $(10 \mathrm{~g})$ prior to be subjected to isothermal treatments from 55 to $125^{\circ} \mathrm{C}$, with $5^{\circ}$ increments. After thorough mixing, the meat samples were packed and vacuum-sealed in polyethylene bags and immersed in water and or silicon oil at the established temperatures. Surviving salmonellae were enumerated by plating serial dilutions in duplicate on XLD plates with a TSA overlay to aid in the recovery of injured and stressed cells and incubated at $37^{\circ} \mathrm{C}$ for $24 \mathrm{~h}$. The D value of Salmonella at each temperature was calculated from the negative inverse slope of the $\log _{10}(\mathrm{cfu} / \mathrm{g}$ ) vs. time plot. The $z$ value were determined from the negative inverse slope of the $\log _{10}(\mathrm{D})$ vs. temperature plot.

Results: Inactivation isotherms for the Salmonella cocktail at each temperature tested were developed. The $D$ values at 55 to $95^{\circ} \mathrm{C}$ were 4.17 to $0.23 \mathrm{~min}$ in high fat ground beef by-products.

Conclusion: The results from this study are useful for predicting process lethality of Salmonella in products that contain high fat ground beef by-products, validate rendering thermal conditions and ensure microbial safety of animal by-products.

Keywords: D value, High fat ground beef by-products, Salmonella, Thermal inactivation, $z$ value 


\section{Meat and Poultry Safety}

131

\section{IN-PLANT VALIDATION STUDY TO DETERMINE THE EFFICACY OF LACTIC ACID AS AN ANTIMICROBIAL INTERVENTION ON BEEF HEADS AND VARIETY MEATS}

S. Pokharel ${ }^{1, *}$, M. F. Miller ${ }^{1}$, A. R. Parks ${ }^{1}$, M. M. Brashears ${ }^{1}$

1Animal and Food Sciences, Texas Tech University, Lubbock, United States

Objectives: There are an array of techniques to control microbial load on carcasses including lactic acid treatment. Several studies have demonstrated a substantial reduction of indicator microorganisms when carcasses were sprayed with lactic acid at a concentration of 2 to $5 \%$. This study was designed to demonstrate the efficacy of lactic acid $(4.5 \%)$ as an antimicrobial intervention on beef heads and variety meats.

Materials and Methods: For this study, we collected ( $n=180$ ) swabs randomly (in $25 \mathrm{ml} B P W$ ) throughout a day that covered early, mid, and end shifts at a beef processing facility. Swabs were collected from head/ check meat, heart, and liver. A total of 10 swabs were collected for each meat type before (positive control) and 10 swabs after $4.5 \%$ lactic acid spray. Lactic acid was sprayed topically on carcasses at room temperature with a minimum pressure of 15 psi. Collected swabs were serially diluted and plated on generic Escherichia coli and APC petrifilms.

Results: On beef heads swabs, treatment using $4.5 \%$ lactic acid spray significantly $(P<0.05)$ reduces generic Escherichia coli, Coliforms and Total Aerobes by $0.15,0.41$, and 1.96 log cycles respectively. Similarly for beef hearts, the treatment showed significant reduction $(P<0.05)$ in indicator microorganisms. For beef hearts, E. coli, Coliforms, and Total Aerobes were reduced by $0.41,1.06$, and 1.3 logs respectively. Likewise, beef livers also showed significant reduction $(P$ $<0.05)$ in indicator microorganisms after the treatment. The result showed E. coli, Coliforms, and Total Aerobes were reduced by $0.5,1.16$, and 1.08 logs respectively.

Conclusion: The lactic acid intervention program was effective in significantly reducing total microbial indicator organisms on beef heads, hearts, and livers.

Keywords: Beef, Indicator organisms, Lactic Acid, Variety meats 


\title{
Meat and Poultry Safety
}

132

\section{VALIDATION OF THE EFFICACY OF 4.55\% FCC 88 LACTIC ACID AND 2.5\% LACTIC ACID/ACETIC ACID (50/50) BLEND ON OFFAL MEATS AND CARCASS SURFACES UNDER SIMULATED INDUSTRY CONDITIONS}

\author{
A. R. Parks ${ }^{1,{ }^{*},}$ M. F. Miller ${ }^{1}$, K. Hanlon ${ }^{1}$, S. Pokharel ${ }^{1}$, K. Spivey ${ }^{1}$, M. M. Brashears ${ }^{1}$ \\ 1Department of Animal and Food Sciences, Texas Tech University, Lubbock, United States
}

Objectives: The objective of this study was to determine the efficacy of $4.55 \%$ FCC 88 lactic acid (cool, 70F), 4.55\% FCC 88 lactic acid (warm, 100F), 4.55\% FCC 88 lactic acid (heated, 130F), 2.5\% lactic acid/acetic acid blend (cool, 70F), 2.5\% lactic acid/acetic acid blend (warm, 100F), and 2.5\% lactic acid/acetic acid blend (hot, 130F) in reducing a cocktail mixture of 7 major serogroups of Shiga toxin-producing Escherichia coli (STEC) considered adulterants by the USDA-FSIS (O157:H7, O26, O111, O45, O145, O103, 0121) and Salmonella on offal meats and on carcass surfaces.

Materials and Methods: Cocktails of each pathogen (STEC $=7$ strains, Salmonella $=5$ strains) were used to individually inoculate either pre-rigor fat samples from the outside of the carcass or cheek meat (offal) measuring $150 \mathrm{~cm}^{2}$. Product samples ( $n=1 /$ cocktail) were then assigned to treatment (listed above plus inoculated, no treatment; or water at the three previously listed temperatures). Treatments were applied for 15 seconds in an industry equivalent spray cabinet. After treatment, the samples were swabbed on 0 ( $1 \mathrm{~h}$ after), 1 , and 2 days to determine reduction of each pathogen. At the same time, samples of pre-rigor Cutaneous truncii or cheek meat (offal) were obtained and the treatments were applied to the non-inoculated product. Trained color panel and colorimeter scores were obtained on days 0 ( $1 \mathrm{~h}$ after), 3 , and 5. The study was repeated 2 times for each pathogen ( $n=20 /$ pathogen).

Results: For carcass surface treatments, there was a significant $(p=0.0002)$ difference in STEC populations by treatment. Salmonella populations on carcass surfaces were significantly $(p=0.0099)$ different among treatments. Hot $4.55 \%$ lactic acid showed the largest pathogen reductions on carcass surfaces. For offal treatments, there was no treatment effect on STEC populations $(p=0.1412)$. No treatment effects $(p>0.05)$ were found among offal Salmonella populations. Decreases in bacterial populations occurred over time for both types of meat and both pathogens analyzed. Conclusion: All intervention treatments used in this study resulted in reduced STEC and Salmonella populations on prerigor carcasses and offal (cheek meat) when applied using the manufacturer's instructions as compared to the untreated, inoculated controls. The application of hot $4.55 \%$ lactic acid showed the greatest reductions for both STECs and Salmonella, when compared to the inoculated, untreated controls. Further, all chemical interventions showed a reduction of at least $0.8 \mathrm{log} \mathrm{cfu} / \mathrm{cm}^{2}$ in STEC populations and $1.29 \mathrm{log} \mathrm{cfu} / \mathrm{cm}^{2}$ in Salmonella populations. Objective Hunter $\mathrm{L}^{*} \mathrm{a}^{*} \mathrm{~b}^{*}$ and trained color panelists did not find a significant change in color by treatment over time for both carcass and offal meat surfaces. 
Keywords: Acetic acid, Beef, Lactic acid, Salmonella, STEC 


\title{
Meat and Poultry Safety
}

133

\section{VALIDATION OF PATHOGEN DESTRUCTION IN DRY PET FOODS AFTER PRODUCTION AND BAGGING UNDER SIMULATED INDUSTRY CONDITIONS}

\author{
A. R. Parks ${ }^{1, *}$, M. M. Brashears ${ }^{1}$ \\ 1Department of Animal and Food Sciences, Texas Tech University, Lubbock, United States
}

Objectives: The objective was to validate the destruction of pathogens after in-plant production and bagging of dry kibble using Salmonella and mimicked drying conditions in the pathogen processing laboratory.

Materials and Methods: A dry inoculum cocktail of five strains (S. Enteritidis 13076 and 31194, S. Typhimurium 13311 and 14028, and $S$. Heidelberg 3347-1) of Salmonella associated with outbreaks or isolated from cattle were used for this study. Experimental thermal drying parameters were programmed into the Enviropak ${ }^{\text {TM }}$ Minipak series commercial oven. On the day of testing, the dog food was inoculated at a level of $10^{4} \mathrm{cfu} / \mathrm{g}$ with the dry inoculum, mixed to ensure even coating, and portioned into bags provided by the processor. Samples were dried up to $24 \mathrm{hrs}$ at either 165, 175, or $185^{\circ} \mathrm{F}$. The samples were diluted and plated onto XLT4 agar with a tryptic soy agar overlay to aid in recovering injured and stressed cells. After a $24 \mathrm{~h}$ incubation at $37^{\circ} \mathrm{C}$, the counts were converted to $\log _{10} \mathrm{cfu} / \mathrm{g}$ prior to reporting.

Results: At $165^{\circ} \mathrm{F}$, Salmonella was eliminated after $3 \mathrm{~h}$ of dry time resulting in a $3.41 \mathrm{log}$ cfu/g reduction. Further, similar results were noted at $175^{\circ} \mathrm{F}$, with a $4.20 \mathrm{log}$ cfu/g reduction of Salmonella after 3 hours of drying. Finally, at $185^{\circ} \mathrm{F}$, Salmonella reductions of $2.0 \mathrm{log}$ cfu/g were noted after 1 hour of drying and $3.10 \mathrm{log}$ cfu/g after 3 hours of drying.

Conclusion: This study shows that low levels of Salmonella that may come into contact with the production after extrusion, but prior to bagging, would be eliminated after 3 hours of dry time at either 165,175 , and $185^{\circ} \mathrm{F}$. Under the proposed Food Safety Modernization Act (FSMA), pet food producers will be required to validate their current production processes for destruction of pathogens. This study supports the use of a post-packaged dry heat step to eliminate pathogens in the finished product.

Keywords: Kibble, Pet Food, Salmonella, Validation 


\title{
Muscle and Lipid Biology and Biochemistry
}

\section{4}

\section{LIPID OXIDATION-INDUCED OXIDATION IN BEEF AND PORK CARBOXYMYOGLOBIN}

\author{
S. Li ${ }^{1}$, M. N. Nair ${ }^{1}$, J. Wu ${ }^{1}$, S. P. Suman $1{ }^{*}$
}

1 University of Kentucky, Lexington, United States

Objectives: Consumer-desirable red color of fresh meat can be stabilized and improved by modified atmosphere packaging (MAP) containing carbon monoxide (CO). CO binds with myoglobin (Mb) to form carboxymyoglobin (COMb), which provide bright cherry-red color to fresh meats. Several studies documented that hydroxynonenal (HNE), a reactive lipid oxidation product, can compromise the redox stability of livestock oxymyoglobins and accelerate brown discoloration in red meats. Our previous research indicated that HNE can also accelerate browning in equine COMb. However, lipid oxidation-induced oxidation in beef and pork $\mathrm{COMb}$ has not been investigated. Therefore, the objective of this study was to evaluate lipid oxidation-induced oxidation in beef and pork COMb, using HNE as a model aldehyde.

Materials and Methods: Myoglobin was purified from cardiac muscles of beef and pork. Deoxymyoglobin was prepared by sodium hydrosulfite-meditated reduction of $\mathrm{Mb}$ in $50 \mathrm{mM}$ sodium phosphate buffer ( $\mathrm{pH}$ 7.4). COMb was prepared by bubbling deoxymyoglobin with a gas mixture containing $0.4 \% \mathrm{CO}, 30 \% \mathrm{CO}_{2}$, and $69.6 \% \mathrm{~N}_{2}$ for $40 \mathrm{~min}$. Beef $\mathrm{COMb}(0.15$ $\mathrm{mM})$ and pork $\mathrm{COMb}(0.075 \mathrm{mM})$ were incubated with $1.0 \mathrm{mM} \mathrm{HNE}$ at $\mathrm{pH} 7.4$ and $37^{\circ} \mathrm{C}$ (physiological condition) for 360 min. Controls consisted of COMb plus an equivalent volume of ethanol used to deliver HNE. Samples were scanned spectrophotometrically from $700 \mathrm{~nm}$ to $450 \mathrm{~nm}$ every $90 \mathrm{~min}$. Browning Index (BI), calculated as $A_{503} / A_{581}$, was used to estimate heme oxidation. The data were analyzed using the MIXED procedure of SAS.

Results: $\mathrm{Bl}$ increased $(P<0.05)$ over time in both species, and lipid oxidation accelerated $(P<0.05)$ COMb oxidation irrespective of species. Nonetheless, lipid oxidation-induced oxidation was greater $(P<0.05)$ in beef COMb than in pork COMb.

Conclusion: The results suggested that beef and pork $\mathrm{COMb}$ are susceptible to lipid oxidation-induced browning.

Furthermore, the findings indicated that lipid oxidation is more critical to color in beef than in pork when retailing fresh red meats in CO MAP.

Keywords: Carboxymyoglobin, Lipid oxidation, Meat color stability 


\title{
Muscle and Lipid Biology and Biochemistry
}

135

\section{EFFECT OF TEMPERATURE ON FLUORESCENT PROPERTIES OF OXYMYOGLOBIN}

\author{
B. Djimsa 1,*, A. R. English 1, G. G. Mafi 1, D. L. Vanoverbeke 1, R. Ramanathan ${ }^{1}$
}

${ }^{1}$ Animal Science, Oklahoma State University, Stillwater, United States

Objectives: The characteristic dull brown color in cooked meat is primarily due to myoglobin denaturation and is influenced by the redox state of myoglobin within the interior of a patty/steak prior to cooking. Myoglobin forms differ in their thermal stability, and can lead to food safety concerns when the cooked color is used as an indicator of doneness. Denaturation occurs by unfolding of proteins thereby exposing the fluorescent amino acids located close to the heme crevice to the periphery. Hence, quantification of changes in fluorescent intensity can be a valuable tool to study protein unfolding or denaturation properties. Although several studies have utilized fluorescent properties to study protein denaturation, limited studies have characterized the unfolding properties to understand heat-induced myoglobin denaturation. Therefore, the objective of the present study was to determine the effect of temperature on fluorescent properties of oxymyoglobin at $\mathrm{pH} 5.6$ in vitro.

Materials and Methods: Oxymyoglobin $(0.15 \mathrm{mM}$; $\mathrm{pH}$ 5.6) prepared via sodium hydrosulfite mediated reduction was incubated in a continuous heat increment $\left(3.6^{\circ} \mathrm{C} / \mathrm{min}\right)$ water bath. At specific temperature points $\left(65,71,78\right.$, and $\left.84^{\circ} \mathrm{C}\right)$, oxymyoglobin containing tubes were withdrawn and cooled immediately to prevent post-incubation temperature rise. Samples were centrifuged and the supernatant was used to measure fluorescent intensity and percentage myoglobin denaturation using a microplate reader. Protein unfolding was determined by measuring the fluorescence at $279 \mathrm{~nm}$ (excitation) and $555 \mathrm{~nm}$ (emission). In addition, absorbance at $409 \mathrm{~nm}$ was also monitored to study protein unfolding. The absorbance at $525 \mathrm{~nm}$ was determined to measure myoglobin denaturation. The experimental design was completely randomized and the data were analyzed using the Mixed Procedure of SAS ( $n=6$ replications).

Results: A greater temperature increased percentage myoglobin denaturation $\left(65<71<77=84{ }^{\circ} \mathrm{C}\right.$; $\mathrm{P}<$ 0.05). Myoglobin unfolding was characterized by measuring the absorbance at $409 \mathrm{~nm}$ and the fluorescent properties. Intact protein will demonstrate a greater absorbance at $409 \mathrm{~nm}$, whereas unfolding will lead to a decrease in absorbance. In the current study, absorbance at $409 \mathrm{~nm}$ was $3.3,3.2,1.8$, and 1.2 for $65,71,77$, and $84{ }^{\circ} \mathrm{C}$, respectively $(\mathrm{P}<0.05)$. Similarly, protein denaturation exposed the fluorescent amino acids within the hydrophobic core to outside resulting in greater unfolding or increased fluorescent intensity $\left(65=71<77<84{ }^{\circ} \mathrm{C} ; \mathrm{P}<0.05\right)$. The results indicate that temperature can influence protein unfolding and denaturation.

Conclusion: Monitoring the changes in absorbance at 409 and $525 \mathrm{~nm}$ and fluorescent intensity will provide additional information about the conformational changes during heat-induced myoglobin denaturation. Characterizing the effects of other meat components on the thermal stability of myoglobin will help to better understand the cooked color formation. 
Keywords: Beef Myoglobin, heat-induced denaturation, fluorescence 


\title{
Muscle and Lipid Biology and Biochemistry
}

\section{6}

\section{SARCOPLASMIC PROTEOME PROFILE OF SEMIMEMBRANOSUS MUSCLE FROM RACTOPAMINE-FED PIGS}

\author{
J. Wu ${ }^{1}$, M. N. Nair ${ }^{2}$, S. P. Suman 2, ${ }^{\star}$, S. Li ${ }^{2}$, X. Luo ${ }^{1}$, C. M. Beach ${ }^{2}$, B. M. Bohrer ${ }^{3}$, D. D. Boler ${ }^{3}$
}

1Shandong Agricultural University, Taian, China, ${ }^{2}$ University of Kentucky, Lexington, ${ }^{3}$ University of Illinois, Urbana, United States

Objectives: Ractopamine is a beta-adrenergic agonist used in the finishing diet of pigs to improve leanness and carcass weight. Previous research indicated that ractopamine influenced the abundance of glycolytic enzymes and chaperones in pork Longissimus thoracis muscle, which is primarily retailed as fresh meat. Semimembranosus is an important muscle in pork carcass, often further-processed to ham for retailing. The impact of ractopamine on pig semimembranosus sarcoplasmic proteome has not been examined. Therefore, the objective of the present study was to examine the influence of ractopamine on sarcoplasmic proteome profile of semimembranosus muscle from pigs.

Materials and Methods: Purebred Berkshire barrows $(n=10)$ were finished on a step-up ractopamine diet (RAC; 7.4 ppm ractopamine for 14 days and then increased to $10.0 \mathrm{ppm}$ ractopamine for an additional 14 days) or without ractopamine for 28 days (CON). The pigs were harvested, and the carcasses were fabricated after chilling at $2^{\circ} \mathrm{C}$ for $24 \mathrm{~h}$. Fresh hams from the right side of the carcasses were used for muscle sample collection. From the center of the inside portion of the hams, a $2.54-\mathrm{cm}$ thick slice of semimembranosus muscle was removed. The muscle samples were individually vacuumpackaged and frozen at $-80^{\circ} \mathrm{C}$ for proteome analysis. Sarcoplasmic proteome was analyzed using two-dimensional electrophoresis, and the digital images of the stained gels were analyzed. The protein spots exhibiting 1.5-fold or more intensity differences $(P<0.05)$ between RAC and CON were subjected to in-gel tryptic digestion and identified by tandem mass spectrometry.

Results: Hemoglobin subunit beta chain, alpha-crystallin B chain, and titin fragments were over-abundant $(P<0.05)$ in CON, whereas myosin light chain 1/3 (MLC1/3) and tripartite motif-containing protein 72 were over-abundant $(P<0.05)$ in RAC. The lower $(P<0.05)$ abundance of hemoglobin subunit beta and alpha crystallin $B$ (molecular chaperone) in RAC than in CON could be attributed to the shifts in metabolism and fiber type from oxidative to glycolytic, whereas the overabundance $(P<0.05)$ of titin fragments in CON could be due to decreased proteolysis in response to ractopamine feeding. The greater abundance $(P<0.05)$ of MLC $1 / 3$ and tripartite motif-containing protein 72 (a plasma membrane repair protein) in RAC than in CON could be due to the increased myofibrillar protein synthesis and muscle mass in ractopamine-fed animals.

Conclusion: The results indicated that dietary ractopamine influences the abundance of proteins involved in oxidative metabolism, chaperone, and plasma membrane repair in the sarcoplasmic proteome of pork semimembranosus muscle. 
Keywords: Ractopamine, Sarcoplasmic proteome, Semimembranosus 


\section{Muscle and Lipid Biology and Biochemistry}

137

\section{DIFFERENTIAL ABUNDANCE OF MITOCHONDRIAL PROTEOME IN BEEF MUSCLES}

R. A. Mancini 1, S. P. Suman 2,", M. N. Nair 2, K. Belskie 1, S. Li 2, C. M. Beach 2, R. Ramanathan ${ }^{3}$

1 University of Connecticut, Storrs, 2 University of Kentucky, Lexington, ${ }^{3}$ Oklahoma State University, Stillwater, United States

Objectives: Beef color stability is a muscle-specific trait. Longissimus lumborum (LL) is a color-stable muscle, whereas Psoas major (PM) is a color-labile muscle. Previous research indicated that differential abundance of sarcoplasmic proteome contributes to muscle-specific beef color stability. Mitochondria also affect beef color stability by influencing oxygen consumption and metmyoglobin reducing activity. Nonetheless, the mitochondrial proteome profile of LL and PM is yet to be examined. Therefore, the objective of the present study was to characterize the mitochondrial proteome profile of beef LL and PM.

Materials and Methods: Five $(n=5)$ USDA choice (24 h post-mortem) strip loins $(L L)$ and tenderloins (PM) were obtained locally from a beef purveyor within 72 hours of slaughter. From each muscle, 2.5 -cm thick steaks were fabricated, individually packaged in PVC over-wrap, and displayed under continuous lighting (900 to 1,365 Ix) for seven days. Mitochondria were isolated from LL and PM steaks on day 3. Mitochondrial proteome was extracted and analyzed employing two-dimensional electrophoresis. The gels were stained, and the images were analyzed to determine differences $(P<0.05)$ in the abundance of protein spots. The proteins spots exhibiting 1.5 -fold or more intensity differences $(P<0.05)$ between the muscles were subjected to tryptic digestion and identified by tandem mass spectrometry.

Results: Eight proteins were differentially abundant in LL and PM. Succinyl-CoA ligase subunit beta, ubiquinone biosynthesis protein COQ9, ATP synthase subunit beta, ES1 protein homolog, and very long-chain specific acyl-CoA dehydrogenase were over-abundant $(P<0.05)$ in PM. On the other hand, carbonic anhydrase 3, creatine kinase S-type, and aspartate aminotransferase were over-abundant $(P<0.05)$ in LL. Majority of these proteins are associated with mitochondrial functions and ATP metabolism.

Conclusion: The results of the present study indicated that several metabolic enzymes are differentially abundant in the mitochondrial proteome of color-stable and color-labile beef muscles.

Keywords: Beef color stability, Mitochondria, Proteome 


\section{Muscle and Lipid Biology and Biochemistry}

138

\section{EVALUATION OF CHOLESTEROL AND FATTY ACID CONTENT OF LAMB AND GOAT LONGISSIMUS MUSCLE}

C. L. Thomas 1, ${ }^{1}$, B. C. Shanks ${ }^{1}$, K. L. Basinger ${ }^{2}$, J. K. Apple ${ }^{2}$, B. R. Wiegand ${ }^{3}$, J. D. Caldwell ${ }^{1}$, L. S. Wilbers ${ }^{1}$, A. L. Bax 1, S. A. Marler 4

${ }^{1}$ Animal Science, Lincoln University, Jefferson City, ${ }^{2}$ Animal Science, University of Arkansas, Fayettevile, ${ }^{3}$ Animal Science, University of Missouri, Columbia, ${ }^{4}$ Missouri Enterprise, Rolla, United States

Objectives: Sheep and goats are becoming increasingly popular alternative sources of protein, especially among certain classes of consumers. However, consumers have become more health conscious and are concerned about fat and cholesterol intakes. Thus, the objective of this study was to evaluate cholesterol and fatty acid content of lamb and goat. Materials and Methods: In a completely randomized design, crossbred intact ram and ewe hair lambs $(n=20 ; 37.9 \pm 1.26$ $\mathrm{kg}$ live weight) and similar-aged crossbred meat-type intact buck and ewe kids ( $n=24 ; 16.7 \pm 0.57 \mathrm{~kg}$ live weight) were transported approximately $249 \mathrm{~km}$ from Southwest Missouri to the University of Arkansas abattoir and harvested on August $4^{\text {th }}$ and $5^{\text {th }}, 2014$, respectively. All lambs and kids were supplied by commercial Amish producers and were offered a high concentrate diet with the addition of a PHP Peak Performance nutritional product (the key ingredient is psyllium seed husk from the plantain ovarta plant). At $24 \mathrm{~h}$ postmortem, 2 longissimus muscle (LM) chops were removed from each carcass, vacuum packaged, and stored frozen $\left(-20^{\circ} \mathrm{C}\right)$ for subsequent cholesterol and fatty acid profile determination. Data were analyzed using PROC MIXED of SAS (SAS Inst., Cary, NC, USA), with animal as the experimental unit.

Results: Cholesterol content was greater $(P \leq 0.005)$ in goat than lamb LM. Among the various saturated fatty acids (SFA), mg of C16:0, C17:0, C18:0, and C20:0 were greater $(P \leq 0.02)$ in lamb compared to goats, whereas mg of C12:0 was greater $(P \leq .02)$ in goat than lamb. No differences $(P \geq 0.43)$ were found between species for all other minor SFA. Monounsaturated fatty acids (MUFA) C17:1t, C18:1c, C18:1t, C18:1c9 and C20:1 were greater $(P \leq 0.04)$ in lamb than goat LM. The predominant fatty acid was C18:1c9 in both lamb $(26 \mathrm{mg})$ and goat (15 mg) LM. Goat LM tended to have greater $(P \leq 0.08) \mathrm{mg}$ of $\mathrm{C} 14: 1$ than lamb, while $\mathrm{C} 16: 1 \mathrm{t}$ tended to be greater $(P \leq 0.09)$ in lamb than goat $L M$. The proportion of $\mathrm{C} 16: 1 \mathrm{c}$ was similar $(P \geq 0.60)$ across species. Polyunsaturated fatty acids (PUFA), including C20:4n-6, C20:5, C22:5, and C22:6 were greater $(P \leq 0.02)$ in goat compared with lamb LM, but lamb LM had greater $(P \leq 0.02)$ proportions of $\mathrm{C} 18: 3 \mathrm{n} 3, \mathrm{CLA}$ (especially the $\mathrm{c} 9,-\mathrm{c} 11$ and $\mathrm{t} 9,-\mathrm{t} 11$ isomers), $\mathrm{C} 20: 2$ and $\mathrm{C} 20: 3 \mathrm{n}-3$ compared with goat $\mathrm{LM}$. Milligrams of $C 18: 3 n 6$ and $C 20: 3 n-6$ were similar $(P \geq .35)$ across species. However, total fatty acid content was greater $(P \leq 0.003)$ in lamb $(80 \mathrm{mg})$ than in goat $(50 \mathrm{mg}) \mathrm{LM}$.

Conclusion: Results of this study indicated that goat LM had greater quantities of cholesterol compared with lamb LM. Lamb LM had greater proportions of MUFA, especially long chain C18:1c9, n-3 PUFA, and CLA than goat LM. Thus, these results suggest that lamb maybe a healthier dietary choice than goat based on conditions of this study. 
Keywords: cholesterol, fatty acid, goat, lamb 


\title{
Muscle and Lipid Biology and Biochemistry
}

139

\section{EFFECTS OF FREEZE THAWING ON THE OXYGENATION PROPERTIES OF DARK CUTTING BEEF}

\author{
A. R. English 1, ${ }^{\star}$, B. N. Harsh ${ }^{1}$, K. M. Wills 1, G. G. Mafi ${ }^{1}$, D. L. VanOverbeke ${ }^{1}$, R. Ramanathan ${ }^{1}$ \\ ${ }^{1}$ Animal Science, Oklahoma State University, Stillwater, United States
}

Objectives: Previous studies have reported that increased mitochondrial oxygen consumption can be attributed to decreased bloom in dark cutting beef. The hypothesis of the current study was that altering the mitochondrial function will improve the oxygenation properties of dark cutting beef. Therefore, the objective of this study was to evaluate the effects of freeze thawing on oxygenation properties of dark cutting beef.

Materials and Methods: Ten USDA choice $(\mathrm{pH}=5.6)$ and ten no-roll dark cutter $(\mathrm{pH}>6.4)$ strip loins (IMPS \#180) were obtained from a commercial packing plant within $72 \mathrm{~h}$ of harvest. Loins were vacuum packaged and aged for $62 \mathrm{~d}$ at $2^{\circ} \mathrm{C}$. Following aging, from each normal and dark cutting loin section, a $2.5-\mathrm{cm}$ thick steak was cut (without freeze thawing) and the remaining portion of dark cutting roast was vacuum packaged and subjected to three cycles of freeze thawing $\left(-20^{\circ} \mathrm{C}\right.$ and thawing at $15^{\circ} \mathrm{C}$ ). Following freeze thawing, $2.5-\mathrm{cm}$ thick steak was cut, and oxygenation properties were measured at $4^{\circ} \mathrm{C}$ using a Hunter Lab Miniscan XE Plus spectrophotometer. Oxymyoglobin level, chroma, and $a^{*}$ values were recorded on normal pH steaks without freeze thawing, dark cutting steaks without freeze thawing, and dark cutting steaks following freeze thawing at 0,30,60,90, and $120 \mathrm{~min}$. The reference standards for $100 \%$ myoglobin redox forms were prepared for steaks from normal and dark cutters. The reflectance values were converted to K/S ratios to calculate \% oxymyoglobin levels on the steaks. The experiment was replicated 10 times. The data were analyzed using the Mixed Procedure of SAS and significance was determined at $P<0.05$. The repeated option in MIXED was used for blooming analysis in order to model variance structure.

Results: A treatment by bloom time interaction $(P<0.05)$, resulted for oxymyoglobin level, chroma, and $a^{*}$ values. Normal $\mathrm{pH}$ steaks had the greatest amount of oxymyoglobin at all bloom time points. Freeze thawing improved $(\mathrm{P}$ $<0.05)$ the oxygenation properties of dark cutter compared with control dark cutter without freeze thawing. Freeze thawed dark cutter steaks had $32 \%$ greater $(P<0.05)$ oxymyoglobin compared with control dark cutters after 120 min of bloom. Hunter Lab $a^{*}$ value and chroma were greater $(P<0.05)$ in freeze thawed dark cutter steaks compared with dark cutter controls. The results suggest that freeze thawing can effectively increase bloom characteristics in dark cutting beef. Conclusion: In addition to lowering the muscle $\mathrm{pH}$ of dark cutting beef, altering the muscle structure and mitochondrial function will be a practical approach to improving the oxygenation properties in dark cutting beef.

Keywords: aging, bloom, dark cutter, freeze thawing, mitochondria 


\section{Muscle and Lipid Biology and Biochemistry}

140

\section{GENOME-WIDE MAPPING OF LOCI AFFECTING RIB EYE AREA IN BRAZILIAN NELLORE CATTLE}

A. G. T. Pereira ${ }^{1}$, Y. T. Utsunomiya ${ }^{2}$, P. K. R. K. Ito ${ }^{3}$, F. M. Rezende ${ }^{4}$, M. D. N. Bonin ${ }^{4}$, F. A. Ribeiro ${ }^{1,{ }^{*}}$, J. B. S. Ferraz ${ }^{4}$, J. F. Garcia ${ }^{3}$, C. J. C. Castillo ${ }^{1}$

1 University of São Paulo, Piracicaba, ${ }^{2}$ São Paulo State University, Jaboticabal, ${ }^{3}$ São Paulo State University, Araçatuba, 4University of São Paulo, Pirassununga, Brazil

Objectives: This study aimed at evaluating and identifying putative genomic regions explaining differences in Nellore cattle rib eye area via genome-wide mapping.

Materials and Methods: A dataset of 407 Nellore steers genotyped with the Illumina® BovineHD BeadChip assay was used. The rib eye area (cm2) phenotypic data was measured by transparent graph paper. Only autosomal markers satisfying the following inclusion criteria were used in the downstream analyses: 1) minor allele frequency greater than $0.02,2)$ Fisher's exact test $P$-value for Hardy-Weinberg Equilibrium greater than $1 \times 10-20$ and 3) call rate of at least 0.95 . All individuals had call rate greater than 0.9. The following mixed linear model was used for the association analysis: ribeye $\sim$ mean + age + batch + SNP + animal + error. Animal and error were modeled as random effects, assuming multivariate normal distributions. Errors were assumed independently and identically distributed, whereas the covariance in animal effects was modeled using an additive relationship matrix computed from marker genotypes. All remaining variables were fitted as fixed effects. Markers presenting $p<1 \times 10-4$ were prioritized for investigation.

Results: After data filtering, 513,724 SNPs were included in the association analyses. The inflation factor was close to 1 ( $\lambda$ =1.012), indicating that no important confounding effects were neglected. The phenotype distribution was approximately normal, and markers presenting $\mathrm{p}<1 \times 10^{-4}$ were detected on chromosomes 4, 5, 8, 9, 10, 14, 15, 18 and 20 (Figure).

The chromosome 14 peak maps to the PLAG1 chromosome domain, a pleiotropic locus affecting growth and reproductive traits in different cattle breeds. Particularly, our study reinforces associations found for birth weight and scrotal circumference in Nellore cattle, which also map to this chromosome segment.

Image:

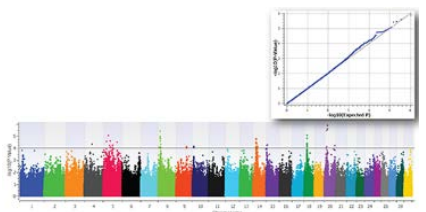

Conclusion: The PLAG1 region is associated with rib eye area in Nellore cattle. This result indicates strong genetic correlation (marker significance threshold: $p<1 \times 10^{-4}$ ) among rib eye area, birth weight and scrotal circumference, which suggests that these traits are capturing variance from an underlying, latent, common subtrait (e.g. body size/stature). 
Keywords: genomic association, meat quality, chromosome 14, PLAG1 


\title{
Muscle and Lipid Biology and Biochemistry
}

141

\section{EFFECTS OF EXTENDING AGING ON BIOCHEMICAL PROPERTIES OF DARK CUTTING BEEF}

\author{
A. R. English 1,*, G. G. Mafi ${ }^{1}$, D. L. VanOverbeke ${ }^{1}$, G. Xiaoping ${ }^{1}$, U. Desilva ${ }^{1}$, R. Ramanathan ${ }^{1}$
}

${ }^{1}$ Animal Science, Oklahoma State University , Stillwater , United States

Objectives: Elevated muscle pH in dark cutting beef can enhance mitochondrial activity and stability of enzymes involved in oxygen consumption. Both processes can greatly influence the myoglobin oxygenation, hence the beef color. Limited studies have characterized the effects of extended aging on biochemical properties of dark cutting beef. Therefore, the objectives were: (1) to determine the effects of extended aging on biochemical factors involved in dark cutting beef, and (2) to quantify the mitochondrial content in normal $\mathrm{pH}$ and dark cutting beef using real time quantitative polymerase chain reaction (q-PCR).

Materials and Methods: Ten USDA choice $(\mathrm{pH}=5.6)$ and ten no-roll dark cutter $(\mathrm{pH}>6.4)$ strip loins (IMPS \#180) were obtained from a commercial packing plant within $3 \mathrm{~d}$ of harvest. Loins were cut into four equal sections, vacuum packaged, and aged for $0,16,38$, and $58 \mathrm{~d}$ at $2^{\circ} \mathrm{C}$. Following aging of normal $\mathrm{pH}$ and dark cutting loin sections, two 2.5$\mathrm{cm}$ thick steaks were cut and used to determine blooming properties, oxygen consumption, metmyoglobin reducing activity, lipid oxidation, mitochondrial quantification, and myoglobin concentration. Surface color readings were measured using a Hunter Lab Miniscan XE Plus spectrophotometer. Oxygen consumption rate and metmyoglobin reducing activity were measured as oxygenation capacity and initial metmyoglobin formation, respectively. q-PCR was used to quantify mitochondrial concentration. The experiment was replicated 10 times. The data were analyzed using the Mixed Procedure of SAS and significance was determined at $P<0.05$.

Results: A muscle $\mathrm{pH}$ type $\mathrm{x}$ blooming time $\mathrm{x}$ aging interaction $(\mathrm{P}<0.05)$ resulted for oxymyoglobin level and $\mathrm{a}^{*}$ values. Normal $\mathrm{pH}$ beef had greater oxymyoglobin and $\mathrm{a}^{*}$ values at all bloom time points. Initial metmyoglobin formation was lower $(\mathrm{P}<0.05)$ for dark cutting beef compared with normal $\mathrm{pH}$ beef, indicating more metmyoglobin reducing activity. Aging improved blooming properties of both normal and dark cutting beef. Lipid oxidation was greater in normal pH beef $(P<0.05)$ compared with dark cutter. In the current study, relative mitochondria concentration were determined rather than absolute number. Mitochondria content was 2.04 fold greater in dark cutting beef compared with normal pH beef. Conclusion: Better understanding the biochemical properties will help to design strategies to improve blooming properties in dark cutting beef.

Keywords: aging, bloom, dark cutter , mitochondria 


\section{Muscle and Lipid Biology and Biochemistry}

142

\section{ACTIVITY OF SKELETAL MUSCLE SATELLITE CELLS AND SHIFT OF SKELETAL MUSCLE FIBER TYPES OVER TIME IN FINISHING CATTLE}

J. Baggerman ${ }^{1,{ }^{*}}$, J. Hergenreder ${ }^{1}$, B. Johnson ${ }^{1}$

${ }^{1}$ Animal and Food Sciences, Texas Tech University, Lubbock, United States

Objectives: The proliferation and fusion of muscle satellite cells have been shown to be a rate limiting step to postnatal skeletal muscle hypertrophy.

Materials and Methods: Skeletal muscle fiber type and satellite cell populations were examined using longissimus dorsi biopsies from feedlot steers ( $n=10$; estimated 16 months of age) every 2 weeks during a $56 \mathrm{~d}$ window of the finishing period. The longissimus dorsisample that was collected was used to evaluate myosin heavy chain expression using real time quantitative PCR and SDS-PAGE, as well as muscle fiber type distribution, cross-sectional area, and satellite cell populations via immunohistochemical staining. Cross-sectional area data were analyzed using the MIXED procedure of SAS 9.3, and all other data were analyzed using the GLIMMIX procedure of SAS 9.3.

Results: There was an increase in abundance of myosin heavy chain (MHC) type I, IIA, and IIX mRNA on d 42 and 56 . An increase in abundance of $\mathrm{MHC}-\mathrm{I}$ and II protein isoforms was observed during the feeding period. Immunohistochemical staining showed a decrease $(P<0.05)$ in the proportion of type I fibers with an increase $(P<0.05)$ in the combination of type IIA and IIX fibers from d 1 to 56 . Muscle fiber cross-sectional area increased $(P<0.05)$ from d 1 to 56 . The density of PAX7-positive satellite cells increased $(P<0.05)$ as days on feed increased. The density of Myf5- and dual-positive satellite cells decreased $(P<0.05)$ on $\mathrm{d} 42$ and 56 . Total nuclei density was not different on $\mathrm{d} 1$ and 56 , but the density of nuclei associated with the muscle fibers increased $(P<0.05)$ as days on feed increased.

Conclusion: These data indicate that during the $56 \mathrm{~d}$ window of the finishing phase in the study, satellite cells fused into muscle fibers to support hypertrophy of muscle fibers as evidenced by the decrease in Myf5- and dual-positive satellite cells and increase in nuclei associated with muscle fibers. In addition, this observed change in satellite cell activity was associated with an increased expression of MHC types I, IIA, and IIX found in bovine skeletal muscle.

Keywords: myosin heavy chain, satellite cells, skeletal muscle hypertrophy 


\title{
Muscle and Lipid Biology and Biochemistry
}

143

\section{HEAT SHOCK PROTEIN 27 RESPONSE TO ACUTE HEAT STRESS IN THE PORCINE SEMITENDINOSUS}

\author{
K. B. Carlson 1,, , S. C. Pearce 1, L. H. Baumgard ${ }^{1}$, N. K. Gabler ${ }^{1}$, S. M. Lonergan ${ }^{1}$, S. M. Cruzen ${ }^{1}$
}

${ }^{1}$ Animal Science, lowa State University, Ames, United States

Objectives: Heat stress (HS) is a threat to efficient production of high quality pork. Heat shock protein 27 (Hsp27) plays a role in the animal's response to stress by preventing apoptosis, stabilizing denatured proteins, and maintaining organization of the muscle cytoskeleton. The objective of this experiment was to examine Hsp27 expression and localization during acute HS in myofibrillar (MYO) and sarcoplasmic (SARC) protein fractions of the porcine semitendinosus.

Materials and Methods: Groups of crossbred gilts ( $64 \pm 3 \mathrm{~kg} ; \mathrm{n}=8$ per treatment) were exposed to thermal neutral ( 0 hour $\mathrm{HS}, 20^{\circ} \mathrm{C}, 40 \%$ relative humidity) or $\mathrm{HS}\left(37^{\circ} \mathrm{C}, 40 \%\right.$ relative humidity) conditions for $2,4,6$, or 12 hours with ad-libitum feed intake. At the conclusion of HS, gilts were euthanized and the semitendinosus was separated into predominantly red oxidative (RST) and white glycolytic (WST) portions and snap frozen. Western blot analyses were performed on whole muscle (WM), (SARC), and (MYO) extracts to measure Hsp27 abundance. Data were analyzed using a complete randomized block design with random effect of day euthanized. In addition to comparisons between individual treatments, a contrast statement was used to analyze the overall effect of HS versus 0 hour HS on Hsp27 abundance.

Results: The effect of HS versus 0 hour HS was not significant in the WM portion of the RST or WST. However, HS resulted in a $46 \%$ increase in Hsp27 between 4 and 6 hours $(P=0.03)$ in the WST. Further, HS tended to increase Hsp27 abundance between 0 and 6 hours HS exposure (30\% increase, $P=0.10)$ in the WST. In the SARC fraction, the effect of HS versus 0 hour HS was not significant in the RST or WST. However, Hsp27 abundance in the RST SARC did have a non-significant numerical decrease between 0 and 4 hours of HS ( $17 \%$ decrease, $P=0.12)$. Subsequently, RST SARC Hsp27 was increased by $25 \%$ between 4 and 12 hours $(P=0.02)$. Although not significant, the SARC WST followed a similar pattern of decreasing Hsp27 abundance between 0 and 4 hours HS $(P=0.57)$ followed by a slight increase $(P=$ 0.40). The effect of HS versus 0 hour HS was significant in the MYO WST portion $(P=0.01)$, but not in the RST. Hsp27 abundance increased by $68 \%$ between 0 and 2 hours HS $(P<0.01)$ and decreased by $37 \%$ between 2 and 12 hours HS exposure $(P=0.02)$ in the MYO WST.

Conclusion: These data indicate the WST may be more affected by HS than the RST, although an increase in overall Hsp27 abundance did not occur until 6 hours. The rapid increase in overall protein abundance of Hsp27 in the WST MYO provides evidence that translocation of Hsp27 occurs between SARC and MYO fractions in response to HS. In the RST, WM and MYO fractions were not affected by HS. However, the slight decrease in the RST SARC fraction after early exposure to HS suggests the possibility of a similar translocation to the MYO fraction. Translocation to the MYO fraction may be a mechanism by which Hsp27 protects the myofibril from damage that could result from HS. Hsp27 has been 
observed to bind to actin filaments in times of stress to aid in stabilization of the cellular cytoskeleton. These novel results provide insight on how Hsp27 abundance is affected by acute HS conditions in different muscle fractions and fiber types. This project was supported by the Agriculture and Food Research Initiative Competitive Grant no. 2011-67003-30007 from the USDA National Institute of Food and Agriculture.

Keywords: heat shock protein, heat stress, pork 


\title{
Muscle and Lipid Biology and Biochemistry
}

144

\section{CORRELATING MYOGLOBIN AND LIPID OXIDATION WITH REDUCTION POTENTIAL IN A SARCOPLASM- LIPOSOME SYSTEM}

\author{
A. Abraham ${ }^{1, *}$, K. B. Bjugstad ${ }^{2}$, G. G. Mafi ${ }^{1}$, D. L. VanOverbeke ${ }^{1}$, C. Gifford ${ }^{1}$, L. T. Rael ${ }^{2}$, R. Bar-Or ${ }^{2}$, R. Ramanathan ${ }^{1}$ \\ ${ }_{1}^{1}$ Animal Science, Oklahoma State University, Stillwater, 2Luoxis, Englewood, United States
}

Objectives: Antioxidant level in muscle prior to slaughter can play a significant role in meat quality. Measures of oxidation reduction potential (ORP) provides a snap shot of the current net balance of all oxidants and reductants (sORP) and can provide measures of the antioxidant ORP capacity (cORP), thus it could be used to assess the relative levels of oxidative stress in muscle. Protein and lipid oxidation are interrelated by-products of oxidative stress, and provides an insight into the degree of oxidative damage in the postmortem muscle. The aim of this study was to correlate the myoglobin and lipid oxidation with ORP measures in a sarcoplasm-liposome system.

Materials and Methods: Sarcoplasm was extracted from five $21 \mathrm{~d}$ aged beef strip loins (five different animals). Briefly, $5 \mathrm{~g}$ of meat from each loin was mixed with $15 \mathrm{~mL}$ of $50 \mathrm{mM}$ phosphate buffer at $\mathrm{pH} 5.6$ and homogenized for $30 \mathrm{~s}$ using a Polytron tissue homogenizer. The homogenates were centrifuged at $15,000 \mathrm{xg}$ for $3 \mathrm{~min}$ and the supernatant was used as sarcoplasm. Sarcoplasm was incorporated within a phosphatidylcholine liposome preparation and incubated at $4^{\circ} \mathrm{C}$ under a continuous fluorescent lighting for $24 \mathrm{~h}$. At specific time points (0, 3, 6, and $24 \mathrm{~h}$ ), liposome-sarcoplasm mixture was used to measure thiobarbituric acid reactive substances (TBARS), percentage metmyoglobin, sORP, and cORP. Metmyoglobin formation was determined using a Shimadzu U V - 2600 spectrophotometer connected with an integrated sphere assembly, while sORP and cORP were measured using a RedoxSYS analyzer. The experiments were replicated five times $(n=5)$. The data were analyzed using the Mixed Procedure of SAS and the significance was determined at $P<0.05$. Linear relationships between two types of ORP and lipid/myoglobin oxidation were evaluated using PROC CORR in SAS to calculate Pearson correlation coefficients.

Results: Lipid oxidation, sORP, and metmyoglobin formation of sarcoplasm-liposome mixture increased $(P<0.05)$ with time. In support, the antioxidant capacity (cORP) of sarcoplasm-liposome mixture decreased $(P<0.05)$ with time. A greater SORP represents more oxidative stress. Metmyoglobin formation was positively correlated with sORP and lipid peroxidation $(\mathrm{P}<0.05)$. However, percentage metmyoglobin was negatively correlated with cORP (antioxidant capacity; $\mathrm{P}$ $<0.05)$.

Conclusion: The results indicate that SORP and cORP have the potential to correlate metmyoglobin formation and lipid oxidation in beef. 
Keywords: Antioxidant, Lipid oxidation, Myoglobin, Reduction Potential 


\section{Muscle and Lipid Biology and Biochemistry}

145

\section{RUMINAL ACETATE INFUSION INCREASED MARBLING SCORES AND FLAVOR ATTRIBUTES OF BEEF RELATIVE TO BEEF FROM ABOMASAL OR RUMINAL GLUCOSE-INFUSED STEERS}

T. L. Blackmon 1, ${ }^{*}$, J. R. Baber ${ }^{1}$, J. C. Morrill ${ }^{1}$, T. A. Wickersham ${ }^{1}$, J. E. Sawyer ${ }^{1}$, R. K. Miller ${ }^{1}$, S. B. Smith ${ }^{1}$

${ }^{1}$ Animal Science, Texas A\&M University, College Station, United States

Objectives: The objective of this research was to demonstrate that abomasal infusion of glucose, which would provide more glucose for absorption from the small intestine, would promote marbling development, hence juiciness, to a greater extent than ruminal infusion of acetate, propionate, or glucose.

Materials and Methods: Angus crossbred steers $(n=24)$ were grown using conventional diets until approximately 22 mo of age, when they were fitted with ruminal cannulas. Prior to the initiation of treatments, steers were adapted to a standard, corn/sorghum finishing diet over a 2-wk period. After the adaptation period, the steers were infused with isocaloric amounts (3.76 Mcal/d) of glucose, propionate, or acetate for $30 \mathrm{~d}$. Glucose was infused either into the rumen or into the abomasum, whereas propionate and acetate were infused into the rumen.

Results: . Acetate-infused steers had higher marbling scores than abomasal or ruminal glucose-infused steers ( $\mathrm{Md}^{22} \mathrm{vs}$ $\mathrm{Sm}^{163}$ and $\mathrm{Sm}^{17}$, respectively; $\left.P \leq 0.08\right)$. Loin muscle from acetate-infused steers also had higher percentages of intramuscular lipid $(8.38 \%)$ and kidney, pelvic, and heart fat $(2.40 \%)$ than abomasal glucose-infused steers $(4.25$ and $2.00 \%$, respectively; $P \leq 0.08$ ). Fatty acid composition of i.m. adipose tissue did not differ between the ruminal glucose steers and the other treatment groups. Ribeye steaks from abomasal glucose-infused steers had higher shear force values $(2.62 \mathrm{~kg})$ than steaks from ruminal glucose-infused or propionate-infused steers $(2.15$ and $2.33 \mathrm{~kg}$, respectively; $P$ $\leq 0.05$ ). Ribeye steaks from the acetate, abomasal glucose-infused, and ruminal glucose-infused steers were higher in the flavor attributes brown/roasted, fat-like, and overall sweet, and lower in bitter off-flavor, than steaks from propionateinfused steers $(P \leq 0.05)$. Steaks from acetate-infused steers were higher in the flavor attribute bloody/serumy than steaks from abomasal and ruminal glucose-infused steers $(P \leq 0.07)$. Steaks from propionate-infused steers were higher in metallic off-flavor than steaks from ruminal glucose-infused steers $(P=0.03)$, and were higher in sour off-flavor than abomasal and ruminal glucose-infused steers $(P \leq 0.02)$. For taste panel texture analysis, ribeye steaks from acetateinfused steers had higher juiciness scores than steaks from all other infusion groups $(P \leq 0.04)$, and had higher myofibrillar and overall tenderness scores than steaks from abomasal glucose-infused steers $(P \leq 0.08)$. Steaks from propionate-infused steers had higher myofibrillar and overall tenderness scores than steaks from abomasal glucoseinfused steers $(P \leq 0.006)$, whereas steaks from acetate and propionate-infused steers had higher connective tissue scores than steaks from ruminal glucose-infused steers $(P \leq 0.06)$. 
Conclusion: We conclude that, contrary to our initial hypothesis, ruminal acetate infusion produced beef that had higher marbling scores, more intramuscular lipid, and more positive flavor attributes than beef from either ruminal or abomasal glucose-infused steers. Funded by the Beef Checkoff.

Keywords: Acetate, Beef flavor, beef quality, Glucose, Infusion 


\section{Muscle and Lipid Biology and Biochemistry}

146

\section{REFLECTANCE AND ABSORBANCE PROPERTIES OF DARK CUTTING BEEF}

B. Djimsa ${ }^{1,}{ }^{\star}$, A. R. English ${ }^{1}$, G. G. Mafi ${ }^{1}$, D. L. VanOverbeke ${ }^{1}$, K. L. Bailey ${ }^{2}$

${ }^{1}$ Animal Science, ${ }^{2} \mathrm{OK}$ Animal Disease Diagnosis Laboratory, Veterinary Pathobiology, Okahoma State University, Stillwater, United States

Objectives: Beef color is primarily due to the presence of chromophores such as myoglobin, and to a lesser extent by hemoglobin and cytochromes. When the ultimate meat $\mathrm{pH}$ is high, the net charge of the proteins will be above their isoelectric point. Proteins will associate with more water in muscle, resulting in a tightly packed fiber. The muscle surface does not scatter light to the same extent as the more open surface of meat with a lower ultimate $\mathrm{pH}$. This increased absorption and decreased reflectance from the surface leads to an undesirable, dark, firm, and dry cut lean surface. The objective of this study was to determine the absorbance and reflectance properties of dark cutting beef following the removal of chromophores.

Materials and Methods: A completely randomized block design was used to determine the effects of reflectance and absorbance properties of dark cutting beef. Eight no-roll dark cutter and eight USDA choice strip loins (IMPS \#180) were obtained from a beef purveyor within $3 \mathrm{~d}$ of slaughter. Each loin served as a block. The average pH of choice and dark cutter were 5.6 and 6.5 , respectively. The loins were vacuum packaged and aged for $21 \mathrm{~d}$ total at $2^{\circ} \mathrm{C}$. A $2.5-\mathrm{cm}$ thick steak was cut from each loin and was bloomed for $1 \mathrm{~h}$ at $4^{\circ} \mathrm{C}$. Following blooming, $2.5 \times 2.5 \times 1 \mathrm{~cm}$ sections were cut from normal and dark cutting steaks and was used to measure surface color reading from 400 to $700 \mathrm{~nm}$ using a Shimadzu UV-2600 spectrophotometer with an integrating sphere assembly. Following measurements of absorbance and reflectance of bloomed sections, chromophores on the normal $\mathrm{pH}$ and dark cutter were removed according to the published literature. In addition, sarcoplasm was extracted from both muscle types to measure the refractive index using a refractometer. Hematoxylin and eosin staining (H\&E) was used for morphometric evaluation. The experiment was replicated 8 times. The data were analyzed using the Mixed Procedure of SAS and significance was determined at $P<$ 0.05 .

Results: No difference $(P>0.05)$ in refractive indices were noted in sarcoplasm of dark cutting and normal pH beef. Muscle swelling as indicated by bulged muscle fibers were observed in dark cutting muscle when compared with normal $\mathrm{pH}$ muscle. The reflectance was lower $(\mathrm{P}<0.05)$ in steaks with and without removal of chromophores in dark cutting beef when compared with normal $\mathrm{pH}$ beef. The reflectance from 600 to $700 \mathrm{~nm}$ showed significant differences in dark cutting beef. Absorbance was greater in steaks with and without chromophores of dark cutting beef when compared with normal $\mathrm{pH}$ beef.

Conclusion: The results indicate that muscle structure plays a critical role in reflectance and absorbance properties of dark cutting beef. 
Keywords: Dark cutter, reflectance, absorbance, myoglobin 


\section{Muscle and Lipid Biology and Biochemistry}

147

\section{METABOLOMIC PROFILING TO UNDERSTAND CHANGES IN OXIDATION STABILITY OF DIFFERENT BOVINE MUSCLES WITH POSTMORTEM AGING}

D. Ma ${ }^{1,{ }^{*}}$, Y. H. B. Kim ${ }^{1}$, J.-H. Choe ${ }^{1}$, B. Cooper ${ }^{2}$

${ }^{1}$ Animal Science, 2 Bindley Bioscience Center, Purdue University, West Lafayette, United States

Objectives: Postmortem aging improves meat quality attributes such as tenderness, juiciness and flavor through protein degradation. Numerous metabolites can be either generated or decreased during aging process. Some metabolites that impart antioxidant properties may be inversely related to the extended aging time, leading aged muscle to exhibit more oxidation related quality defects such as rapid discoloration and/or lipid oxidation. Metabolomics is a powerful tool to provide extensive information of complex metabolic changes in postmortem muscle. Therefore, the objective of this study was to identify metabolomic profiles from different bovine muscles during aging to further characterize possible linkages between metabolic dynamics and oxidation stabilities.

Materials and Methods: Three muscles (longissimus dorsi(LD), semimembranosus (SM), and psoas major (PM)) from 7 beef carcasses were obtained at 1 day postmortem, divided into 3 cuts and assigned to 3 aging periods (9,16 and 23 days). Steak cuts were made after each aging time, overwrap PVC-packaged, and displayed for 7 days under light. Surface color was assessed by Hunter MiniScan and lipid oxidation (TBARS) was measured. Metabolomics was conducted on samples from each aging time in an HPLC-ESI-MS system. Compounds detected by the system were identified using metabolite database libraries METLIN and HMDB. The experimental design was split plot. Data were analyzed by mixed procedure of SAS. Means were separated (F-test, $\mathrm{P}<0.05$ ) by least significant differences.

Compound abundance differed in different muscles or different aging times were determined by paired t-tests.

Results: Lipid oxidation increased with aging for all muscles in general, but LD was more oxidation stable compared to SM and PM $(P<0.05)$. Discoloration development followed a similar pattern, where LD was the most color stable compared to SM and PM $(P<0.05)$ regardless of aging time. The metabolomics initially identified 439 different compounds, among which major groups of metabolites were amino acids, short peptides and nucleotide related compounds. NADH and glutathione, well known antioxidants, were decreased as aging time increased, which could be related to the observed aging effect on color and lipid oxidation stabilities. Conversely, those compounds were not differently expressed in different muscles. A significant increase in short peptides and free amino acids in $23 \mathrm{~d}$ groups was found, presumably due to postmortem proteolysis. Additionally, nucleotide related compounds involved in energy metabolites, such as ADP, IMP and GDP, were also higher in $16 \mathrm{~d}$ and $23 \mathrm{~d}$ groups, whereas ATP and GTP were non-detectable. Fatty acetyl carnitines were higher in $\mathrm{PM}$, which could reflect the oxidative metabolic preference of the red muscle. IMP was higher in LD muscle while ADP was higher in PM, possibly eliciting greater extent of ATP degradation in the white muscle. 
Conclusion: The current results confirmed that LD muscle has higher oxidative stability than SM and PM. Our study also found that metabolic profiles were noticeably affected by muscle type and aging. Some of those identified metabolites could coincide with oxidative stability of different muscles with aging. However further identification and systematic analysis of metabolomics data are required to advance our understanding of possible linkages between metabolic dynamics and oxidation stability.

Keywords: HPLC-MS, Metabolomics, Muscle type, oxidation, Postmortem aging 


\section{Muscle and Lipid Biology and Biochemistry}

148

\section{EFFECTS OF BETA AGONISTS AND MUSCLE TYPE ON POLAR LIPID FATTY ACID CONCENTRATION}

J. Gardner 1, ${ }^{*}$, J. Legako ${ }^{1}$, T. Gardner ${ }^{1}$, T. Dinh ${ }^{2}$, S. Menard ${ }^{2}$, R. Broadway ${ }^{3}$, K. Spivey ${ }^{4}$, J. Hutcheson ${ }^{5}$, M. Corrigan ${ }^{5}$, J. Hergenreder ${ }^{4}$, B. Johnson 4

${ }^{1}$ Nutrition Dietetics and Food Science, Utah State University, Logan, ${ }^{2}$ Animal and Dairy Sciences, Mississippi State University, Starkville, ${ }^{3}$ USDA, ${ }^{4}$ Animal and Food Sciences, Texas Tech Univeristy, Lubbock, ${ }^{5}$ Merck, Desoto, United States

Objectives: Previous data indicates that Beta-adrenergic agonists $(\beta A A)$ and beef muscle type impact muscle fiber-type composition. Polar lipids, primarily phospholipids, are structural components of muscle cell walls. Little information is available regarding the impact of divergent muscle fiber-type on polar lipid fatty acids. Therefore, polar lipid fatty acid concentrations were determined for different muscles of beef animals that were fed a control diet $(n=5)$ or a diet that included $\beta A A(n=5)$, specifically zilpaterol $\mathrm{HCl}(\mathrm{ZH})$, for the last 20 days of the finishing period.

Materials and Methods: At harvest, muscle tissue was collected from the infraspinatus (IF), pectoralis profundi (PP), subscapularis (SS), latissimus dorsi (LA), longissimus dorsi (LD), trapezius (TP); Pelvic: adductor femoris (AD), biceps femoris (BF), gluteus medius (GM) and semitendinosus (ST). Polar lipid fatty acids were determined from each sample combination by Gas Chromatography-Flame Ionization Detection.

Results: An interaction between $\beta A A$ treatment and muscle was determined for concentrations of $C 14: 1 \mathrm{n} 5(P=0.023)$ and $C 18$ :1trans $(P=0.040)$. While a higher $(P<0.05)$ concentration of both of these fatty acids were found in the TP, SS, and LD muscles of the control diet animals, the $\beta A A$ animals showed a higher $(P<0.05)$ concentration in the $P P$ and $B F$ muscles. The $\beta A A$ treatment was found to impact concentrations of $C 14: 0(P=0.029), C 15: 0(P=0.034), C 16: 1 n 7(P=$ 0.035), $C 17: 0(P=0.029), C 17: 1 n 8(P=0.048)$ and $C 18: 1 n 9(P=0.031)$. All of these acids were found in higher concentration in control diet animals. In addition, a higher total concentration of monounsaturated fatty acids $(P=0.036)$ was found, primarily driven by $\mathrm{C} 18: 1 \mathrm{n} 9$. Percent of total fatty acid was also determined for each fatty acid. Muscle showed a difference in percentages of $C 16: 0(P=0.033), C 18: 1$ trans $(P=0.025), C 20: 3 n 6(P=0.0489)$, and C20:5n3 $(P=$ 0.045). The $C 20: 3 n 6$ and $C 20: 5 n 3$ acids rated to have a high percent in the $G M$ and $A D$ muscles and a lower $(P<0.05)$ percent in the SS muscle. Meanwhile, C16:0 was found in a high percentage in the LD muscle while a low percentage in the PP muscle.

Conclusion: These results reveal a profound impact of $\beta A A$ on polar lipid fatty acids. It may be implied that muscle fiber size increases in response to $\beta A A$ altered the polar lipid fatty acid concentrations. Surprisingly, muscle type had a lesser impact on polar lipid fatty acids. However, it should be noted that most muscles in this study are considered to be white or intermediate muscle-type. 
Keywords: Polar Lipid Fatty Acid 


\title{
Muscle and Lipid Biology and Biochemistry
}

149

\section{METABOLOMICS APPROACH TO ELUCIDATE MEAT QUALILTY TRAITS OF LOINS FROM CALLIPYGE SHEEP}

\author{
Y. H. B. Kim ${ }^{1}$, M. L. Penick 1, ${ }^{*}$, T. Cramer ${ }^{1}$, J. N. Waddell ${ }^{2}$, C. A. Bidwell ${ }^{1}$, B. R. Cooper ${ }^{3}$
}

${ }^{1}$ Animal Science, Purdue University, West Lafayette, ${ }^{2}$ Animal Science, Tarlenton State University, Stphenville, ${ }^{3}$ Purdue University, West Lafayette, United States

Objectives: Callipyge sheep unique phenotype is the result of polar overdominance, paternally inheriting a mutated allele within the CLPG gene. Callipyge (CN) sheep are known for increased muscle mass, decreased fat accretion and less desirable carcass quality attributes especially tenderness compared to "normal" lamb's genotypes (NN, NC, and CC). While it has been well established that the decrease in tenderness of meat from $\mathrm{CN}$ is associated with up-regulation of calpastatin, which inhibits calpain activity resulting in decrease protein degradation, how different extent of protein degradation would result in generation of metabolites and subsequently affect meat quality attributes is largely unknown. The objective of this study was to further elucidate the effects of the callipyge mutation on biological changes and subsequent meat quality attributes by assessing metabolites that may be differently expressed by different callipyge genotypes.

Materials and Methods: A total of 17 lambs (4 replicates of the 3 genotypes, and 5 for NN; $~ 8$ months; averaged $49.89 \mathrm{~kg}$ ) were harvested. A paired loin (M. Longissimus) was separated from each carcass at $3 \mathrm{~d}$ postmortem, cut into 3 equal length of chops, individually vacuum-packaged, and assigned for 3 different aging times $(3,6$, and $9 \mathrm{~d})$ at $4^{\circ} \mathrm{C}$, then stored in $-80^{\circ} \mathrm{C}$. Muscle samples at $3 \mathrm{~d}$ postmortem were used for metabolomic analysis, using HPLC-ESI MS method. The extracted samples were divided into polar/non-polar fractions and further identified by referencing METLIN and HMDB databases to annotate identified compounds. The remaining chops were cooked for the Warner-Bratzler shear force measurement. Purge and cook loss of chops were also measured. The experimental design was a randomized complete block design, and data were analyzed by using mixed procedure of SAS. Means were separated (F-test, $P<0.05)$ by least significant differences. Metabolites compound abundance differed in different genotypes were determined by paired $t-$ tests.

Results: CN for each set of aged samples required the highest values of shear force as expected. Purge loss of loin samples was not effected by either genotype or aging $(P>0.05)$. However, a significantly higher cook loss in loins from $C N$ was found compared to the loins from the other genotypes $(P<0.05)$ regardless of aging times. METLIN identified 21 metabolites differentially expressed comparing CC vs CN (11 polar and 8 non-polar). For the comparison of NN vs CN, 20 metabolites were identified, which were 14 polar and 8 non-polar. Comparing NC vs CN, 28 metabolites (22 polar and 6 non-polar) were identified. The majority of identified metabolites were peptides and free fatty acids. Among those identified polar metabolites, some metabolites including histidinyl-glutamate, phenylalayl-glutamate and N6Methyladenosine were all down-regulated compared to $\mathrm{CN}$. Although the levels of expression varied within compounds, 
the "normal" genotypes followed the same trend of expression, NC, the most down-regulated, CC, intermediately expressed then followed by NN, the least down-regulated. Zero non-polar metabolites, consisting of lipids and sterols were identified in each of the "normal" genotypes by METLIN to be differentially expressed compared to CN.

Conclusion: These results indicate there are differences in the metabolomic profiles of each genotype compared to callipyge, but determining the effect of the metabolites differently expressed is still to be determined.

Keywords: Callipyge, Meat Quality, Metabolomics, shear force, Sheep 


\section{Undergraduate Research Competition}

153

\section{USE OF REDOXSYS TO MEASURE OXIDATION REDUCTION POTENTIAL IN BEEF}

K. M. Wills 1, ${ }^{*}$, A. R. English 1, G. G. Mafi 1, D. L. VanOverbeke 1, C. Gifford 1, K. B. Bjugstad 2, R. Ramanathan ${ }^{1}$

${ }^{1}$ Animal Science , Oklahoma State University , Stillwater, 2Luoxis, Englewood, United States

Objectives: Metmyoglobin reducing property of meat is an important inherent biochemical characteristic that influences color stability. Although there are different methods to estimate the reducing capacity of meat, limited studies have utilized oxidation reduction potential (ORP) properties to study meat color. The RedoxSYS analyzer is a fast and new proprietary diagnostic system that efficiently determines the ORP properties of biological systems. ORP measures the net balance between total oxidants and total reductants; it is not limited to specific oxidants or reductant families. It has been used previously to reveal that multi-trauma patients have higher serum ORP values than healthy controls. The objective of the study was to use RedoxSYS to measure total ORP in beef.

Materials and Methods: For the first experiment, sarcoplasm was extracted from $21 \mathrm{~d}$ aged normal pH and high-pH beef longissimus steaks. The average $\mathrm{pH}$ values of normal and high-pH beef were 5.6 and 6.5 , respectively (standard error = 0.2). For the second experiment, steaks from normal $\mathrm{pH}$ beef longissimus loins were packaged in either PVC or HiOx ( $80 \%$ oxygen and $20 \%$ carbon dioxide), and displayed under continuous fluorescent lighting for $5 \mathrm{~d}$ (display temperature was $4{ }^{\circ} \mathrm{C}$; average $\mathrm{pH}=5.5$ ). For both experiments, $5 \mathrm{~g}$ of meat was mixed with $15 \mathrm{~mL}$ of $50 \mathrm{mM}$ phosphate buffer at $\mathrm{pH}$ 7.4 and homogenized for $30 \mathrm{~s}$ using a Polytron tissue homogenizer. The homogenates were centrifuged at $15,000 \times \mathrm{g}$ for $3 \mathrm{~min}$ and $25 \mu \mathrm{L}$ of supernatant was used to measure ORP. In addition to ORP measurements, steaks were also used to measure metmyoglobin reducing activity using nitric oxide metmyoglobin reduction method. The experiments were replicated eight times $(n=8)$. The data for the experiment 1 and 2 were analyzed using the Mixed Procedure of SAS and the significance was determined at $\mathrm{P}<0.05$.

Results: The average reduction potential values of normal and high-pH beef were $262 \pm 5$ and $239 \pm 8 \mathrm{mV}$, respectively $(\mathrm{P}<0.05)$. The greater $\mathrm{pH}$ aged beef had significantly lower ORP values and thus was under lower levels of oxidative stress. In support, metmyoglobin reducing activity was greater $(\mathrm{P}<0.05)$ in high-pH beef compared with normal pH beef. Packaging in HiOx conditions increased the oxidative stress compared with PVC packaging $(\mathrm{HiOx}=282 \pm 7$ and $\mathrm{PVC}=$ $255 \pm 8 \mathrm{mV} ; \mathrm{P}<0.05)$.

Conclusion: The results indicate that ORP is related to metmyoglobin reducing activity. Future studies will determine the utility of RedoxSyS diagnostic system to predict color stability of beef.

Keywords: Beef color, MRA, Myoglobin , reduction potential 



\section{Undergraduate Research Competition}

154

\section{EFFECTS OF SOY HULL FIBERS AND FREEZING ON QUALITY ATTRIBUTES OF BEEF PATTIES}

D. K. Miller ${ }^{1,{ }^{*}}$, H.-W. Kim ${ }^{1}$, Y. Lee ${ }^{2}$, Y. H. B. Kim ${ }^{1}$

${ }^{1}$ Animal Science, Purdue University, West Lafayette, ${ }^{2}$ Separation Sciences, Food Protein R\&D Center, Texas A\&M

University, College Station, United States

Objectives: Soy hulls are a valuable food ingredient due to high dietary fiber composition and renewable abundance as an under-utilized agricultural by-product. Previously, the addition of soy hull fibers to the emulsion improved water-holding capacity and hardness likely due to high water retention ability of dietary fiber contained in soy hulls. In addition, a cryoprotective effect of the soluble soy hull fiber (pectin), to prevent quality deterioration of the frozen surimi model, has been reported. In general, freezing and thawing cause negative quality impacts on meat products. Upon thawing, the decreased water-holding capacity also causes excessive drip loss from frozen meat products and an unpleasant appearance. Given the superior water-binding ability of soy hull fibers, it can be hypothesized that the addition of soy hull fibers to beef patties will reduce quality defects associated with the freezing and thawing process. Therefore, the objective of this study was to evaluate the effects of insoluble soy hull fibers (SHF), soluble soy hull fibers (pectin) and freezing on the color, waterholding capacity, texture and lipid oxidation of beef patties.

Materials and Methods: Three fiber suspensions (1:5 ratios, w/w) were prepared with insoluble soy hull fiber (SHF), soy hull pectin (SHP) and combination of insoluble soy hull fiber and pectin (1:1, SHFP), respectively. Beef patties (control) were formulated with $80.75 \%$ ground beef, $14.25 \%$ beef fat and $5 \%$ cold water. Treatments were prepared by replacing $1 \%$ ground beef with each suspension. Beef round ( $M$. semimembranosus) and fat were ground using a meat grinder equipped with $3 / 8$ inch plate. All ingredients were hand-mixed for 5 minutes and re-ground to $1 / 4$ inch. Half of the patties from each treatment were frozen immediately at $-18^{\circ} \mathrm{C}$ for 3 weeks and thawed at $2{ }^{\circ} \mathrm{C}$ for 2 days. Color $\left(\mathrm{CIE} L^{*} a^{*} b^{*}\right)$, drip loss, cooking loss (core temperature of $71^{\circ} \mathrm{C}$ ), texture profile analysis, and lipid oxidation (2-thiobarbituric acid assay) were conducted. The data was analyzed using the general linear model (GLM) procedure of SPSS 18.0 software.

Results: Color of cooked beef patties was not affect by the addition of soy hull fiber suspension $(P>0.05)$. Drip loss of treatments was significantly lower than that of the control $(P<0.05)$. The addition of fiber suspension increased the final yield (after cooking) of both fresh and frozen treatments. Particularly, SHP and SHFP treatments resulted in higher final yield compared to control and SHF $(P<0.05)$. Springiness, gumminess and chewiness were significantly lower in the treatments, when compared to the control. The addition of SHF accelerated the lipid oxidation of both fresh and frozen beef patties, likely due to a pro-oxidant component in soy hull such as lipoxygenase.

Conclusion: These results indicate that soy hull fiber and pectin could improve water-holding capacity of the beef patties under further processing such as freezing, thawing, cooking and displaying. Further studies determining the 
pro/antioxidant impacts of soy hull fiber and pectin on lipid oxidation and sensory attributes of beef patties would be warranted.

Keywords: beef patties, cryo-protectant, dietary fiber, pectin, soy hull 


\title{
Undergraduate Research Competition
}

155

\section{DOCUMENTATION OF 50\% WATER CONSERVATION IN A SINGLE PROCESS AT A BEEF ABATTOIR}

\author{
C. L. Drennan ${ }^{1,}{ }^{*}$, R. E. DeOtte ${ }^{1}$, T. E. Lawrence ${ }^{2}$ \\ 1Engineering \& Computer Science, ${ }^{2}$ Agricultural Sciences, West Texas A\&M University, Canyon, United States
}

Objectives: The objective of this research was to evaluate methods to modify existing commercial Cary head wash equipment to reduce water consumption in a beef processing facility. Current industry practices use approximately 190 liters of water per head washed. Due to variability and subjectivity among inspectors and the cost of failed inspection, the head wash process is susceptible to the use of excess water. To provide objective measures of relative cleanliness, changes in red saturation levels before and after wash were determined.

Materials and Methods: Digital cameras were mounted at three locations, 1) immediately after head-body separation once head was placed upon moving head conveyor, 2) after manual wash process - prior to Cary mechanical wash and 3) after Cary mechanical wash cabinet. Images were captured at each location. Image analysis software was used to quantify percentage red saturation for each head before and after mechanical washing. To relate head cleanliness with water consumption, flow was recorded using an electronic turbine meter. The number of nozzles and configuration, flow rate, and system pressure determine water consumption and system efficiency. A 3-D CAD model of spray coverage was developed to identify surface coverage for each nozzle, repetitive coverage, and alternate spray locations that would maximize water contact. Nozzles that excessively duplicated coverage were capped. When pressure is constant, decreasing the number of nozzles decreases volume output. Correct pressure is critical for controlling droplet size and decreasing volume. Droplet momentum assists in cleaning the head surface. Water flow for the mechanical head wash system was decreased in small increments, substantially reducing water consumption while cleaning adequately to meet subjective USDA FSIS inspection criteria.

Results: Wash effectiveness was measured as change in red saturation in the mechanical wash with the pre-wash average of $40 \%$. The original 112 nozzle configuration operated at $275 \mathrm{kPa}$, used an average $152 \mathrm{~L} / \mathrm{hd}$, and resulted in a final saturation of $5 \%$, reducing saturation by 35 percentage points. After identifying redundant nozzles and optimizing the configuration, 28 nozzles were removed (84 remained); operating at $275 \mathrm{kPa}$, post wash saturation increased to $7 \%$, a reduction of 33 percentage points, however heads were still deemed adequately clean for inspection. After further optimization 12 more nozzles were removed (72 remained) and operating pressure was decreased to $138 \mathrm{kPa}$; post wash saturation increased to $7.5 \%$, a reduction of 32.5 percentage points. This dropped the system usage to $78.4 \mathrm{~L} / \mathrm{hd}$ ( $48 \%$ reduction).

Conclusion: Although the post wash red saturation percentage increased slightly from base level to the final wash configuration, all heads were cleansed adequately to pass inspection. Fifty-percent of water has been saved in a single process use, a total of $3 \%$ for the beef processor. This will decrease the amount spent on water and treatment costs both 
by $3 \%$ yielding a significant economic impact. Further savings can be achieved by implementing water conservation in other areas of beef processing, and the facility owners have asked that research on this commence.

Keywords: Beef, Harvest, Water Conservation 


\section{Undergraduate Research Competition}

157

\section{COMPARISON OF CONSUMER AND TRAINED SENSORY EVALUATIONS AND PROXIMATE COMPOSITION OF BEEF STRIP LOIN STEAKS}

L. N. Drey 1, ${ }^{1}$, L. D. Woolley ${ }^{1}$, T. G. O'Quinn ${ }^{2}$, J. F. Legako ${ }^{3}$, J. C. Brooks ${ }^{1}$, M. F. Miller ${ }^{1}$

1Department of Animal and Food Sciences, Texas Tech University, Lubbock, 2Department of Animal Sciences and Industry, Kansas State University, Manhattan, ${ }^{3}$ Department of Nutrition, Dietetics, and Food Sciences, Utah State University, Logan, United States

Objectives: The purpose of this study was to determine relationships between consumer and trained panel evaluation scores of beef strip steaks and proximate composition.

Materials and Methods: Sixty strip loins were selected to equally represent five quality treatments, including USDA Prime, upper 2/3 Choice, lower 1/3 Choice, Select, and Standard. An additional 24 USDA Select strip loins were selected for enhancement with a water, salt, and alkaline phosphate solution at two injection levels: High Enhanced (112\% of raw weight) and Low Enhanced (107\% of raw weight). Strip loins were vacuum packaged and aged $21 \mathrm{~d}$ at 2 to $4^{\circ} \mathrm{C}$ then fabricated into $2.5 \mathrm{~cm}$ thick steaks and cooked on a belt grill to three degrees of doneness (DOD); rare $\left(60^{\circ} \mathrm{C}\right)$, medium $\left(71^{\circ} \mathrm{C}\right)$, or well-done $\left(77^{\circ} \mathrm{C}\right)$. Consumers $(n=252)$ were screened for DOD preference and randomly served one sample from each treatment prepared at their preferred DOD. Each sample was evaluated for tenderness, juiciness, flavor identity, flavor liking and overall liking on a $10-\mathrm{cm}$, verbally anchored line-scale. Additionally, 36 (12/DOD) panels consisting of a 7 to 10-member trained panel were conducted. Samples were evaluated for initial juiciness, sustained juiciness, initial tenderness, sustained tenderness, beef flavor ID, beef flavor intensity, and off flavor intensity on a 10-cm, verbally anchored line scale. Proximate analysis of the raw "face" steak of each strip loin was conducted by an AOAC official method using a near infrared spectrophotometer (FOSS FoodScan). The chemical percentages of fat, moisture and protein of each strip loin were determined.

Results: The strongest correlation $(P<0.05)$ with consumer overall liking occurred with consumer flavor liking $(r=0.95)$, followed by tenderness $(r=0.89)$, and juiciness $(r=0.81)$. Also, consumer tenderness was strongly correlated $(P<0.05)$ to consumer to juiciness $(r=0.80)$. Similarly, trained initial tenderness and sustained tenderness were highly correlated to trained initial juiciness $(r=0.76,0.73)$ and sustained juiciness $(r=0.77,0.76)$, consumer tenderness $(r=0.69,0.70)$ and to consumer overall like $(r=0.64,0.65)$. Additionally, trained initial juiciness and sustained juiciness were highly correlated $(P<0.05)$ to consumer juiciness $(r=0.62,0.63)$. Although consumers did not evaluate samples for off-flavors, consumer flavor liking was positively correlated $(P<0.05)$ with trained salty off-flavor $(\mathrm{r}=0.43)$. No correlation $(P>0.05)$ between consumer flavor liking and trained beef flavor ID $(r=-0.11)$ and beef flavor intensity $(r=-0.03)$ was found. When comparing sensory results to proximate composition, the strongest negative correlations $(P<0.05)$ were between percent protein and consumer juiciness $(r=-0.55)$, consumer tenderness $(r=-0.51)$ and overall liking $(r=-0.51)$. Moreover, fat 
percentage was positively correlated $(P<0.05)$ to trained beef flavor ID $(r=0.46)$, beef flavor intensity $(r=0.50)$ and consumer juiciness $(r=0.37)$.

Conclusion: Overall, all palatability traits were highly associated with consumers overall liking. Also, consumers evaluated palatability traits similarly to trained panel members except for beef flavor characteristics.

Keywords: beef, composition, consumer, sensory, trained panel 


\title{
Undergraduate Research Competition
}

158

\section{RELATIONSHIP BETWEEN USDA INSTRUMENT GRADING MEASUREMENTS AND TRAINED PERSONNEL EVALUATION OF BEEF CARCASS TRAITS AND PROXIMATE COMPOSITION}

\author{
A. M. Ritchey ${ }^{1, *}$, L. D. Woolley ${ }^{1}$, T. G. O'Quinn ${ }^{2}$, J. F. Legako ${ }^{3}$, J. C. Brooks ${ }^{1}$, M. F. Miller ${ }^{1}$ \\ ${ }^{1}$ Animal \& Food Science, Texas Tech University, Lubbock, ${ }^{2}$ Animal Sciences \& Industry, Kansas State University, \\ Manhattan, ${ }^{3}$ Nutrition, Dietetics \& Food Sciences, Utah State University, Logan, United States
}

Objectives: The objective of this study was to compare beef grading measures between Texas Tech University (TTU) trained personnel, in-plant cold carcass instrument grading data and proximate composition data of raw beef strip loins. Materials and Methods: Beef carcasses $(n=84)$ were selected in a beef processing facility to be evaluated for marbling score, preliminary fat thickness, ribeye area, and yield grade by trained TTU personnel. Since instrument grading is used widespread in the U.S. beef industry, data files containing instrument grading measurements of marbling score, ribeye area (REA), fat thickness, and calculated yield grade for each side of the selected carcass were retrieved from the processing facility. From the carcasses selected for evaluation, beef strip loins (IMPS \#180) were collected, vacuumpackaged and transported to the Texas Tech University Gordon W. Davis Meat Science Lab where they were aged at 2 to $4^{\circ} \mathrm{C}$ for $21 \mathrm{~d}$. Chemical percentages of fat, moisture and protein were determined by an AOAC official method using a near infrared spectrophotometer. Correlation analyses were used to identify and quantify relationships among beef processing facility instrument grading, TTU trained personnel carcass grading and proximate composition.

Results: High correlations $(P<0.05)$ were found between instrument grading and TTU trained personnel marbling scores $(r=0.96)$, preliminary fat thickness $(r=0.90)$, REA $(r=0.73)$, and yield grade $(r=0.86)$ measurements. High correlations $(P<0.05)$ were also found between fat percentage and marbling score of TTU trained personnel $(r=0.93)$ and of instrument grading marbling score $(r=0.93)$. Also, fat percentage was positively correlated $(P<0.05)$ with preliminary fat thickness measured by TTU trained personnel $(r=0.65)$ and instrument grading preliminary fat thickness $(r=0.55)$. Protein percentage was positively correlated $(P<0.05)$ with TTU trained personnel REA $(r=0.33)$ and instrument grading REA $(r=0.28)$. There was a strong negative correlation $(P<0.05)$ between moisture percentage and marbling score of TTU trained personnel $(r=-0.90)$ and instrument grading marbling score $(r=-0.89)$.

Conclusion: Results of this study indicate a close relationship between instrument grading and trained personnel evaluation of beef carcass traits. Also, both instrument grading marbling and trained personnel marbling scores were closely related to fat percentage in beef strip steaks. Yield grades calculated by TTU personnel were a good indicator of instrument grading calculations for yield grade. 
Keywords: fat, instrument grading, marbling, proximate, yield grade 


\title{
Undergraduate Research Competition
}

161

\section{UTILIZATION OF BIOMETRIC MEASUREMENTS TO PREDICT CARCASS QUALITY AND YIELD CHARACTERISTICS OF CALF-FED HOLSTEIN STEERS.}

\author{
C. L. Rogers ${ }^{1, *}$, T. E. Lawrence ${ }^{1}$, T. J. McEvers ${ }^{1}$ \\ 1Beef Carcass Research Center, West Texas A\&M University, Canyon, United States
}

Objectives: Calf-fed Holstein steers $(n=77)$ were randomely selected to quantify changes in carcass growth performance and grading characteristics during a $54 \mathrm{~d}$ marketing window.

Materials and Methods: Cattle were selected from a commercial feeding operation in Texas representing three days on feed (DOF) endpoints 289 DOF (26 steers); 310 DOF (26 steers); and 343 DOF(25 steers)\}. On the day of harvest. cattle were weighed by DOF endpoint with the 289, 310, and 343 DOF groups weighing $527.9,555.1$, and $614.1 \mathrm{~kg}$ respectively. Individual biometric measurements obtained during harvest included shackled body length (BL,mm; distance from nostrils to distal tarsals), head width (HW,mm; distance between the inner eye sockets), and head length ( $\mathrm{HL}, \mathrm{mm}$; distance from the pole to the nostril). Carcass characteristics included hot carcass weight $(\mathrm{HCW}, \mathrm{kg})$, marbling score (MARB), subcutaneous fat thickness $(F T, c m)$, ribeye area $\left(R E A, \mathrm{~cm}^{2}\right)$, estimated kidney-pelvic-heart fat $(\mathrm{KPH}, \%)$, medial-lateral ribeye length $(\mathrm{RL}, \mathrm{mm})$, dorsal-ventral ribeye depth at 50 percent the length of the ribeye (RW50,mm), dorsal-ventral ribeye depth at 75 percent the length of the ribeye (RW75,mm), and calculated yield grade (YG). A mixed model was utilized to analyze biometric and carcass information with the fixed effect of DOF. Predictive models were calculated using the REG procedure of SAS for the estimation of carcass grading characteristics with collinearity diagnostics achieved using the VIF option.

Results: No differences $(P \geq 0.21)$ were detected for REA, RL, RW50, or RW75 regardless of DOF endpoint. A trend ( $P=$ 0.06 ) was calculated for MARB; cattle from the $289 \mathrm{~d}$ treatment were less marbled than the 310 and $343 \mathrm{~d}$ endpoints (Slight 70 vs a Small 10 and Small 0 for the 310 and 343 d endpoints, respectively). Head length differed $(P<0.01)$ amongst DOF endpoints; the $289 \mathrm{~d}$ cattle were shorter than those of the 310 and $343 \mathrm{~d}$ treatments $(20.2$ and $30.2 \mathrm{~mm}$, respectively). Head width differed $(P<0.01) ; 289 \mathrm{~d}$ cattle were narrower than those of the 310 and $343 \mathrm{~d}$ treatments (13.3 and 12.6mm, respectively). Differences in BL indicated cattle of the 289 and $310 \mathrm{~d}$ treatments were shorter than those of the $343 \mathrm{~d}$ treatment $(P<0.01 ; 114.7$ and $82.8 \mathrm{~mm}$, respectively). Differences between the three treatments indicated cattle from the $289 \mathrm{~d}$ endpoint had decreased $(P \leq 0.02)$ calculated $Y G(0.47)$ and FT $(0.16 \mathrm{~cm})$ compared to those with 343 DOF. Hot carcass weights differed $(P<0.01)$ amongst endpoints; $289 \mathrm{~d}$ cattle had less compared to those with 310 and 343 DOF (21.6 and $54.83 \mathrm{~kg}$, respectively). Moreover, cattle of the $310 \mathrm{~d}$ treatment had less $\mathrm{HCW}(P<0.01$; $33.2 \mathrm{~kg}$ ) compared to the $343 \mathrm{~d}$ cattle. Utilizing biometric measurements and DOF to estimate carcass characteristics, a one variable equation with a root mean square error (RMSE) of 5.5 and adjusted $R^{2}$ of 0.0492 was calculated for MARB $\left\{\right.$ MARB $\left.=-19.06+\left(0.01757^{\star} \mathrm{BL}\right)\right\}$. For estimation of USDA calculated YG a one variable equation with a RMSE of 0.44 
and adjusted $R^{2}$ of 0.3285 was calculated $\left\{Y G=-10.31+\left(0.0039^{*} \mathrm{BL}\right)\right\}$. For estimation of $\mathrm{HCW}$, a three variable equation with a RMSE of 18.7 and adjusted $R^{2}$ of 0.6821 was calculated $\left\{\mathrm{HCW}, \mathrm{kg}=-646.94+\left(0.4637^{*} \mathrm{DOF}\right)+\left(0.24079^{*} \mathrm{HW}\right)+\right.$ $\left.\left(0.23197^{*} \mathrm{BL}\right)\right\}$.

Conclusion: This investigation indicated the limited ability of biometric measurements to accurately predict carcass quality and yield grading characteristics.

Keywords: Beef, Biometrics, Grading, Holstein 


\title{
Undergraduate Research Competition
}

162

\section{IMMUNE SYSTEM STIMULATION BY REPEATED LIPOPOLYSACCHARIDE INJECTIONS ALTERS LONGISSIMUS DORSI SARCOPLASMIC PROTEIN PROFILE IN PIGS}

\author{
A. Outhouse ${ }^{1, *}$, J. Grubbs ${ }^{1}$, C. Tuggle ${ }^{1}$, N. Gabler ${ }^{1}$, A. Rakhshandeh ${ }^{2}$, S. Lonergan ${ }^{1}$ \\ 1Department of Animal Science, lowa State University, Ames, ${ }^{2}$ Texas Tech University, Lubbock, United States
}

Objectives: The objective of this study was to investigate the effects of immune system stimulation (ISS) in pigs divergently selected for residual feed intake (RFI) on the longissimus dorsi (LD) sarcoplasmic protein profile of pigs. Defining these changes will provide insight into how lean tissue growth is impacted by feed efficiency and ISS.

Materials and Methods: Twelve pigs ( 6 per line, BW $63 \pm 4 \mathrm{~kg}$ ) from the lowa State RFI project were used. Low RFI pigs are more efficient than their high RFI counterparts, providing a tool to study the underlying biology of feed efficiency in pigs. Three gilts from each line were injected intramuscularly every $48 \mathrm{~h}$, for $7 \mathrm{~d}$, with increasing amounts of E.coli lipopolysaccharide (ISS; initial dose: $30 \mu \mathrm{g} / \mathrm{kg} \mathrm{BW}$ ). The remaining three pigs from each line were injected with saline. Pigs were euthanized (day 7); LD tissue was collected and frozen. The sarcoplasmic protein fraction was then isolated and two-dimensional difference in gel electrophoresis (2D-DIGE) determined changes in the protein profile between ISS and Control and line (high verses low RFI). Protein identities were determined by mass spectrometry and were confirmed through 2D Western blots.

Results: A total of 354 protein spots were resolved using 2D-DIGE. Fifty-five, and 29, protein spots were different in response to ISS, and selection for $\mathrm{RFI}$, respectively $(P<0.05)$. Fourteen spots were selected for identification. Aldose reductase decreased in response to ISS by $32 \%(P=0.002)$. Aldose reductase catalyzes the conversion of glucose to sorbitol. Fructose produced from sorbitol can be used as an energy source for glycolysis and glyconeogenesis. A decrease in abundance of aldose reductase may be due to a shift in energy utilization during ISS. Tripartite motifcontaining protein 72 (TRIM-72) and alpha-enolase were both found to be changed in abundance due to RFI selection. Both TRIM-72 and alpha-enolase were increased in low RFI pigs by $88 \%(P=0.03)$ and $45 \%(P=0.005)$, respectively. A central role of TRIM-72 is cellular membrane repair. The observed increase in TRIM-72 may indicate low RFI pigs are better equipped to handle membrane damage due to cellular stress. Additionally, relative to the high RFI line, expression of the enzyme alpha-enolase, was higher in low RFI pigs indicating an increase in the metabolic activity of low RFI pigs. Bisphosphoglycerate mutase (BPGM), was affected by both ISS and genetic line ( $P=0.0074)$. BPGM decreased $21 \%$ in response to ISS $(P=0.0036)$ and was increased $11 \%$ in low RFI pigs $(P=0.063)$. BPGM is responsible for the catalytic synthesis of 2,3-bisphosphoglycerate (2,3-BPG). When 2,3-BPG binds with to hemoglobin oxygen is released. An increase in BPGM shows a potential change in oxygen release in the muscle between the RFI lines and ISS.

Conclusion: Based on protein abundance, ISS alters the capacity for energy metabolism in the muscle. Moreover, selection for reduced RFI alters the abundance of membrane repair proteins and enzymes involved in energy metabolism. 
Selection for RFI did not alter the response of and enzymes involved in energy metabolism. Selection for RFI did not alter the response of porcine muscle to ISS.

This work was supported by the Agriculture and Food Research Initiative Competitive Grant no. 2011-68004-30336 from the USDA National Institute of Food and Agriculture.

Keywords: 2D-DIGE, immune system stimulation, protein profile, residual feed intake 


\title{
Undergraduate Research Competition
}

163

\section{SMALL HEAT SHOCK PROTEIN 27 MAY BE RELATED TO TOUGHNESS IN LOINS OF CALLIPYGE LAMBS}

\author{
T. Cramer ${ }^{1,{ }^{*}}$, Y. H. B. Kim ${ }^{1}$, M. Penick ${ }^{1}$, J. Waddell ${ }^{2}$, C. Bidwell ${ }^{1}$
}

${ }^{1}$ Animal Sciences, Purdue University, West Lafayette, ${ }^{2 T}$ Tarleton State University, Stephenville, United States

Objectives: Callipyge lambs have a genetic mutation that produces tough meat. The responsible gene causes upregulated expression of calpastatin, which blocks the proteolytic activity of $\mu$-calpain during aging. Callipyge lambs have the genotype $\mathrm{CN}$, with a paternal callipyge allele and a maternal allele, and produce tougher meat than the normal genotypes CC, NC, and NN. Small heat shock proteins (sHSP) are chaperone proteins that have a protective role in cell death. This process could be reversely related to the postmortem meat tenderization by hindering proteolytic enzymes from breaking down structural myofibrillar proteins. While several proteomic studies found that higher sHSP expression were observed in tougher meat compared to tender counterparts, the role of sHSP in toughness of CN lambs has never been investigated. Therefore, the objective of this study was to determine an involvement of sHSP in tenderness development of loins from callipyge lambs during postmortem aging.

Materials and Methods: A total of 16 lambs, four from each genotype, was slaughtered. Muscle samples (M. longissmus dorsi) were collected at $15 \mathrm{~min}, 3,6$, and 9 days postmortem for protein extraction and tenderness measurement. Western blots were performed to determine the extent of degradation of the myofibrillar proteins desmin and troponin $T$ over aging, as well as $\mu$-calpain autolysis, calpastatin, HSP27 and aB-crystallin. Warner- Bratzler shear force (WBSF) measurements of loin chops across these aging times were conducted. The experimental design was a randomized complete block design, and data were analyzed by using mixed procedure of SAS to compare the traits across different genotypes and aging periods. Means were separated (F-test, $\mathrm{P}<0.05)$ by least significant differences.

Results: A significantly higher shear force value was observed in loins from CN compared to other genotypes regardless of aging time $(P<0.05)$, as expected. Western blots for desmin and troponin $T$ showed increased degradation products of those myofibrillar proteins with an increase in aging time, with less degradation products in the $\mathrm{CN}$ genotype than in the others $(P<0.05)$. The extent of $\mu$-calpain autolysis was also affected by genotype, where loins from $\mathrm{CN}$ exhibited more intact $\mu$-calpain than loins from other genotypes throughout each aging time $(P<0.05)$. Higher calpastatin expression in $\mathrm{CN}$ compared other genotypes was also found. A significant decrease in the extent of intact HSP27 with an increase in aging time was observed, while higher levels of intact HSP27 in CN compared to others was found in loins from CN regardless of aging time $(P=0.09)$. Further, the lower extent of degraded HSP27 in CN compared other genotype was also found over time $(P<0.001)$. No significant effects of genotypes and aging were found for aB-crystallin.

Conclusion: A higher level of HSP27 was found in the CN genotype, which coincided with greater intact desmin and troponin $\mathrm{T}$, less $\mu$-calpain autolysis, and eventually higher shears force values as compared to other genotypes. This observation leads us to postulate that the up-regulation of HSP27 could be related to meat toughness in callipyge lamb 
meat by delaying muscle protein degradation during aging through its anti-apoptotic function. Further studies for the elucidation of the specific mechanisms and possible differences in sHSP behaviors across different muscle fiber types would be highly warranted.

Keywords: Callipyge, Small Heat Shock Proteins, Tenderness 